\title{
Spatial and Temporal Investigation of Real World Crosswind Effects on Transient Aerodynamic Drag Losses in Heavy Duty Truck Trailers in the US
}

\author{
Bharadwaj Sathiamoorthy
}

Follow this and additional works at: https://researchrepository.wvu.edu/etd

\section{Recommended Citation}

Sathiamoorthy, Bharadwaj, "Spatial and Temporal Investigation of Real World Crosswind Effects on Transient Aerodynamic Drag Losses in Heavy Duty Truck Trailers in the US" (2015). Graduate Theses, Dissertations, and Problem Reports. 6570.

https://researchrepository.wvu.edu/etd/6570

This Dissertation is protected by copyright and/or related rights. It has been brought to you by the The Research Repository @ WVU with permission from the rights-holder(s). You are free to use this Dissertation in any way that is permitted by the copyright and related rights legislation that applies to your use. For other uses you must obtain permission from the rights-holder(s) directly, unless additional rights are indicated by a Creative Commons license in the record and/ or on the work itself. This Dissertation has been accepted for inclusion in WVU Graduate Theses, Dissertations, and Problem Reports collection by an authorized administrator of The Research Repository @ WVU.

For more information, please contact researchrepository@mail.wvu.edu. 


\title{
Spatial and Temporal Investigation of Real World Crosswind Effects on Transient Aerodynamic Drag Losses in Heavy Duty Truck Trailers in the US
}

\author{
Bharadwaj Sathiamoorthy
}

\author{
Dissertation submitted \\ to the Statler College of Engineering and Mineral Resources \\ at West Virginia University \\ in partial fulfillment of the requirements for the degree of
}

Doctor of Philosophy in

Mechanical Engineering/Automotive Power Improvement Technologies

\author{
Committee Members: \\ Nigel N. Clark, Ph.D., Chair \\ Mridul Gautam, Ph.D. \\ Avinash Unnikrishnan, Ph.D. \\ Hailin Li, Ph.D. \\ Patrick Browning, Ph.D. \\ Nithi Sivaneri, Ph.D. \\ Department of Mechanical Engineering \\ Morgantown, West Virginia \\ 2015
}

Keywords: truck aerodynamics, wind tunnel testing, crosswinds and yaw angle Copyright 2015 Bharadwaj Sathiamoorthy 


\section{ABSTRACT \\ Spatial and Temporal Investigation of Real World Crosswind Effects on Transient Aerodynamic Drag Losses in Heavy Duty Truck Trailers in the US}

Bharadwaj Sathiamoorthy

Decreasing truck fuel usage and climate change gas production is of national and global importance. This study focuses on large, heavy-duty on-road tractor trailer combinations because of their impact in terms of fuel consumption levels, emissions, and their dominance in freight transportation in the United States, which offers substantial potential to improve efficiency of the transportation sector and reduce emissions. The US Department of Energy completed a study of this topic in 2009, and the EPA and NHTSA are both engaged in regulating truck efficiency. The Energy Information Administration (EIA) reported that more than 50 percent of the total diesel consumed was for transportation and this percentage will increase. With about 65 percent of the total engine-out energy consumed by a typical heavy-duty tractor trailer being spent on overcoming aerodynamic drag at highway speeds (55mph in the USA), improvements to aerodynamic performance offers a substantial avenue for reduction in fuel usage and emissions. Besides being directly related to fuel consumption, emissions, maximum speed and acceleration, aerodynamic phenomena also influence the stability characteristics of road vehicles, and their response to crosswinds. Crosswinds from any directions will affect the drag losses and will cause a significant change in pressure distribution along the truck body. The main objective of this research is to provide a better understanding of the influence of crosswinds on the aerodynamic performance of heavy-duty tractor trailers in the United States.

A model to calculate on-road crosswinds for any temporal and spatial conditions from time-varying weather data, vehicle position and road data was developed. This transient model combined with drag data obtained from experimental, steady-state wind tunnel testing and numerical simulations for various tractor trailer configurations, the transient nature of coefficient of drag due to on-road crosswind conditions (from the model) was analyzed. Variations in yaw angle of up to 17 degrees were observed in some cases where the average yaw angle was recorded at only 3 degrees. Relationships between wind speed, yaw angle, drag and overall truck efficiency were clearly established. The research statistically measured the interaction between aerodynamic add-on devices, on-road crosswinds, and drag reduction efficiency. A region-based and time-based analysis was conducted to provide a better understanding of the aerodynamic performance of a baseline 
tractor-trailer configuration and aerodynamic add on devices. In several cases, the coefficient of drag varied as much as $60 \%$ on the routes analyzed and reductions in aerodynamic drag force up to $25 \%$ could realized by using the appropriate aerodynamic configurations. The application of these results will improve the estimation accuracy in fuel, emissions prediction models by allowing temporally and spatially disaggregated data input parameters. Finally, the study presented the different methods in which coefficient of drag is estimated and how these differences could play a role in misleading information about the aerodynamic characteristics of a tractor trailer. 


\section{Acknowledgements}

I dedicate the degree I have earned and my work to my parents, Mrs. Alamelu Sathiamoothy and Mr. Sathiamoorthy Ramachandran without whose support none of this would have been possible and would have remained a distant dream. I also want to thank my lovely wife, Roshni for her infinite love and patience.

I had always been told and taught that in order to get that feeling of accomplishment, to achieve that glorified dream, to beat the odds, one needs to sacrifice, go through hard and tough times, push harder than they can to get to the light at the end of the tunnel. Honestly, my journey was very delightful, I enjoyed my academic career all the way, endured moderate stress, and went through some bumps but nothing more than an average person can't handle. I worked genuinely with a passion to learn and was committed to make the people who supported me proud. Now, I do feel accomplished, happy and satisfied. The full credit for such a journey goes to the amazing people who have been and are around me.

It is truly a pleasure and a great experience to work as a graduate student under Dr. Nigel Clark. Nigel is not only a great mentor, he is simply a great human being and to learn from him is a treat. Thank you for sharing your wisdom with me through the years and giving me the opportunity to know you and work with you. I thank my committee members, Dr. Avinash Unnikrishnan, Dr. Mridul Gautam and Dr. Hailin Li for being very supportive and for providing innumerous valuable inputs through the course of my graduate studies. I want to specially thank, Dr. Patrick Browning for his invaluable help in the wind tunnel laboratory and his time for helping with several analytical issues without which the study would never have been fully complete. I would like to express my appreciation to Dr. Nithi Sivaneri for helping me at several stages of my graduate career and supporting me in the time of need apart from serving on my committee as a 
valuable member. I would like to thank Jeff Grossmann at AT-Dynamics for serving as an auxiliary member of my committee and for his constructive criticism. I would also like to thank the Environmental Defense Funds and the Benjamin Statler College of Engineering for funding my graduate studies and giving me the opportunity to pursue my goals.

I want to thank everyone at the Center for Alternative Fuels, Engines and Emissions and Daniel Carder for accepting me as part of the crew and giving me the opportunity to work and learn from some of the best minds. I want to thank Arvind and Marc for their incredible support and for the time they have spent teaching and training me at the lab, office and off campus. I also want to thank Pragalath, Saroj and John for their friendship and support on and off campus. To find such an amazing group in any future work place would be very hard if not impossible.

A special thanks to Ravi Sivasankaran who has been my guardian away from home and an inspiration to me in several aspects. Finally, I want to thank some of my close friends who made life away from home much like home, Mark, Praveena, Lokesh, Pushkar, Ravi Shankar, Vidya and Aditi.

Thank you all for being a part of my life and making it wonderful. 


\section{Table of Contents}

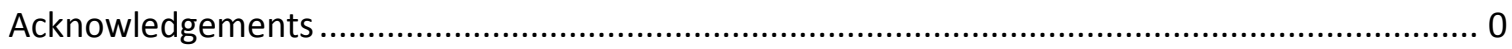

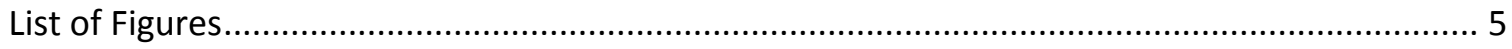

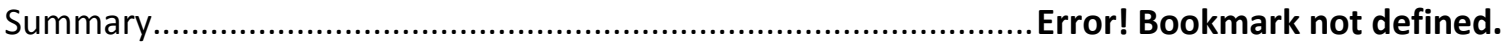

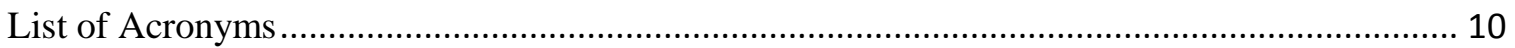

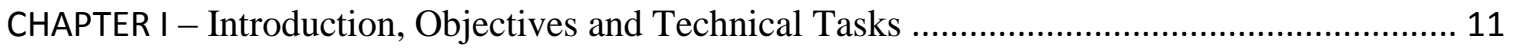

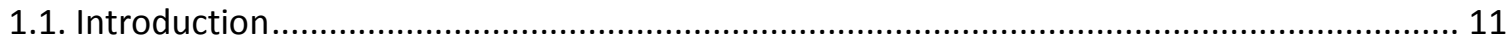

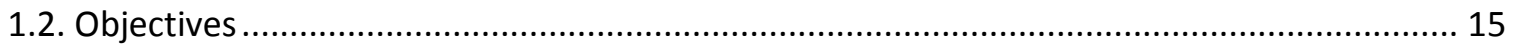

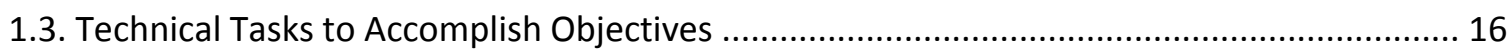

CHAPTER II - Definitions, Literature Review and Introduction to Wind Tunnel Setup ................. 17

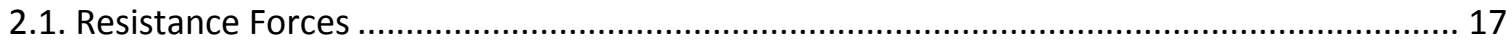

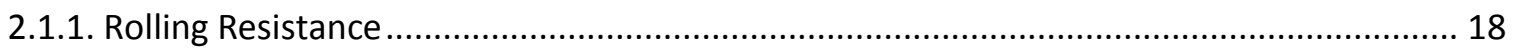

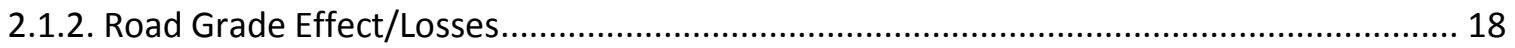

2.1.3. Drivetrain Frictional Losses/Transmission Losses/Chassis Resistance Forces..................... 19

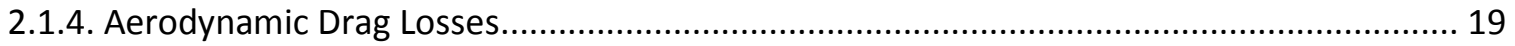

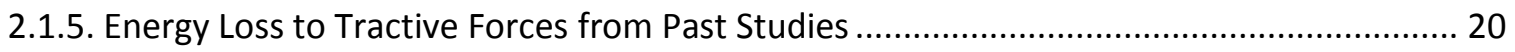

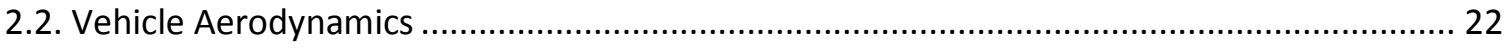

2.2.1. Definitions and Properties of Incompressible Fluids ...................................................... 23

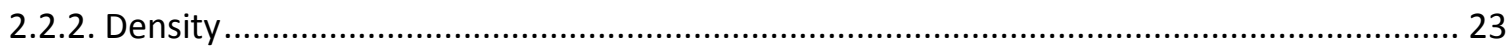

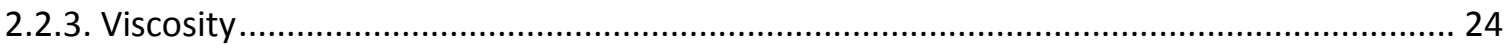

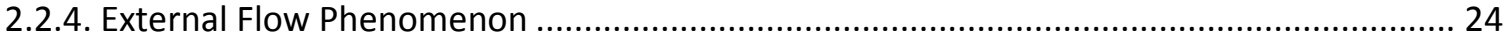

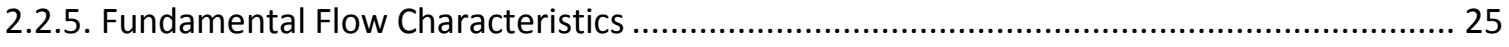

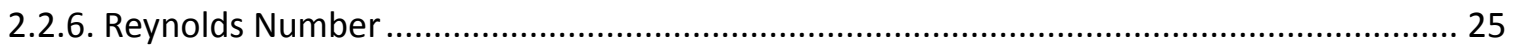

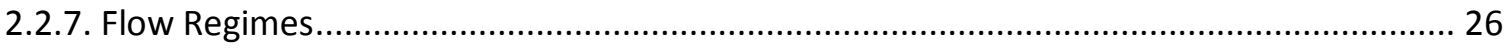

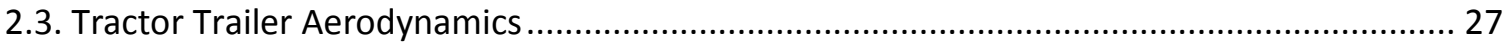

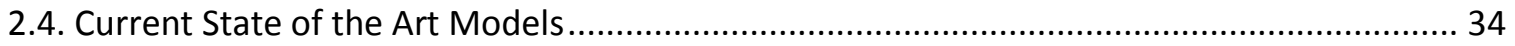

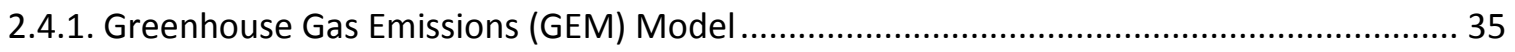

2.4.2. Motor Vehicle Emission Simulator (MOVES) Model ........................................................ 37

2.5. Introduction to Wind Tunnel Experimentation and WVU Setup .......................................... 38 
2.5.1. The Parts and Design of a Wind Tunnel and West Virginia University's Closed Loop Wind Tunnel Setup.

CHAPTER III - Fundamental Analysis, Experimentation, Modeling, Case Study and Conclusions 44

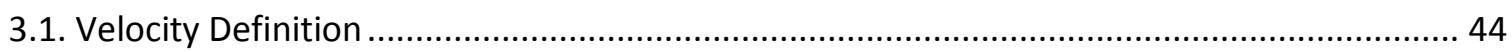

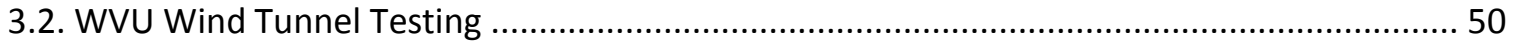

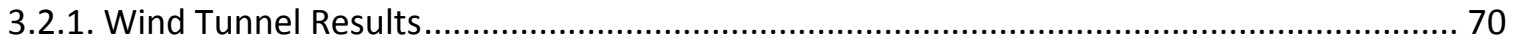

3.3. Numerical Simulations to Validate Wind Tunnel Experimental Data.................................... 84

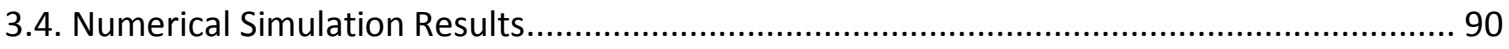

3.5. On-Road Yaw Angle Prediction Model .................................................................................. 95

3.6. On-Road Yaw Angle Prediction Model Case Studies and Results ..................................... 105

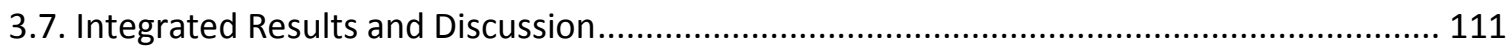

3.8. Impact of Variations in Velocity Used to Estimate Drag Coefficient ................................... 134

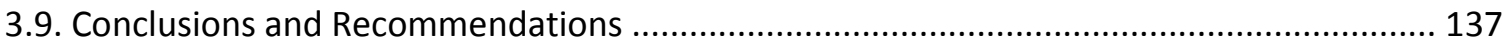

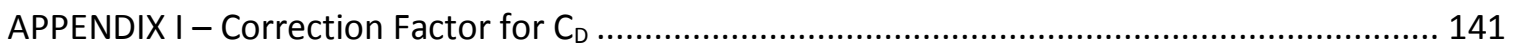

APPENDIX II - Values Calculated for Numerical Simulation ....................................................... 144

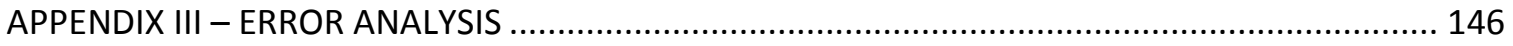

APPENDIX IV - Python Code for Calculating Transient Yaw Angles from User Defined Input

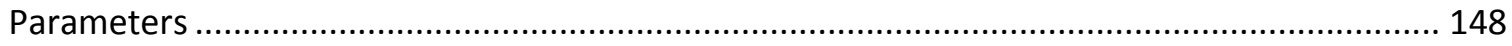

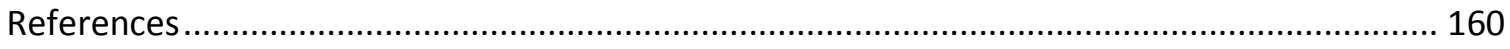




\section{List of Figures}

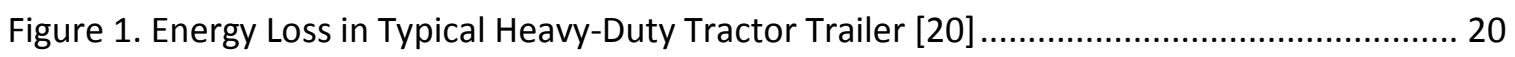

Figure 2. EPA Estimated Energy Loss for Class 8 Trucks at $65 \mathrm{mph}$ and $80,000 \mathrm{lb} \ldots \ldots \ldots \ldots \ldots \ldots \ldots \ldots . . . . . . . . . .21$

Figure 3. Flow Around Streamlined and Non-aerodynamic Shape Bodies [25] .......................... 23

Figure 4. Laminar and Turbulent Flow (Top and Bottom Respectively) Around Pipe Posts. (Credit:

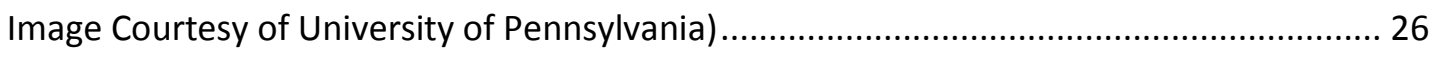

Figure 5. Ground Vehicle with Cab-mounted Air Deflector/Add-on Device [32] ......................... 29

Figure 6. Difference Between Standard Tractor Trailer and Tractor Trailer with Deflector [28].. 29

Figure 7. SAE/DOT Study - Different Trucks Tested .................................................................. 30

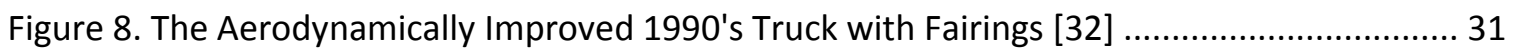

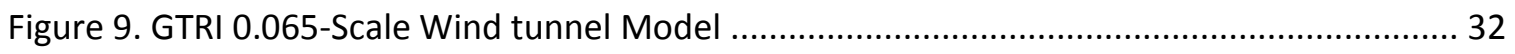

Figure 10. VSD (left) and UFD (right) Treatment Devices Tested by Wood and Bauer................. 33

Figure 11. Geometry of Trailer Base Flaps Tested at UT [38] ................................................... 34

Figure 12. Open-Circuit Wind Tunnel Schematic Diagram [52] ............................................... 40

Figure 13. Schematic Diagram of a Closed-Circuit Wind Tunnel .............................................. 41

Figure 14. Picture of 1:15 Scale Tractor-Trailer Model in the Test Section.................................. 43

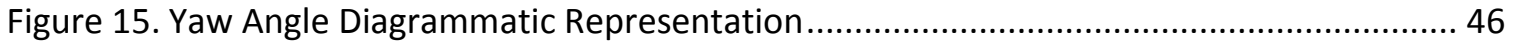

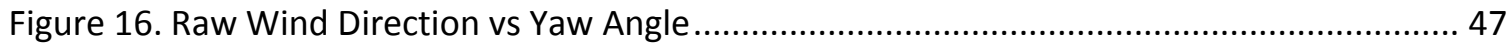

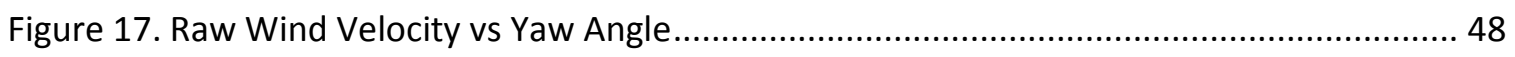

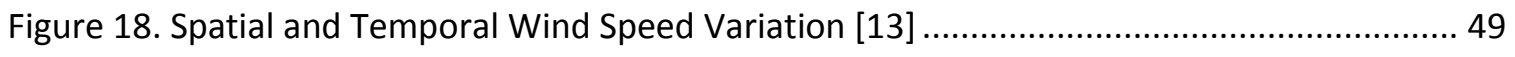

Figure 19. Spatial and Temporal Variation of Wind Direction [13] ............................................ 49

Figure 20. The 1:14.5 Scale Peterbilt 379 Wind Tunnel Model (Front and Rear View)................. 54

Figure 21. Underbody View of T-mount Model Support Uniting Tractor and Trailer................... 55

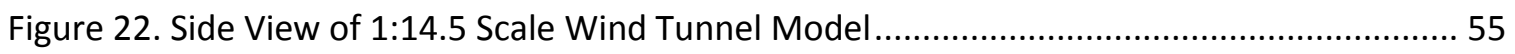

Figure 23. S-Beam Load Cell Linearly Constrained and Mounted to tunnel Floor ......................... 57

Figure 24. Probes Placed Across Test Section to Record Static and Dynamic Pressure................ 59

Figure 25. Manometer Reading Water in Inches (Flow at Test Section)..................................... 59

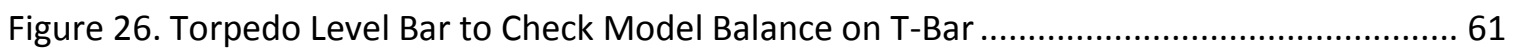

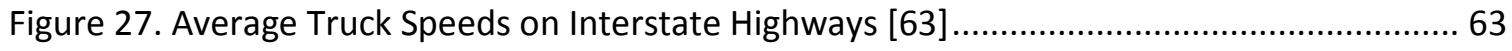




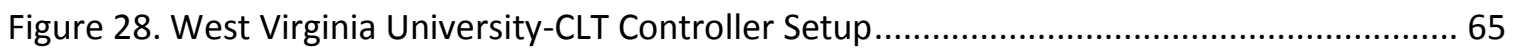

Figure 29. Diagrammatic Representation of Forces on a Truck (Including Side/lateral) .............. 67

Figure 30. Peterbilt Model Resting on 1:87 Scale Rollers on Tracks. ........................................... 70

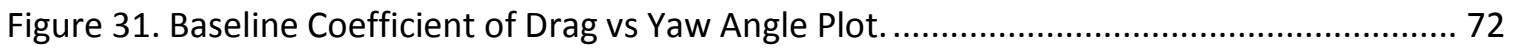

Figure 32. Visualization of Flow Pattern on the Baseline Configuration ..................................... 72

Figure 33. Coefficient of Drag vs Yaw Angle Plot (Wind Deflector - 30 degrees)......................... 74

Figure 34. Coefficient of Drag vs Yaw Angle Plot (Wind Deflector - 45 degrees)........................ 75

Figure 35. Coefficient of Drag vs Yaw Angle Plot (Wind Deflector - 60 degrees)......................... 76

Figure 36. Coefficient of Drag vs Yaw Angle Plot (Wind Deflector - 30 degrees and Tractor Trailer Gap Fairings)

Figure 37. Visualization of Flow Pattern on the Aero Configuration 4 - Wind Deflector at 30

degrees and Tractor Trailer Gap Fairings. ......................................................................... 78

Figure 38. Coefficient of Drag vs Yaw Angle Plot (Wind Deflector - 45 degrees and Tractor Trailer Gap Fairings) 80

Figure 39. Coefficient of Drag vs Yaw Angle Plot (Wind Deflector - 60 degrees and Tractor Trailer Gap Fairings). 81

Figure 40. Coefficient of Drag vs Yaw Angle Plot (Wind Deflector - 60 degrees and Tractor Trailer Gap Fairings). 82

Figure 41. Integrated Plot with all 6 Aero Configurations and the Baseline Configuration.......... 82

Figure 42. 3D Geometry of the Peterbilt 379 Model used for Numerical Analysis....................... 86

Figure 43. Finalized Mesh Geometry Shown as Cut-Sections in the X, Y, Z Planes....................... 88

Figure 44. Front View of the Cut Section Mesh Structure in the Z-plane. ................................... 89

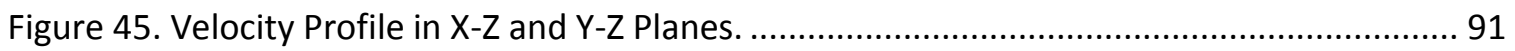

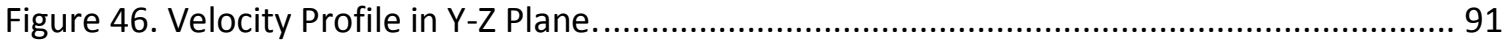

Figure 47. Velocity Profile in X-Z and Y-Z Plane

Figure 48. Chart Displaying Reynolds Number Effect on Coefficient of Drag. ............................ 94

Figure 49. Screen Capture of the 'tkdegrib' Decoder Used for Parsing GRIB2 Format Wind Data.

Figure 50. A cut section from Interstate 179 split at vertices. 100 
Figure 51. Algorithm/Pseudo Code for GIS Yaw Angle Prediction Model................................... 104

Figure 52. Yaw Angle Variation through Interstate 79, WV on March $3^{\text {rd }} 2012$........................ 105

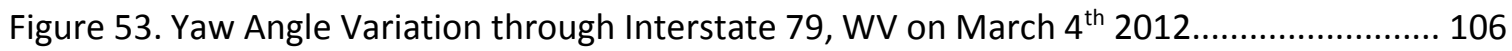

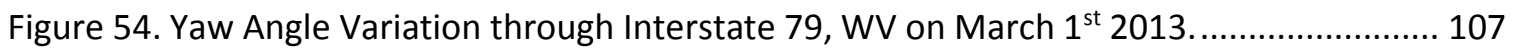

Figure 55. Yaw Angle Variation through Interstate 79, WV on March 2 ${ }^{\text {nd }}$ 2013........................ 107

Figure 56. I-79 Running Through West Virginia Layered over Wind Maps in ArcGIS 10.1......... 109

Figure 57. Cross Country Route Employed (I-70) with Varying Vehicle Speeds......................... 110

Figure 58. Yaw Angle Variation through Interstate 70 through Missouri and Kansas, October $10^{\text {th }}$ 2011. 110

Figure 59. $C_{D}$ Variation on 1-79, March $3^{\text {rd }} 2012$ for Baseline Configuration. 112

Figure 60. C Variation on I-79, March $3^{\text {rd }} 2012$ for Baseline with Wind Deflector Placed at $30^{\circ}$.

Figure 61. $C_{D}$ Variation on I-79, March $3^{\text {rd }} 2012$ for Baseline with Wind Deflector Placed at $45^{\circ}$.

Figure 62. $C_{D}$ Variation on I-79, March $3^{\text {rd }} 2012$ for Baseline with Wind Deflector Placed at $60^{\circ}$.

Figure 63. $C_{D}$ Variation on I-79, March $3^{\text {rd }} 2012$ for Baseline with Gap Fairings and Wind Deflector Placed at $30^{\circ}$.

Figure 64. C Variation on 1-79, March $3^{\text {rd }} 2012$ for Baseline with Gap Fairings and Wind Deflector Placed at $45^{\circ}$.

Figure 65. $C_{D}$ Variation on 1-79, March $3^{\text {rd }} 2012$ for Baseline with Gap Fairings and Wind Deflector Placed at $60^{\circ}$.

Figure 66. $C_{D}$ Variation on I-79, March 4 2012 for Baseline Configuration.

Figure 67. CD Variation on I-79, March $4^{\text {th }} 2012$ for Baseline with Wind Deflector Placed at $30^{\circ}$.

Figure 68. $C_{D}$ Variation on I-79, March $4^{\text {th }} 2012$ for Baseline with Wind Deflector Placed at $45^{\circ}$.

Figure 69. $C_{D}$ Variation on I-79, March $4^{\text {th }} 2012$ for Baseline with Wind Deflector Placed at $60^{\circ}$. 
Figure 70. $C_{D}$ Variation on I-79, March $4^{\text {th }} 2012$ for Baseline with Gap Fairings and Wind Deflector Placed at $30^{\circ}$.

Figure 71. $C_{D}$ Variation on 1-79, March $4^{\text {th }} 2012$ for Baseline with Gap Fairings and Wind Deflector Placed at $45^{\circ}$.

Figure 72. $C_{D}$ Variation on I-79, March $4^{\text {th }} 2012$ for Baseline with Gap Fairings and Wind Deflector Placed at $60^{\circ}$.

Figure 73. $C_{D}$ Variation on 1-79, March $1^{\text {st }} 2013$ for Baseline Configuration. 120

Figure 74. $C_{D}$ Variation on I-79, March $1^{\text {st }} 2013$ for Baseline with Wind Deflector Placed at $30^{\circ}$.

Figure 75. $C_{D}$ Variation on I-79, March $1^{\text {st }} 2013$ for Baseline with Wind Deflector Placed at $45^{\circ}$.

Figure 76. $C_{D}$ Variation on I-79, March $1^{\text {st }} 2013$ for Baseline with Wind Deflector Placed at $60^{\circ}$.

Figure 77. $C_{D}$ Variation on I-79, March $1^{\text {st }} 2013$ for Baseline with Gap Fairings and Wind Deflector Placed at $30^{\circ}$.

Figure 78. C Variation on I-79, March 1st 2013 for Baseline with Gap Fairings and Wind Deflector Placed at $45^{\circ}$.

Figure 79. $C_{D}$ Variation on I-79, March $1^{\text {st }} 2013$ for Baseline with Gap Fairings and Wind Deflector Placed at $60^{\circ}$.

Figure 80. $C_{D}$ Variation on 1-79, March $2^{\text {nd }} 2013$ for Baseline Configuration.

Figure 81. $C_{D}$ Variation on I-79, March $2^{\text {nd }} 2013$ for Baseline with Wind Deflector Placed at $30^{\circ}$.

Figure 82. $C_{D}$ Variation on I-79, March $2^{\text {nd }} 2013$ for Baseline with Wind Deflector Placed at $45^{\circ}$.

Figure 83. $C_{D}$ Variation on I-79, March $2^{\text {nd }} 2013$ for Baseline with Wind Deflector Placed at $60^{\circ}$.

Figure 84. C Variation on 1-79, March $2^{\text {nd }} 2013$ for Baseline with Gap Fairings and Wind Deflector Placed at $30^{\circ}$. 
Figure 85. C V Variation on 1-79, March $2^{\text {nd }} 2013$ for Baseline with Gap Fairings and Wind

Deflector Placed at $45^{\circ}$.

Figure 86. $C_{D}$ Variation on I-79, March $2^{\text {nd }} 2013$ for Baseline with Gap Fairings and Wind

Deflector Placed at $60^{\circ}$.

Figure 87. $C_{D}$ Variation in I-70 (Missouri-Kansas Cross Country Route), October 10 ${ }^{\text {th }}, 2011$ for

Baseline Configuration.

Figure 88. $C_{D}$ Variation in I-70 (Missouri-Kansas Cross Country Route), October 10 ${ }^{\text {th }}, 2011$ for

Baseline Configuration with Wind Deflector at $30^{\circ}$.

Figure 89. $C_{D}$ Variation in I-70 (Missouri-Kansas Cross Country Route), October 10 ${ }^{\text {th }}, 2011$ for

Baseline Configuration with Wind Deflector at $45^{\circ}$.

Figure 90. $C_{D}$ Variation in I-70 (Missouri-Kansas Cross Country Route), October 10 $0^{\text {th }}, 2011$ for

Baseline Configuration with Wind Deflector at $60^{\circ}$.

Figure 91. $C_{D}$ Variation in I-70 (Missouri-Kansas Cross Country Route), October 10 ${ }^{\text {th }}, 2011$ for

Baseline Configuration with Wind Deflector at $30^{\circ}$ and Gap Fairings.

Figure 92. $C_{D}$ Variation in I-70 (Missouri-Kansas Cross Country Route), October 10 ${ }^{\text {th }}, 2011$ for

Baseline Configuration with Wind Deflector at $45^{\circ}$ and Gap Fairings.

Figure 93. $C_{D}$ Variation in I-70 (Missouri-Kansas Cross Country Route), October 10 ${ }^{\text {th }}, 2011$ for

Baseline Configuration with Wind Deflector at $45^{\circ}$ and Gap Fairings.

Figure 94. The Route Traced by the Vehicle with Input Starting Point and Vehicle Speed. ....... 132

Figure 95. The Yaw Angles Experienced by the Vehicle along its Travel Path. ........................... 133

Figure 96. Vector Representation for Forces Measured and Analyzed in the Study.

Figure 97. Force Diagram While Calculating the Load Cell Response Factor Based on Assumed

Aerodynamic Center.

Figure 98. Force Diagram While Calculating the Load Cell Response Factor Based on Actual

Aerodynamic Center. 


\section{List of Acronyms}

$\alpha$ - Grade angle, degree

A - $\quad$ Frontal area or reference area, $\mathrm{m}^{2}$ or $\mathrm{in}^{2}$

$\beta$ - $\quad$ Road angle/curvature, degree or radian

$C_{D}$ - Coefficient of drag obtained from wind tunnel experiments

$\mathrm{C}_{\mathrm{D} \text {-numerical-CLT }}$ - Coefficient of drag obtained from numerical simulations (while matching Reynolds Number of the wind tunnel experiments)

$\mathrm{C}_{\mathrm{D} \text {-numerical-OR }}$ - Coefficient of drag obtained from numerical simulations (while matching Reynolds Number of the on road condition)

$\varepsilon$ - Turbulence dissipation rate, $\mathrm{m}^{2} / \mathrm{s}^{3}$

$\mathrm{F}_{\text {rolling resistance }}$ - Rolling resistance force, $\mathrm{N}$

$F_{x^{\prime}}$ - Force in the direction of $V_{r}$ or force in the direction of free stream velocity, $V_{\infty \text {-wind tunnel }}$

$F_{r}$ - Ultimate resultant force

$f_{r}$ - Coefficient of rolling resistance

g - Acceleration due to gravity, $\mathrm{m} / \mathrm{sec}^{2}$

I - Characteristic length, meter or inch

$I_{\text {tunnel }}$ - Characteristic length of scaled model used for wind tunnel experiments, meter or inch

$L_{y^{\prime}}$ - Side/lateral drag force

$\mathrm{m}$ - Gross vehicle weight, $\mathrm{kg}$ or $\mathrm{lb}$

$\Theta$ - Raw wind direction, degree or radian

$\phi$ - Relative wind-truck angle, degree or radian

$\rho$ - Density of ambient air, $\mathrm{kg} / \mathrm{m}^{3}$

$\rho_{\text {tunnel }}$ - Density of ambient air inside the test section, $\mathrm{kg} / \mathrm{m}^{3}$ 
$\mathrm{T}$ - Temperature of ambient air, $\mathrm{K}$

$\mu$ - Dynamic viscosity, $\mathrm{kg} / \mathrm{m}-\mathrm{sec}$

$\mathrm{u}$ - Kinematic viscosity, $\mathrm{m}^{2} / \mathrm{sec}$

$\mathrm{V}$ - Raw truck velocity, $\mathrm{m} / \mathrm{sec}$ or $\mathrm{mph}$

$\mathrm{V}_{\mathrm{r}}$ - Relative wind-truck speed, $\mathrm{m} / \mathrm{sec}$ or $\mathrm{mph}$

$V_{W}$ - Raw wind speed, $\mathrm{m} / \mathrm{sec}$ or $\mathrm{mph}$

$\mathrm{V}_{\infty \text {-wind tunnel }}$ - Free stream velocity inside the tunnel, $\mathrm{m} / \mathrm{sec}$ or $\mathrm{mph}$

$\psi$ - Yaw angle, degree

\section{CHAPTER I - Introduction, Objectives and Technical Tasks}

\subsection{Introduction}

According to the American Transportation Research Institute (ATRI), fuel prices currently constitute the largest share of cost amongst trucking fleets with over 35 percent [1]. With the cost of diesel prices consistently growing with on-highway prices subject to increase due to increased vehicle population, it presents a major concern in the heavyduty trucking sector. In support to the other claims, the United States Energy Information Administration [EIA] has reported, 'the energy demand for HDVs-including tractor trailers, vocational vehicles, heavy-duty pickups and vans, and buses will increase at an average annual growth rate of 0.8 percent, which is the highest among transportation modes.' It is evident that heavy-duty trucks dominate fuel consumption levels in the transportation freight sector accounting for 17 percent of transportation oil use and 12 percent of all United States oil consumption [2]. Trucks deliver 64 percent of the goods transported across the United States [3], and as a result all measures to reduce fuel consumption are being considered. The driving instigation for this research 
was that, a 2 - 10 percent increase in fuel economy percentages in this sector will result in substantial annual fuel cost savings; and consequently, energy savings and emissions reduction.

The pollution effects of fuel use and the likely increases of fuel cost in the next few decades have increased the pressure of considering alternative energy sources for heavy-duty tractor trailers [4]. Large engines with high horsepower are used in heavyduty vehicles (HDVs) to provide sufficient capacity to counteract the resistive forces on truck movement. The horsepower of a HDV is an important factor of the truck's overall design. The available power of a vehicle must equal or exceed the total of all resisting forces to maintain the desired speed. The total resistance retarding the vehicles desired motion is the sum all external tractive forces, and internal chassis resistance forces which include, aerodynamic drag, rolling resistance, grade effect and transmission/engine losses [5]. Total resistance force is transferred to the engine through the crankshaft. This research focuses on exploiting the gains offered in reducing the aerodynamic drag losses of heavy-duty tractor trailers. For a better understanding of the context of sentences in this dissertation, it should be noted that the terms HDV (Heavy-duty vehicle), heavy-duty tractor trailer, heavy-duty truck, and truck are used interchangeably.

Large articulated trucks are considered to be aerodynamically inefficient due to the design, size, and shape of their bluff body [6]. Studies conducted in the past have shown that wind blowing in the direction opposite to the direction of vehicle travel (crosswinds) substantially decreases the aerodynamic efficiency of tractor trailers. In 1987, a study conducted at Kenworth Trucking Company [7] showed a 68 percent increase in $C_{D}$ on a Kenworth baseline tractor trailer configuration due to varying crosswinds in the direction opposite to the vehicle's motion. A more recent study conducted at NASA [8] showed up to a 58 percent increase in $C_{D}$ (obtained from wind 
tunnel experiments) on a Kenworth T600A baseline tractor trailer configuration for the same crosswind condition. This shows improvements to truck shapes over the years, but an inability to substantially reduce the impact of wind blowing in the direction opposing the direction of vehicle travel. Other studies conducted by Subrata Roy [9] showed the effectiveness of an improved truck geometry (in a tractor trailer configuration) resulting in a 30 percent reduction of $C_{D}$ (obtained from Computational Fluid Dynamic results). Other studies, such as those listed in [10], [11], have indicated the effectiveness of aerodynamic add-on devices for tractor trailers to reduce $C_{D}$. The velocity based on which the coefficient of drag was calculated in these studies was not clearly defined. Although each study has its individual value, a direct comparison between one study results to another could not be made since there is no established definition for $C_{D}$. The effectiveness of different aerodynamic devices either decrease or increase under varied crosswind conditions. Tractor trailers operating in different regions gain varied benefits from the same add-on devices. The trailer side skirts are more effective in cases of crosswinds rather than zero crosswind conditions; whereas, the effectiveness of a wind deflector decreases with the slightest impact of crosswinds [11]. The current generation of fuel and emission factor models, including the U.S. EPA's Motor Vehicle Emissions Simulator (MOVES) are based on predetermined drag terms. The aerodynamic drag coefficients $\left(C_{D}\right)$ are fixed values which are binned based on vehicle type and class. However, it has been well established that the coefficient of drag of vehicles which are affected by crosswinds vary significantly [10] [11] [12]. There is a lack of realistic aerodynamic parameter representative of the vehicle activity regime. In a simplified view, most of the aerodynamic developments, optimization and result validations are carried out in wind tunnels or a regulated test track but these results are expected to prove themselves on the road. 
Several studies have been conducted in the area of heavy-duty tractor trailer aerodynamics examining different cases, but no study has effectively used the results obtained by regulated testing to predict the aerodynamic characteristics as realized under real-world operating conditions. A study to claim, "Predicting the real-world aerodynamic experience of heavy-duty tractor trailers" could never be successfully accomplished, primarily due to the prevailing weather conditions in the vehicle's path of travel [13] [14], and also due to inconsistency in reference velocity used to calculate the coefficient of drag $\left(C_{D}\right)$. This study verifies the statement, 'The efficiencies of aerodynamic add-on devices cannot be consistently realized by all heavy-duty tractortrailers operating in real-world conditions across the nation at different time frames'. In real-world operations, $C_{D}$ is a function of several factors and can no longer be represented in its conventional constant form.

In this study, the subsonic wind tunnel, a low turbulence flow tunnel developed at West Virginia University was used to record drag values and test aerodynamic add-on devices on a scaled, conventional tractor trailer. This study utilized the drag measurement, flow analysis capabilities and the vast datasets that reside at the National Oceanic and Atmospheric Administration (NOAA), and combines them with an advanced transient yaw angle prediction model to predict power loss due to on-road aerodynamic drag force. The California Air Resource Board (CARB) has announced that, beginning Jan. 1, 2013, all 2010 model year or newer tractors and trailers must comply with the tractor trailer greenhouse gas (GHG) regulation to reduce GHG emissions from long-haul tractor trailer combination vehicles operating in California. This includes retrofitting the tractor trailers with Smartway verified aerodynamic devices such as trailer skirts, and fairings in order for tractors to meet specified fuel efficiency improvements [15]. As a first attempt, the model built in this study uses values obtained from a 2007 model year tractor trailer configuration for all analyses. 


\subsection{Objectives}

The ultimate objective of this study was to develop and integrate a continuous drag coefficient prediction model with drag coefficient data obtained from experimental results to analyze spatial and temporal variation of aerodynamic performance and aerodynamic add-on device effectiveness. To achieve this objective it was necessary to perform data collection, validation, analysis of different tractor trailer configurations, including tests for aerodynamic add-on devices and analysis of flow regime around the model. The following tasks were necessary to accomplish these objectives:

1. Obtain reliable drag measurements from wind tunnel experiments simulating highway operations and validate it using numerical simulations.

2. Clearly establish, the different velocities and forces interacting with an on-road tractor trailer and a wind tunnel tractor trailer.

3. Perform statistical analysis to determine the correlation between crosswinds and coefficient of drag.

4. Region-based and time-based efficiency analysis of all tested aerodynamic devices.

5. Employ spatial analysis techniques in GIS to formulate the drag coefficient prediction model, with inputs being the vehicle position, trajectory, and NOAA wind datasets.

The major contribution of this study was aimed at explaining the significance of variations in aerodynamic performance and efficiencies of aerodynamic devices due to the region and time at which a truck operates. 


\subsection{Technical Tasks to Accomplish Objectives}

The above objectives were accomplished following the tasks in the phases described below:

Phase-1: $\quad$ The first phase of the research focus was to develop a database of $C_{D}$ values corresponding to yaw angles which later acted as a lookup table. Wind tunnel experiments on a 1:15 scale 2007 Peterbilt 379 were conducted at the West Virginia University subsonic wind tunnel. The validation of data was provided by numerical simulations on corresponding model configurations and conditions. FloExpress, Solidworks and ICEM are commercially available simulation, design and meshing tools used for the purpose of numerical simulation.

Phase-II: The second phase of the research focus was to establish a method to calculate the continuous yaw angles over any topographical region based on vehicle position, trajectory, and NOAA wind data sets. NOAA's vast wind datasets, which give access to wind data in vector format over the Continental United States (CONUS), were used for this purpose. Geographical Information Systems developed by the Earth System Research Laboratory, is a commercially available, geoprocessing software that was used for the purpose of building this model.

Phase-III: The third phase focused on integrating the model developed in phase I and the results obtained in phase II. The model built in phase II enabled the prediction of crosswind conditions as realized by a tractor trailer travelling any user-defined route. A code was written in Matlab (also a commercially available tool developed by Mathworks) to extract continuous $C_{D}$ values from the database generated in phase I corresponding to vehicle path of travel and the continuous yaw angle predicted in phase I. 
Phase-IV: In the final phase of the research, several case studies were conducted to analyze how spatial and temporal variations affect the effectiveness of the tested aerodynamic add-on devices (from phase II). The correlation between on-road power consumption, emissions and crosswinds was established by comparing the results obtained from the model and results obtained from on-road testing.

\section{CHAPTER II - Definitions, Literature Review and Introduction to Wind Tunnel Setup}

\subsection{Resistance Forces}

Internal combustion engines convert fuel energy to heat and mechanical energy. The efficiency of diesel engines is comparatively more than gasoline engines because they operate at higher compression ratios (which yields more work output on engine expansion stroke) [16]. In modern-day diesel truck engines, 53 percent of the fuel energy is lost as heat through exhaust and cooling systems, another 5 percent is lost in engine friction and pumping losses and only 42 percent is available as engine output [17]. This is the total available energy to overcome aerodynamic drag, rolling resistance, drivetrain friction, negotiate grade effects (inertial forces) and provide power to accessories such as cooling and heating units. The effect of these factors to energy and fuel consumption varies greatly depending on driving speed, truck weight, terrain, driving attitude, wind speed and angle, and pavement conditions [6]. Unlike other resistive forces, however, aerodynamic drag force increases steeply with velocity and becomes the largest source of energy loss at typical highway speeds. Being the highest contributor for power loss, it also provides the substantial potential for fuel savings. 


\subsubsection{Rolling Resistance}

The total force exerted by the tires of a vehicle on the road surface acting against the direction of movement is called rolling resistance. This is primarily caused by the deformation which occurs at the contact area between the tire and road surface. Studies have shown that rolling resistance accounts for about one-third of the engine power required to propel the HDV at highway speeds, and that the fuel consumption is inversely proportional to the coefficients of rolling resistance/constant [18]. However, surface adhesion is the result of several factors combined including the size of the tires, tire pressure, tire wear, tire temperature, and road surface. The general equation used to calculate rolling resistance,

$$
F_{\text {rolling resistance }}=f_{r} \times m \times g
$$

Where,

$$
\begin{gathered}
\text { Frolling resistance = rolling resistance force in } \mathrm{N}, \\
f_{r}=\text { coefficient of rolling resistance, } \\
m=\text { gross vehicle weight in } \mathrm{kg}, \text { and } \\
g=\text { acceleration due to gravity in } \mathrm{m} / \mathrm{sec}^{2} .
\end{gathered}
$$

The rate of increase in rolling resistance at highway speeds is not prominent in HDVs as compared to lighter vehicles.

\subsubsection{Road Grade Effect/Losses}

The force of vehicle weight acting at an angle is referred to as grade resistance. This usually occurs when the vehicle is making a climb at an angle. The magnitude of grade resistance is affected only by the vehicle weight and the angle of the climb [5], and is usually calculated as,

$$
F_{\text {grade }}=m \times g \times \sin \alpha
$$


Where, $\alpha$ is the grade angle in degrees.

\subsubsection{Drivetrain Frictional Losses/Transmission Losses/Chassis Resistance Forces}

The free motion of a HDV along its desired path at its desired speed is retarded by numerous other forces other than the above described external tractive forces, and is referred to as internal resistance forces. Chassis resistance forces, or drivetrain losses, are the primary contributor. Driveline resistance power losses occur in the transmission, universal joints, axle differentials, seals, and bearings due to mechanical friction and several other mechanical components which are involved in the power transmission system. The magnitude of the loss is related to the friction quality, lubrication efficiency between components, and wear. Other factors, which could also add to drivetrain losses, include ambient temperature and vehicle speed. Drivetrain losses generally account for less than 5 percent of the energy demand (at the wheel hub) at highway speeds [19]

\subsubsection{Aerodynamic Drag Losses}

Aerodynamic drag resistance is the air resistance or the force exerted on the vehicle by the pressure of air surrounding it. The general theory is, as the truck moves and gains speed, the resistance offered by the fluid (air) surrounding it increases and impedes the motion of the truck. This force exerted on the vehicle in motion is known as aerodynamic drag force.

$$
F_{\text {aero }}=\frac{1}{2} \rho A C_{D} V^{2}
$$

The magnitude of aerodynamic drag force is affected by the vehicle's shape/design, frontal area $(A)$, speed $(V)$, drag coefficient $\left(C_{D}\right)$ and density of ambient air $(\rho)$. Since aerodynamic drag force increases exponentially with velocity, it becomes the largest 
source of power consumption at typical highway speeds [6]. At 65mph, aerodynamic drag accounts for approximately 65 percent of the total shaft-out energy for a typical heavy-duty tractor trailer [19], [8]. This provided the driving instigation to research the factors influencing the major source of energy loss, and gain more insight into the dynamics of the on-road tractor trailers.

\subsubsection{Energy Loss to Tractive Forces from Past Studies}

Several studies have indicated energy loss percentages from heavy-duty tractor trailer configurations. Although the results from varying studies were slightly different, they all conferred on the fact that the energy loss due to aerodynamic drag was the most dominant among all tractive/resistance losses.

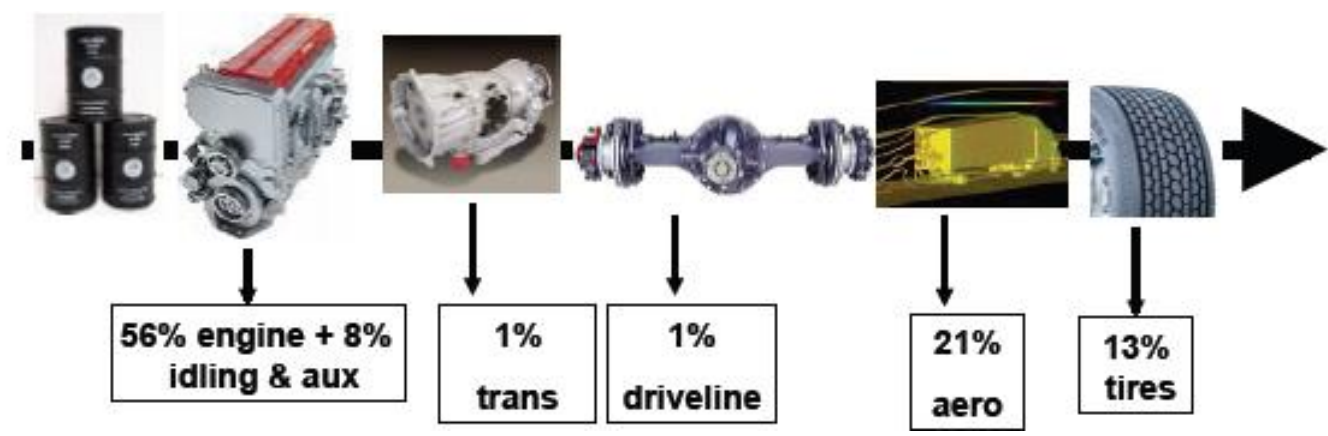

Figure 1. Energy Loss in Typical Heavy-Duty Tractor Trailer [20]

The U.S. DOE reported that the energy loss in tractor trailers travelling on the highway due to external tractive forces is highest in the form of aerodynamic drag loss at 21 percent and that proposed efforts to increase fuel economy by reducing the aerodynamic drag on the vehicle [21]. In 2010, the National Academy of Sciences prepared a report assessing fuel economy technologies for medium-and heavy-duty vehicles. The assessment concluded that aerodynamic drag impacted fuel economy the 
most and was reported to be dominant accounting for 55 percent of the total energy consumption at highway operating conditions [22]. Table 1 below depicts the energy consumption percentages between the various sources at both highway and urban operating conditions.

Table 1. Engine Power Consumption by Source for Fully-Loaded Class 8 Tractor Trailer

\begin{tabular}{|l|l|l|}
\hline Source & Urban & Highway \\
\hline Drivetrain & $10-15 \%$ & $5-10 \%$ \\
\hline Inertia/Braking/Grade & $35-50 \%$ & $0-5 \%$ \\
\hline Rolling Resistance & $20-30 \%$ & $30-40 \%$ \\
\hline Auxiliary Loads & $15-20 \%$ & $2-10 \%$ \\
\hline Aerodynamic Losses & $10-25 \%$ & $35-55 \%$ \\
\hline
\end{tabular}

\section{Total Engine Loss $57-59 \%$}

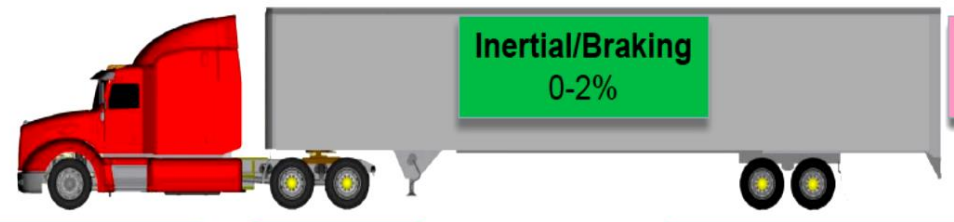

Aerodynamic Loss $15-22 \%$

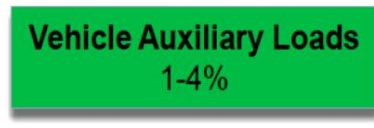

Drivetrain

$2-4 \%$

Rolling Resistance

$13-16 \%$

Figure 2. EPA Estimated Energy Loss for Class 8 Trucks at $65 \mathrm{mph}$ and $80,000 \mathrm{lb}$ 
The EPA certified GEM (Greenhouse Gas Emission Model) predicts 15-22 percent of the total energy is lost due to aerodynamic drag [23].

\subsection{Vehicle Aerodynamics}

The behavior of fluid around a body may be described by considering the fluid as a continuous medium and not accounting for the motion of single molecules. The term 'fluid' can be described in many different ways, but the general understanding is, it is a substance that deforms continuously under the action of tangential stresses. When no motion is present (in conditions of static equilibrium), the fluid particles are subject only to normal stresses, which are also referred to as pressure stresses. When studying the fluid dynamics with respect to a complex state such as a bluff body in motion, it is generally assumed that the fluid present is incompressible (which means that the density of the fluid is constant). It is also worthwhile to note that the variation in density of the fluid is significant only when the velocity of the moving body is comparable with the speed of sound. In terms of fluid dynamics, on-road tractor trailers are bluff bodies. Bluff body is the term used for objects which are not aerodynamically efficient, or as opposed to streamlined objects. In general the flow around a streamlined object remains attached, producing no boundary layer separation and comparatively smaller pressure drag. However, the flow around a non-aerodynamic body or bluff body separates, resulting in a region of high surface pressure on the front side and low surface pressure on the back side causing significant pressure drag [24]. The external geometries of tractor trailers are complex. The internal ducts, cavities, gaps and rotating wheels add further complexity to the exterior geometry. 
Non-aerodynamic shape

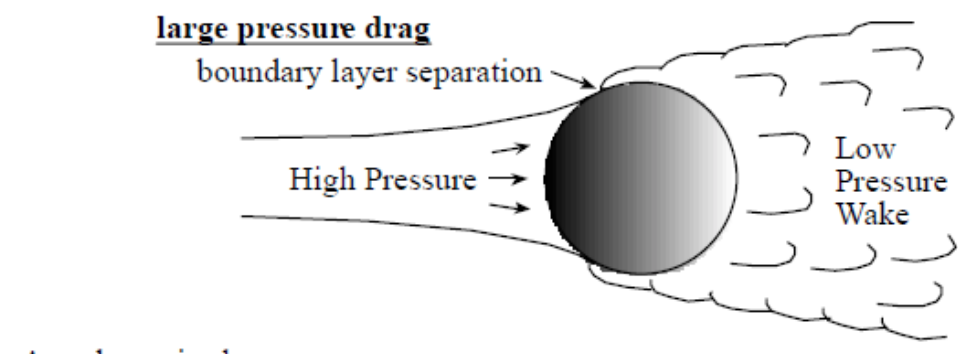

Aerodynamic shape

low pressure drag no separated flow region

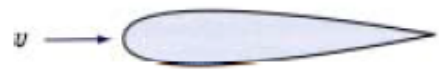

Figure 3. Flow around Streamlined/Aerodynamic and Non-aerodynamic Shape Bodies [25]

Figure 3 shown above provides an illustrated view of a flow around the streamlined airfoil which is referred to as aerodynamically shaped body where there is no boundary layer separation and comparatively small pressure drag. However, the flow around the circular cylinder which is considered to be less aerodynamic results in a region of high surface pressure and thus, significant pressure drag.

\subsubsection{Definitions and Properties of Incompressible Fluids}

Listed below in the following subjections, are definitions and properties needed to correctly ascertain the full meaning of fluid dynamics as they pertain to on-road tractor trailer aerodynamics.

\subsubsection{Density}

Fluid density $(\rho)$ depends on pressure and temperature. The compressibility or the incompressibility property of the fluid is the tendency to vary in density due to changes in pressure and temperature. Tractor trailers in motion, are exposed to a free stream of fluid and always operate at speeds/velocities which are lower than $1 / 3^{\text {rd }}$ of the speed of 
sound. For this velocity range $(55 \mathrm{mph}-65 \mathrm{mph})$, the variations in pressure and temperature in the flow field are small, and therefore the corresponding change in density is negligible and can be neglected. Thus, the fluid can be regarded as incompressible.

\subsubsection{Viscosity}

Viscosity is a measure of resistance caused by molecular friction between the fluid particles. In general, fluids would possess viscosity or internal resistance. According to Newton's law,

$$
\tau=\mu \times \frac{d V}{d y}
$$

The shear stress $\tau$ is proportional to the velocity gradient $\frac{d V}{d y}$. The constant $\mu$ is a property of the fluid called dynamic viscosity and it generally depends on the temperature.

$$
v=\frac{\mu}{\rho}
$$

Where, $\mathrm{u}$ is called kinematic viscosity which also depends on pressure and temperature. It should be noted that, for incompressible fluids, only temperature dependence exists for $\mu$ and $u[26]$.

\subsubsection{External Flow Phenomenon}

The thickness of the layer of fluid dispersion as it flows over or around the surface of a body is known as boundary layer thickness. This dispersion is wide and breaks in the case of bluff body and this phenomenon is known as boundary layer separation; the flow is entirely governed by viscous effects. In vehicle-fixed coordinates, the ground 
plane is a surface with constant velocity, $V$ or $V_{\infty}$ and no boundary layer is present at this surface.

\subsubsection{Fundamental Flow Characteristics}

The flow over a tractor trailer is three-dimensional. In general, the flow separation occurs and the boundary layers are turbulent. Typically for bluff bodies such as tractor trailers, pressure drag is the primary drag component overshadowing skin-friction drag. The flow around a moving HDV is generally governed by the dispersed boundary layer and the viscous effects. Wherever an adverse pressure gradient is too severe, the flow separates from the contour and goes its own way. The boundary layer is present over wide regions of the surrounding space and is quite significant as compared to the characteristic length of the vehicle. The flow around bluff bodies is generally turbulent and this is characterized by the Reynolds number.

\subsubsection{Reynolds Number}

It is a dimensionless number and is a function of the velocity, $V$, dynamic viscosity, $\mu$ of the fluid, and the characteristic length, $I$. It is defined as the ratio of inertial forces to viscous forces. The character of the viscous flow around a body depends only on the body shape and the Reynolds number. The flow regime varies with variations in Reynolds number. When studying aerodynamics of road vehicles, experiments are conducted to mimic the real-world operating conditions to ensure valid results. Apart from achieving geometric similarities, it is important to also achieve dynamic similitude (matching dynamic properties as in the real application). The Reynolds number needs to be carefully assessed for a model-scale laboratory experiment involving fluid to be representative of full-scale conditions [27]. There is a transition in the flow regime from 
laminar (where smooth, streamlined, constant viscous forces are dominant) to turbulent flow (where instable, irregular inertial forces are dominant).

$$
R e=(\rho \times V \times l) / \mu
$$

\subsubsection{Flow Regimes}

At low flow rates, fluids move in "layers." The velocity of molecules contained within these layers does not cross the streamlines. This behaviour is called laminar flow. In pressure driven flows, laminar flow is predominant at low flow rates but at higher flow rates, the streamlined layers are disrupted by eddies moving in all directions. This is known as turbulent flow. The transition between laminar and turblent flow is complex and depends on many fluid flow parameters. This region of transition is only significant to discuss in cases where the flow is neither fully laminar nor fully turbulent.

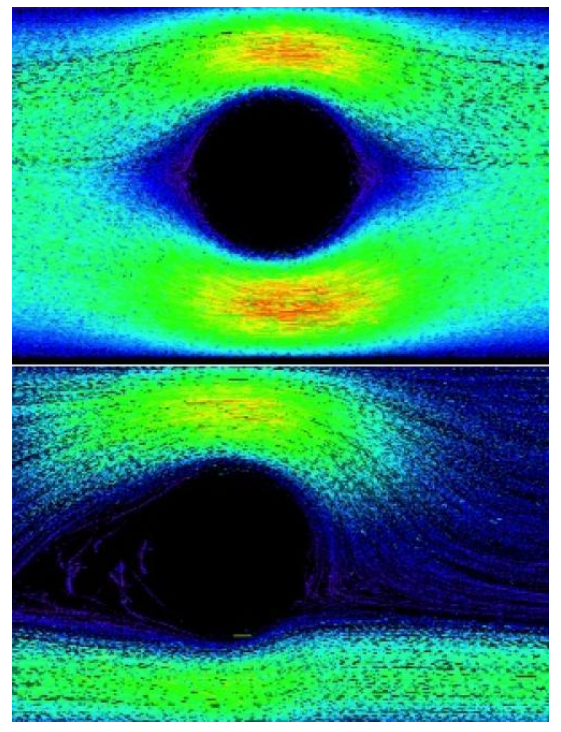

Figure 4. Laminar and Turbulent Flow (Top and Bottom Respectively) Around Pipe Posts.

(Credit: Image Courtesy of University of Pennsylvania) 
In laminar flow or linear flow, there is a direct connection between the force applied to the fluid and how fast it moves. This implies, once the force applied is removed, viscous forces stop the fluid's motion. However, this is not the case in turbulent flows which are more complex. The inertial forces (which are nonlinear in nature) have developed as part of the moving fluid, and keep the fluid moving even after the applied force is removed.

\subsection{Tractor Trailer Aerodynamics}

Fuel savings through aerodynamic drag reduction have been viewed as a potential area for energy and fuel savings since 1914 as the need for high-speed trucks and buses arose with the construction of more sophisticated roadways. Reducing aerodynamic drag losses to improve fuel economy in heavy-duty vehicles has been an ongoing study for nearly 100 years, yet further research is needed before it can be completely exploited. During the first few decades after the introduction of long-haul vehicles such as busses and trucks, the focus was on power. The ability to transport goods, aesthetics, driver comfort and cargo loading capacity became of secondary importance. From 19972003, the overall energy consumption by heavy trucks in the US increased by 3.7 percent annually. Considering that the number of heavy-duty tractor trailers operating is relatively smaller compared to light duty and medium duty vehicles, the increase in energy consumption is significant [22]. As the gradual realization to decrease energy demand of these vehicles became more prevalent, steps were taken to optimize the shape and smart structural design was adopted to make the vehicles more energy efficient. Minimizing fluid-dynamic drag through redesigning and reshaping structures of boats and ships has been practiced for many hundreds of years. Similar theories have been applied to road vehicles, especially to bluff bodies. 
The Society of Automobile Engineers and Department of Transportation were the first to attempt reshaping [28] the front ends which are the primary areas that provided large drag reductions. In trucking's infancy, the edges of the tractors and trailers were sharp and square. While this design proved to be easy to manufacture, it was inefficient. The SAE and DOT program exploited this area of inefficiency by rounding the edges and corners which made the vehicle far more aerodynamically efficient by supporting a smooth flow of air around the corners, unlike earlier designs. Aerodynamic technologies were not developed for a tractor trailer configuration considering it as a single unit and much of the focus was on the truck/tractor aerodynamics alone. Different trailers would be hinged to one tractor and there was no one dedicated trailer for a tractor.

Most of the earlier studies (mid 1970's), expected fuel savings to be approximately onhalf of the percentage reduction in aerodynamic drag [29]. Before the oil crises of the 1970's, the University of Maryland in 1953 performed research on heavy-duty truck's drag reduction by redesigning the shape. Tests were conducted in the University of Maryland's Wind Tunnel Operations Department to explore methods of drag reduction for standard tractor trailer configuration. Various modifications were made to tractor trailer configurations to examine the effectiveness to reduce wind resistance. Over 7,000 wind tunnel tests were carried out and they were all concerned with methods of streamlining to negotiate the boundary layer separation and keep it attached as air passes the trailer [30]. This introduced a detailed look at truck aerodynamics. In the 1960's Selden Saunders introduced the first aerodynamic add-on device, a drag reducer for a gap in land moving vehicle [31]. The device was aimed at stabilizing the stagnant air in the gap between a truck and its trailer. Figure 5 typifies the air deflector/drag reducer device invented by Saunders and Figure 6 show the difference in air flow caused by employing the air deflector. 


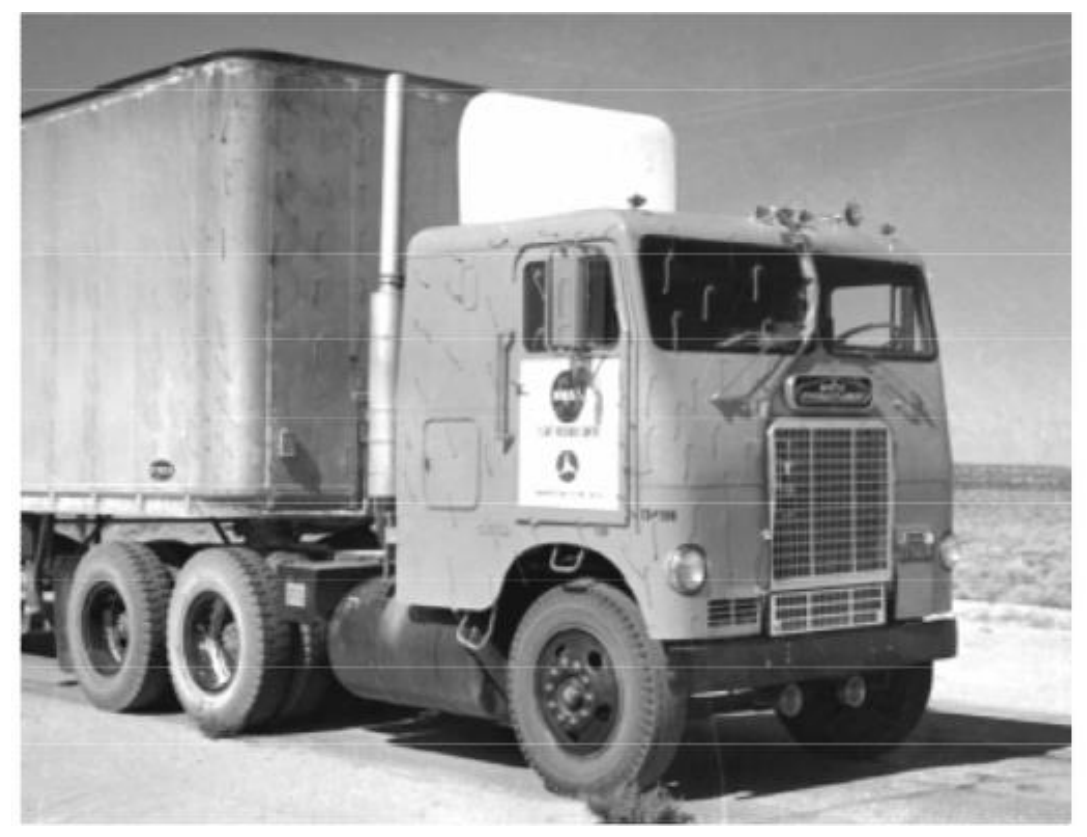

Figure 5. Ground Vehicle with Cab-mounted Air Deflector/Add-on Device [32]
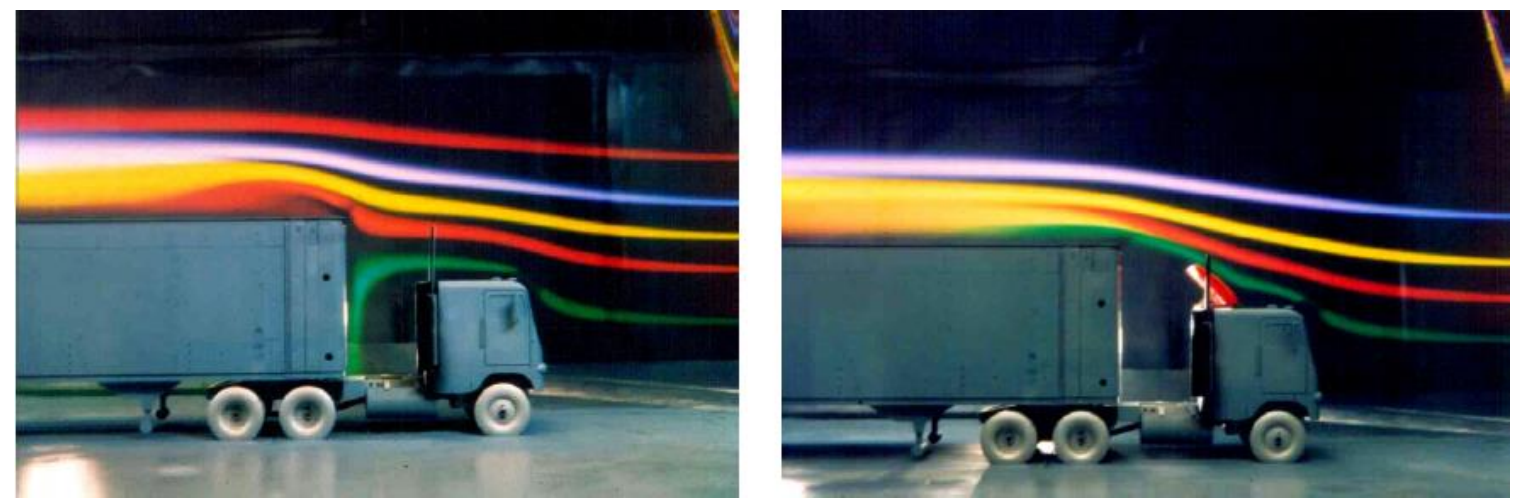

Figure 6. Difference Between Standard Tractor Trailer and Tractor Trailer with Deflector [28]

In the late 1970's and early 1980's, the U.S. DOT was actively engaged in improving fuel consumption through aerodynamic means, resulting in the reduced-drag fleets of today. The study was aimed at bringing awareness to the trucking industry that truck fuel consumption could be significantly reduced. For the first time, tractor trailers were tested both, separately and combined. The results were reported not based on the tractor alone, but also as a tractor trailer combination. Four pairs of trucks, two tractor 
trailer combinations, and two straight trucks were tested. Each pair consisted of a standard truck and an identical partner equipped with the aerodynamic package to be tested. Comprehensive testing on track, road, and fleet service was conducted. Figure 7 shows the different trucks involved in the testing [33].

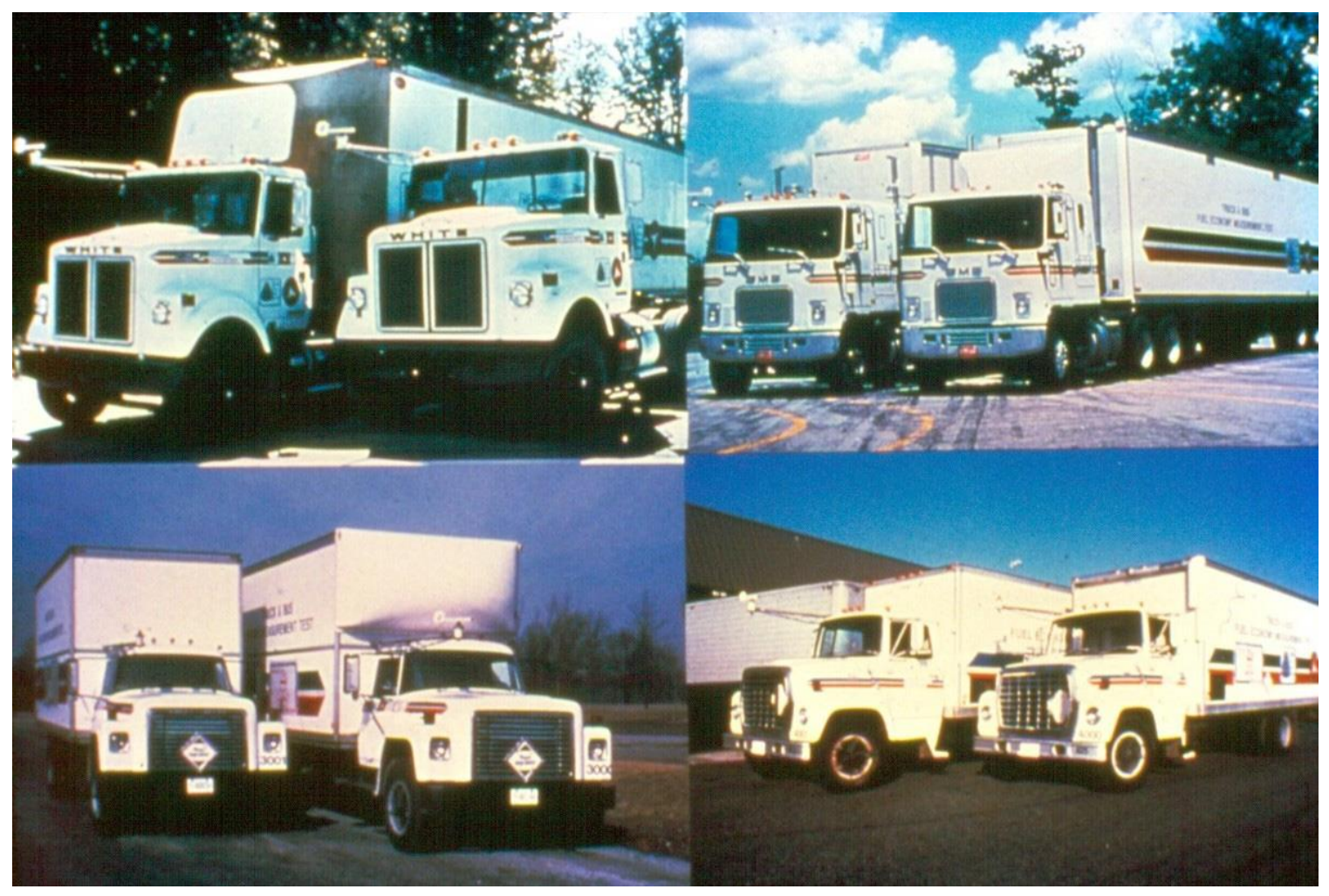

Figure 7. SAE/DOT Study - Different Trucks Tested

These tests also formed the basis of developing test technology for the laboratory and for the fleet. Other notable studies in the late 1970's and early 80's include the 3-year program to investigate aerodynamic means to reduce fuel consumption [33]. This was the first study conducted to examine effects of wind turbulence. Tests were conducted for national average wind conditions and, basic aerodynamic data was obtained. The results concluded that the wind turbulence effect causes full-scale drag reductions produced by retrofit devices to be less than what was recorded in the wind tunnel [34]. 
The topic of edge rounding and base-drag reduction was revisited by Cooper in 1982 [35]. Rectangular vehicle-like shapes and detailed scaled-model trucks were tested to define the optimum front and rear end geometries that minimize aerodynamic drag.

Most of the recent studies conducted in the 1990's and after 2000 were inspired from the concepts developed in the 70's and 80's. In the 1990's, tractor models had a smoother profile from the hood region (the surface covering the engine block where boundary layer separation is prone to happen).

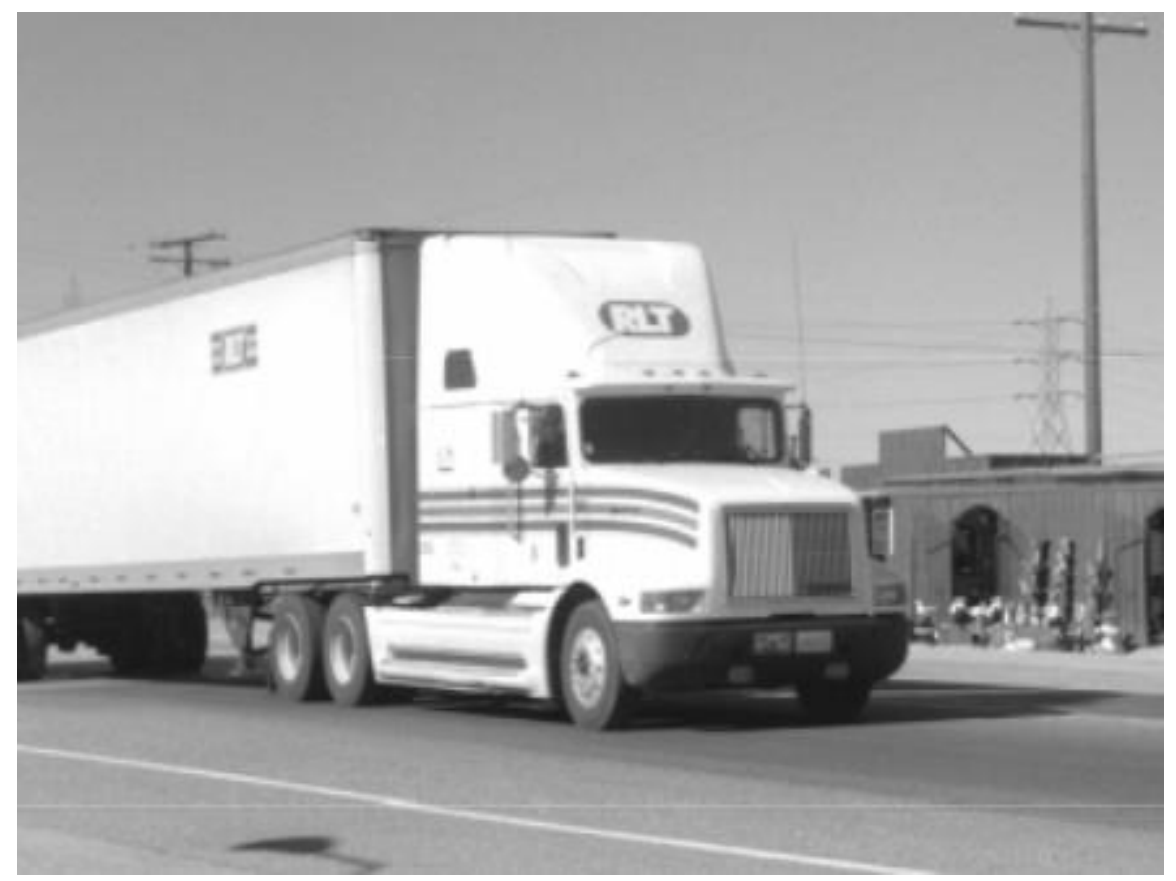

Figure 8. The Aerodynamically Improved 1990's Truck with Fairings [32]

Between 1990 and 2005 heavy truck registrations increased by 37 percent and annual fleet vehicle miles traveled increased by 52 percent. The U.S. Department of Energy (DOE) began the fuel efficiency project in contract with Georgia Tech Research Institute (GTRI). The initial study conducted at GTRI tested using simple scaled tractor trailer models, but the results were not accurate, so a detailed study was later conducted in 
2000. The tests were aimed at evaluating the performance of pneumatic aerodynamic devices. The study concluded that the pneumatic devices employed at the back of the trailer yielded aerodynamic control, drag, and turbulence reduction [36].

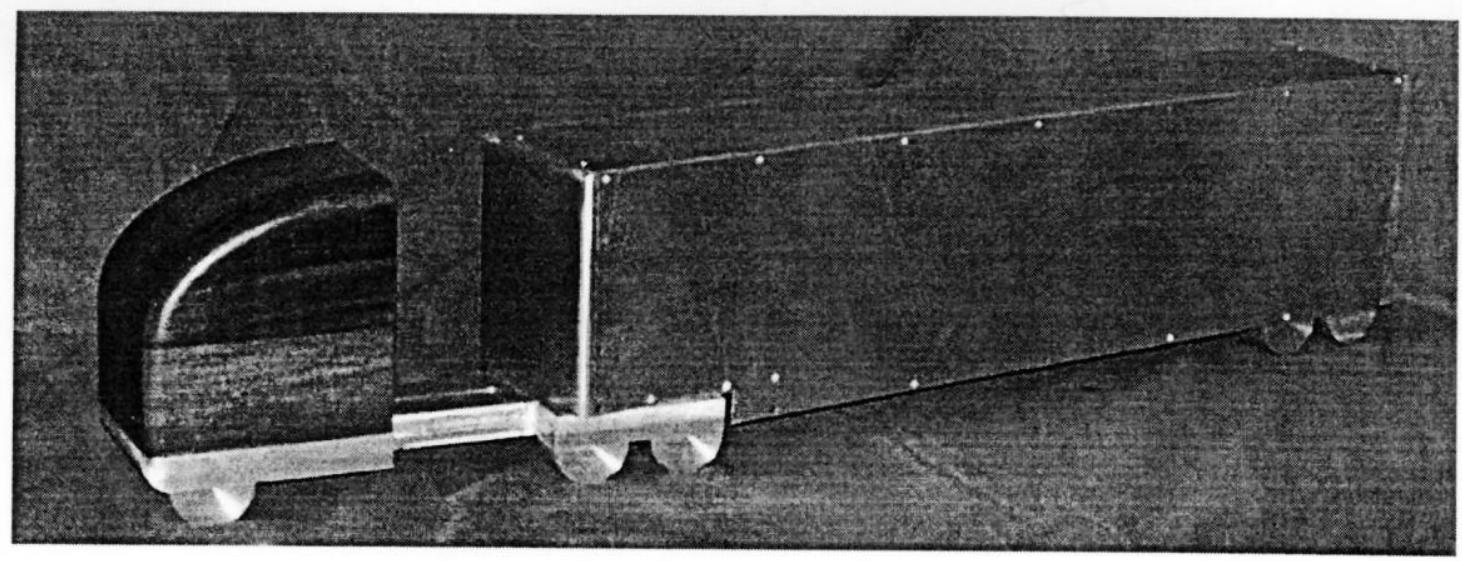

Full-Height Tractor and Yawed Trailer

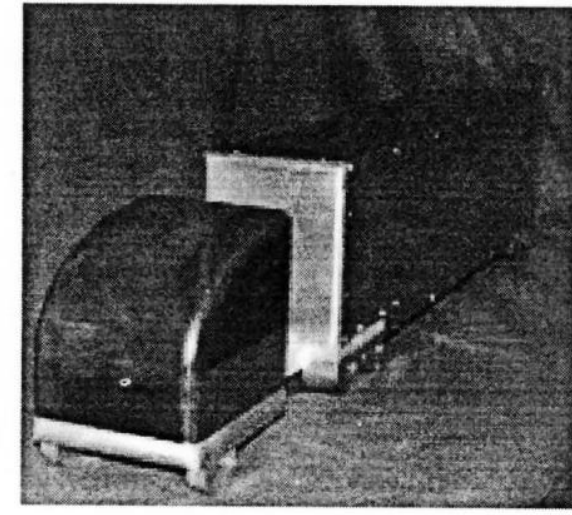

Shorter-Height Tractor, Unyawed Trailer

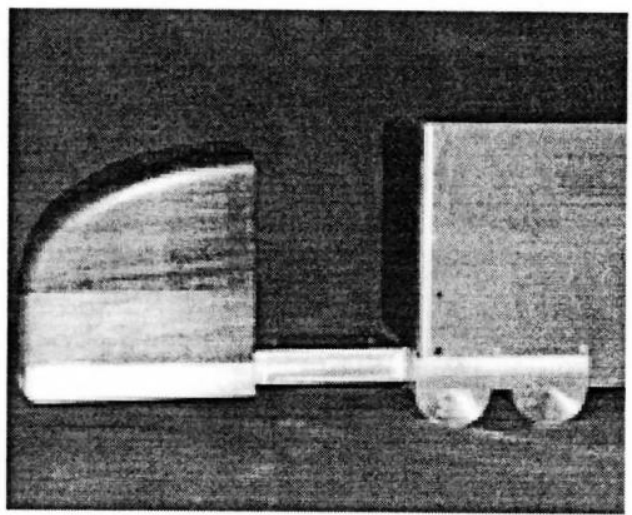

Front Wheels Removed

Figure 9. GTRI 0.065-Scale Wind tunnel Model

Another study conducted by Subrata Roy [9] tested two aerodynamic designs at a $30 \mathrm{mph}$ crosswind condition to show a 30 percent reduction in $C_{D}$ for improved truck geometry. Richard Wood and Steven Bauer [10] tested two technologies, the Vortex Strake Device (VSD) and the Undercarriage Flow Device (UFD), to show a 30 percent reduction in $C_{D}$ (based on longitudinal force only) at $47.5 \mathrm{mph}$. Flow structures and forces around a bluff body have been studied 
generically under constant crosswind conditions to determine the effect of variation in vortex size and strength on the dynamic stability of the bluff body [37].
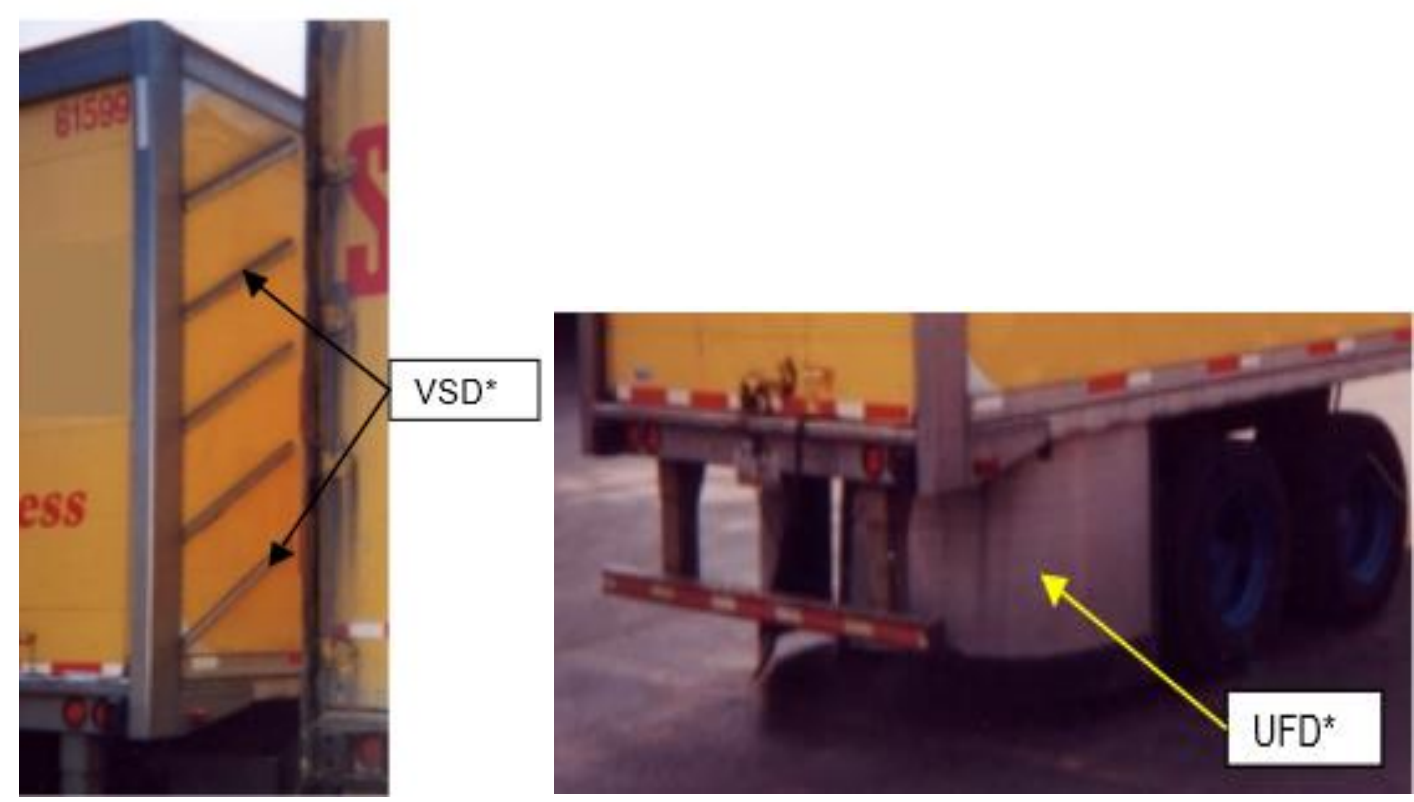

Figure 10. VSD (left) and UFD (right) Treatment Devices Tested by Wood and Bauer

In 2006, the NASA Ames Research Center and Lawrence Livermore National Laboratory conducted a study with the goal of examining methods to reduce aerodynamic drag in heavy-duty tractor trailers under a DOE project. The study was conducted on a 1:20 scale model. The study revealed that the trailer bleeding decreased the amount of freestream flow entrained into gaps and reduced the $C_{D}$ value by 0.015 or 0.024 depending on the gap size [11]. The University of Tennessee SimCenter conducted a study to evaluate trailer base flaps in 2009 and estimated a drag reduction of about 15 percent. 


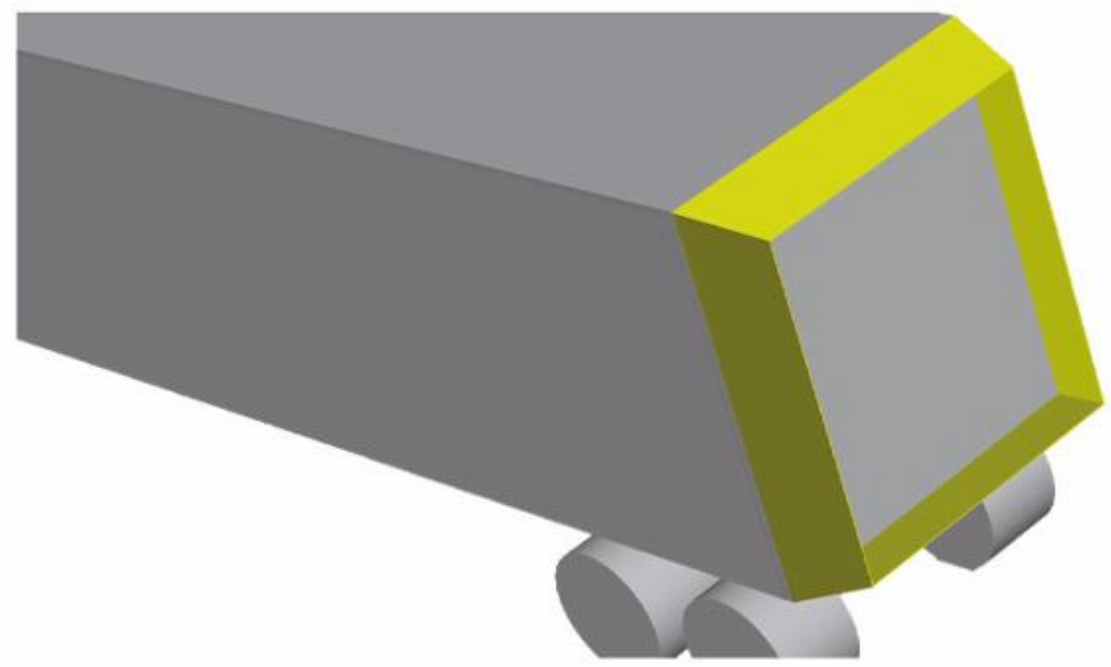

Figure 11. Geometry of Trailer Base Flaps Tested at UT [38]

In 2012, Yang and Tang studied several truck structure parameters and their sensitivity to $C_{D}[39$ ]. The individual and combined sensitivity evaluation was studied on a tractor trailer model. A comprehensive optimization yielded a 15 percent reduction in aerodynamic drag [39]. There are several other studies that are not discussed in this literature which are also aimed at reducing aerodynamic drag by aerodynamic reshaping of tractor cab, reducing the drag on the trailer face, and adding aerodynamic fairings either to the tractor or the trailer [12], [40], [41], [42], [43]. There have been several other studies which have focused on controlling the flow near the wake of the tractor trailer using specialized drag reducing devices based on wake flow dynamics [41], [44]. Although several studies have been conducted for aerodynamic drag reduction technologies, these improvements have not been consistently realized under operational conditions.

\subsection{Current State of the Art Models}

There are several commercially available models which are used in the market to predict fuel consumption by fleet owners, engine manufacturers and other engineers around 
the world. The input parameters which are used to determine the values predicted are sensitive and need to be respected carefully to predict at a significant level of accuracy (which is expected in terms of fuel consumption prediction models). Since this study deals only with aerodynamics of tractor trailers, focus is shifted towards the input parameters defining the aerodynamic force as experienced by the vehicle to predict the fuel consumption. The Environmental Protection Agency created the GEM for class 7 and 8 tractor trailers and class $2 b-8$ vocational vehicles to verify their compliance with EPA's GHG emissions and NHTSA's fuel consumption vehicle standards. The EPA also developed the Motor Vehicle Emission Simulator which can now be used to develop state implementation plans and also for transportation conformity. Both of these tools are allowed to perform high-end regulation conformity verification tasks, preparing emissions inventories for conformity purposes [45]. These are sensitive and important from both the EMA (Engine Manufacturers' Association) and the EPA's perspectives.

\subsubsection{Greenhouse Gas Emissions (GEM) Model}

Input parameters govern the accuracy of predicted emissions and hence it is important that these values are fed correctly to the model. Among the several predefined input parameters, the coefficient of drag $\left(C_{D}\right)$ which is a common measure of aerodynamic efficiency was one of them [46]. Based on coast down testing methods (refers to a procedure where vehicle is accelerated to a specific speed and is let to decelerate owing to tractive forces on the vehicle), aerodynamic bins have been developed by the EPA. Predefined bins can be viewed as a database in several EPA reports. Although the EPA recognizes that wind effects have a significant effect on $\mathrm{CO}_{2}$ emissions, no efforts have been taken to incorporate these factors into the model [46]. The model only deals with values which represent zero wind conditions to avoid complexity and this presents a potential area where the values predicted could be misleading. There are five 
aerodynamic bins described in the following federal regulations, which the user is allowed to choose an appropriate coefficient of the drag $\left(C_{D}\right)$ matching to his vehicle configuration [47]. The manufacturers are required to choose from one of these aerodynamic bins to demonstrate the vehicle's aerodynamic performance, and they are required to be in compliance with the federal regulations without any discrepancies [46], [48].

Table 2. Aerodynamic Bins Used as Inputs to the GEM Model [47]

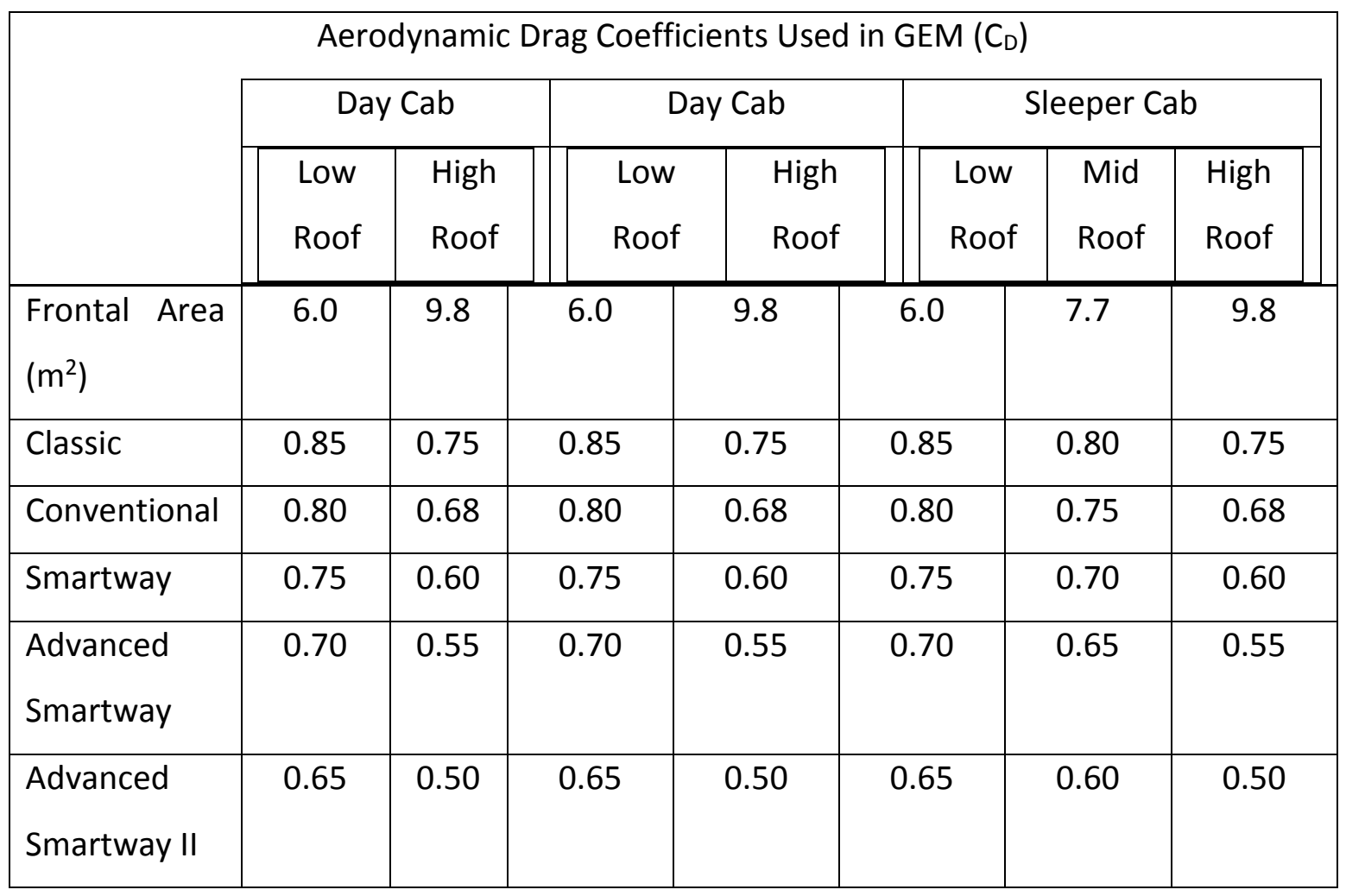

The bins account for a comprehensive database of vehicles, but still fail to accurately represent the in-use drag force [48] because of the incapability to represent the drag coefficient $\left(C_{D}\right)$ of the vehicles when affected by crosswinds as in real-world operating 
conditions. The requirements for compliance [48] (aerodynamic performance) can still be met by adopting the standard test methods to get $C_{D}$ values under the range prescribed. However progressive calculations using these values to predict the aerodynamic force realized by the vehicle on the road, consequently the GHG emissions and fuel consumption over a period of time could be significantly inaccurate.

\subsubsection{Motor Vehicle Emission Simulator (MOVES) Model}

EPA's official model for estimating on-road vehicle emissions is the MOVES model. The emissions rate and other values calculated by the model are based on a defined set of input parameters similar to the GEM model discussed above. The coefficient of drag $\left(C_{D}\right)$ values used as inputs to the MOVES model came from a comprehensive study (also referred to as Petrushov's study [49], [50]) conducted on vehicles from the Euro-Russian fleet, which are not consistent with the US fleets [51]. For instance the European trucks typically do not represent the US conventional hood trucks. The drag coefficients obtained through this study for HDV's was divided into three categories. The categories are single unit delivery trucks and long-haul tractor trailers where, single unit delivery trucks are further divided into two categories based on length. The aerodynamic parameters used in MOVES for the different categories are listed in the table below.

Table 3. Mass Based Aerodynamic Parameter Inputs to the MOVES Model Developed in the Petrushov Study

\begin{tabular}{|l|c|c|c|c|}
\hline \multicolumn{5}{|c|}{ Road Load Coefficients for Heavy-Duty Trucks and Buses } \\
\hline \hline & $\begin{array}{c}8500-14000 \\
\text { lbs }\end{array}$ & $14000-33000 \mathrm{lbs}$ & $>33000 \mathrm{lbs}$ & Buses \\
\hline $\mathrm{C}\left(\mathrm{kW}-\mathrm{s}^{3} / \mathrm{m}^{3}\right)$ & $1.47+\frac{5.22 \times 10^{-5} M}{2204.6}$ & $1.47+\frac{0.0875 M}{2204.6}$ & $1.47+\frac{0.0661 M}{2204.6}$ & $1.47+\frac{0.0643 M}{2204.6}$ \\
\hline
\end{tabular}


The coefficients are all mass based $(M)$ and are predefined. The aerodynamic coefficients employed in MOVES are lower than what might be expected in the U.S. fleet. The values imported from Petrushov's study have an uncertainty of about 25 percent and it has been proposed that the future version on the MOVES models will reflect the updated coefficients [51]. The uncertainty in the coefficients is primarily due to variation in the aerodynamic design between vehicles accounting for 17 percent of the uncertainty. The measurement error accounts for 5 percent variability. It should also be noted that all aerodynamic parameters used in MOVES correspond to zero crosswind conditions.

Such discrepancies in sensitive model inputs could lead to inaccurate representations of on-road power consumption levels. A more detailed characterization of aerodynamic parameters is required to more accurately predict the power required by a HDV during on-road operating conditions.

\subsection{Introduction to Wind Tunnel Experimentation and WVU Setup}

Analyzing aerodynamic drag forms the basis of this entire study which consequently establishes several cause and effect relationships. Predominantly, aerodynamic development and optimization work are conducted either through wind tunnel experiments or Computational Fluid Dynamics (CFD-Numerical Simulation) [41]. To study forces and moments around tractor-trailers which determine stability and performance of the vehicle, it is important to replicate the scenario of actual air flow around the vehicle as closely as possible. For the speeds at which on-road vehicles (tractor-trailers) operate, compressibility effects can be neglected. A subsonic wind tunnel is the appropriate choice of tunnel for testing at such flow speeds. Wind tunnels provide a platform to simulate ambient conditions by the matching flow characteristics inside the tunnel. All wind tunnel studies start with a model, either small-scale or full- 
scale. By making careful measurements of the desired force on the model inside the tunnel at appropriate flow conditions, predictions for real-world conditions are extrapolated. In this study, the model used in the experiments was chosen to closely represent a typical tractor-trailer configuration. The accuracy of the data measured from the wind tunnel experiments depends primarily on the wind tunnel design used for the experimentation and the wind tunnel model. Scaled wind tunnel experimental testing can provide reliable insight into the flow characteristics around a three-dimensional object and provide reasonable simulations to real-world scenarios. Natural crosswind conditions were simulated in the wind tunnel in an idealized manner. The deviation from reality is quantified only in a statistical manner and this may induce an unknown/immeasurable magnitude of error in the values measure compared to reality.

\subsubsection{The Parts and Design of a Wind Tunnel and West Virginia University's Closed Loop Wind Tunnel Setup}

The use of a wind tunnel is essential in several engineering studies involving model tests, research and development work. Understanding the different types of tunnels and their working principles helps choose the right design type which might best be suitable for specific testing. The two wide spread wind tunnel designs include open-circuit and closed-circuit wind tunnels. Both layouts are used in existing automotive wind tunnels.

Open-Circuit Wind Tunnel: The main difference in layout from the other one is that the exhaust air is never rerouted back to the intake system. The air is sucked through the intake chamber and driven through the test section by a fan, and then expelled through the exhaust usually to the atmosphere since the exhaust and intake are not connected. The major drawback in this layout is the temperature of the air driven through the test section largely depends on the atmospheric temperature or the surrounding air temperature, whence the intake air enters. Furthermore, the flow quality can be 
affected in the test section due to wind effects in case the intake air is sucked from the atmosphere. This can be controlled by using a filter screen in front of the intake nozzle to eliminate the influence of wind and turbulence intensity from the intake air. This would cause a loss in pressure and this decrease in pressure will have to be compensated with additional fan power depending on the speeds expected in the test section. This was not the preferred choice of wind tunnel in this study primarily because of the disadvantages mentioned. The implications of using an open-circuit wind tunnel for this study would have been worse since the flow pattern dealt with is not necessarily symmetrical with respect to the mid plane of the test section. In an open-circuit wind tunnel, the streamlines downstream of the model are deflected to a deviated path compared to free air during unsymmetrical flow conditions [41].

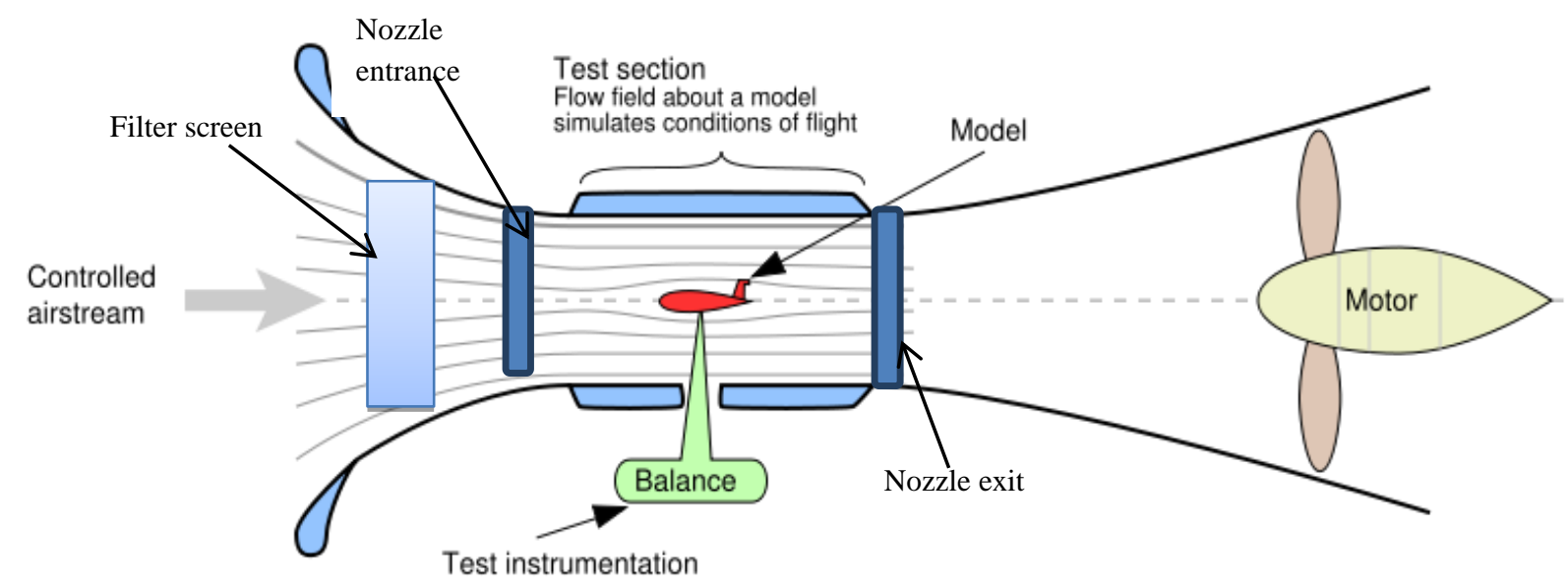

Figure 12. Open-Circuit Wind Tunnel Schematic Diagram [52]

Closed-Circuit Wind Tunnel: The closed-circuit or closed-return type tunnels are oval in the layout and recirculates the air around the same loop like a racetrack. The main advantage of this tunnel is that since there are not many chances of a pressure drop, variations in pressure inside the circuit, the blower or the fan requires lesser and consistent power as compared to the open-circuit tunnel. This also eliminates the chances of atmospheric effects on the flow quality. Thermal exchangers can be fitted to 
the system to conduct experiments which are sensitive to temperature or require thermal modeling.

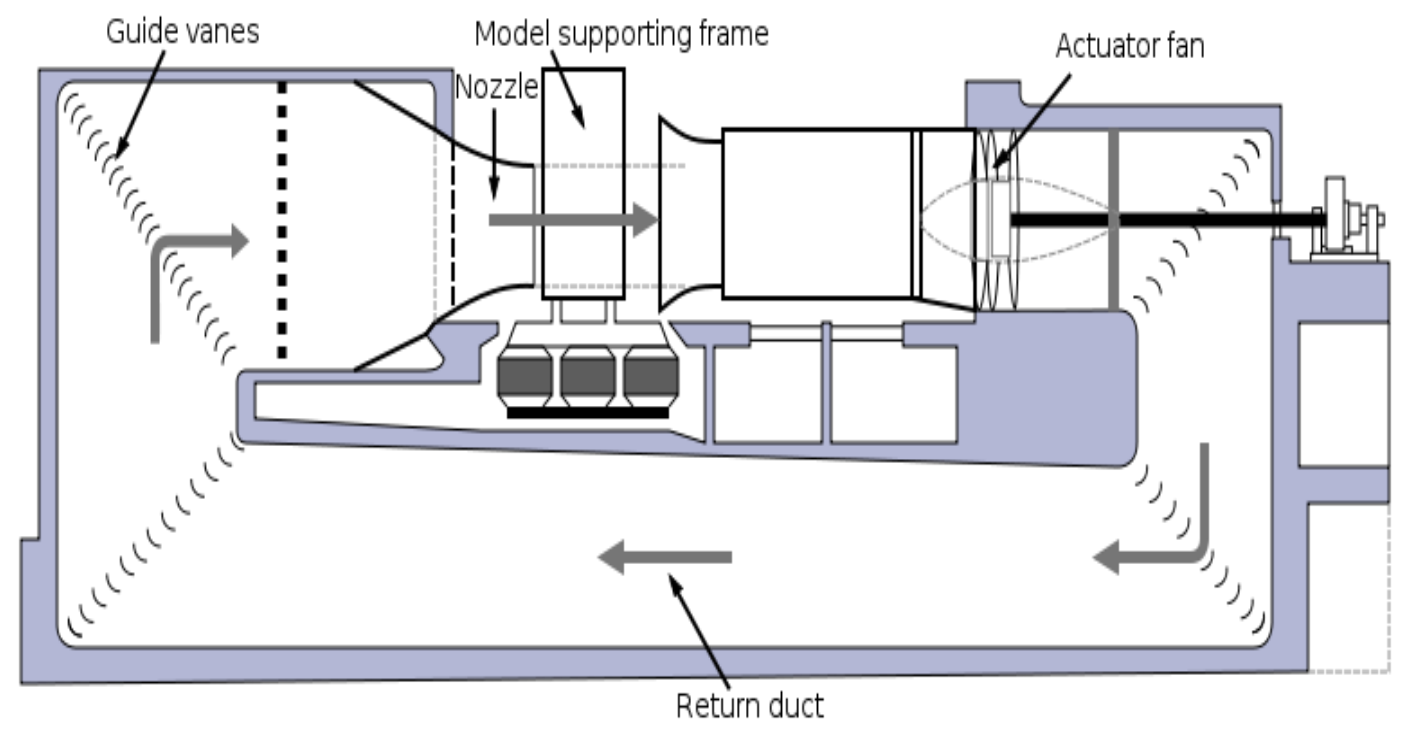

Figure 13. Schematic Diagram of a Closed-Circuit Wind Tunnel

The WVU subsonic wind tunnel facility located at the aerodynamics laboratory is a Closed Loop Tunnel (CLT), and it serves as the Aerodynamics Laboratory main test facility for subsonic research. The air flow inside the two different wind tunnel layouts is shown in the Figures 12 and 13. As depicted in Figure 12 there is no recirculation of air inside the tunnel in the open circuit; whereas the closed circuit is equipped with a return duct which circulates the air inside the tunnel [53] [54]. There are some common and pivotal parts in both systems, such as axial fans (actuator fans or just fans). The driving unit section is the houses the axial fan/fans, which enables high-speed airflow inside the tunnel. The fans are always placed downstream of the test section, at the end of the tunnel, and never at the entrance. Axial fans were used in the 1970's since they were cheap and did not occupy much space. Axial fans were later on replaced by electric motor-driven radial fans which offered better performance in terms of flow 
characteristics [53]. Choosing a fan with adjustable pitch is preferred to fixed blades as it allows for a larger range of stable flow conditions and stalling problems can be avoided [55]. The WVU CLT wind tunnel has a variable pitch radial blade blower. The blower is rated at 5,800 CFM and flow possible is at 12 inches water.

The next common component in both layouts is the test section. It is a pivotal component in the wind tunnel design where the highest velocity in the wind tunnel occurs [56]. It is characterized by two properties, the cross-sectional area of the nozzle at the test section entrance and the length between the nozzle entrance and nozzle exit. Apart from geometric and dynamic similitude inside the tunnel, kinematic similarity is also of equal importance. Having kinematic similitude confirms that the fluid flow pattern inside the tunnel matches with the fluid streamlines in real application on fullscale models. The kinematic similarity is confirmed by conforming to blockage ratio standards.

The SAEJ1252 [57] blockage standards were maintained for the experiments conducted in the wind tunnel. The WVU CLT's test section is closed and is $3 \times 4 \mathrm{ft}$. in size. Recent test section qualification results showed turbulence intensities of less than 0.2 percent which indicates minimal flow fluctuation from mean velocity inside the tunnel, highly uniform cross-sectional velocity profiles, and demonstrated flow directionality at the test section speeds up to Mach 0.2. Further directionality checks were conducted to verify if the free-stream at zero degrees remained the same during the course of all experiments. 


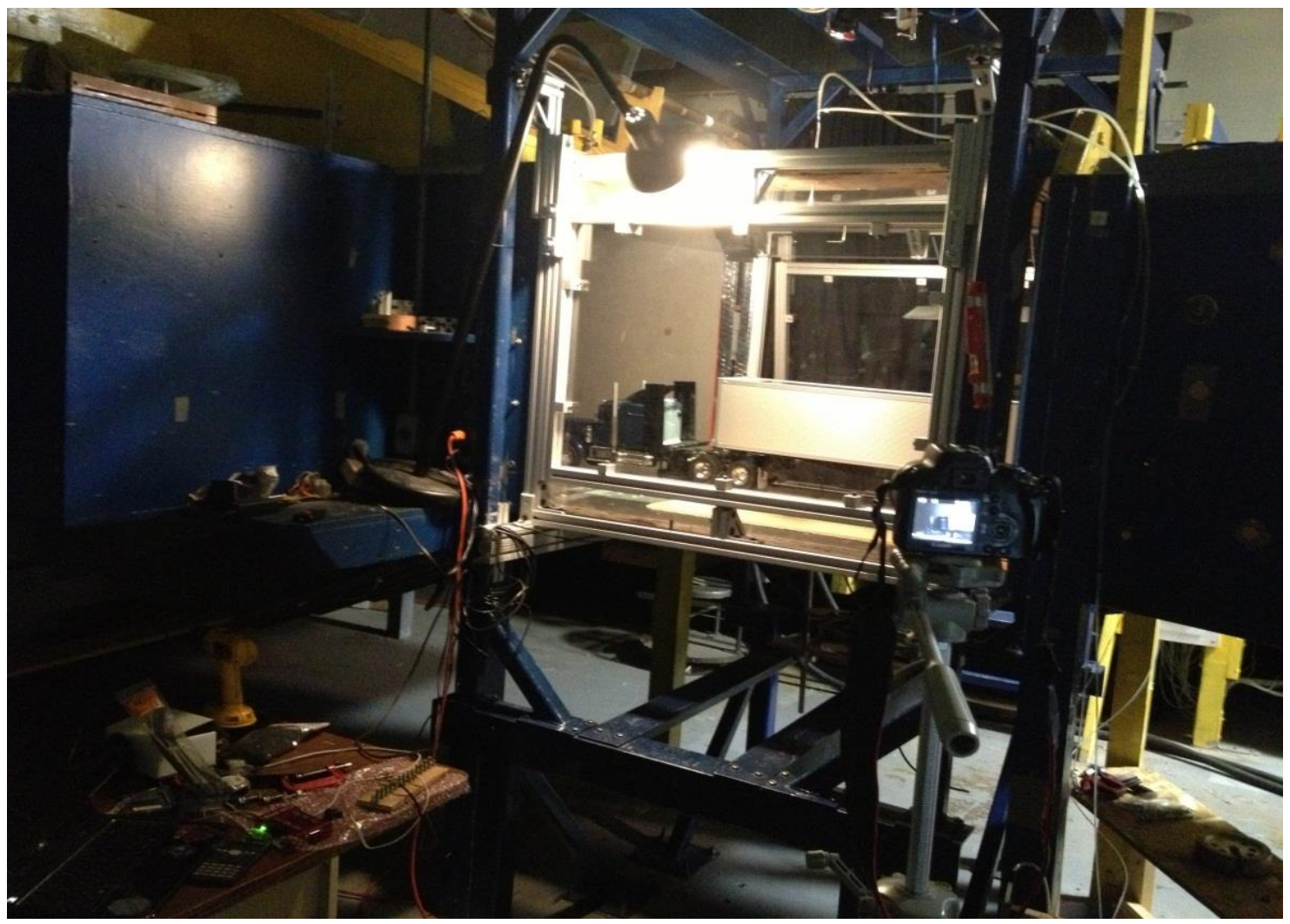

Figure 14. Picture of 1:15 Scale Tractor-Trailer Model in the Test Section

The wind tunnel diffuser/plenum section is the component right after the test section along the flow direction. It is used to reduce air stream/free-stream velocity while minimizing losses. The WVU CLT diffuser section widens out in a conical shape right after the test section. This slows the air velocity, smoothens and reduces the turbulence in the test section, and further prevents boundary layer separation downstream.

The upstream section of the wind tunnel is the settling chamber. This section consists of multiple flow straightening elements including screens and honeycomb filters. The settling chamber inside the WVU-CLT consists of two turbulence mesh screens which help in smoothening flow and are used to create a uniform velocity profile across the cross section of the tunnel section. The screens break the larger eddies and their 
primary function is to reduce the fluctuations in the stream wise component [56]. The number of mesh screens can be increased but this will reduce the free-stream velocity [58]. The honeycomb is used to straighten the flow. It is suggested that in order to straighten flow without impeding it or reducing its velocity, the number of cells should be 25,000 inside the honeycomb [59]. The flow is directed into each section of the wind tunnel through the corners where guided vanes are located to direct the flow in the desired direction.

The last component in the wind tunnel structure through which the air passes through upstream before flowing into the test section is the contraction region. The contraction component increases the fluid/air velocity rapidly. While this process increases the freestream velocity significantly, it also minimizes flow separation, variability, and pressure loss. The rapid increase in the fluid velocity results in large streamwise strain, that reduces the mean flow variation. The larger the contraction ratio in this region, the larger the streamwise strain which leads to reduced mean flow variation in the test section.

\section{CHAPTER III - Fundamental Analysis, Experimentation, Modeling, Case Study and Conclusions}

\subsection{Velocity Definition}

Generally velocity refers to the rate at which a body changes its current position to a different position. Since this dissertation deals with tractor-trailer velocities in different environments, it is vital for the study that velocity is clearly defined in each case and how they differ from one another. For instance in real-world operation, under zero crosswind condition, the vehicle speed changes its position along the road as it moves 
but inside a wind tunnel, the same scenario is simulated and the model does not change position. The Plane of Reference (POR) relative to which the velocities are defined is the distinguishing factor. There arises a need to define all velocities independently and how they are relative to each other.

Real-world Tractor-Trailer Velocity: When a tractor-trailer is operating in real-world conditions and is moving from one position on the road to another, there are multiple velocities that are associated with the vehicle that need to be defined. In this study, it is assumed that the direction of the tractor-trailer is always parallel to the direction of the road surface it is on. In other words, there is no angular difference between the tractortrailer and the road surface.

- Raw wind speed $\left(\mathrm{V}_{\mathrm{W}}\right)$ : The magnitude of wind velocity with respect to the road surface (POR).

- Raw wind direction $(\Theta)$ : The direction of the wind velocity with respect to the road surface (POR).

- Tractor-trailer direction/Road angle/Road curvature ( $\beta)$ : The direction in which the vehicle is travelling on the road or the direction of the road surface in Geographical Coordinate System (GCS). The degrees represented are always relative to due North.

- Relative wind-truck angle $(\phi)$ : The difference in angle between the tractortrailer/road surface and the raw wind direction.

- Raw truck velocity (V): The magnitude of truck velocity with respect to the road surface.

- Relative wind-truck speed $\left(\mathrm{V}_{\mathrm{r}}\right)$ : The magnitude of the wind velocity with respect to the truck speed.

- Yaw angle $(\psi)$ : The angle between $\mathrm{V}_{\mathrm{r}}$ and $\mathrm{V}$. 
Figure 15 shows a vehicle travelling in the direction of velocity, $V$, which is experiencing a head wind with raw wind velocity, $V_{w}$. The same wind, $V_{w}$ makes an angle, $\theta$, with respect to the ground (where $\theta$ is an angle due North, not shown in Figure 15). Figure 15 illustrates a case where a road is straight without any curves or is oriented at 0 or 360 degrees due North.

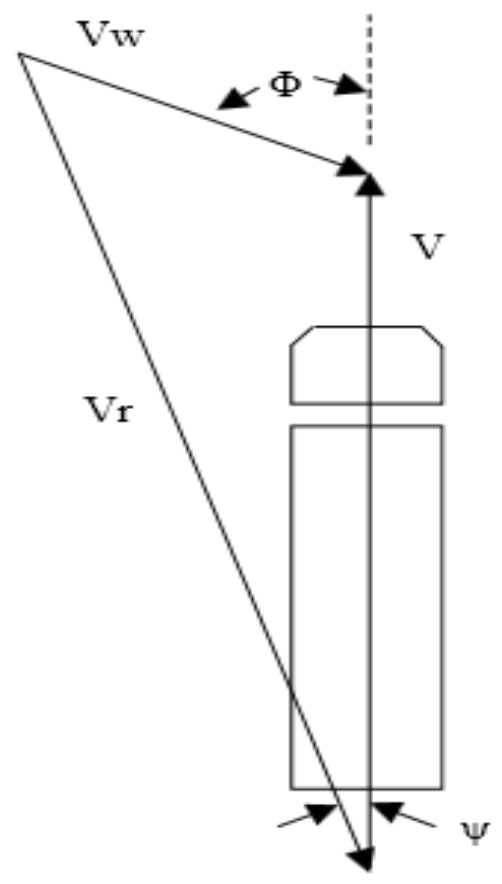

\section{Figure 15. Yaw Angle Diagrammatic Representation}

With the assumption that the vehicle is always parallel to the road surface, the direction of the raw wind, $\theta$ relative to the ground will be equal to the direction of the wind with respect to the vehicle, $\varphi$. This is not the case during on-road vehicle operation. The roads are curvy and they are oriented at different angles due North. This affects the angle at which wind will impact the vehicle. In other words, when wind attacks a vehicle at a particular angle it could either be an effect of a road curvature, changing raw wind direction, or both simultaneously. 
With Figure 15 as a reference, the generic calculations involved in obtaining the windtruck velocity and yaw angle are described below:-

$$
\begin{gathered}
V_{r} \text { in mph }=\sqrt{V^{2}+V_{w}^{2}-2 V V_{w} \cos \phi} \\
\text { Yaw angle, } \psi \text { in degrees }=\sin ^{-1}\left\{\left(V_{w} \sin \phi\right) / V_{r}\right\}
\end{gathered}
$$

In Figure 16, raw wind direction was varied sinusoidally between -30 and +30 degrees, which translates as -30 to +30 degrees wind direction.

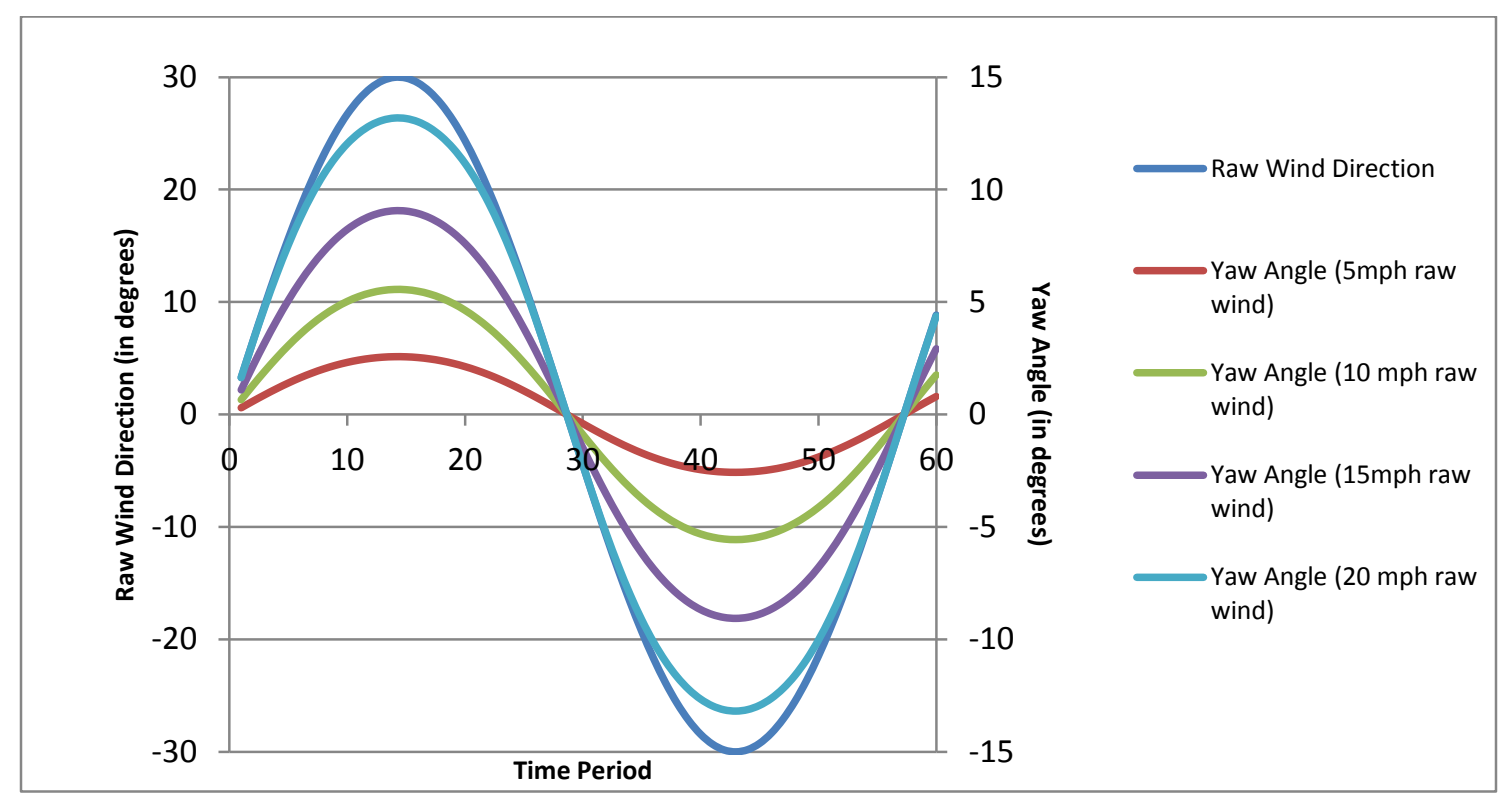

Figure 16. Raw Wind Direction vs Yaw Angle

In Figure 16, the raw wind direction is assumed to be equal to the wind direction with respect to the vehicle, suggesting zero road curvature. The variation in yaw angle can be observed as a factor of both raw wind speed and raw wind direction in this figure. If only average values were considered, then the average wind direction for the time period considered above would be zero. This will filter out all the variation in yaw angle actually induced during the time period and is not representative. 
In Figure 17 the raw wind velocity was varied sinusoidally between -20 and $+20 \mathrm{mph}$, where any positive value implied head wind and negative values will imply tail wind for the three raw wind directions illustrated.

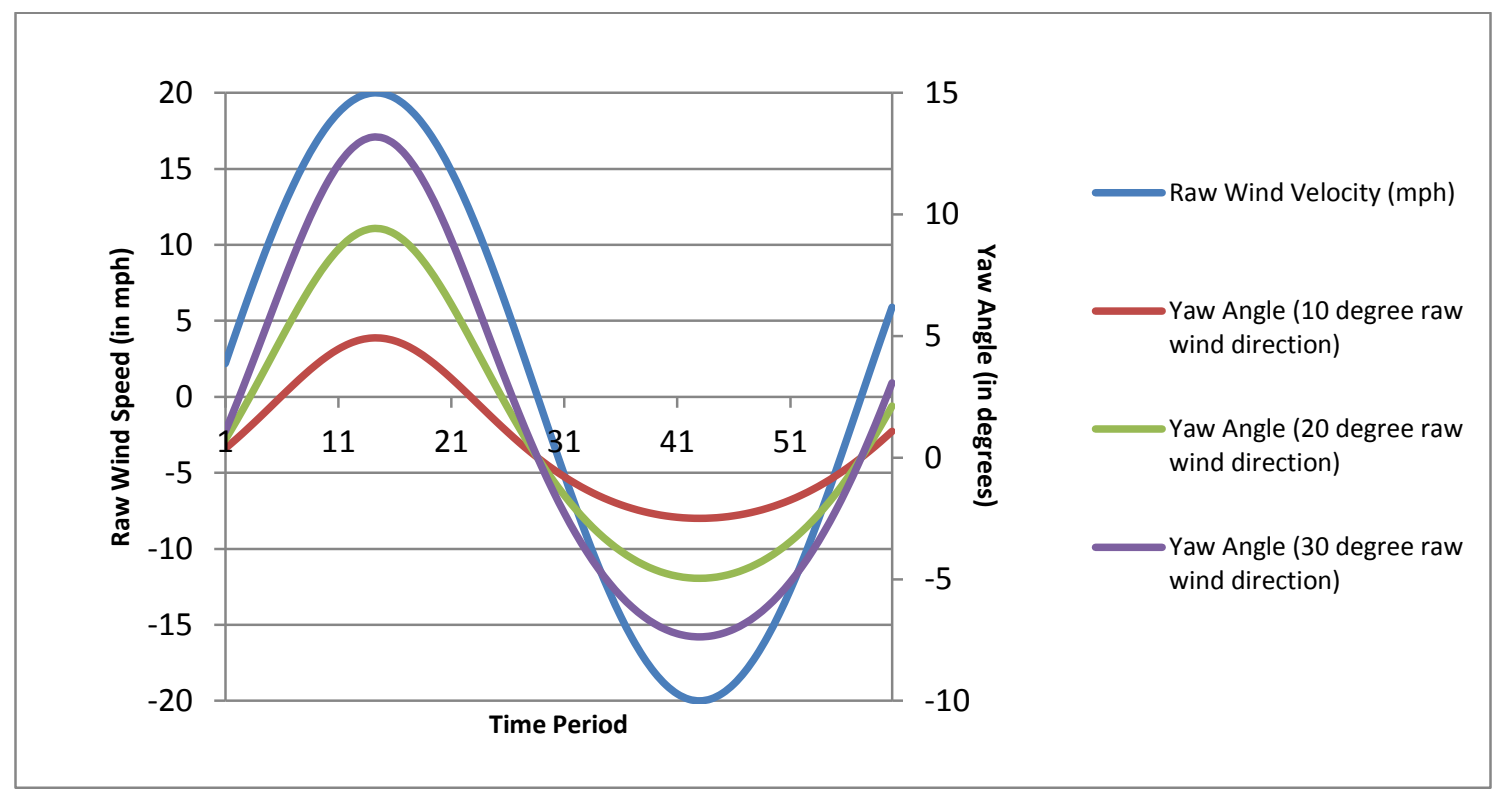

Figure 17. Raw Wind Velocity vs Yaw Angle

The average wind velocity over the time period is zero which reflects no on-road crosswinds but it is evident that a vehicle in this time period will have actually been subjected to significant crosswinds.

Averaging raw wind velocity or direction might lead to unrealistic results while computing the effects of wind on power [60]. One-minute Automated Surface Observing System (ASOS) data were obtained from the National Climatic Data Center database to elaborate wind variation over time in different regions. Wind data averaged at one minute intervals for values recorded at 5 second frequency/interval at 2-meter height are used in this illustration. This will smooth all the short, sharp gusts that might have occurred in the interval, which will not fully immerse the truck and cannot fully develop the flow field or the drag. The plots in Figures 18 and 19 show how raw wind speed and 
raw wind direction differed significantly from one location to another over a period of time. Three places, Alban, NY, Wichita, KS and Abilene, TX were chosen at random

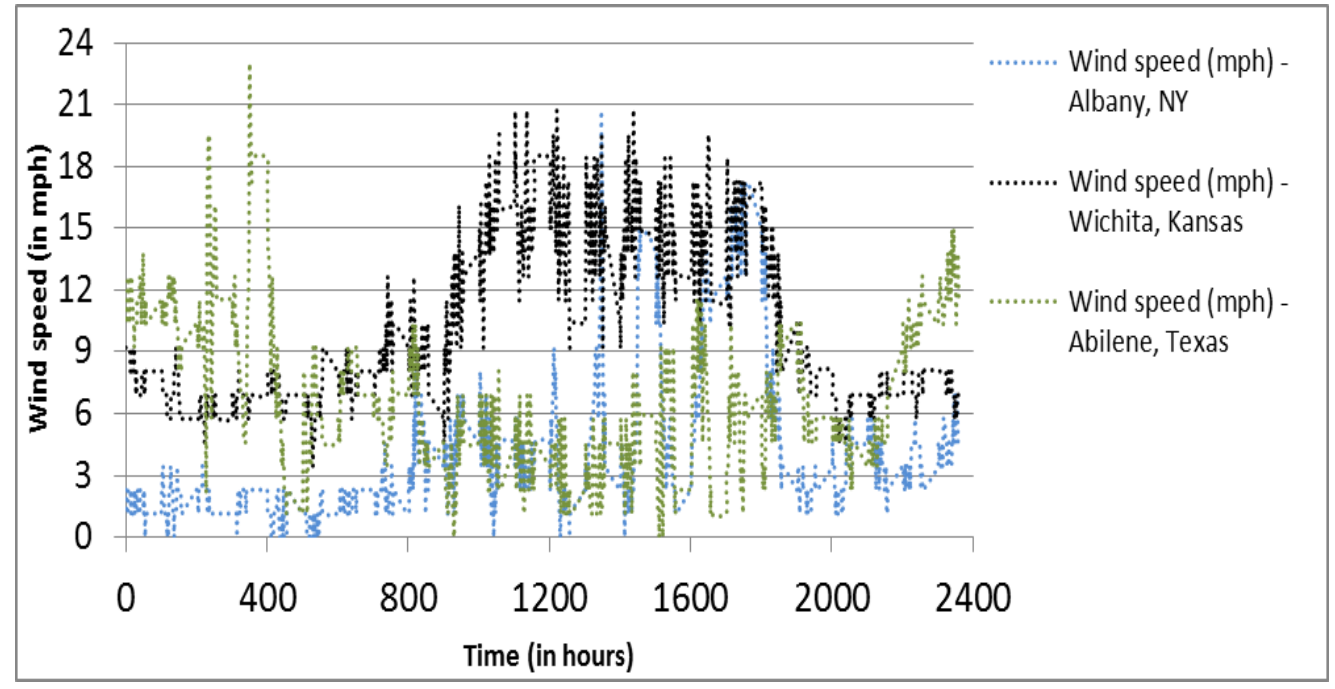

Figure 18. Spatial and Temporal Wind Speed Variation [13] across the United States for a fundamental study of wind speed and direction variation.

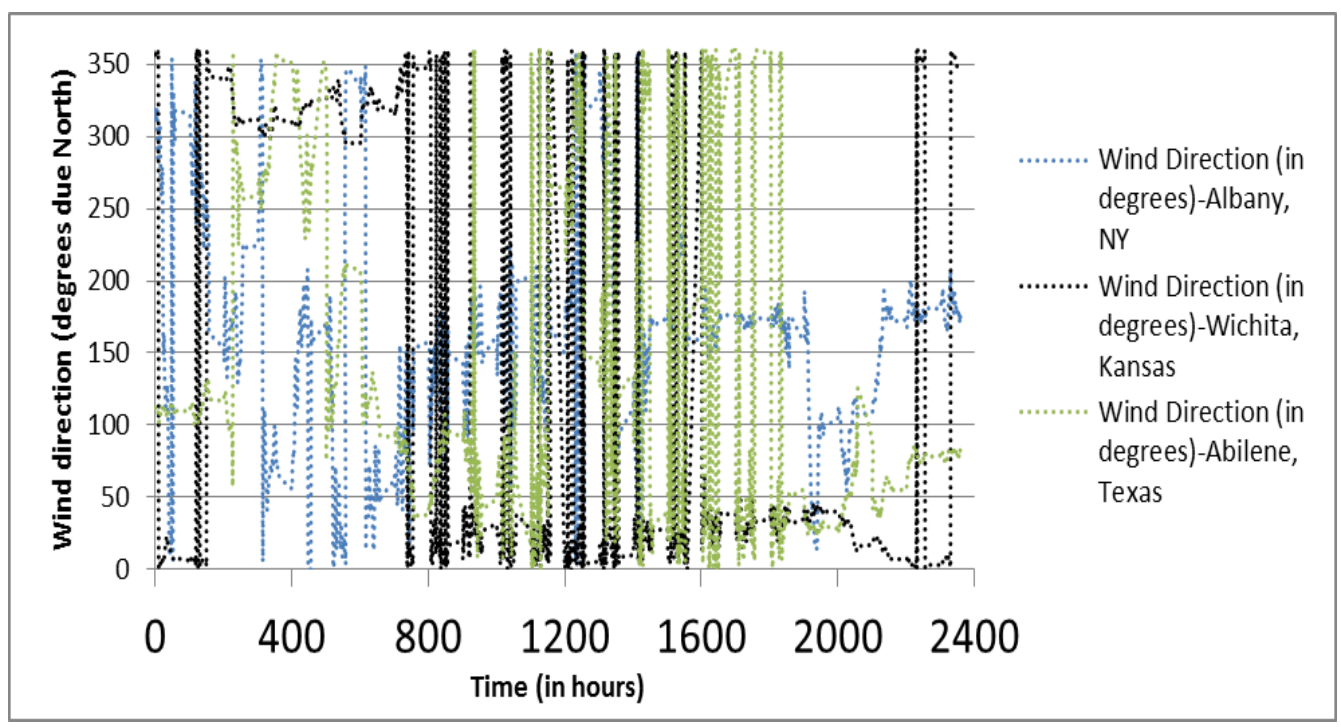

Figure 19. Spatial and Temporal Variation of Wind Direction [13] 
In the above illustration, Figure 19, the average speed in Abilene, Texas was $6.8 \mathrm{mph}$ but from Figure 18, it is clear that this average is not representative of wind speeds recorded between 0000-0400 and 2200-2400. The average speed in Albany, NY was $4.1 \mathrm{mph}$, but this is not representative of wind speeds between $1400-1800$. Similarly, changes in raw wind direction can have significant changes to the wind effects on a vehicle. Variations in raw wind direction will change the relative wind wind-truck angle (see definition) and consequently may or may not affect the yaw angle based on variation in raw wind speed (refer Equations (7) and (8)). A change in raw wind direction on a road with zero curves or a road at 0 degrees due North, could change a tail wind to a head wind and vice versa if the change in direction is greater than 90 degrees over time. For instance, the average wind direction in Wichita, KS is 146 degrees, but this is certainly not representative most of the time through 06/30/2013. The average information on wind is very misleading in this case. The wind direction hovered between 300 and 360 degrees from 0100-0800, which itself provides ample variation to trigger changes in wind effects. This raises a need to employ wind data with higher resolution (in order of minutes or even seconds, if available).

\subsection{WVU Wind Tunnel Testing}

On-road aerodynamic drag testing on a full scale tractor trailer was not performed in this study. In this dissertation, results from wind tunnel studies were applied to realworld scenarios and this extrapolation persuades the need to understand the wind tunnel set up, model configurations, operating parameters, and calculations in detail. Wind tunnel testing of tractor-trailers has been conducted for several decades to simulate real-world conditions in a controlled environment to study aerodynamics of the vehicle structure effectively. There are several ways to simulate truck operation in a wind tunnel and this depends on the wind tunnel structure and facility. Tests conducted 
for this study were in the subsonic wind tunnel facility at West Virginia University (WVU) located in, Morgantown, WV. In order to define the velocities inside the wind tunnel, the wind tunnel setup is described in detailed to make relative references.

Scaled Model Set-up inside CLT: It is always ideal to conduct tests on a full-scale tractortrailer geometry which would be representative of an on-road truck, but this is not always possible given the structural constraints posed by the facility, test section size, and most of all financial constraints, which is the case in this study. There are several manufacturers of tucks and a representative tractor-trailer model was chosen for all tests. The Peterbilt 379 with a box-type trailer was chosen based on the simplicity of the model and its representative geometry of trucks in general.

The test section size is 45 - by 32 -inches in size and the wind tunnel is a single return closed-loop test section. This information combined with the blockage ratio to be maintained inside the test section provides certain inputs to decide the model size. The SAE J1252 recommends a blockage of less than 5 percent of the active test section area (the area above the ground board). The SAE J1252 also recommends that the model height should not exceed 0.3 of the test section height and frontal model width should not exceed 0.3 of the test section width. The model design is not only based on the having a similar geometry as in the case of a full scale, the kinematic similitude also needs to be considered as explained in chapter 2.5.1.

In order to obtain a geometric similarity, the model is designed as detailed as possible with as many parts as in the full scale model. Importance was given to underbody structural details and to the parts which are located near regions of possible flow separation. On the other hand, to maintain kinematic similarity, the flow pattern or the dynamics of the flow inside the wind tunnel needs to be the same as the flow that would be around a full scale truck in real-world operation. To achieve kinematic 
similarity, the Reynolds number of both trucks (operating in real-world conditions and inside the wind tunnel) need to be matched.

From the Reynolds number Equation (6) in section 2.2.6, it is seen that, Reynolds number is governed by density $(\rho)$, characteristic length $(I)$, velocity and kinematic viscosity $(u)$. Density and kinematic viscosity are not operating parameters and are not available for variation unless tests are conducted inside an atmospheric wind tunnel. The only parameters that can be altered in the WVU CLT are the velocity inside the wind tunnel and the characteristic length of the model, but these both are subject to constraints, too. The Reynolds number of a truck operating on a road at highway speeds (55mph) is approximately $3.85 \times 10^{6}$ (using the width of a full scale truck, 102 inches as characteristic length) and to obtain this number inside the WVU CLT would be impossible due to structural constraints. The maximum possible speed inside the tunnel is $45 \mathrm{~m} / \mathrm{sec}$ and the dimensions of the model have to be designed at a level to keep the blockage minimized. With these factors in mind, a 1/14.5 scale model with a frontal width (from widest left to widest right of the model at zero yaw angle) of 7.1 inches was built to produce maximum Reynolds number while keeping the blockage at 4.7 percent. The blockage was maintained at $<10$ percent (of the cross section of the test section) for all tests to avoid any extraneous effects that may arise from the tunnel walls [34] [61]. The model included underbody details such as engine block, front and rear axles, drive shaft, underbody chassis, and frame. The cab details included rear view mirrors, exhaust stacks, door steps, tank fairings, head and tail lights. The model dimensions and part details are shown below. 
Table 4. Scaled Wind Tunnel Model Dimensions

\begin{tabular}{|c|c|}
\hline Description & Dimension/Length/Gap (in inches) \\
\hline Model Frontal Width (at zero yaw angle) & 7.1 \\
\hline Model height (from tire base to trailer top) & 11.6 \\
\hline $\begin{array}{r}\text { Model total length (from front end to back } \\
\text { end including trailer) }\end{array}$ & 53 \\
\hline $\begin{array}{r}\text { Tractor-trailer gap width (from back face } \\
\text { of cab to front face of trailer) }\end{array}$ & 4.8 \\
\hline Tire diameter & 3.2 \\
\hline Trailer length & 36.5 \\
\hline Tractor cab height (without any add-on) & 8 \\
\hline
\end{tabular}

The bigger components including trailer walls, and cab structure were designed in Solidworks 2010 and were machined either using CNC machines or a 3D printer at West Virginia University, Wilson Works and Kraftwurx, Inc. The cab was made using ABS plastic, while the trailer frame and walls were made from stainless steel. The wheels, rear view mirrors, engine block, exhaust stack, and other underbody accessories were bought at scale size 1/14.5 from commercially available stores (McMaster-Carr, Tamiya America, Inc.). The model was constructed rigidly with sufficient detail to reproduce all 
or most of the full-scale local flow disturbances. These efforts combined to achieve maximum possible geometric similitude with the full-scale Peterbilt 379 model.

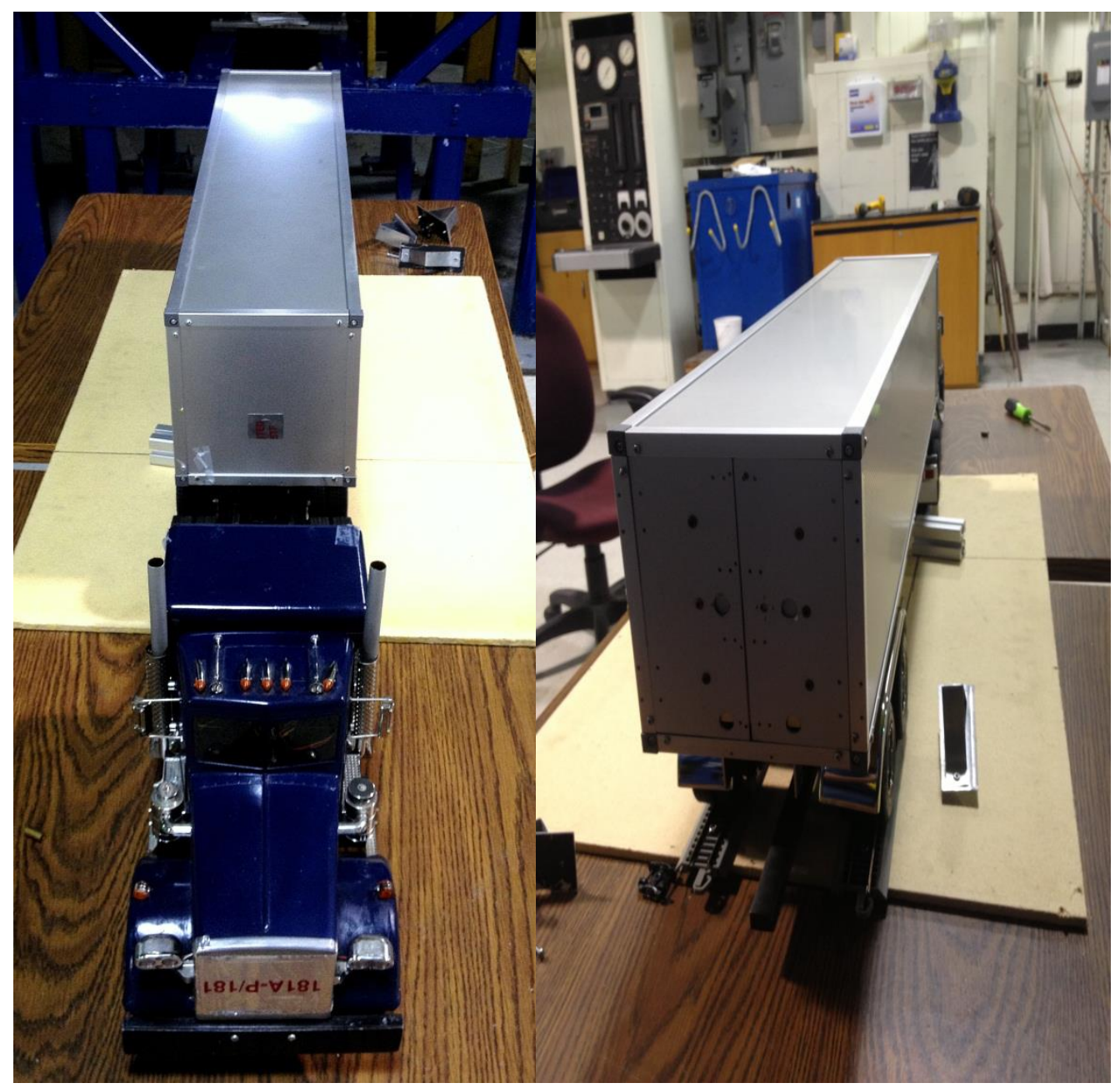

Figure 20. The 1:14.5 Scale Peterbilt 379 Wind Tunnel Model (Front and Rear View) 


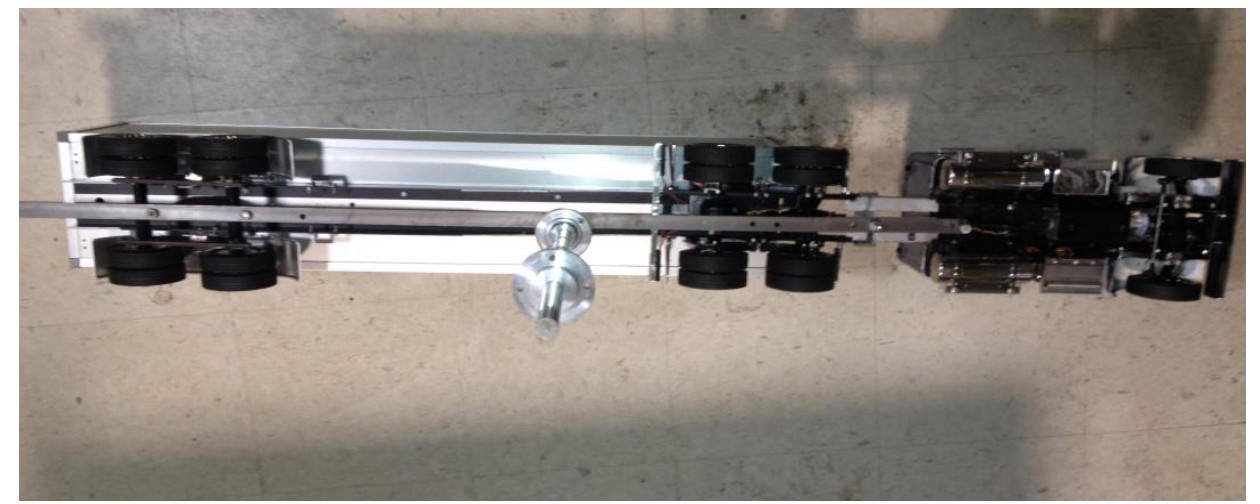

Figure 21. Underbody View of T-mount Model Support Uniting Tractor and Trailer

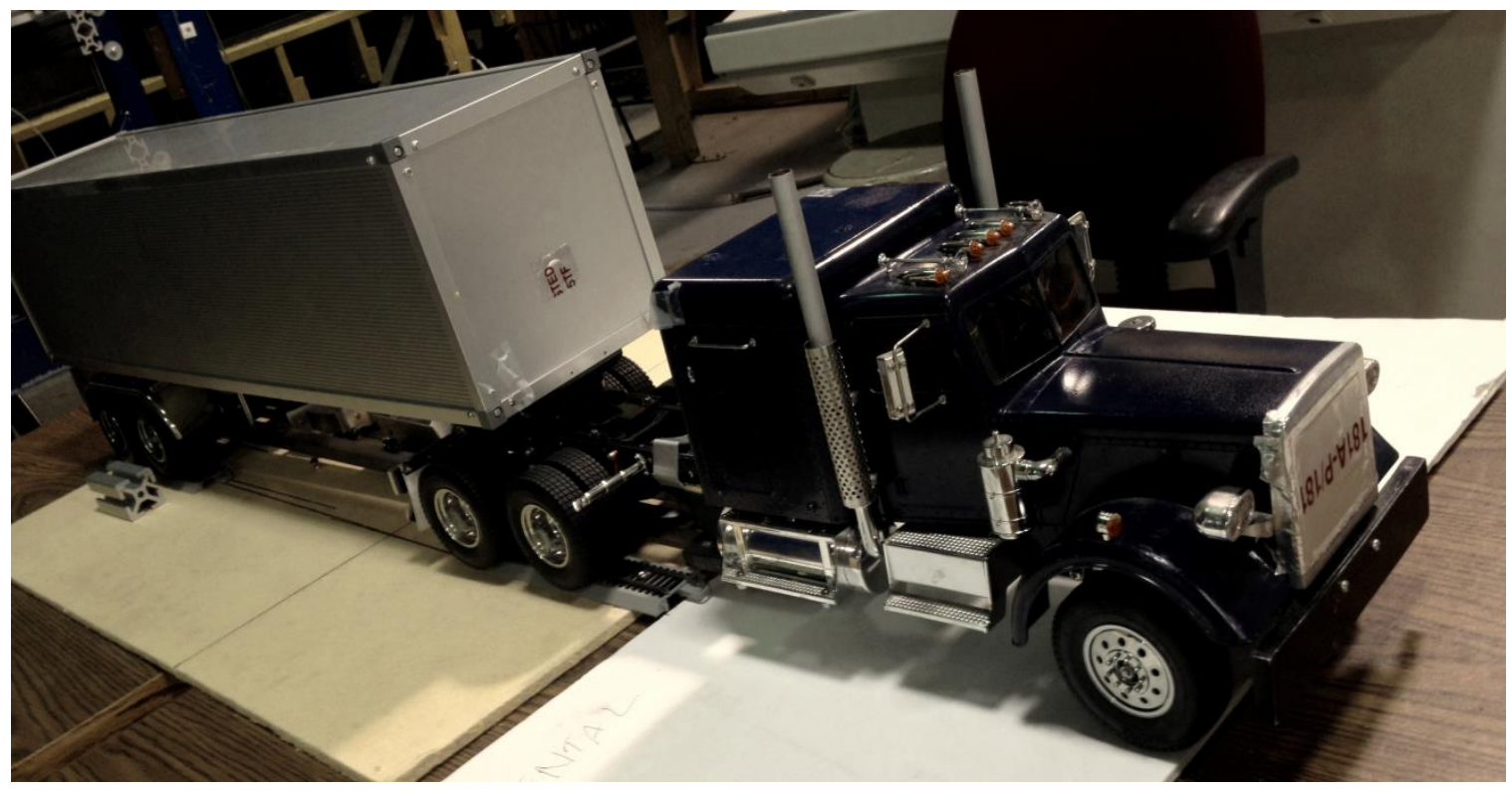

Figure 22. Side View of 1:14.5 Scale Wind Tunnel Model

Once the geometric similitude was satisfied, focus shifted on achieving kinematic similitude. A series of measurements was made above the test section ground plane with no model to define the characteristics of the flow in which tests would be conducted. These characteristics help in identifying the critical Reynolds number at which the transition from laminar to turbulent occurs. The flow angularity and the uniformity of the flow field were quantified. Tests revealed less than 0.2 percent 
turbulence intensities and a highly uniform cross-sectional velocity profile. Directionality checks were performed before running each test with the model in the test section to confirm angular uniformity. A custom made uniaxial external force balance was used to measure the drag inside the wind tunnel. The 1:14.5 scale Peterbilt 379 tractor-trailer model rested on a T-mount model support system which also allowed controlling the yaw of the model.

The T-bar was fixed along the length of the model as shown in the Figure 21 and this restricted the pivoting of the trailer with respect to the tractor. The model behaved as one rigid object and was controlled for yaw using an angle turner at the base of the support system. A linearly constrained 50lb stainless steel S-beam load cell was used in the direction of the force. The load cell was mounted to the tunnel floor using an open steel ball bearing, and a set screw shaft collar which allows the shaft to rotate freely using the angle turner. The output from the load cell was observed and recorded using a data acquisition (DAQ) system connected to a laptop. Labjack U3-LV was used as the DAQ system, and Labview 8.6 was used as the software to record data from the device. Since the voltage along the ranges of $0.02-0.03 \mathrm{v}$ at maximum load, a signal conditioning module, LJTick-inamp was used to amplify the signal from the S-beam load cell used in the force balance set-up. 


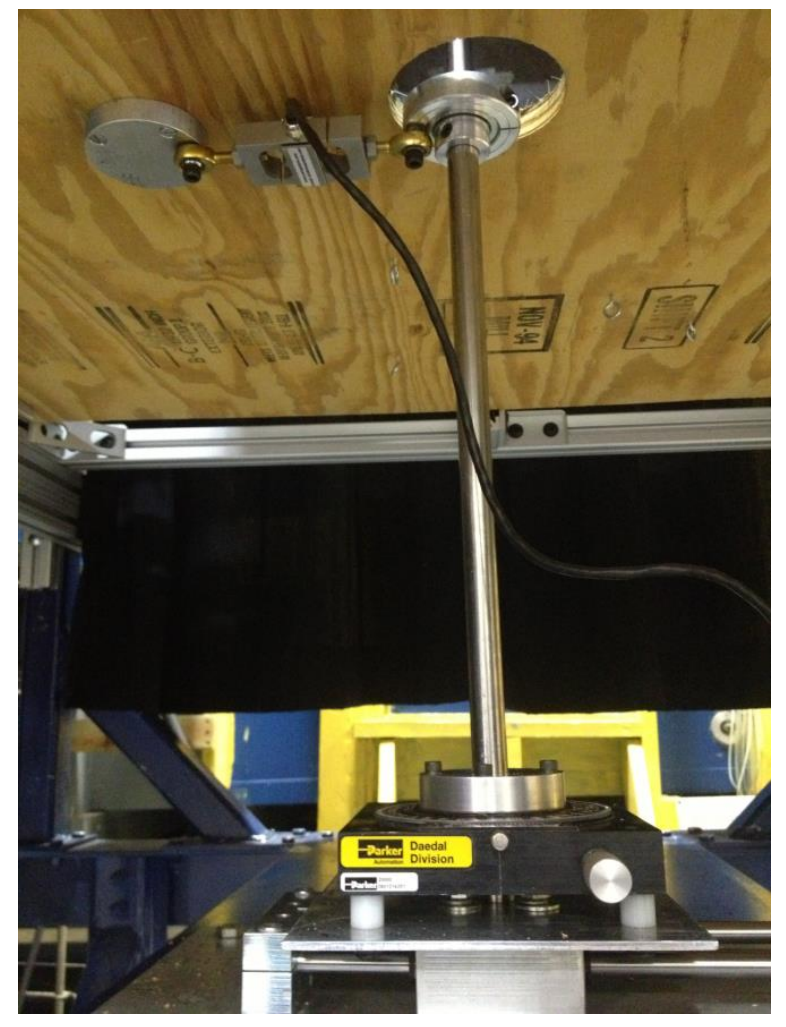

Figure 23. S-Beam Load Cell Linearly Constrained and Mounted to tunnel Floor

Table 5. S-Beam Load Cell Specifications

\begin{tabular}{|c|c|}
\hline Excitation Voltage & $10 \mathrm{Vdc}$ \\
\hline Output & $3 \mathrm{mV} / \mathrm{V}$ \\
\hline Linearity & $+/-0.01 \%$ FSO (0.05\% 40K) \\
\hline Construction & $17-4$ PH Stainless Steel \\
\hline Electrical & LC101: 4-Conductor Shielded Cable \\
\hline
\end{tabular}




\begin{tabular}{|l|c|}
\hline Range & $+/-50 \mathrm{kgF}$ \\
\hline
\end{tabular}

Table 6. Labjack U3-LV Specifications

\begin{tabular}{|c|c|}
\hline Total Number of Digital I/O Ports & 16 \\
\hline USB Configuration & USB 2.0/1.1 full speed interface \\
\hline Analog Outputs & 2 (10-Bit, 0-5 volts) \\
\hline Command/Response Time & $<1$ Millisecond \\
\hline
\end{tabular}

The model was carefully placed inside the wind tunnel and three pitot static probes were placed facing the flow direction in different places across the cross-section of the test section to get distributed static and dynamic pressure, which was measured using a manometer. 


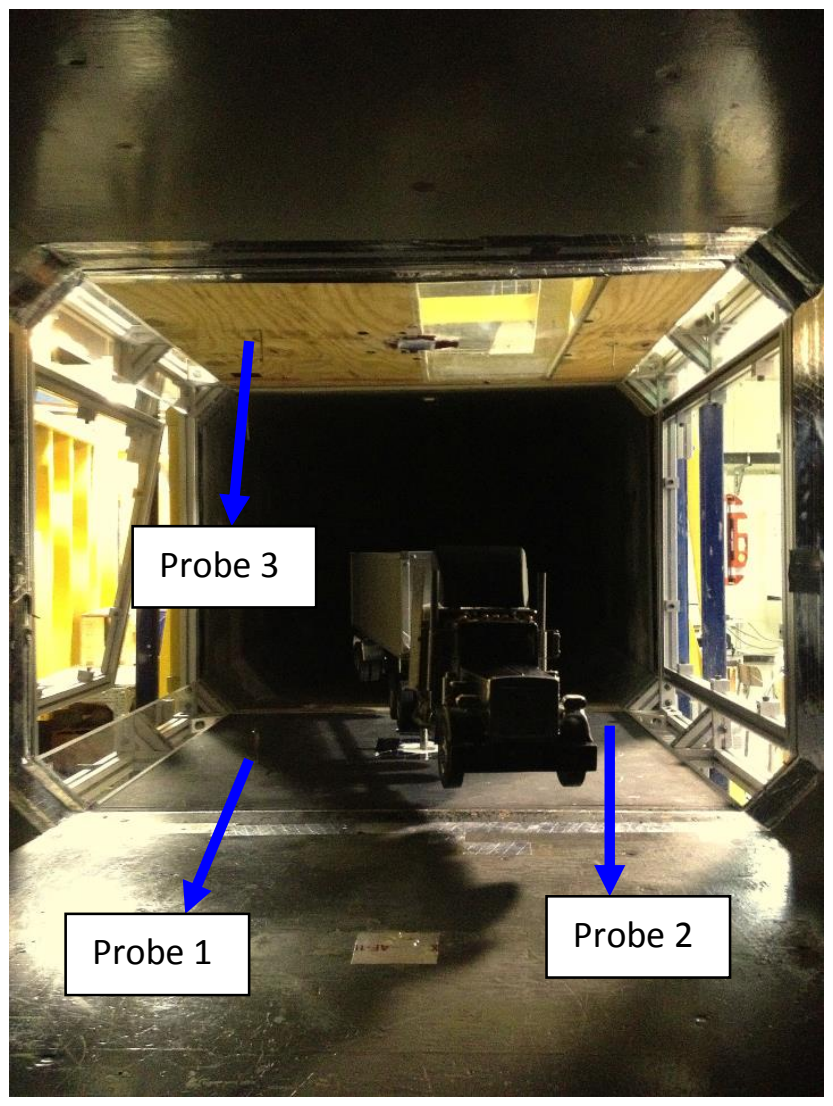

Figure 24. Probes Placed Across Test Section to Record Static and Dynamic Pressure

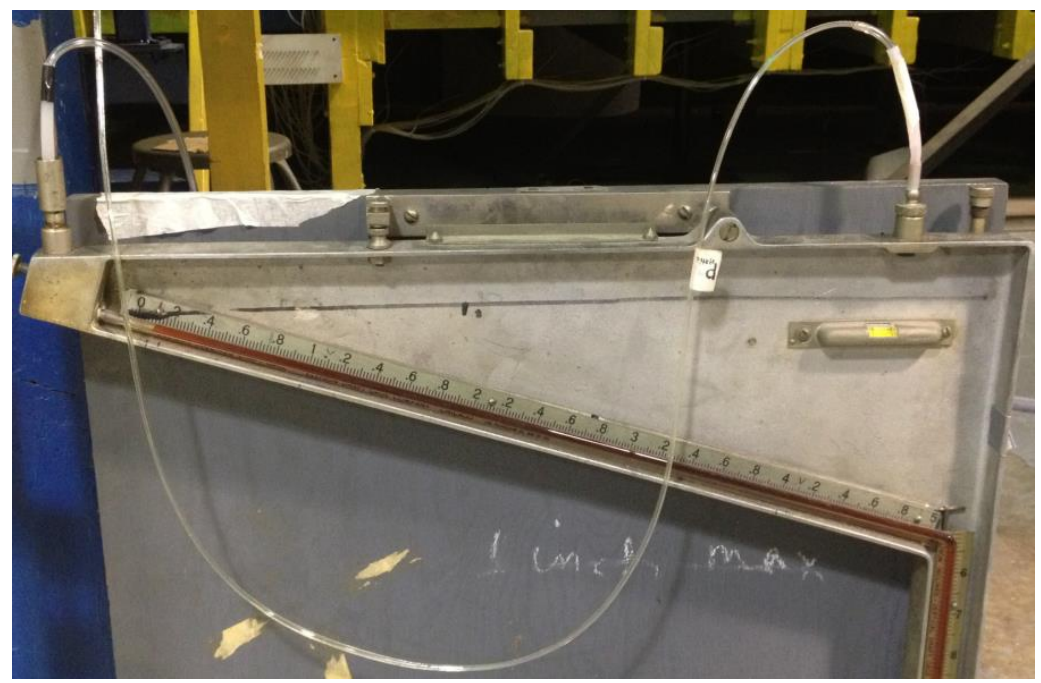

Figure 25. Manometer Reading Water in Inches (Flow at Test Section) 
The air speed inside the tunnel was calculated from the fluid displacement on the manometer. The model was set up inside the test section with the front end of the model facing oncoming air stream. Wind tunnel experiments were conducted for various configurations for a range of yaw angles between zero and thirteen degrees. The motivation to test several configurations came from the necessity to examine the effectiveness of different aerodynamic add-on devices under varied yaw conditions.

The T-mount set up rested on the angle turner at the base where it was controlled for yaw angle turns. In order to replicate actual road conditions closely inside the CLT, the model should have been placed on a moving ground plane (like a conveyor belt) to mimic a moving vehicle on the road which was not possible given the financial and structural constraints. To simulate on-road wind inside the CLT, a secondary variable blower unit to provide secondary flow (to simulate wind speed and wind direction) is required, but this was not possible in this study either. An alternative technique to mimic these on-road scenes with the single, variable blower unit was considered and the model set up was accommodated accordingly. In the absence of a moving ground plane, the model was positioned 2 inches above the tunnel floor as shown in Figure 24. A level bar was used to confirm if the model was at a uniform 2 inch distance above the floor across the length and width of the model. The load cell was constrained linearly to record only the force exerted in the flow direction. It should be noted that this setup does not directly translate to represent the coefficient of drag of an actual truck on the road because of the effects of other lateral forces, ground effects and these issues are addressed later in this dissertation. 


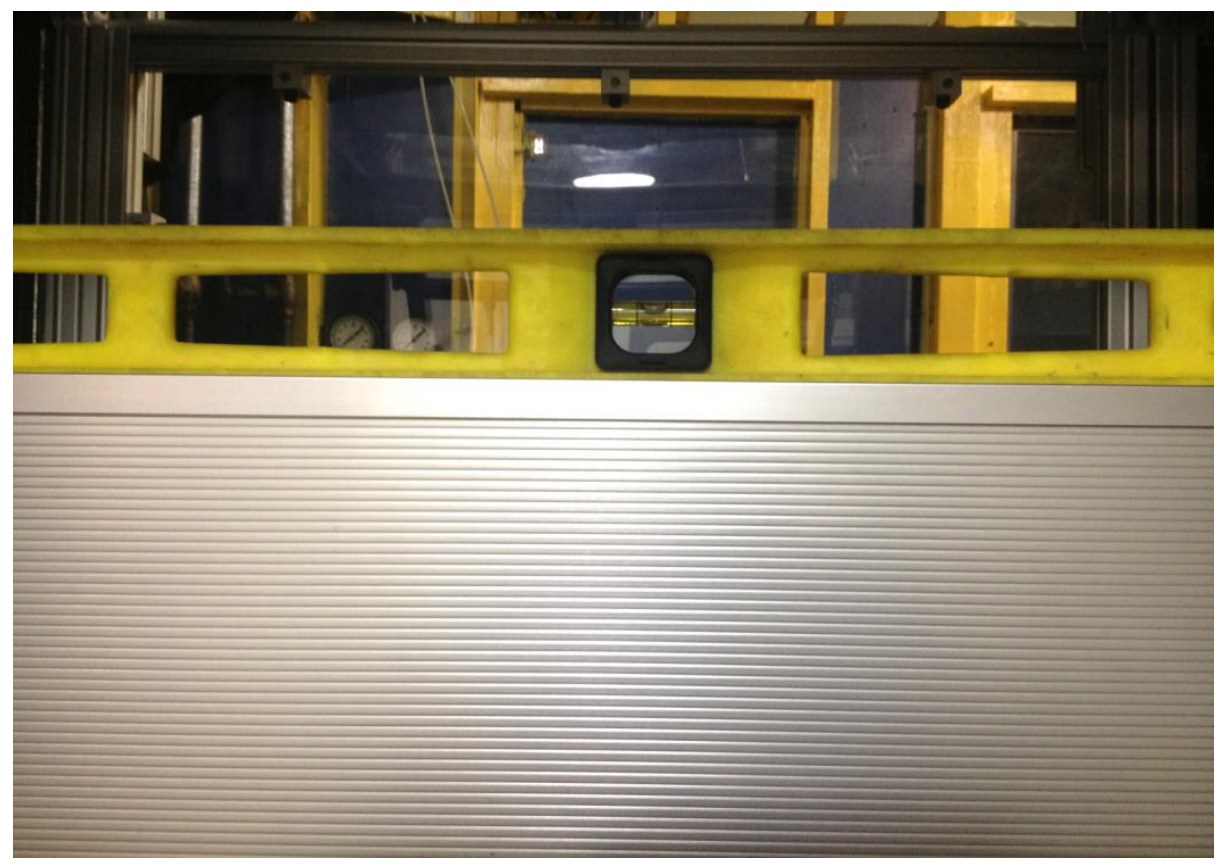

Figure 26. Torpedo Level Bar to Check Model Balance on T-Bar

Wind Tunnel Experiments and Calculations: The first operation performed once the test cell was set up was calibration. The S-beam load cell which was used to measure the force was calibrated using known weights. The calibration tests were done using one pound calibration weights. A five-point calibration was performed to calculate the response factor of the S-beam load cell used for the testing (see Appendix 1). Measurements for any test point were recorded for 30 seconds at $10 \mathrm{~Hz}$ frequency and the average values over the entire time period were used for calculations. To also account for any error due to electrical noise in the tunnel, the calibrations were done with the blower running at $1200 \mathrm{rpm}$, which is the set blower speed for all tests. The calibration tests were performed without knowing the precise location of the aerodynamic center [62] for the model; and so, an approximation was made for calculation purposes (see Appendix 1). The aerodynamic center for the model was assumed to be exactly at the center of the model (at 0.5 times the total height of the model). The calibration weights were loaded (1lb each) one at a time, 2 inches above 
the tunnel floor and 7.5 inches below the assumed aerodynamic center. The measurements were recorded when each calibration weight was added and then measurements were recorded when each weight was unloaded. The zero reading was measured before and after the calibration with no flow and the blower running at $1200 \mathrm{rpm}$. The response factor was determined using the assumed aerodynamic center and it was found to be $18.93 \mathrm{lbs} /$ volt.

$$
\begin{aligned}
& \text { Load Cell Response Factor (from assumed aerodynamic center) } \\
& =18.93 \mathrm{lbs} / \text { volt }
\end{aligned}
$$

Since all measurements made were in voltage, this response factor was used to convert voltage readings to force. It is important to finalize the initial conditions for testing, tunnel flow conditions. This research was aimed at studying the characteristics of a tractor-trailer operating at highway speeds. 


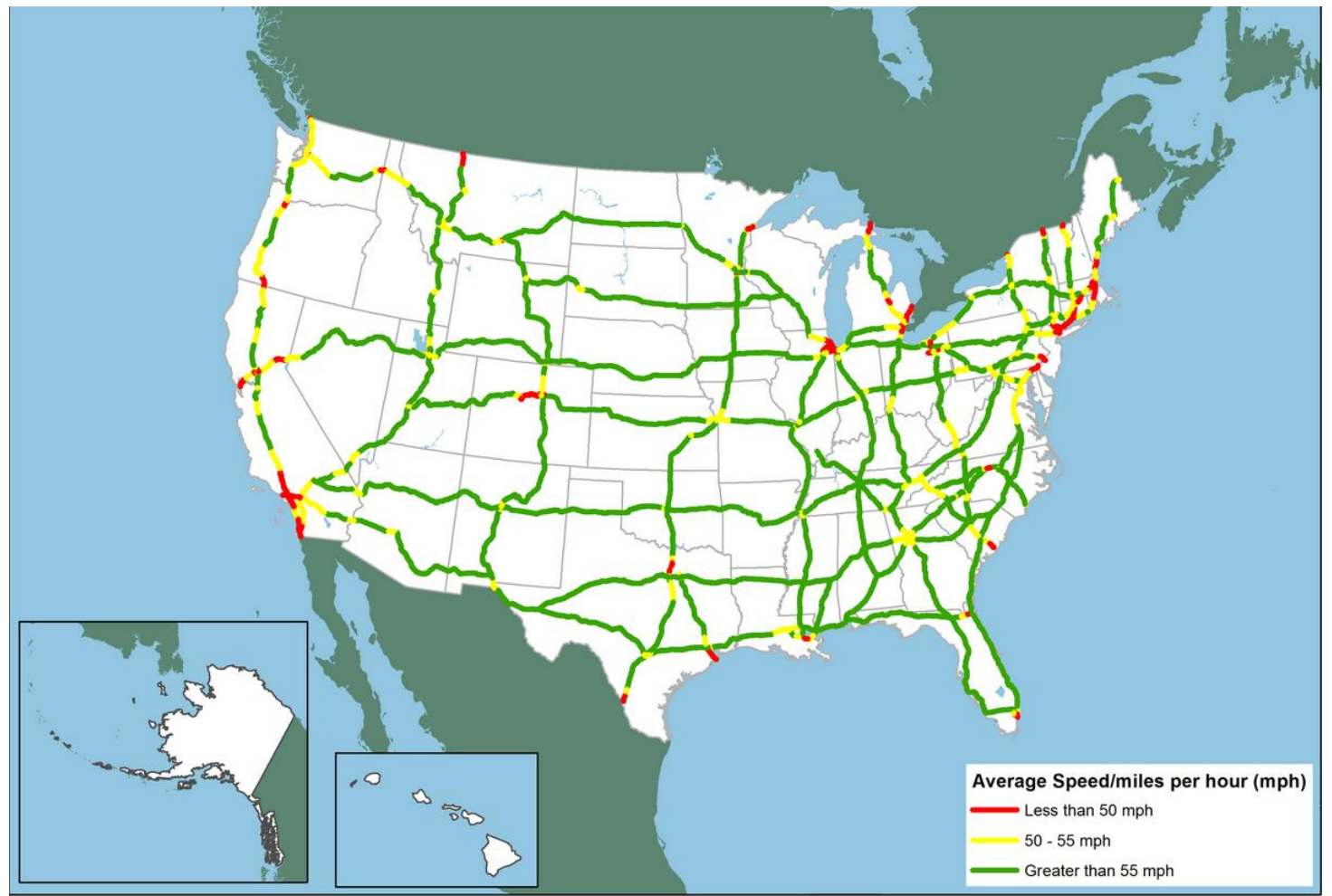

Figure 27. Average Truck Speeds on Interstate Highways [63]

From Figure 27 it can be seen that a significant portion of the highways in the United States have a minimum posted speed limit of $55 \mathrm{mph}$. Assuming that the truck drivers adhere to speed limits, the average operating highway speed of trucks in the United States is 55mph. Using Equation 6, the Reynolds number was computed at $55 \mathrm{mph}$ and this was used as on-road Reynolds number through the dissertation. Following recommendations from SAE J1252, the frontal width of the truck is used as hydraulic diameter/characteristic length, ' $l$ ' in Equation 6 . The maximum width limit for commercial motor vehicles in the United States is set at 102 inches [64].

$$
\text { On - Road Reynolds Number at 55mph }=3853354.45
$$

where, 
Dynamic viscosity $(\mu)=1.983 \times 10^{-5} \mathrm{~kg} / \mathrm{m}-\mathrm{sec}$ (dynamic viscosity of air at standard temperature and pressure).

Density $(\rho)=1.2041 \mathrm{~kg} / \mathrm{m}^{3}$ (density of air at standard conditions).

Velocity (V) = $55 \mathrm{mph}$ or $24.5872 \mathrm{~m} / \mathrm{sec}$ (truck speed).

Characteristic length $(I)=102$ inches (maximum truck width allowed by regulations).

However, it is impossible to simulate conditions to obtain Reynolds number of the order of approximately 3 million inside the CLT due to structural constraints and this is the primary reason, a scaled model was opted. The maximum Reynolds number which is possible inside the tunnel was determined at the maximum velocity inside the tunnel (blower at $1200 \mathrm{rpm}$ ) and the blade pitch fully open. A variable pitch controller was used to control the blade inside the tunnel, which in turn controlled the flow inside the tunnel. 


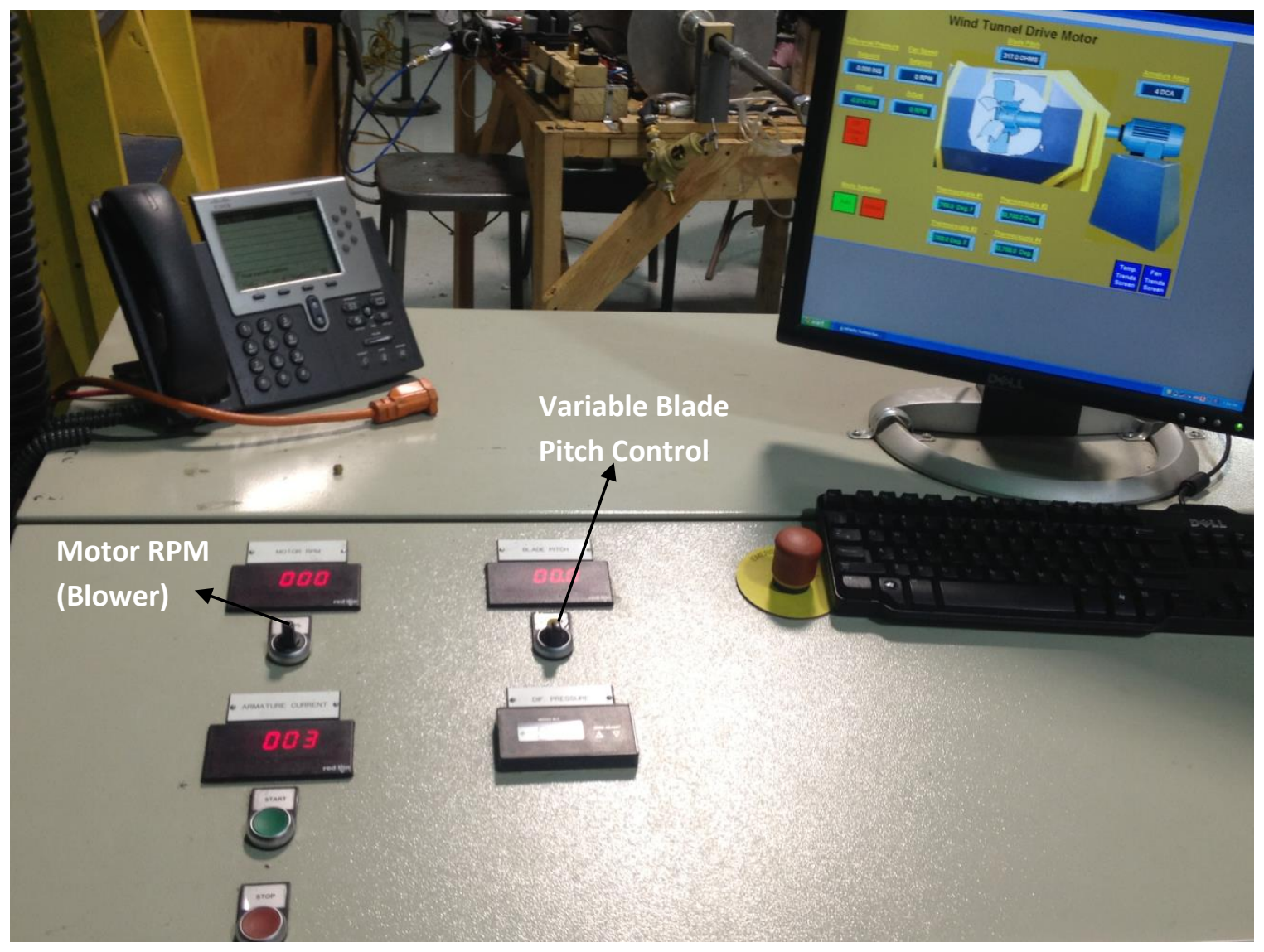

Figure 28. West Virginia University-CLT Controller Setup

The Reynolds number inside the tunnel was calculated using Equation 6. In this case, the hydraulic diameter/characteristic length used was the width of the scaled 14.5 Peterbilt tractor-trailer model, 7.1 inches. It should also be noted that the CLT does not have a moving ground plane.

CLT Reynolds Number $(0$ yaw anlge $)=\frac{\rho_{\text {tunnel }} V_{\infty-\text { wind tunnel }} l_{\text {tunnel }}}{\mu}=499,648.9$

Where,

$\rho_{\text {tunnel }}=$ Density of ambient air inside the test section $=1.18006 \mathrm{~kg} / \mathrm{m}^{3}$. 
$\mathrm{V}_{\infty \text {-wind tunnel }}=$ Free stream velocity inside the tunnel (with respect to a stationary ground plane inside the test section) $=95.85 \mathrm{mph}$ or $42.85 \mathrm{~m} / \mathrm{sec}$.

Dynamic viscosity $(\mu)=1.983 \times 10^{-5} \mathrm{~kg} / \mathrm{m}$-sec (dynamic viscosity corresponding to test section density).

The manometer reading corresponding to test section velocity of $42.85 \mathrm{~m} / \mathrm{sec}$ was 4.35 inches of water and that was the maximum tunnel velocity at which all tests were performed. The tests were performed for a total of 8 configurations including the baseline which does not have any aerodynamic add-on. The Peterbilt model was based on the 2007 Peterbilt model blueprint. Two aerodynamic add-on devices, a wind deflector and tractor-trailer gap reduction fairings were tested individually and together. These choices came from the list of aerodynamic technologies proposed by the EPA Smartway in 2012 for commercial vehicles in the United States [15]. The load cell which measures the volts is linearly constrained as shown in Figure 23 and was always aligned in the direction of the tunnel flow. It should be noted that the freestream velocity is now the acting relative velocity $\left(V_{r}\right)$ shown in Figure 15. All forces recorded by the load cell are directly aligned in the direction corresponding to the freestream velocity inside the tunnel or the acting $V_{r}$. There are two forces when a truck is yawed inside the tunnel or when there is a yaw angle due to on-road crosswinds; - one in the axial direction of the truck's motion, and the other perpendicular to the direction of the truck's motion ( $F_{x}$ and $F_{y}$, where the truck is travelling in the ' $x$ ' direction). 

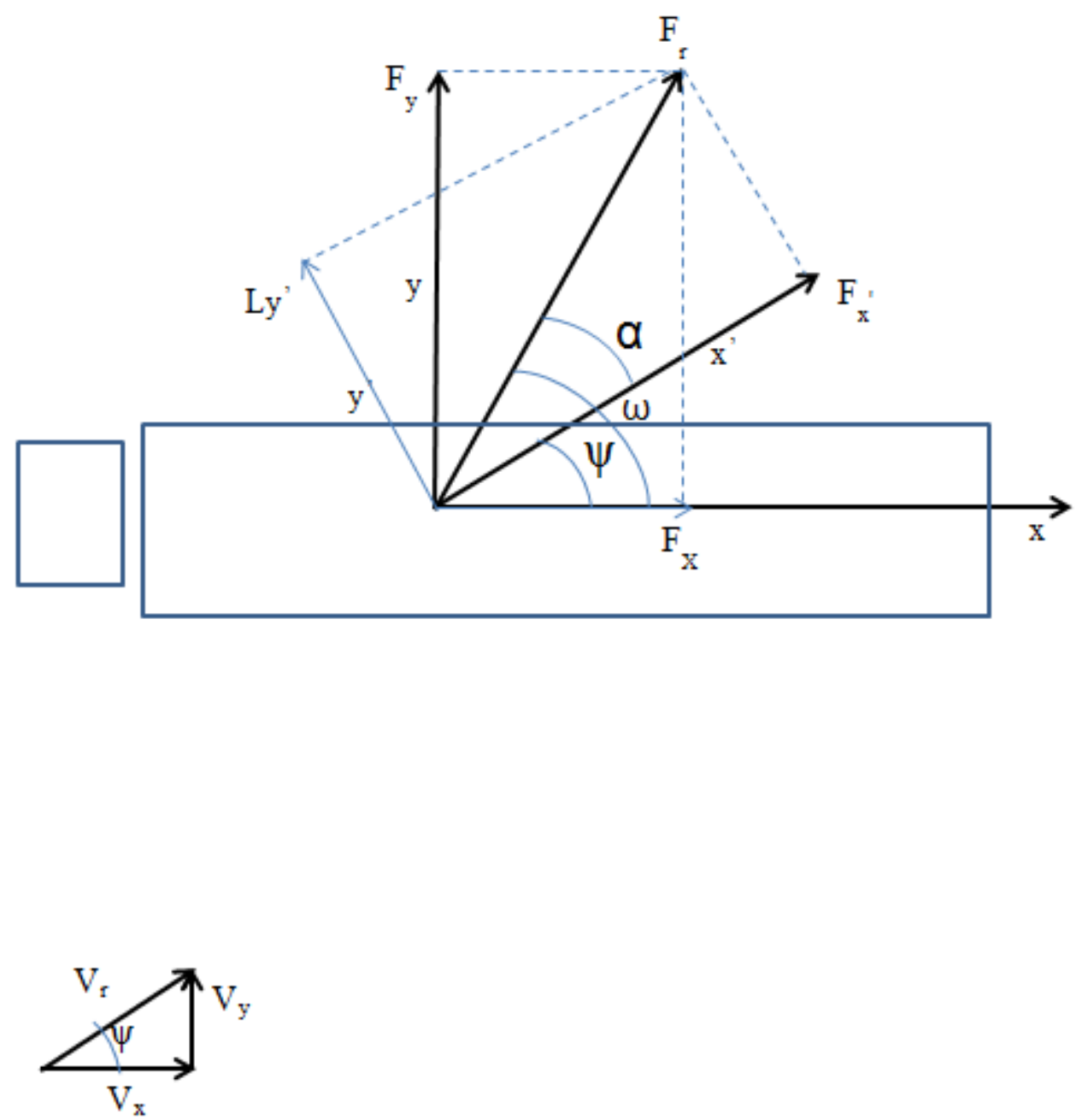

Figure 29. Diagrammatic Representation of Forces on a Truck (Including Side/lateral)

Where,

$\mathrm{F}_{\mathrm{r}}$ - Ultimate resultant force.

$\mathrm{F}_{\mathrm{x}^{\prime}}-$ Force in the direction of $\mathrm{V}_{\mathrm{r}}$ or force in the direction of free stream velocity, $\mathrm{V}_{\infty \text {-wind }}$ tunnel.

$\Psi-$ Yaw angle. 
Now from Figure 29,

$$
\begin{gathered}
\overrightarrow{F_{r}}=\overrightarrow{F_{x^{\prime}}}+\overrightarrow{L_{y^{\prime}}}=\overrightarrow{F_{x}}+\overrightarrow{F_{y}} \\
\omega=\tan ^{-1} F_{y} / F_{x} \\
\alpha=\omega-\psi \\
\psi=\tan ^{-1} V_{y} / V_{x} \\
F_{x^{\prime}}=F_{r} / \cos \alpha
\end{gathered}
$$

From Figure 29, it can be seen that the ultimate resultant force, $F_{r}$ on the truck when a truck is yawed in a tunnel or is experiencing a yaw angle due to on-road crosswinds is not directly aligned in the direction of $\mathrm{V}_{\mathrm{r}}$. The ultimate force component takes into account side/lateral drag as well and is always perpendicular to the resultant velocity, $\mathrm{V}_{\mathrm{r}}$ [65]. On the other hand, $F_{x^{\prime}}$ is a force which is aligned with the resultant velocity, $V_{r}$ but does not take side/lateral drag force into account. The measurements obtained in this study from the wind tunnel experiments only correspond to $F_{x^{\prime}}$ and do not account for the side/lateral drag that could have influenced the total drag on the truck. From the derived Equations 12 and 13, it can be seen that the side/lateral drag reduces total drag or it can be insignificant when the truck is operating at low speeds, below $30 \mathrm{mph}$ and wind speed less than $5 \mathrm{mph}$. From Equation 13, it can be seen that for small angles of ' $\alpha$,' the ultimate resultant force is the same as the force measured in the direction of the resultant velocity, $\mathrm{V}_{\mathrm{r}}$ but as ' $\alpha$ ' grows larger, the difference between $\mathrm{F}_{\mathrm{r}}$ and $\mathrm{F}_{\mathrm{x}}$ ' increases. This difference is caused by the side/lateral drag, $L_{y^{\prime}}$.

$$
C_{D(\text { wind tunnel })}=\frac{F_{x^{\prime}}}{\frac{1}{2} \rho V_{r}^{2} A_{r e f}}
$$


$C_{D}$ (wind tunnel) is calculated from $F_{x^{\prime}}$ as shown in Equation (14) with the reference velocity $V_{r}$, which is equal to the free stream velocity inside the tunnel, $V_{\infty \text {-wind tunnel. The }}$ denominator in Equation (14) remained nearly the same for all tests, until a change in temperature and pressure in the test section caused the density to change in small increments. In most cases, there was no significant difference in the density recorded inside the test section. The 8 configurations were tested from 0 to a maximum of 13 degree yaw angle at 1 degree or 0.5 degree increments. To identify the flow straightness with respect to the model position inside the test section or in other words, zero the yaw turn table, tests were carried out from -3 to +3 degree yaw angle for each configuration. It was assumed that the least amount of force would be measured by the load cell when the yaw angle is zero for tractor trailers [12] [66] [67]. Once the correctional angle was obtained, the values of $C_{D}$ calculated using Equation 14 were shifted such that the value of $C_{D}$ at zero yaw angle for a particular configuration would be the least $C_{D}$ value measured for that configuration. Tests were carried out for the remainder of the yaw angle range (up to +13 degrees) for the different configurations.

Moment-Arm Correction: Once all the configurations were tested for yaw angles, a correctional setup was developed to refine the values obtained. The load cell response factor was calculated from an assumed aerodynamic center (refer Appendix 1) so it became necessary to identify the true aerodynamic centers for each configuration. The model was rested on 1:87.1 scale, nonmagnetic metal rollers (to avoid any resistance offered by the rollers during flow inside the tunnel), which in turn are placed on tracks that are fixed to the tunnel floor and aligned with the flow direction. 


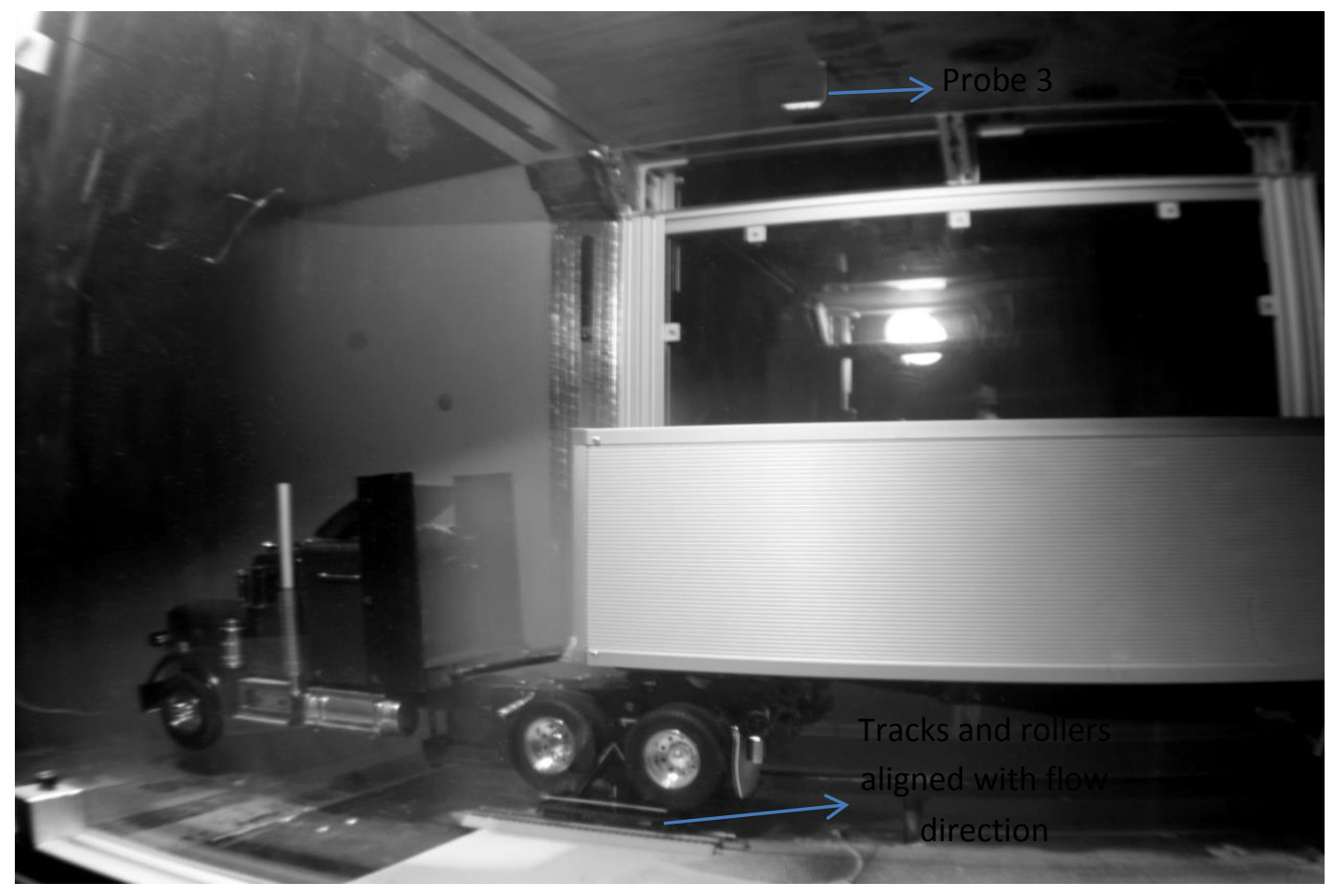

Figure 30. Peterbilt Model Resting on 1:87 Scale Rollers on Tracks.

The alignment of the S-beam load cell was not modified and was still linearly constrained in the flow direction. This arrangement could not be considered for all tests since it would not facilitate change in yaw angles. From Figure 30, it can be seen that any load applied in the flow direction would directly be recorded by the load cell as drag. A new set of measurements were taken for all eight configurations at zero degree yaw angle. The correction factor was obtained and applied to get the corrected $C_{D}$ values for all configurations, at all yaw angles (refer Appendix 1).

\subsubsection{Wind Tunnel Results}

This chapter only summarizes the processed results obtained from the wind tunnel experiments. A total of seven configurations including the baseline was tested between

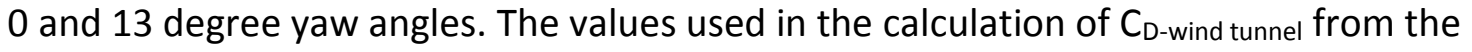


load cell (recorded at $10 \mathrm{~Hz}$ frequency for 30 seconds) were averaged over the time period to negate any errors to electrical noise. The first configuration that was tested was the baseline, which had no aerodynamic add-on devices.

Table 7. Yaw Angle, Coefficient of Drag and Corresponding Test Section Reynolds Numbers for Baseline Model Configuration

\begin{tabular}{|c|c|c|}
\hline Yaw Angle (in degrees) & $C_{D^{-} \text {wind tunnel }}$ & $\begin{array}{c}\text { Test Section Reynolds } \\
\text { Number }\left(\times 10^{5}\right)\end{array}$ \\
\hline 0 & 0.88 & 4.93 \\
\hline 1 & 0.925 & 4.91 \\
\hline 2 & 0.984 & 4.93 \\
\hline 3 & 1.065 & 4.96 \\
\hline 4 & 1.124 & 4.95 \\
\hline 5 & 1.174 & 4.94 \\
\hline 6 & 1.217 & 4.93 \\
\hline 7 & 1.264 & 4.93 \\
\hline 8 & 1.2843 & 4.99 \\
\hline 9 & 1.348 & 4.97 \\
\hline 10 & 1.407 & 4.97 \\
\hline 11 & 1.478 & 4.96 \\
\hline 12 & 1.57 & 4.96 \\
\hline 13 & 1.684 & 4.96 \\
\hline
\end{tabular}




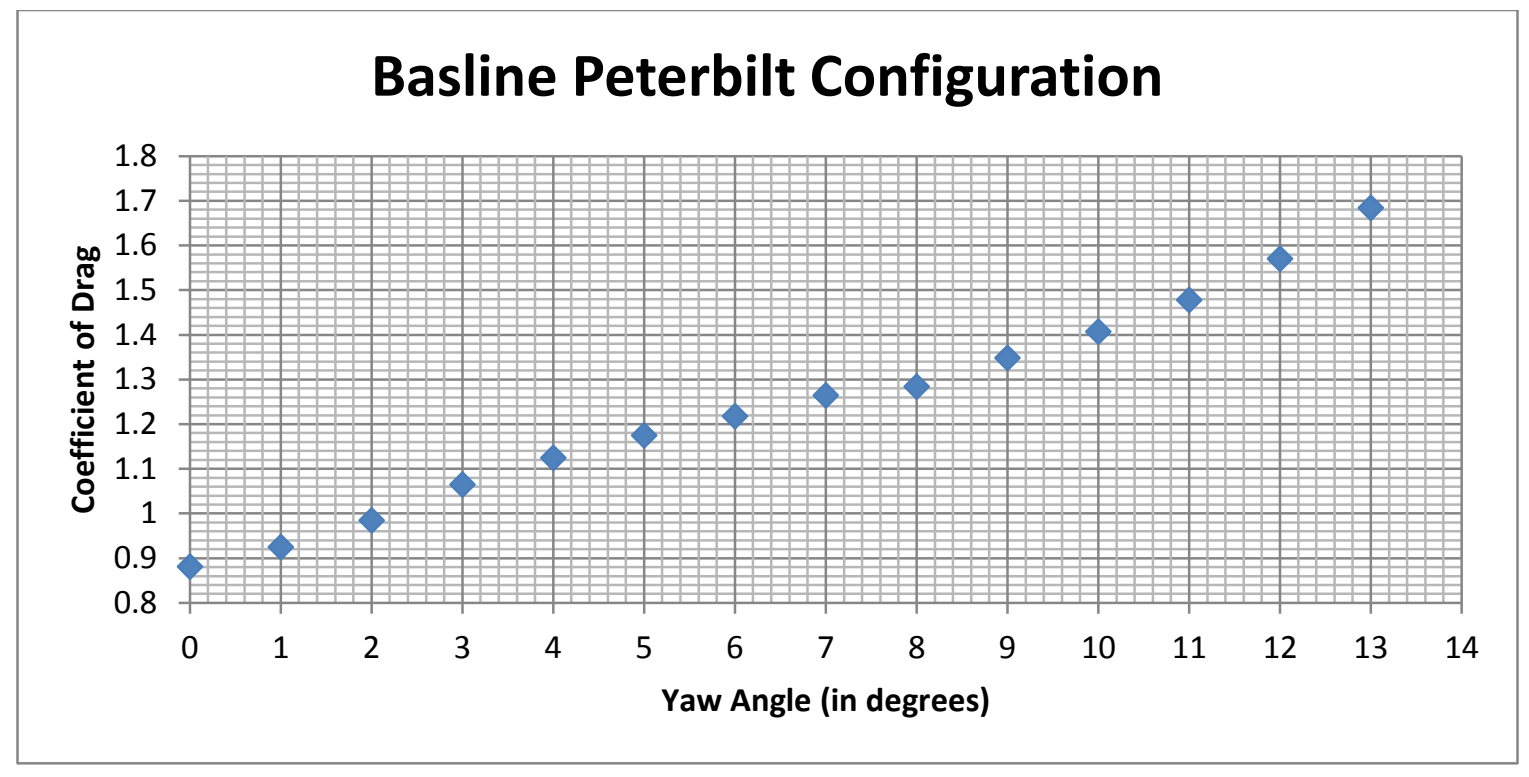

Figure 31. Baseline Coefficient of Drag vs Yaw Angle Plot.

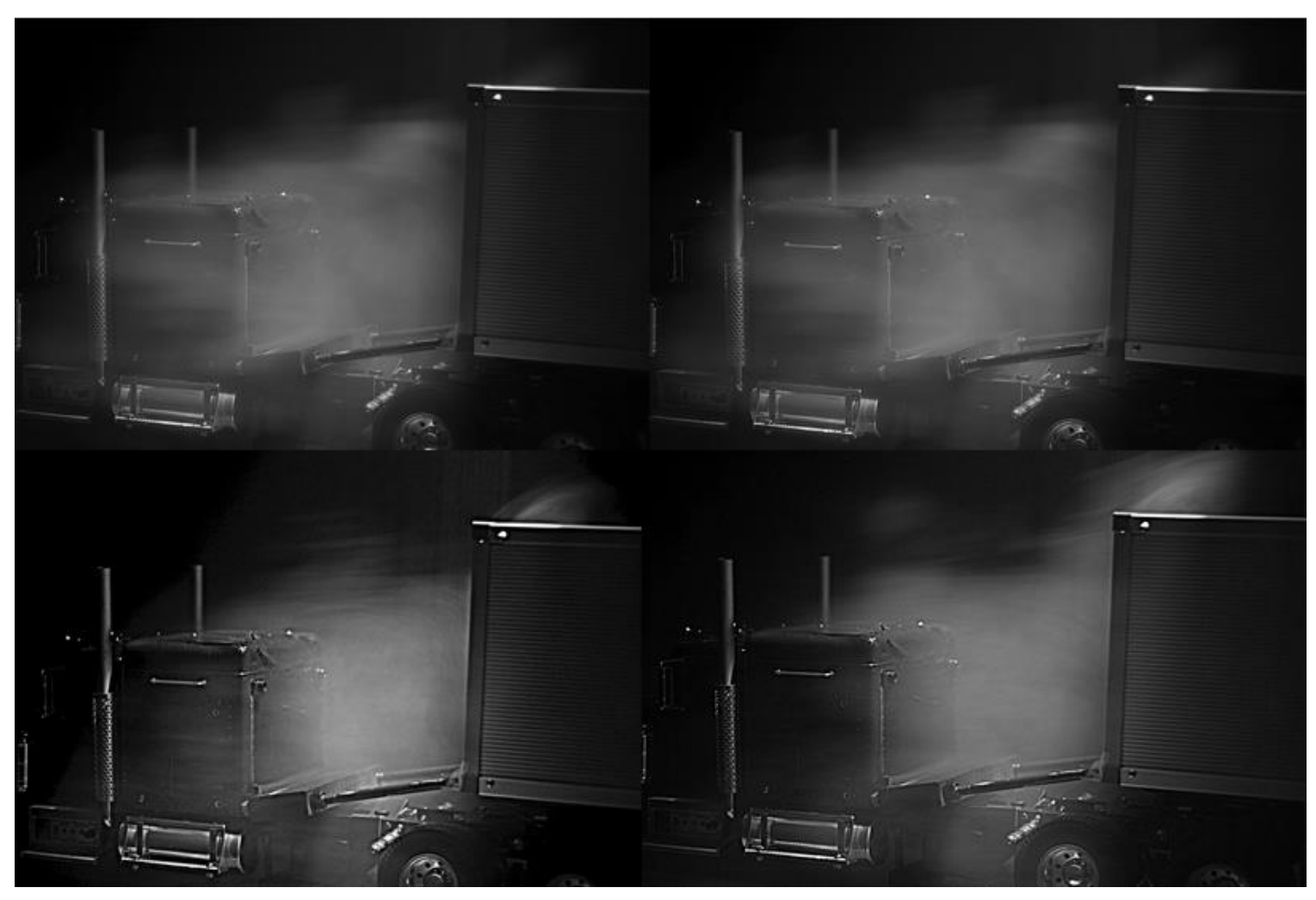

Figure 32. Visualization of Flow Pattern on the Baseline Configuration 
The second, third, and fourth configurations were tested with the addition of a wind deflector to the existing baseline configuration. The wind deflector was attached on top of the day cab and was tested at three different angles of attack: - , 30, 45, and 60 degrees. It was deduced from the resultant data, that different angle placements yielded different efficiencies for the same model.

Table 8. Yaw Angle, Coefficient of Drag and Corresponding Test Section Reynolds Numbers for Baseline Model with Wind Deflector Placed at 30 degree Angle of Attack

\begin{tabular}{|c|c|c|}
\hline Yaw Angle (in degrees) & C $^{- \text {-wind tunnel }}$ & $\begin{array}{c}\text { Test Section Reynolds } \\
\text { Number }\left(\times 10^{5}\right)\end{array}$ \\
\hline 0 & 0.794 & 4.95 \\
\hline 0.5 & 0.801 & 4.94 \\
\hline 1.5 & 0.890 & 4.94 \\
\hline 2.5 & 0.985 & 4.94 \\
\hline 3.5 & 1.038 & 4.94 \\
\hline 4.5 & 1.082 & 4.93 \\
\hline 5.5 & 1.129 & 4.93 \\
\hline 6.5 & 1.202 & 4.93 \\
\hline 7.5 & 1.274 & 4.93 \\
\hline 8.5 & 1.346 & 4.93 \\
\hline 9.5 & 1.45 & 4.93 \\
\hline 10.5 & 1.573 & 4.93 \\
\hline 11.5 & 1.667 & 4.93 \\
\hline 12.5 & 1.768 & 4.93 \\
\hline
\end{tabular}




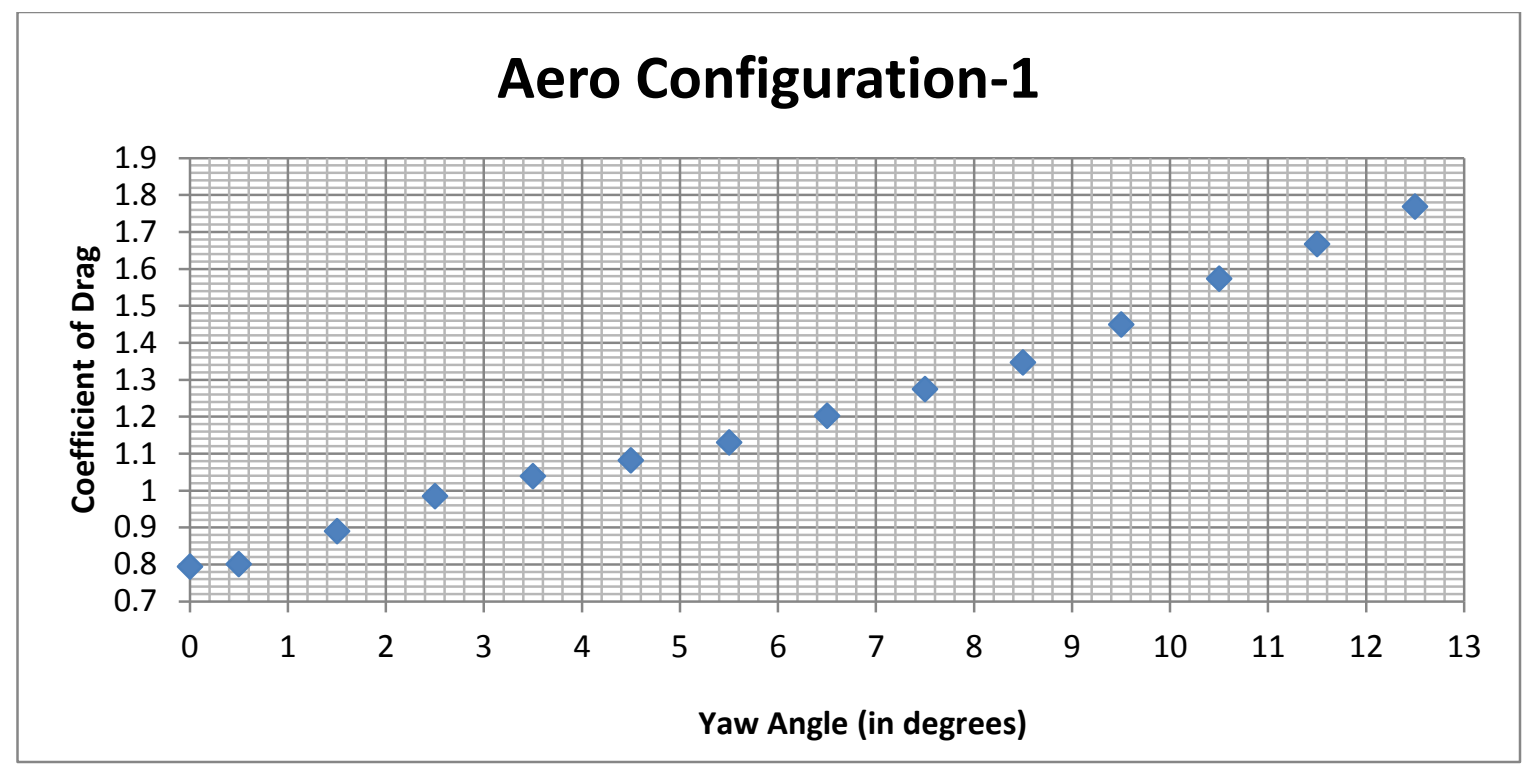

Figure 33. Coefficient of Drag vs Yaw Angle Plot (Wind Deflector - 30 degrees).

Table 9. Yaw Angle, Coefficient of Drag and Corresponding Test Section Reynolds Numbers for Baseline Model with Wind Deflector Placed at 45 degree Angle of Attack

\begin{tabular}{|c|c|c|}
\hline Yaw Angle (in degrees) & C $D^{- \text {wind tunnel }}$ & $\begin{array}{c}\text { Test Section Reynolds } \\
\text { Number }\left(\times 10^{5}\right)\end{array}$ \\
\hline 0 & 0.873 & 4.97 \\
\hline 1 & 0.933 & 4.97 \\
\hline 2 & 1.023 & 4.97 \\
\hline 3 & 1.091 & 4.96 \\
\hline 4 & 1.119 & 4.96 \\
\hline 5 & 1.152 & 4.95 \\
\hline 6 & 1.201 & 4.95 \\
\hline 7 & 1.27 & 4.95 \\
\hline 8 & 1.344 & 4.95 \\
\hline 9 & 1.437 & \\
\hline
\end{tabular}




\begin{tabular}{|c|c|c|}
\hline 10 & 1.527 & 4.95 \\
\hline 11 & 1.621 & 4.95 \\
\hline 12 & 1.717 & 4.93 \\
\hline 13 & 1.811 & 4.93 \\
\hline
\end{tabular}

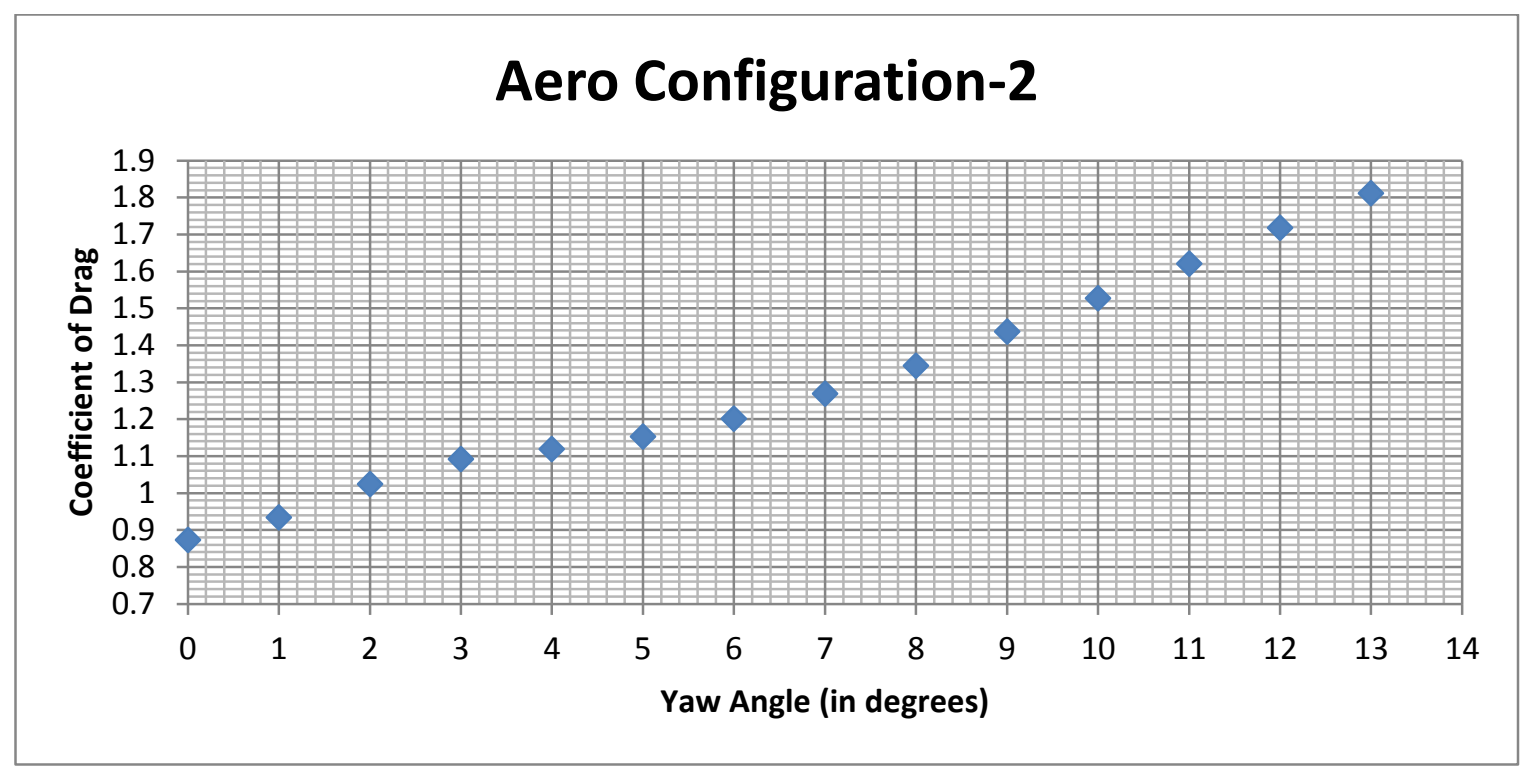

Figure 34. Coefficient of Drag vs Yaw Angle Plot (Wind Deflector - 45 degrees).

Table 10. Yaw Angle, Coefficient of Drag and Corresponding Test Section Reynolds Numbers for Baseline Model with Wind Deflector Placed at 60 degree Angle of Attack

\begin{tabular}{|c|c|c|}
\hline Yaw Angle (in degrees) & C $^{\text {-wind tunnel }}$ & $\begin{array}{c}\text { Test Section Reynolds } \\
\text { Number }\left(\times 10^{5}\right)\end{array}$ \\
\hline 0 & 0.988 & 4.96 \\
\hline 1 & 1.062 & 4.96 \\
\hline 2 & 1.153 & 4.94 \\
\hline 3 & 1.21 & 4.94 \\
\hline
\end{tabular}




\begin{tabular}{|c|c|c|}
\hline 4 & 1.25 & 4.94 \\
\hline 5 & 1.275 & 4.94 \\
\hline 6 & 1.312 & 4.93 \\
\hline 7 & 1.392 & 4.93 \\
\hline 8 & 1.461 & 4.92 \\
\hline 9 & 1.554 & 4.92 \\
\hline 10 & 1.681 & 4.92 \\
\hline 11 & 1.781 & 4.92 \\
\hline 12 & 1.882 & 4.92 \\
\hline 13 & 1.975 & 4.92 \\
\hline
\end{tabular}

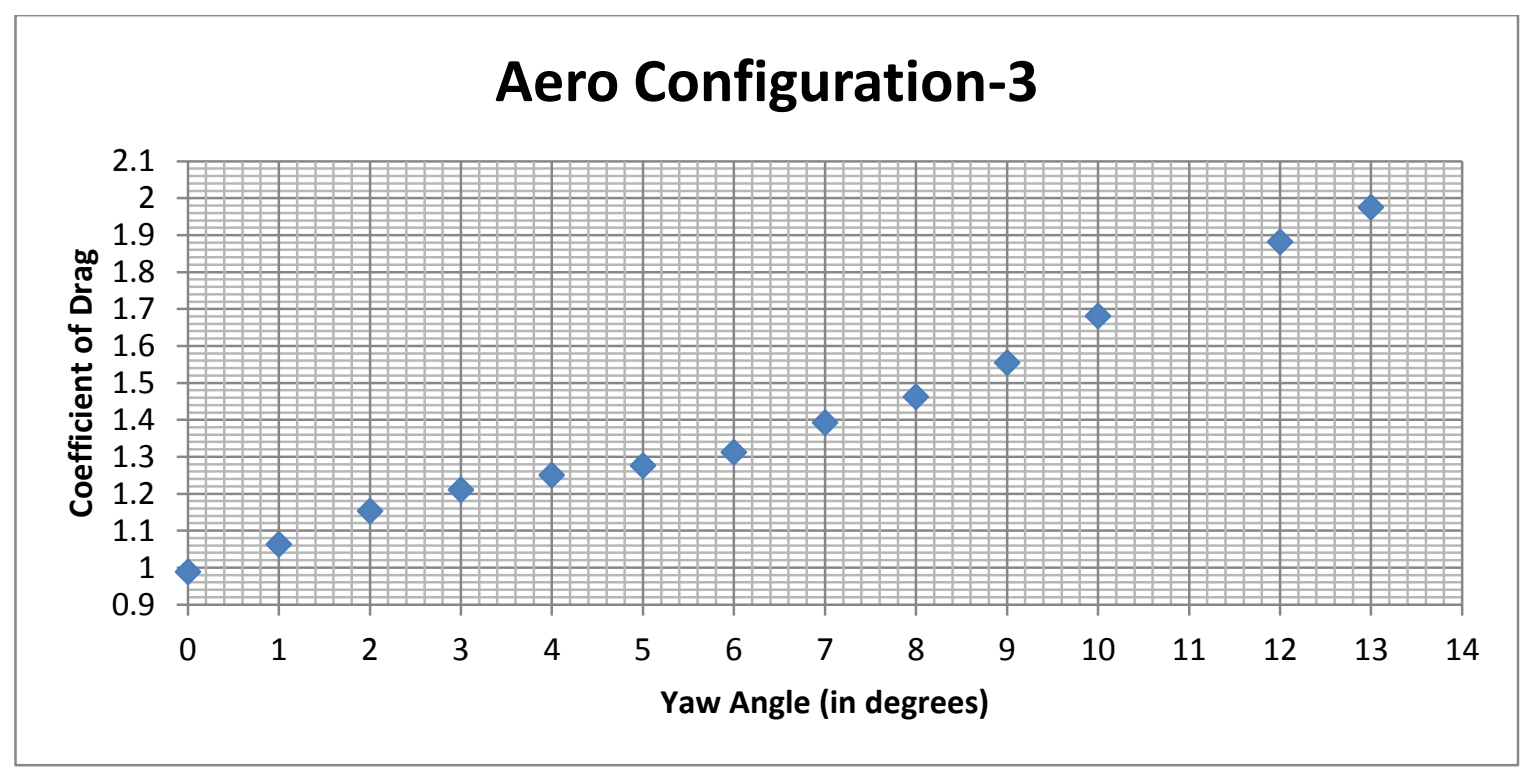

Figure 35. Coefficient of Drag vs Yaw Angle Plot (Wind Deflector - 60 degrees).

The next set of results (aero configuration 4, 5 and 6) present the coefficient of drag obtained for the model equipped with a tractor trailer gap fairing in series with a wind deflector (30, 45 or 60 degrees) on the baseline configuration. 
Table 11. Yaw Angle, Coefficient of Drag and Corresponding Test Section Reynolds Numbers for Aero Configuration 4 - Wind Deflector at 30 degrees and Tractor Trailer Gap Fairings

\begin{tabular}{|c|c|c|}
\hline Yaw Angle (in degrees) & $C_{D^{-} \text {wind tunnel }}$ & $\begin{array}{c}\text { Test Section Reynolds } \\
\text { Number }\left(\times 10^{5}\right)\end{array}$ \\
\hline 0 & 0.795 & 4.83 \\
\hline 1 & 0.849 & 4.83 \\
\hline 2 & 0.946 & 4.83 \\
\hline 3 & 1.044 & 4.83 \\
\hline 4 & 1.112 & 4.83 \\
\hline 5 & 1.177 & 4.83 \\
\hline 6.5 & 1.290 & 4.83 \\
\hline 8 & 1.466 & 4.82 \\
\hline 9 & 1.545 & 4.83 \\
\hline 10.5 & 1.681 & 4.82 \\
\hline 11 & 1.781 & 4.82 \\
\hline 12 & 1.857 & 4.82 \\
\hline 13 & 2.004 & 4.82 \\
\hline
\end{tabular}




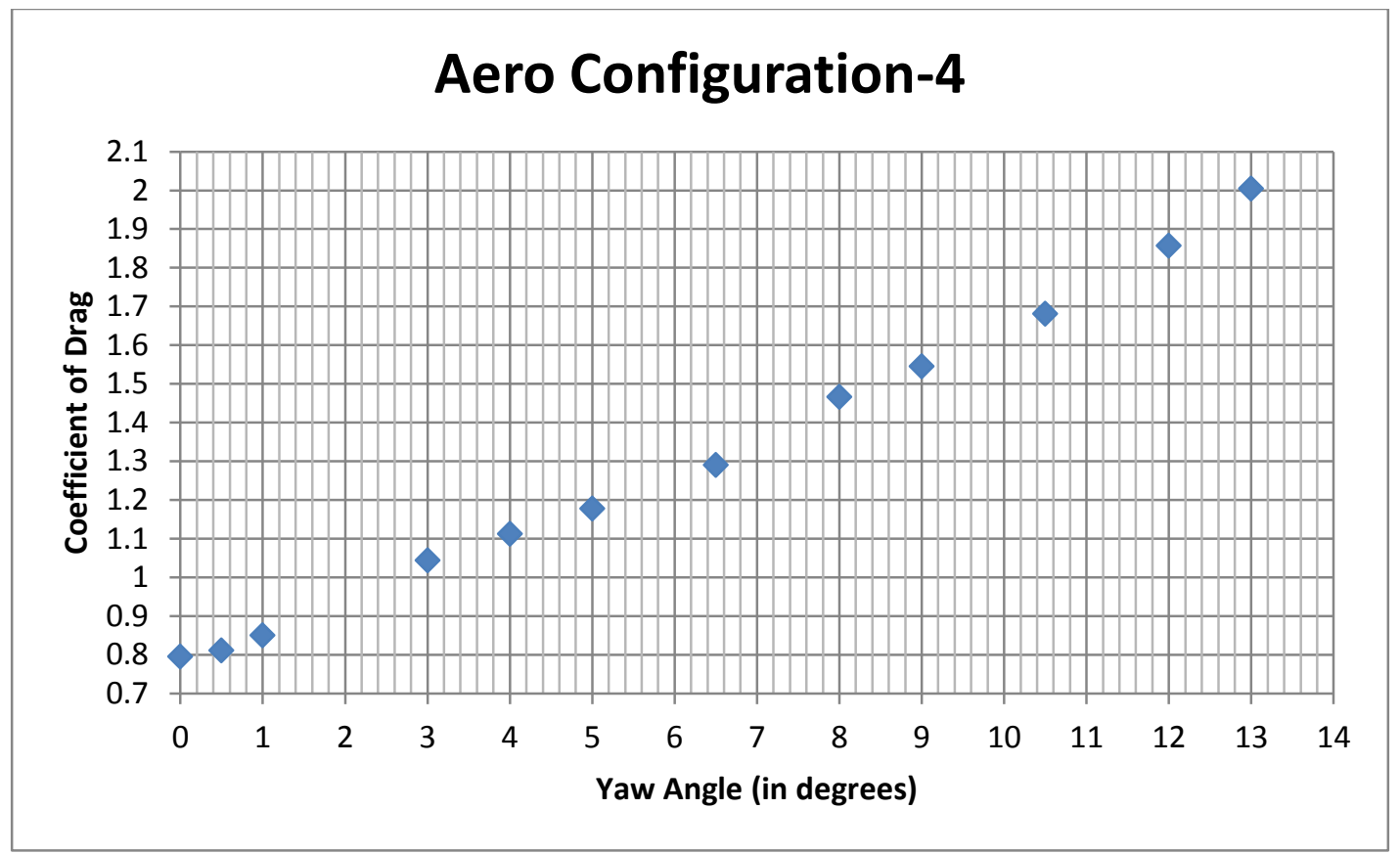

Figure 36. Coefficient of Drag vs Yaw Angle Plot (Wind Deflector - 30 degrees and Tractor Trailer Gap Fairings).

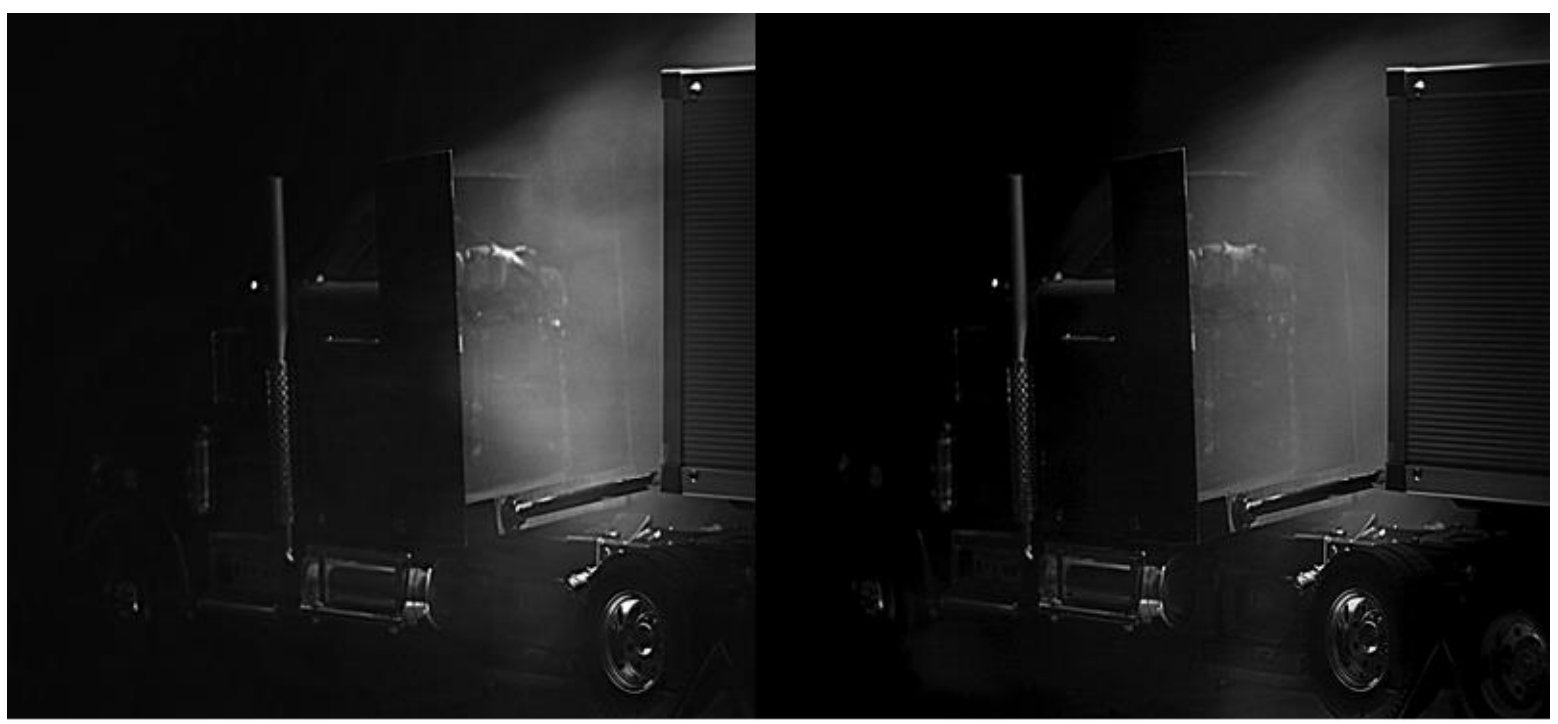

Figure 37. Visualization of Flow Pattern on the Aero Configuration 4 - Wind Deflector at 30 degrees and Tractor Trailer Gap Fairings. 
Table 12. Yaw Angle, Coefficient of Drag and Corresponding Test Section Reynolds Numbers for Aero Configuration 5 - Wind Deflector at 45 degrees and Tractor Trailer Gap Fairings

\begin{tabular}{|c|c|c|}
\hline Yaw Angle (in degrees) & $C_{D^{-} \text {wind tunnel }}$ & $\begin{array}{c}\text { Test Section Reynolds } \\
\text { Number }\left(\times 10^{5}\right)\end{array}$ \\
\hline 0 & 0.872 & 4.9 \\
\hline 0.5 & 0.911 & 4.9 \\
\hline 1.5 & 1.017 & 4.9 \\
\hline 2.5 & 1.118 & 4.89 \\
\hline 3.5 & 1.182 & 4.88 \\
\hline 4.5 & 1.287 & 4.87 \\
\hline 5.5 & 1.343 & 4.88 \\
\hline 7 & 1.449 & 4.88 \\
\hline 8.5 & 1.613 & 4.88 \\
\hline 9.5 & 1.691 & 4.87 \\
\hline 11 & 1.874 & 4.87 \\
\hline 12.5 & 2.082 & 4.87 \\
\hline 13 & 2.162 & 4.88 \\
\hline
\end{tabular}




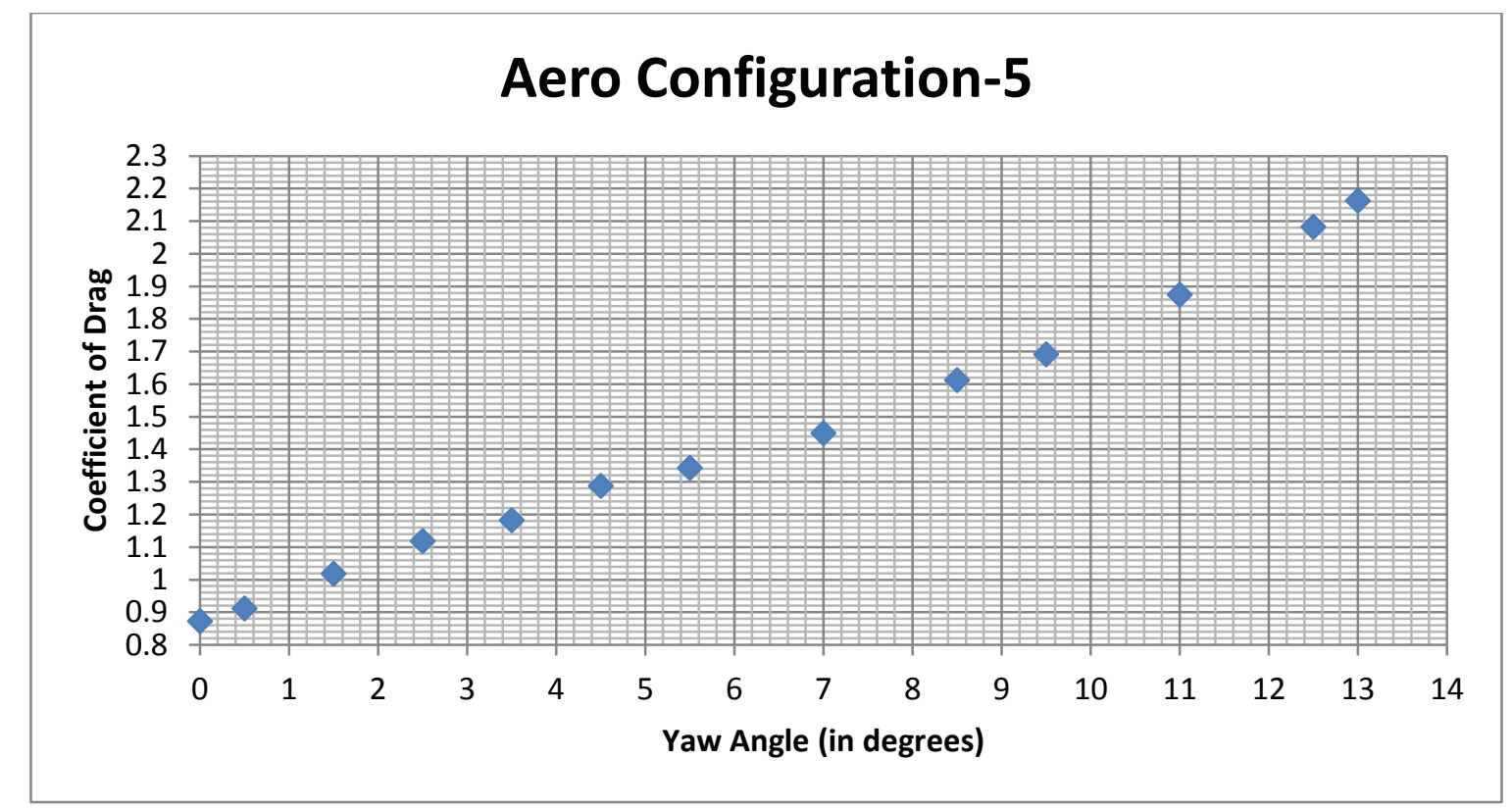

Figure 38. Coefficient of Drag vs Yaw Angle Plot (Wind Deflector - 45 degrees and Tractor Trailer Gap Fairings).

Table 13. Yaw Angle, Coefficient of Drag and Corresponding Test Section Reynolds Numbers for Aero Configuration 6 - Wind Deflector at 60 degrees and Tractor Trailer Gap Fairings

\begin{tabular}{|c|c|c|}
\hline Yaw Angle (in degrees) & C $^{-}$-wind tunnel & $\begin{array}{c}\text { Test Section Reynolds } \\
\text { Number }\left(\times 10^{5}\right)\end{array}$ \\
\hline 0 & 1.041 & 4.92 \\
\hline 0.5 & 1.05 & 4.92 \\
\hline 1 & 1.062 & 4.91 \\
\hline 2 & 1.154 & 4.91 \\
\hline 3.5 & 1.296 & 4.91 \\
\hline 5 & 1.393 & 4.90 \\
\hline 6 & 1.433 & 4.90 \\
\hline
\end{tabular}




\begin{tabular}{|c|c|c|}
\hline 7.5 & 1.516 & 4.90 \\
\hline 9 & 1.681 & 4.90 \\
\hline 10.5 & 1.856 & 4.90 \\
\hline 12 & 2.055 & 4.90 \\
\hline 13 & 2.190 & 4.89 \\
\hline
\end{tabular}

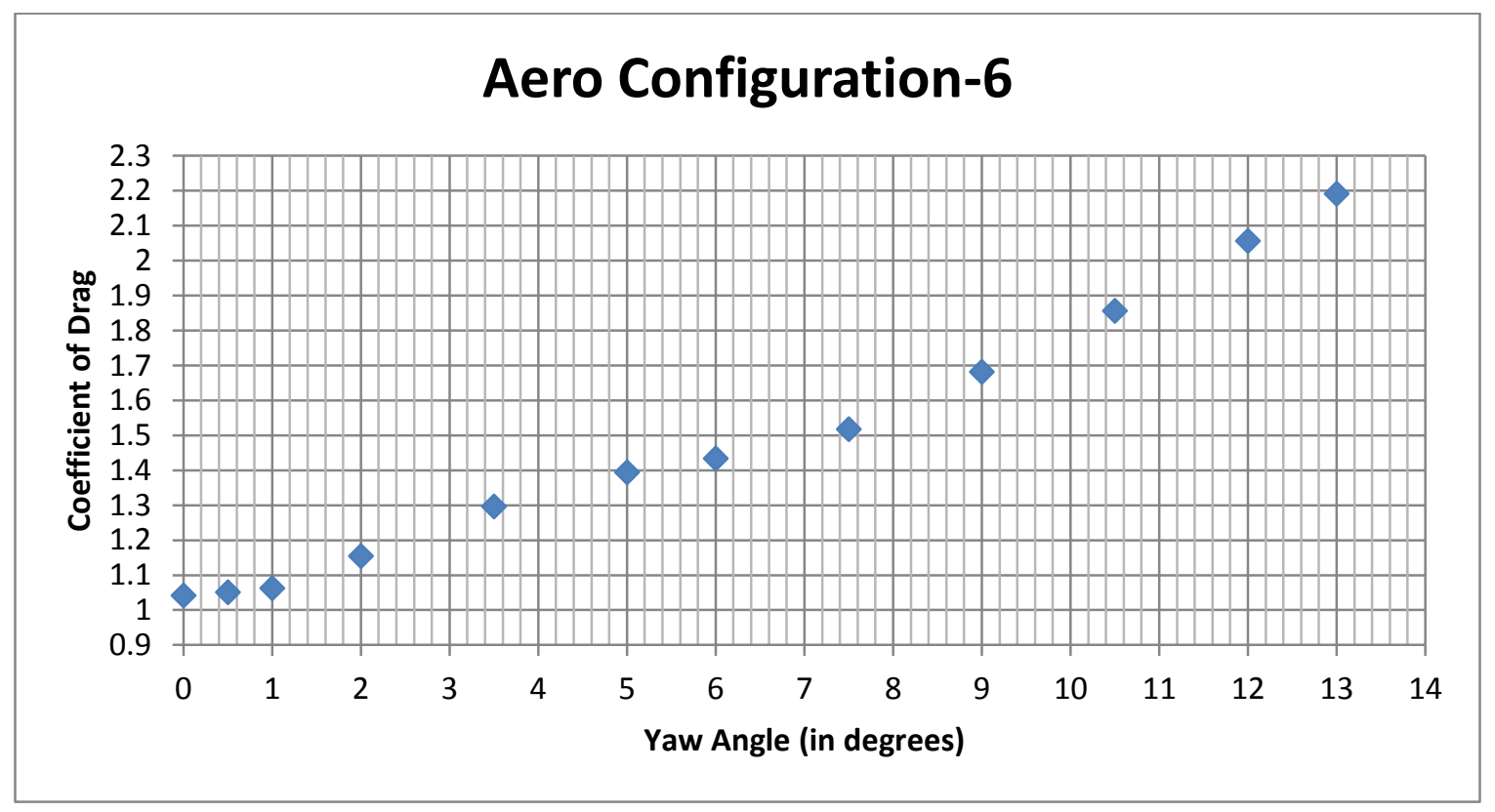

Figure 39. Coefficient of Drag vs Yaw Angle Plot (Wind Deflector - 60 degrees and Tractor Trailer Gap Fairings). 


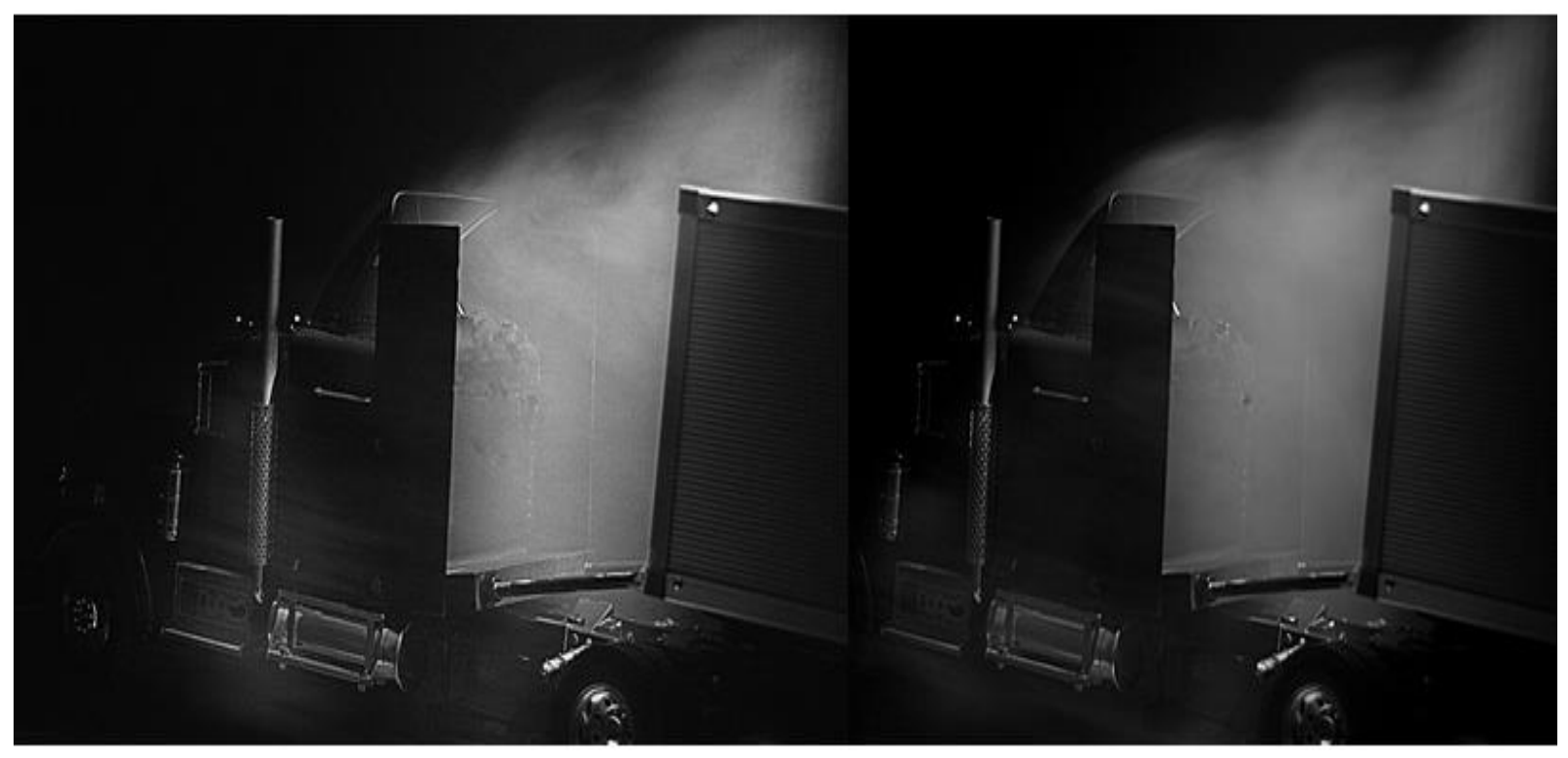

Figure 40. Coefficient of Drag vs Yaw Angle Plot (Wind Deflector - 60 degrees and Tractor Trailer Gap Fairings).

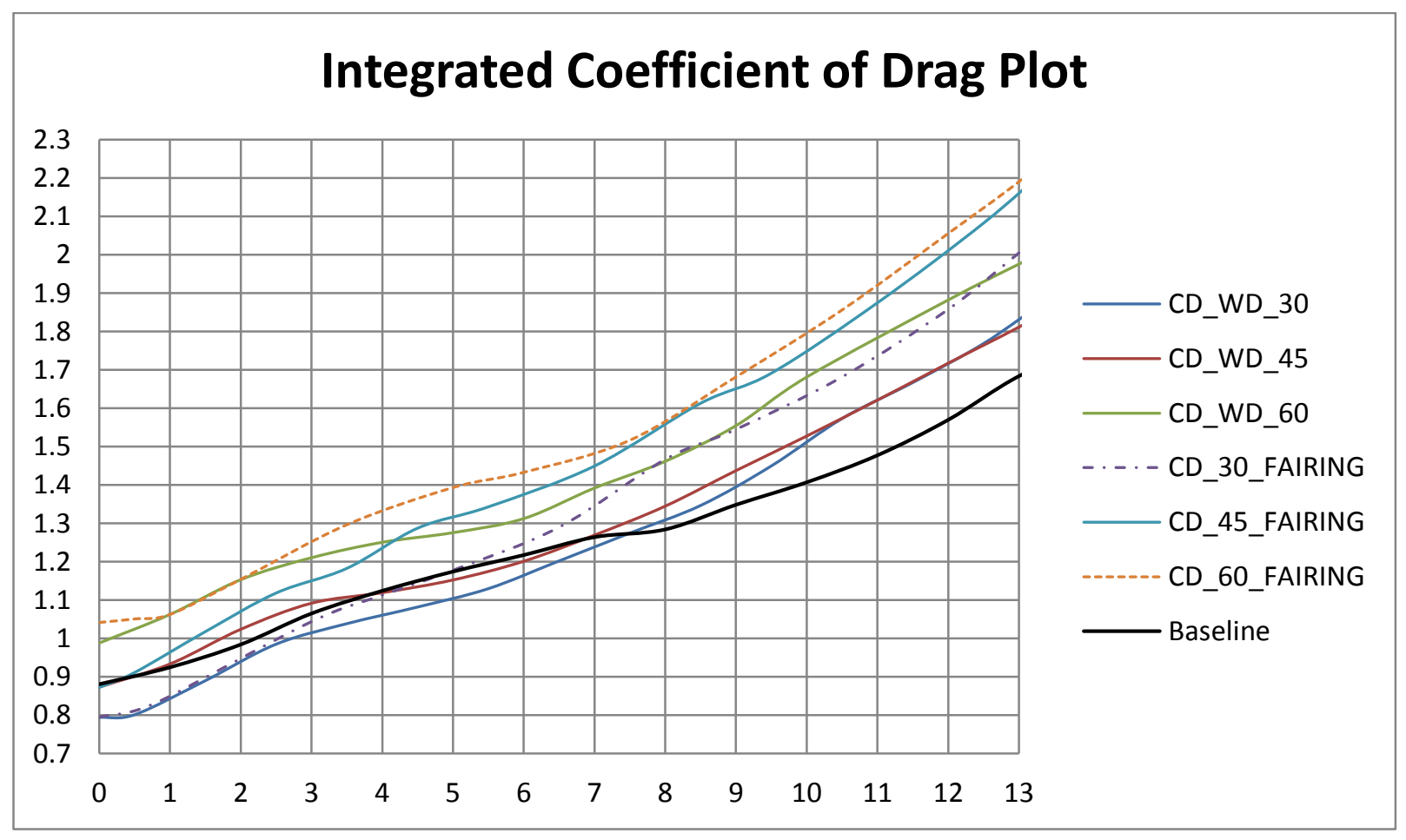

Figure 41. Integrated Plot with all 6 Aero Configurations and the Baseline Configuration. 
A simple error analysis was conducted to show the variation the results due to measurement error. Since the values recorder using the load cell were all averaged values, the analysis was repeated for a variation of one standard deviation from the average value for each measured sample set. With one standard deviation difference in the load cell calibration/response factor, measurement at each yaw angle, load cell zero error, the average cumulative error in the $C_{D}$ calculated at each yaw angle was estimated to be \pm 1.32 percent.

It can be seen from the results obtained from the wind tunnel tests and Figure 41 that different configurations are beneficial in different regions of the yaw angle curve with some of them evidently being not beneficial but detrimental. Configurations 1 and 4 display superior benefits at the lower end of the yaw angle curve (between 0 and 4 degrees). However, configuration 1 proved to be better with increasing yaw angle and this is expected since configuration 4 includes tractor-trailer gap fairings and at higher degrees of yaw angle, it increases the drag due to increased cross sectional area of attack. Figure 32 and 37 shows how the air flow changes at 0 degree yaw angle as a factor of the additional aerodynamic devices on the truck between the baseline and configuration 4 . The addition of the wind deflector and the gap fairings reduces the low pressure region and diverts the air flow up and over this gap thus reducing the impact of the large vortices that are formed in this region. At higher angles of yaw (greater than 8 degrees), the baseline configuration proved to be more efficient than all other configurations. The results obtained for configurations 3,5 and 6 shows that aerodynamic devices can be detrimental and are not beneficial across the yaw angle curve. The estimated percentage error margin is acceptable and the conclusions made from the results obtained are valid. The equations and method for error estimation are discussed in Appendix III. 


\subsection{Numerical Simulations to Validate Wind Tunnel Experimental}

\section{Data}

Reynolds number is an important characteristic that needs to be respected when doing scaled wind tunnel studies. The data obtained from the wind tunnel experiments inside the CLT never matched the on-road Reynolds number. The CLT Reynolds number ranged from $4.8 \times 10^{5}$ to $5 \times 10^{5}$ for all tests, whereas, the on-road Reynolds number is in the range of $3.8 \times 10^{6}$ to $4.2 \times 10^{6}$. This provoked the necessity to validate the conditions in which tests were performed inside the tunnel. Generally bluff bodies enter turbulent flow regime at low ranges of Reynolds numbers [41] [68] [69]. For all 3D objects, once turbulent flow dominates, coefficient of drag is effectively a constant for the appropriate range of Reynolds number. The papers discuss effects of Reynolds number on drag coefficient for various shapes and the summary of conclusion is that coefficient of drag varies with an increase in Reynolds number for bluff bodies until it reaches critical Reynolds number. In 2001, tests were conducted on bluff bodies to identify the critical Reynolds number range and it was concluded that the coefficient of drag decreases with increasing Reynolds number up to $4 \times 10^{5}$, after which coefficient of drag remains constant as Reynolds number continues to increase [70]. Many studies have conducted on bluff body, tractor trailer aerodynamics between a Reynolds number range of $2 \times 10^{5}$ to $4.2 \times 10^{5}$ [71] [72] [73] [74]. The tests conducted at WVU-CLT were between $4.8 \times 10^{5}$ to $5 \times 10^{5}$ Reynolds numbers. Numerical simulations were considered and carried to provide validation to the statement, 'the measurements made for lower values of Reynolds number inside the WVU CLT will match the measurements corresponding to highest values of Reynolds number on-road.'

Numerical Model Setup: A 1:1 scale Peterbilt tractor-trailer 3D geometry was created in Solidworks 2012 and Ansys 13.0, both of which are commercially available tools. The model construction was based on the baseline configuration tested inside the CLT. 
Exterior details such as exhaust stacks, mud flaps, rear view mirrors, tank fairings, underbody support rails, and side door steps were part of the model construction.

Table 14. Dimensions of 1:1 Scale Baseline Peterbilt 379 Model for Numerical Simulations

\begin{tabular}{|c|c|}
\hline Description & Dimension/Length/Gap (in inches) \\
\hline Model Frontal Width (at zero yaw angle) & 102 \\
\hline model height (from bottom most to top & 771 \\
\hline $\begin{array}{c}\text { Model total length (from front end to back } \\
\text { end including trailer) }\end{array}$ & 65.2 \\
\hline Tractor-trailer gap width (from back face \\
of cab to front face of trailer)
\end{tabular}




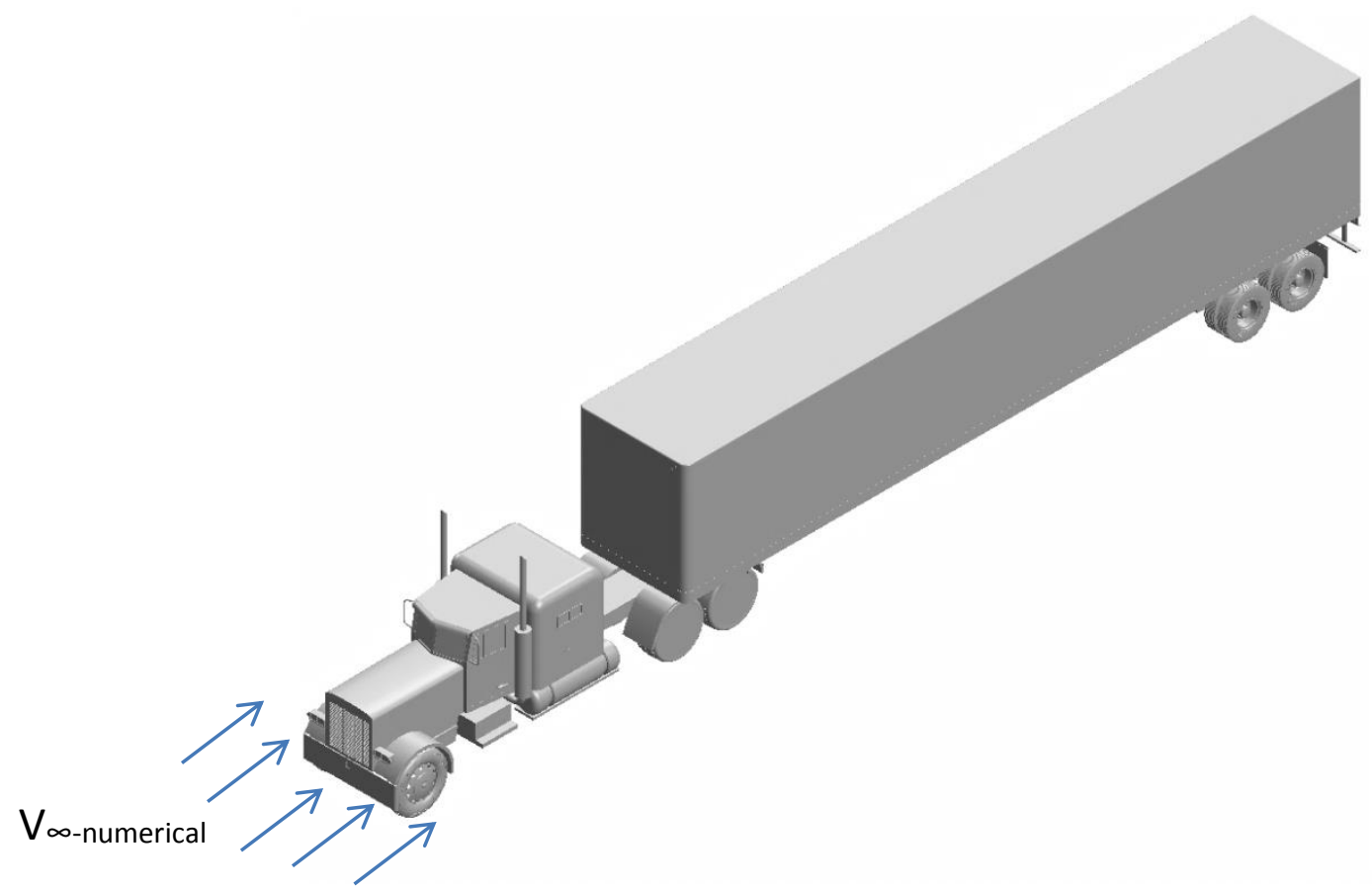

Figure 42. 3D Geometry of the Peterbilt 379 Model used for Numerical Analysis.

COSMOS-FloWorks, Solidworks and Ansys were the commercial tools which were employed to build and run the numerical simulations. Two tests were simulated for the purpose of validation.

1. Test 1:1 scale model at CLT test section Reynolds number.

2. Test 1:1 scale model at highway speed Reynolds number.

A computational domain is a rectangular prism which encompasses the model and the surrounding space within which all calculations are performed. This domain was defined based on the model dimensions. The domain was defined in such a way that it accounted for all perturbations around the model surroundings and covered the entire fluid volume. A trial and error based method was conducted to identify the definition of the computational domain (CPD). It should be noted that, as the volume of the 
computational domain increases, the computation time increases substantially depending on the system configuration used to run the simulations. A conservative approach was used to identify the CPD volume by arbitrarily defining a length, height and width for the domain and then increasing each value by 3 percent until no difference was seen in the results. The finalized CPD volume enclosed 3 times the width of the model on either side of the model, 0.75 times the length up to the front of the

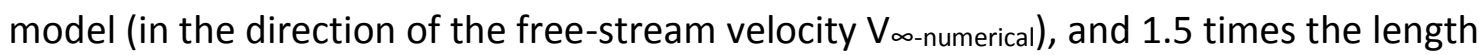
of the model, starting from the rear end of the model. The height of the CPD was finalized at 2 times the height of the model.

The mesh type and size are very important factors while running numerical simulations [75] [76]. It is possible to improve accuracy and reliability of the results with extremely refined (small) mesh size and mesh type [77], but this will also increase the computational time. The tests were setup as steady state cases since only one fluid velocity needed to be analyzed at a time. Detailed studies have been conducted to analyze the sensitivity to mesh size and type, and it has been determined that acceptable accuracy can be obtained by maintaining a near vehicle cell size of $6 \mathrm{~mm}$ or less [77]. COSMOS-FloWorks works with localized structured mesh refining options. By means of several refinement levels and mesh generation type, an initial mesh was created. This basic mesh structure was subject to 6 different types of refinement (small solid features refinement, curvature refinement, tolerance refinement, narrow channel refinement, square difference refinement and cell type refinement) by specifying geometry based criteria for each refinement category. Parametric simulations were done using cell sizes between $6 \mathrm{~mm}-10 \mathrm{~mm}$ to confirm the sensitivity to accuracy with respect to the Peterbilt 379 model and a $7.1 \mathrm{~mm}$ cell size was defined globally through the CPD volume. All curved areas in the model were populated with a slightly complex 
mesh structure compared to other areas with a (prism + cube). The solid/fluid interfaces are meshed finer compared to plain fluid interfaces in the mesh geometry.

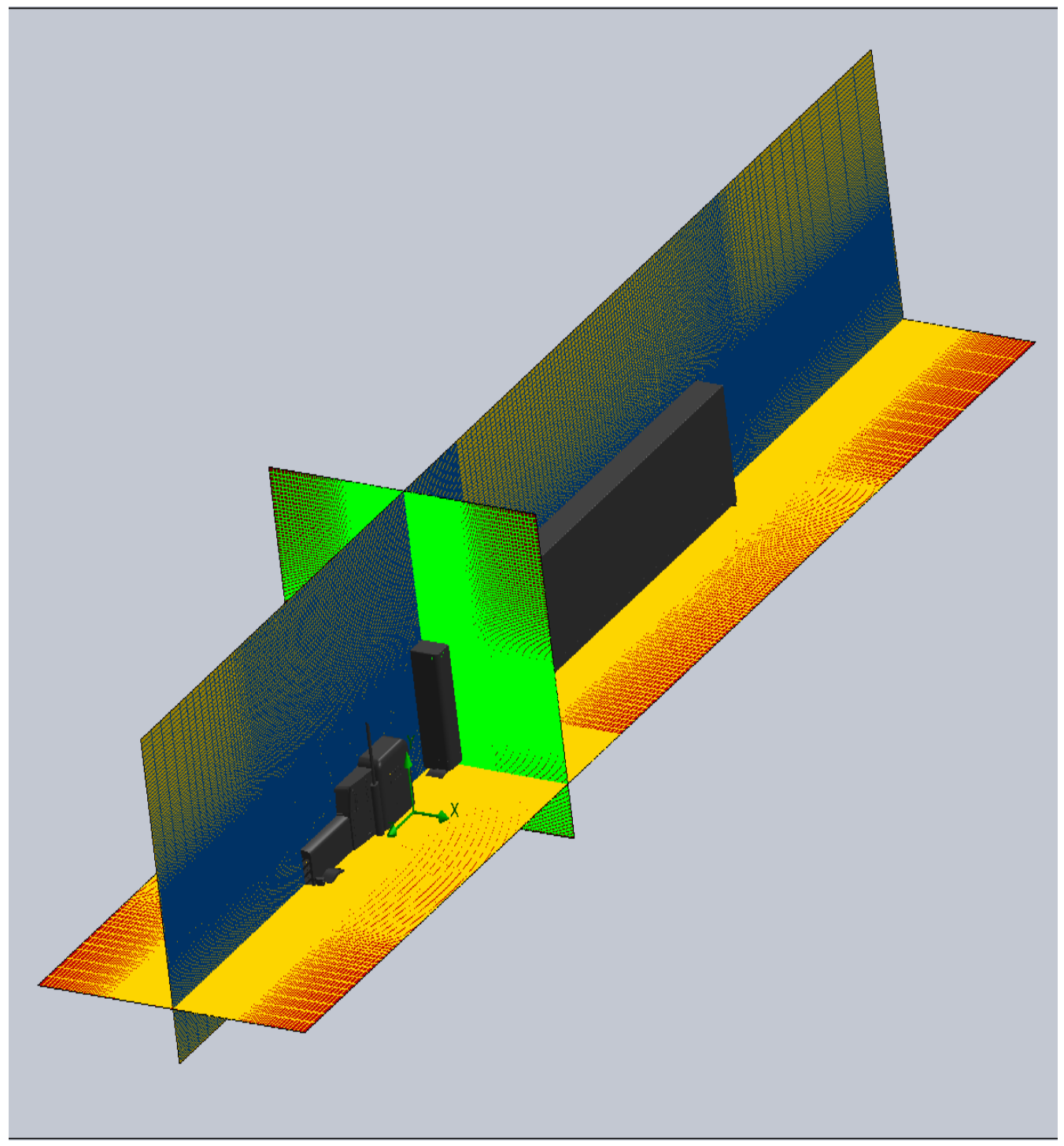

Figure 43. Finalized Mesh Geometry Shown as Cut-Sections in the X, Y, Z Planes. 


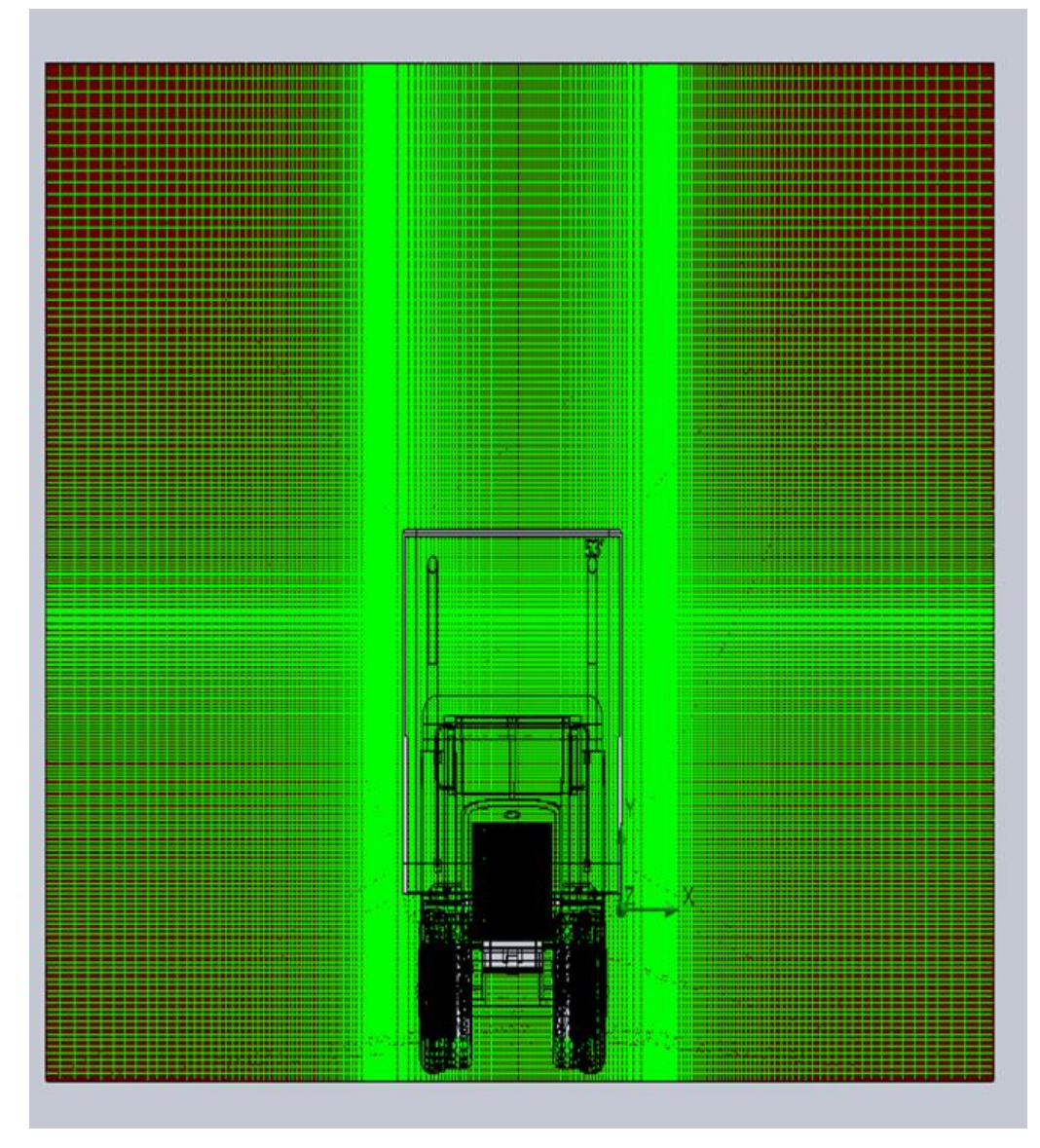

Figure 44. Front View of the Cut Section Mesh Structure in the Z-plane.

The free-stream was employed in the direction as shown in Figure 41. A fully turbulent, fully developed flow was simulated for both tests. The high Reynolds number $k-\epsilon$ (refer Appendix 2 for turbulence and dissipation rates) turbulence model is a very effective model and is well within an acceptable accuracy range of less than 1 percent with predicted drag coefficient [77] [78]. The modified $k-\epsilon$ (turbulence-energy dissipation) turbulence model which includes the Lam-Bremhorst modification (refer Appendix 2) was used in this study for the two numerical simulations. The governing equations of the modified $k-\epsilon$ model were solved on a spatially distributed mesh geometry design in Cartesian coordinates. Force in the direction of the free-stream velocity was measured 
over several iterations and the iterations continue until the measured values for two consecutive iterations are within 1 percent difference between them (refer Appendix 2 for more details).

\subsection{Numerical Simulation Results}

This section summarizes the processed initial test conditions and results obtained for the test cases.

CASE 1 - Low Reynolds Number Test: This test case was set up with the 1:1 scale model at the CLT Reynolds number. This was done by computing variable input parameters in Equation 6 for Reynolds numbers to match CLT-Reynolds number range. The CLT Reynolds numbers were in the range of $4.8 \times 10^{5}$ to $5 \times 10^{5}$. A constant reference width/characteristic length of 102 inches was used to compute the Reynolds number for numerical simulations at a constant density and temperature of $1 \mathrm{~kg} / \mathrm{m}^{3}$ and $293 \mathrm{~K}$. The free stream velocity inside the CPD, $\mathrm{V}_{\infty \text {-numerical }}$ was lowered to $8.39 \mathrm{mph}$ or 3.7506 $\mathrm{m} / \mathrm{sec}$.

Numerial Simulation - Low Reynolds Number $=491,379.667$ 


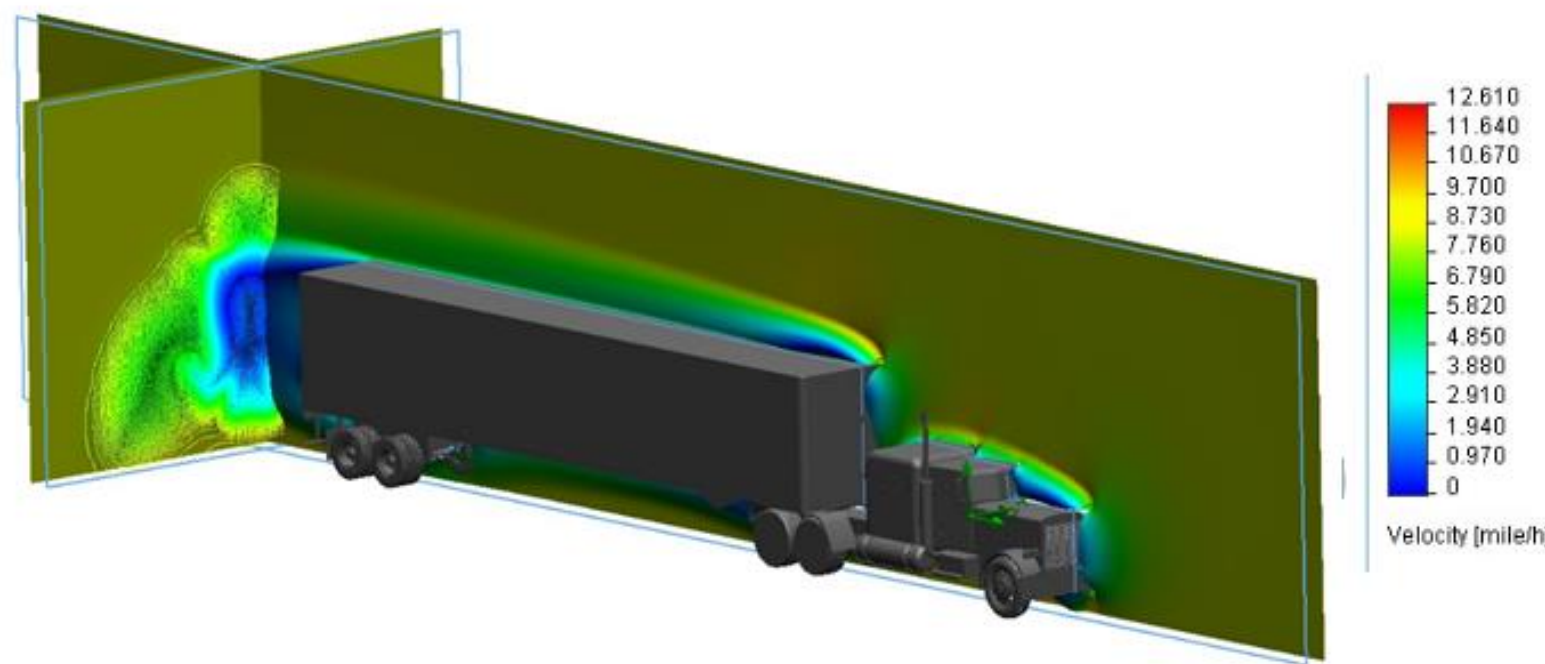

Figure 45. Velocity Profile in X-Z and Y-Z Planes.

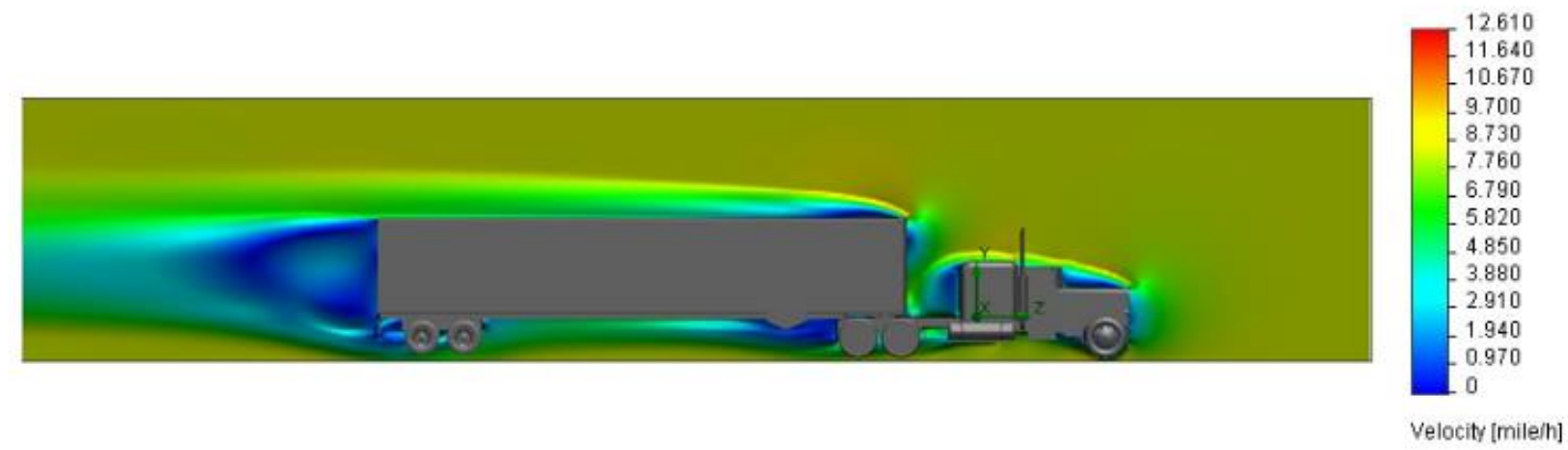

Figure 46. Velocity Profile in Y-Z Plane.

The mesh setup and CPD setup remained the same for both tests and is as described in Chapter 3.3. 
Table 15. Results of Numerical Simulation-Low Reynolds Number Test

\begin{tabular}{ccccc}
\hline Goal Name & $\begin{array}{c}\text { Current Value } \\
\text { (iteration n) (in } \\
\text { Newtons) }\end{array}$ & $\begin{array}{c}\text { Value (n-1) } \\
\text { Iteration (in } \\
\text { Newtons) }\end{array}$ & $\begin{array}{c}\text { Averaged Value } \\
\text { (in Newtons) }\end{array}$ & $\begin{array}{c}\text { Goal } \\
\text { Convergence } \\
\text { Criteria (in } \\
\text { Newtons) }\end{array}$ \\
\hline $\begin{array}{c}\text { Component of } \\
\text { Force - Free } \\
\text { Stream }\end{array}$ & 62.761 & 62.769 & 62.771 & 1 \\
\hline
\end{tabular}

The primary goal was to determine the drag on the 1:1 scale Peterbilt truck model in the direction of the free stream velocity, $\mathrm{V}_{\infty \text {-numerical }}$ inside the CPD volume. Based on Equation 14, the coefficient of drag for the 1:1 model was determined to be:-

$$
C_{D-\text { numerical-CLT }}(C L T \text { Reynolds Number })=\frac{62.7710}{0.5 \times 3.75^{2} \times 1 \times 10.47}=0.852
$$

Where,

$\mathrm{F}_{\mathrm{x}^{\prime}}-$ Average Force (over all iterations) from Table 15, 62.77 N.

$\mathrm{V}_{\mathrm{r}}=\mathrm{V}_{\infty \text {-numerical }}=8.38 \mathrm{mph}$ or $3.75 \mathrm{~m} / \mathrm{sec}$

$\rho=1.00 \mathrm{~kg} / \mathrm{m}^{3}$.

$\mathrm{T}=298 \mathrm{~K}$.

Reference Area, $A_{\text {ref }}=102$ inches $\times 159$ inches $=16218$ sq. inches $=10.47$ sq. meters .

The comparison of $\mathrm{C}_{\mathrm{D} \text {-numerical-CLT }}$ with $\mathrm{C}_{\mathrm{D} \text {-wind tunnel }}$ under the same conditions from Table 7

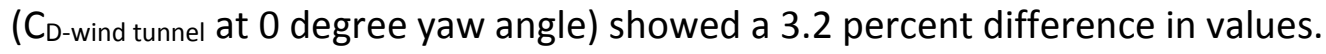

CASE 2 - On-Road Reynolds Number Test: The initial test conditions and setup remained the same as they were in case 1 except that case 2 was performed at on-road 
Reynolds number described in Chapter 3.1. The free stream velocity inside the CPD volume was increased to match the on highway truck speed, $55 \mathrm{mph}$ or $24.5872 \mathrm{~m} / \mathrm{sec}$.

Numerical Simulation - On Road Reynolds Number $=3,212,330.06$

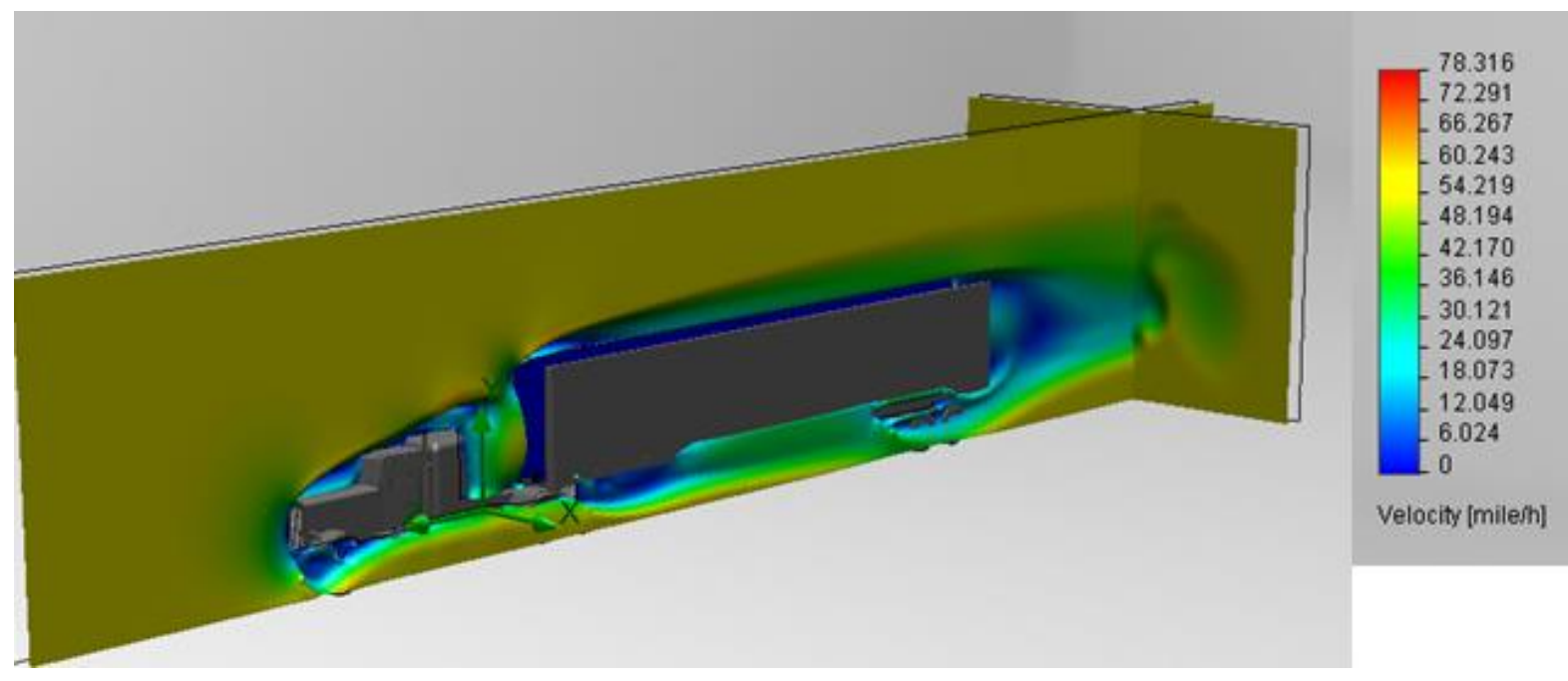

Figure 47. Velocity Profile in X-Z and Y-Z Plane.

The mesh setup remained the same as it was for case 1 .

Table 16. Results of Numerical Simulation- On-Road Reynolds Number

\begin{tabular}{ccccc}
\hline Goal Name & $\begin{array}{c}\text { Current Value } \\
\text { (last iteration- } \\
\mathrm{n} \text { ) (in Newtons) }\end{array}$ & $\begin{array}{c}\text { Value (n-1) } \\
\text { Iteration (in } \\
\text { Newtons) }\end{array}$ & $\begin{array}{c}\text { Averaged Value } \\
\text { (in Newtons) }\end{array}$ & $\begin{array}{c}\text { Goal } \\
\text { Convergence } \\
\text { Criteria (in } \\
\text { Newtons) }\end{array}$ \\
\hline $\begin{array}{c}\text { Component of } \\
\text { Force - Free } \\
\text { Stream }\end{array}$ & 2818.552 & 2818.549 & 2818.545 & 1 \\
\end{tabular}

Iterations to reach convergence: 1351

The primary goal was to determine the drag on the 1:1 scale Peterbilt truck model in the direction of the free-stream velocity, $\mathrm{V}_{\infty \text {-numerical }}$ inside the CPD volume. Based on 
Equation 14, the coefficient of drag for the 1:1 model (at on-road Reynolds Number) was determined to be:-

$$
C_{D-\text { numerical-OR }}(\text { On Road } / \text { On highway })=\frac{2818.545}{0.5 \times 24.5872^{2} \times 1 \times 10.47}=0.888
$$

Where,

$\mathrm{F}_{\mathrm{x}^{\prime}}-$ Average Force (over all iterations) from Table 16, $2818.545 \mathrm{~N}$.

$\mathrm{V}_{\mathrm{r}}=\mathrm{V}_{\text {o-numerical }}=55 \mathrm{mph}$ or $24.5872 \mathrm{~m} / \mathrm{sec}$

$\rho=1.00 \mathrm{~kg} / \mathrm{m}^{3}$.

$\mathrm{T}=298 \mathrm{~K}$.

Reference Area, $A_{\text {ref }}=102$ inches $\times 159$ inches $=16218$ sq. inches $=10.47$ sq. meters .

The comparison of $C_{D-n u m e r i c a l-o R}$ with $C_{D-\text { wind tunnel }}$ under same conditions from Table $7\left(C_{D-}\right.$ wind tunnel at 0 degree yaw angle) showed a 0.8 percent difference in values.

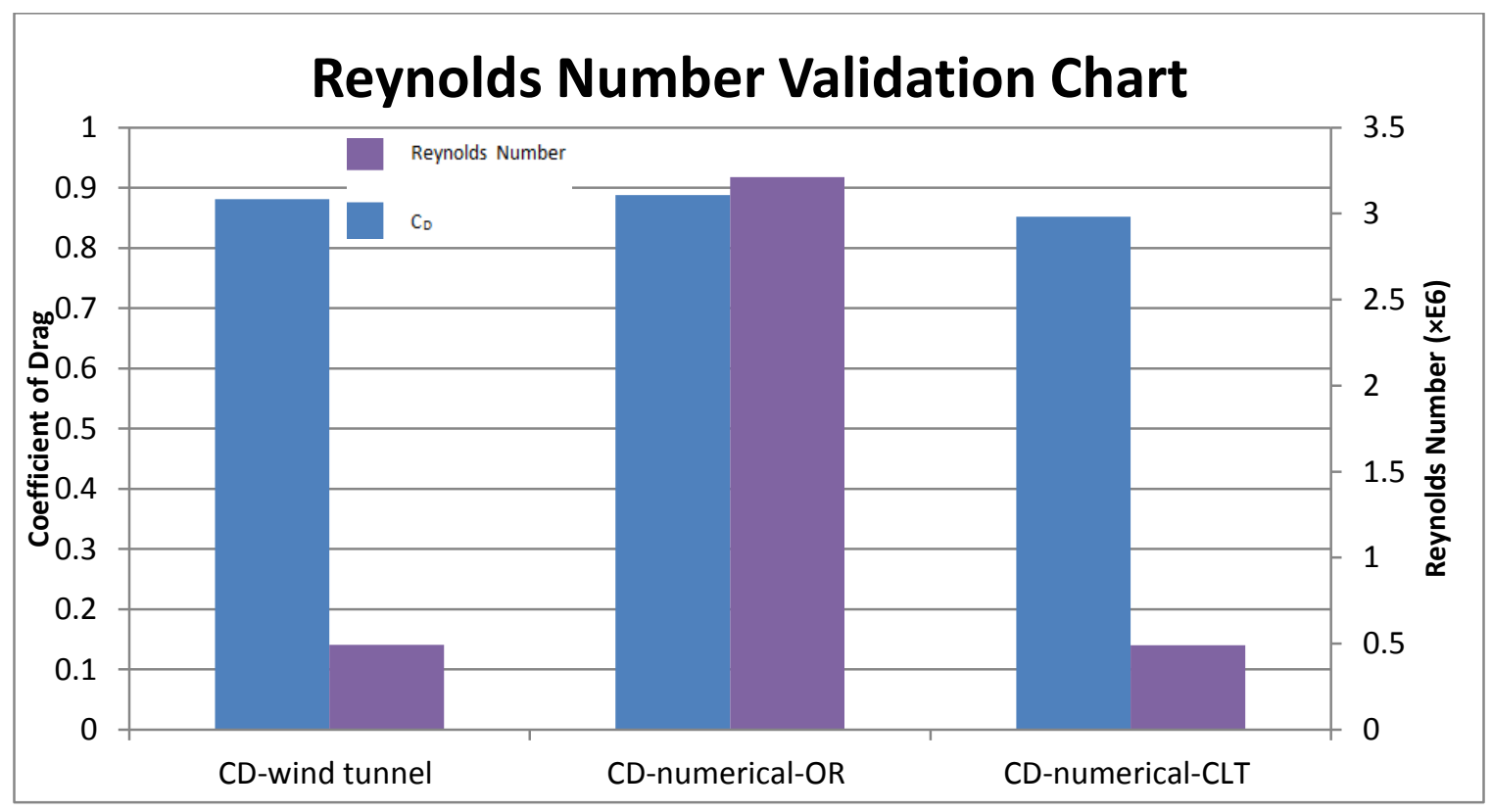

Figure 48. Chart Displaying Reynolds Number Effect on Coefficient of Drag. 
The results from numerical simulations showed variation of 0.8 to 3.2 percent in $C_{D}$ values between the different tests for significant variations in Reynolds number. This validated the Reynolds number range in which tests were conducted in the WVU CLT and consequently validated the results obtained from it.

\subsection{On-Road Yaw Angle Prediction Model}

A method was established to calculate yaw angles over any specific topographical region which would be representative of the crosswind condition over that region. The crux of the study lay in obtaining reliable wind data and resolving them as wind speed relative to ground and wind direction over the specific region of interest.

Geographic Information Systems Wind Data Characteristics: The dissertation was limited to Continental United States. Using Geographical Information Systems (GIS), high resolution (spatial and temporal) wind-grid data were imported over all of the United States as wind speed maps and wind direction maps. The data used in this study came from National Oceanic and Atmospheric Administration (NOAA) Earth System Research Laboratory/Global System Division [79]. The data type chosen was based on an intersection between multiple factors such as the time interval between which each data point was recorded. The smaller time interval means higher data resolution and so a high resolution data was considered to accurately represent the real wind conditions [60]. Data accountancy for wind gusts was important factor to be taken into consideration while choosing the wind data.

In general the wind data recorded for any time interval is usually the average value of that specific data field over that time interval. If the data field is wind speed then the wind speed values recorded are averaged values of wind speed over the time intervals. It is important that these average values have also accounted for wind gusts recorded in that time interval since they could significantly change the average wind speed values. 
An experimental version of the Weather Research and Forecasting (WRF) model called the High Resolution Rapid Refresh (HRRR) model run by NOAA's ESRL GSD laboratory is currently the best available data which meets the required data characteristics. The High Resolution Rapid Refresh model [80] is a 3-km resolution model nested inside the WRF Rapid Update Cycle/Rapid Refresh model. This provides wind speed, wind direction and wind gusts at 10 meter heights at a 15 minute granularity and a 15 minute frequency update, and it is converted into 2 meter heights in order synchronize the wind data to the height at which it would impact on-road vehicles (refer Appendix 3). The $X-Y$ spatial resolution on the raw data obtained is 3 kilometer. However, the data is processed through the GIS model developed in this study and the $\mathrm{X}-\mathrm{Y}$ grid is resolved between $0.016-0.32$ Kilometers and the method used will be discussed later in this chapter.

The HRRR model assimilates three-dimensional radar reflectivity data using a forward (diabatic) Digital Filter Reflectivity technique [81] which improves reflectivity forecasts. This technique avoids all spurious high frequency oscillations in numerical forecasts and is used as an initializing condition and is compatible with model discretization. The HRRR model is based on the WRF-RAP radar data assimilation through the lateral boundaries throughout the forecast and highly improved initial conditions. The high resolution of the HRRR model eliminates the need for convective parameterization [82] which further lessens the uncertainty of the forecast and allows the model to produce realistic convective structures which are the backbone of a more reliable and improved forecast. The HRRR model updates once an hour and generates forecasts up to 15 hours at a $3 \mathrm{~km}$ resolution and is available at a 15 minute time horizon frequency. For instance, the value forecasted by the model at 0015 hours is representative of the wind (speed and direction) between 0000-0015. Studies have proved that the forecasted data had a reasonable agreement with real time observations [83]. Since 2012 the HRRR grid is 
$1799 \times 1059$ over the continental United States domain with 50 vertical levels and the WRF-RAP boundary conditions were used as the parent model. The raw data obtained from the HRRR model are usually parsed in GRIB2 file format. It was decoded using the 'tkdegrib' decoder [79].

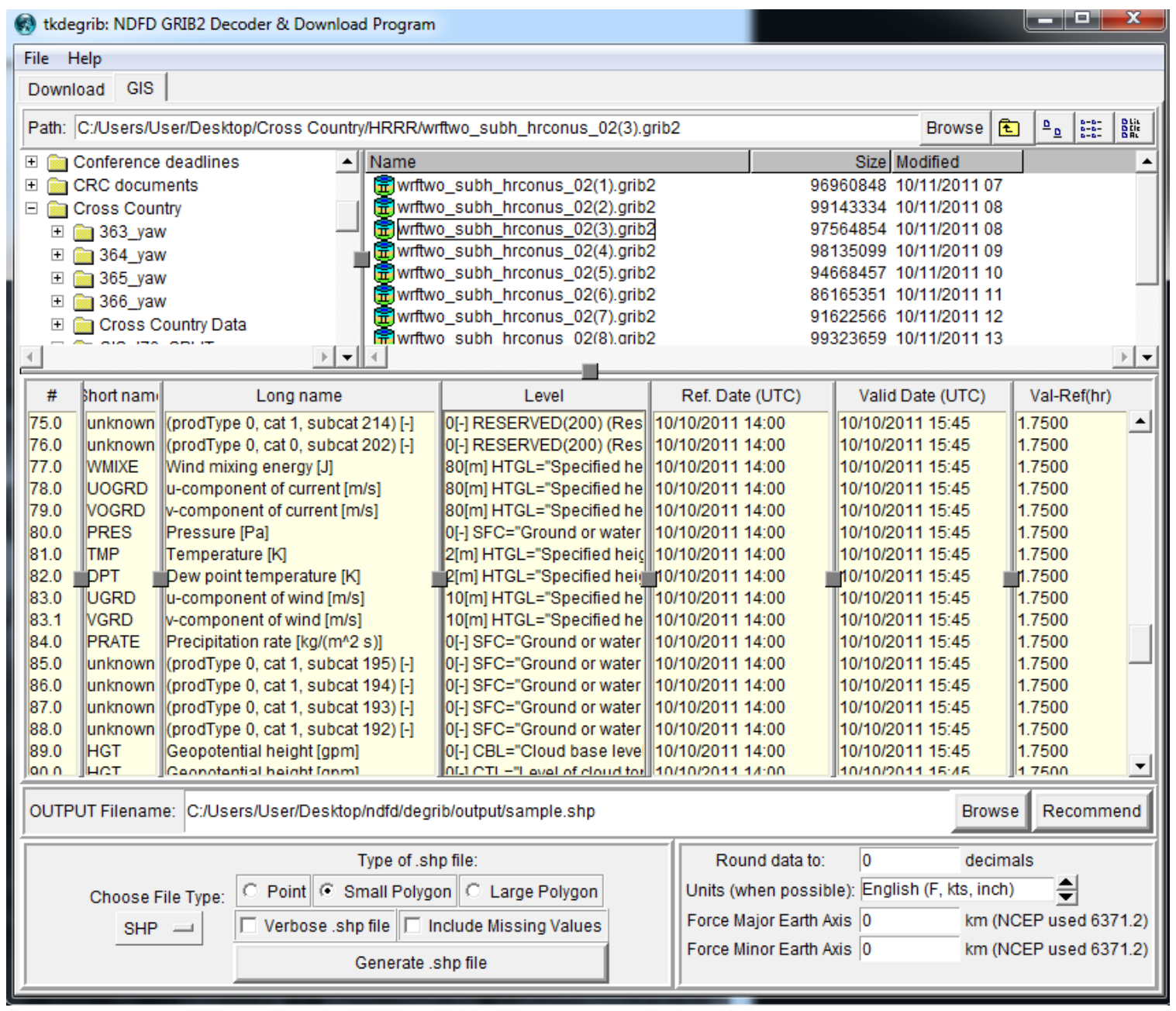

Figure 49. Screen Capture of the 'tkdegrib' Decoder Used for Parsing GRIB2 Format Wind Data.

The respective fields in each data file were then viewed and obtained individually. Wind

direction, wind gust and wind speed (at 10 meter heights) were available as individual

data files when extracted from raw data, which was decoded and generated as shape 
files (GIS map format). Each data file consisted of its respective field corresponding to its forecasted time. Data in each file is valid only for its corresponding forecasted time and is available as shape-files at 15 minute time intervals. Each file can be viewed as wind speed, wind direction and wind gust maps in ArcGIS.

One of the basic and primary functions offered by ArcGIS is geoprocessing. By performing various operations on existing data, it provides a way to create objective oriented new information. However, geoprocessing tasks can be intensive since they have to be performed on large, voluminous datasets with numerous records. Scripting is an efficient method of automating geoprocessing tasks or running a tool many times, converting data and generating geodatabases with different parameters automatically. A Python script was written to automate geoprocessing tasks in ArcGIS. The geoprocessor allows access to all tools inside ArcGIS and it is compliant with the Python scripting language.

GIS Model Pseudo Code: Python is an open source scripting language which supports object-oriented programming used to coordinate and execute geoprocessing tools in ArcGIS. The raw wind data from HRRR are always in vector format. 'UGRD' represents the magnitude of the North-South wind and 'VGRD' represents the magnitude of the East-West wind. The $15 \mathrm{~min}$ HRRR wind data are available as U-component and Vcomponent of wind at $10 \mathrm{~m}$ heights separately for each forecasted time reference. This wind data was first converted to wind at 2 meter heights (refer script in Appendix 3 ). There are different methods using which this adjustment [84] can be done and the most commonly used method is the simple Power Law method [85]. The method has been tested and found to compare favorably with the more elaborate method under near neutral atmospheric stability conditions. The Power Law conversion model was used in this study to convert $10 \mathrm{~m}$ wind profiles to $2 \mathrm{~m}$ wind profiles. 
Once the method to convert raw wind data to a usable format was established, the yaw angle prediction model was built. The raw wind data from the HRRR model were processed into vector format. 'UGRD' represents the magnitude of the North-South wind and 'VGRD' represents the magnitude of the East-West wind. The 15 minute HRRR wind data were processed as U-component and V-component of wind at 2 meter heights. The yaw angle prediction model was constructed with several input parameters. The nature of these input parameters was based on-road curvature, vehicle position, vehicle trajectory and speed, time of travel and duration of travel.

Commercially available tools, ArcGIS 10.1 and Python were both used to build the model (refer Appendix 3).

- Convert Projection: Maps can be projected in several ways given the different coordinate system notations that exist, so it is important that all the files (wind maps and US road map) projected follow the same coordinate system, otherwise the data will be misaligned with respect to each other. NAD 1983 [86] was chosen as the coordinate system in which all maps and datasets were projected.

- Unique Attribute Selection: The United States road map generically consists of all major roadways across the continental United States. Very rarely are roads straight (zero degrees due North) with zero curvature. This means most roads curve along their path. Each roadway was identified with its unique attributed name. For instance, Interstate 79-North is identified by the code as 'I-79N'. With unique names allocated for each route, any route of interest can be analyzed by calling its attributed name.

- Sampling route at vertices: The employed routes of study were all shaped as polylines. Any route that was chosen for the study was split at vertices, i.e. every segment between two consecutive vertices will behave as an independent line feature. 
- Capturing Road Curvature: The angle of each line segment was then determined from the latitudinal and longitudinal coordinates of the vertices that contain each line segment. All angles calculated were due North.

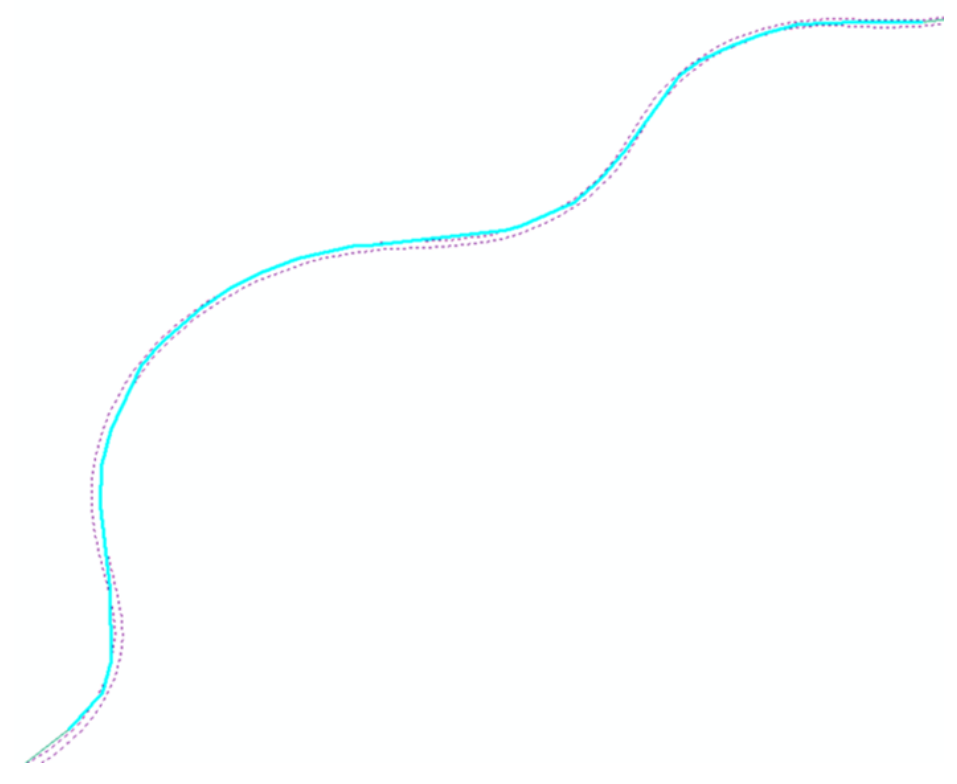

Figure 50. A cut section from Interstate 179 split at vertices. 
Table 17. Angle, Length and Identification Code of Each Segment in 179 Curve in Figure 49

\begin{tabular}{|c|c|c|}
\hline FID & Sectional Angle & Sectional Length in Miles \\
\hline 54 & 41.709596 & 0.085123 \\
\hline 55 & 17.155209 & 0.05953 \\
\hline 56 & -1.502315 & 0.139444 \\
\hline 58 & -6.484502 & 0.158381 \\
\hline 59 & 1.584499 & 0.077097 \\
\hline 60 & 14.365007 & 0.071111 \\
\hline 61 & 25.886663 & 0.130034 \\
\hline 63 & 40.620942 & 0.047318 \\
\hline 64 & 48.567984 & 0.095121 \\
\hline 65 & 56.797913 & 0.059181 \\
\hline 66 & 62.391345 & 0.053663 \\
\hline 68 & 69.971206 & 0.060661 \\
\hline 69 & 77.136141 & 0.088761 \\
\hline 70 & 86.253098 & 0.019096 \\
\hline 71 & 83.856838 & 0.207475 \\
\hline 73 & 74.582758 & 0.024592 \\
\hline 74 & 66.68121 & 0.091948 \\
\hline 75 & 48.831374 & 0.059436 \\
\hline 76 & 40.561862 & 0.068158 \\
\hline 79 & 35.69702 & 0.163137 \\
\hline & 55.196107 & 0.042473 \\
\hline & 63.648351 & 0.055754 \\
\hline & 70.066254 & 0.052837 \\
\hline & 75.250986 & 0.056265 \\
\hline & 87.849382 & 0.088201 \\
\hline & 89.391874 & 0.096844 \\
\hline
\end{tabular}

Figure 49 shows a curved section of Interstate 79, where the dotted line marks the actual interstate and the blue section marks the curve after the original section was resolved at vertices. This figure shows how closely the curvature of the roads would be captured and resolved at high resolution using the model. It can be seen from Table 17, which shows the details of the Blue sectional curve in Figure 49, that the region was resolved into 25 segments and each given unique ID'-s (FID-54 to 79). The total length of the curved region was 1.97 miles and this was split into 25 segments, defined with angles and lengths individually to capture the curve as accurately as possible.

- Spatial Join: The values of UGRD and VGRD over each segmented or resolved line for each time stamp, HHMM at 15 minute intervals, was obtained by joining attributes from one feature to another based on a spatial relationship defined in 
three-dimensional space. Data at each time stamp was extracted from three independent maps, UGRD, VRGD for that time stamp, which are in polygon shape and the United States road map with the employed route split at vertices which are in polyline segments. The features associated with the sample polylines which are spatially contained in the UGRD, VGRD polygons were joined to the corresponding UGRD and, VGRD features. Based on the number of sample lines $(\mathrm{SL})$ created from the road and $\mathrm{HH} \times 4$ time stamps, a $[\{\mathrm{HH} \times 4\} \times$ ' $n$ '] dimensional matrix [M1] was identified. Where ' $n$ ' is the total number of sample lines created and ' $\mathrm{HH}$ ' is the total number of hours in the analysis time frame.

$$
\begin{gathered}
{[M 1]=[\text { ugrd, vgrd }]_{i, j}} \\
\{i=\text { sample line, } 1 \text { to } n\} \\
\{j=\text { start time, } 0015 \text { to } H H \times 4\}
\end{gathered}
$$

- Raw Wind Direction ( $\theta$ in degrees): Corresponding wind direction matrix [M2] was obtained from UGRD, VGRD values using Equation 16 below,

$$
[M 2]=\left[\text { Wind Direction }_{i, j}\right]=\frac{180}{\pi} \times \tan ^{-1} 2\left({ }^{(\text {ugrd })_{i, j}} /(\text { vgrd })_{i, j}\right)
$$

- Relative Wind-Truck Angle ( $\varphi$ in degrees): With the assumption that the angle of the truck is equal to the angle of road $(\beta)$, the relative wind-truck angle matrix [M3] was calculated using Equation 17 below,

$$
[M 3]=\left[\varphi_{i, j}\right]=\left[\beta_{i}\right] \sim[M 2]
$$

- Head Wind/Tail Wind Identification: Based on [M3] and [M2], the vehicle's projected path of travel (given as input), the wind on the vehicle was established either as a head or tail wind (refer to Python code in Appendix 3). 
- Raw Wind Speed (in meter/sec): The wind speed matrix was obtained from [M1] using Equation 18 below,

$$
[M 4]=\left[V_{w(i, j)}\right]=\sqrt{(\text { ugrd })_{i, j}^{2}+(\operatorname{vgrd})_{i, j}^{2}} \times 3600 / 1609.34
$$

- Relative Wind Truck Speed $\left(V_{r}\right.$ in $\left.\mathrm{m} / \mathrm{sec}\right)$ : This is obtained from Equation 7 in $\mathrm{m} / \mathrm{sec}$.

$$
[M 5]=V_{r} \text { in } m / s e c=\sqrt{V^{2}+V_{w}^{2}-2 V V_{w} \cos \phi}
$$

- Yaw Angle (in degrees): This is obtained from Equation 8 in degrees.

$$
\begin{gathered}
\text { Yaw angle, } \psi \text { in degrees }=\sin ^{-1}\left\{\left(V_{w} \sin \phi\right) / V_{r}\right\} \\
\text { or },\left[\psi_{i, j}\right]=\sin ^{-1}([M 4] \sin [M 3]) /[M 5]
\end{gathered}
$$

The model looped through the model parameters one time step at a time to calculate the yaw angle at every point of the chosen route. 


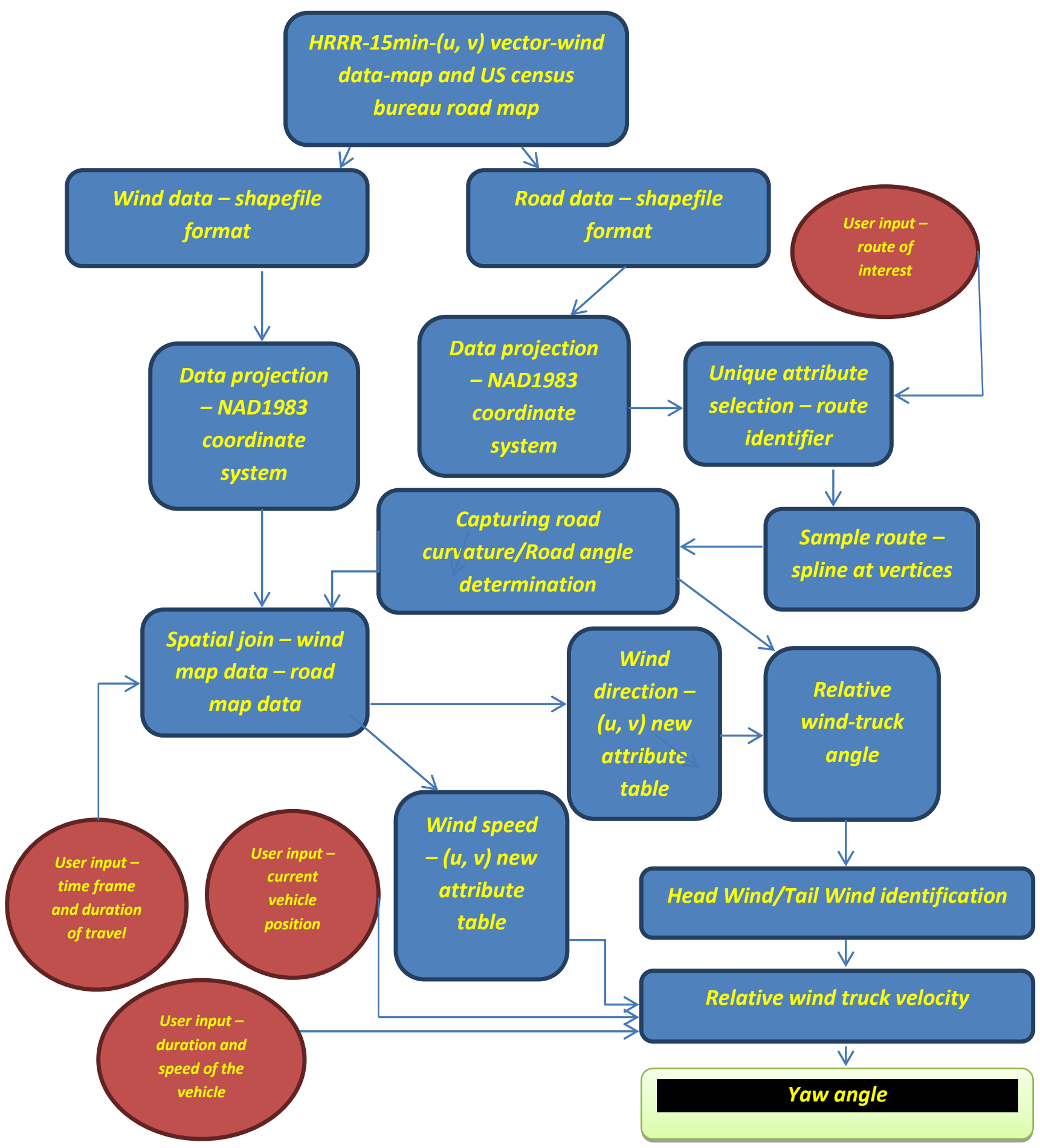

Figure 51. Algorithm/Pseudo Code for GIS Yaw Angle Prediction Model. 
Interstate 79 was chosen as one of the routes of interest which was examined in this study. The other route chosen was a cross country route which passes through several states including Missouri, Kansas, and Indiana to analyze the spatial impact apart from the temporal impact. The flow chart above shows the sequence of command used in the model, where red blocks refer to user input parameters, and blue indicates model calculated or estimated parameters.

\subsection{On-Road Yaw Angle Prediction Model Case Studies and Results} A case study was conducted to show the modeling results and for this purpose Interstate 79 was employed as the route of interest. The transient yaw angles were predicted for the chosen route based on the method described in Chapter 3.5. The days of study were March $3^{\text {rd }}$ and $4^{\text {th }}, 2012$ and March $1^{\text {st }}$ and $2^{\text {nd }}, 2013$. The days chosen were at random at a 1 day and 1 year interval between them.

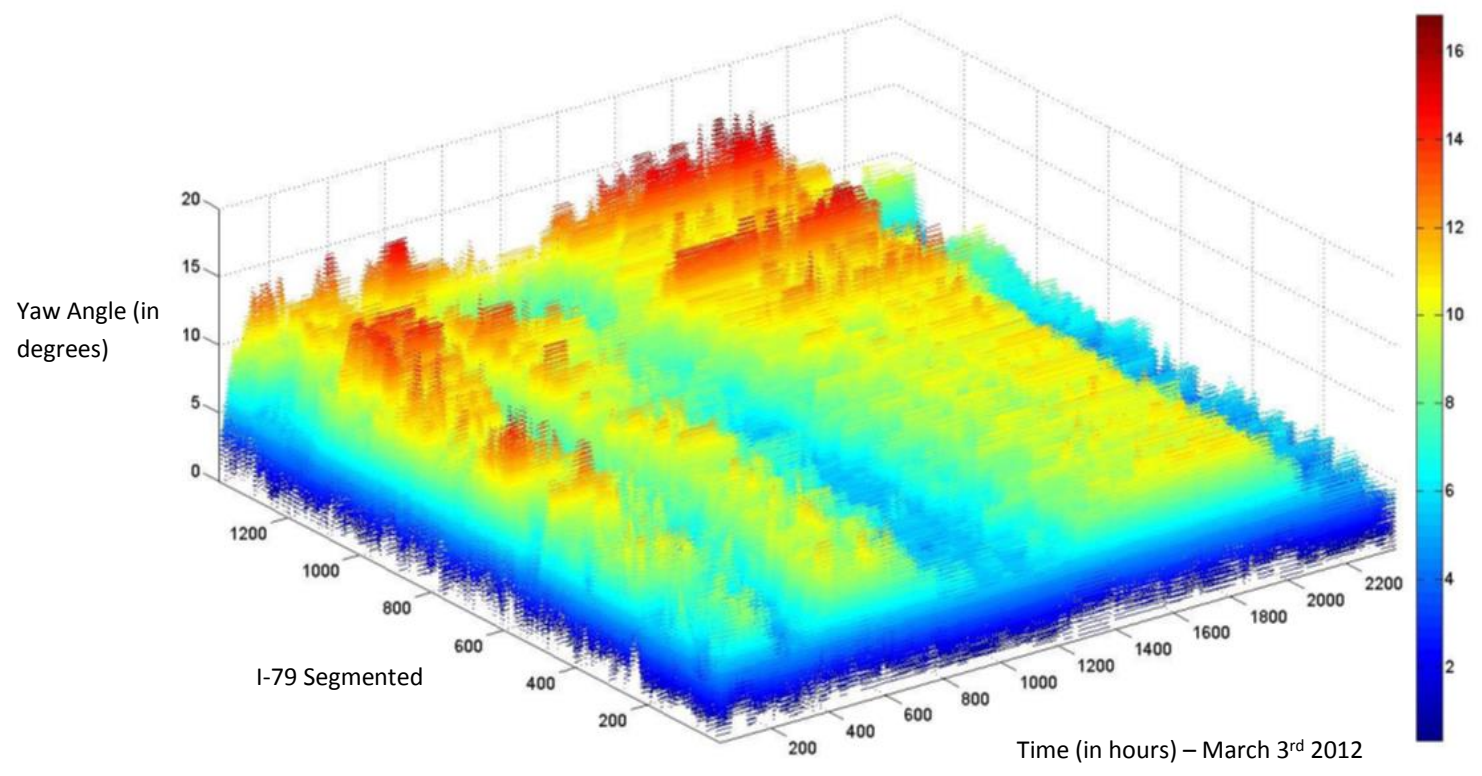

Figure 52. Yaw Angle Variation through Interstate 79, WV on March $3^{\text {rd }} 2012$. 


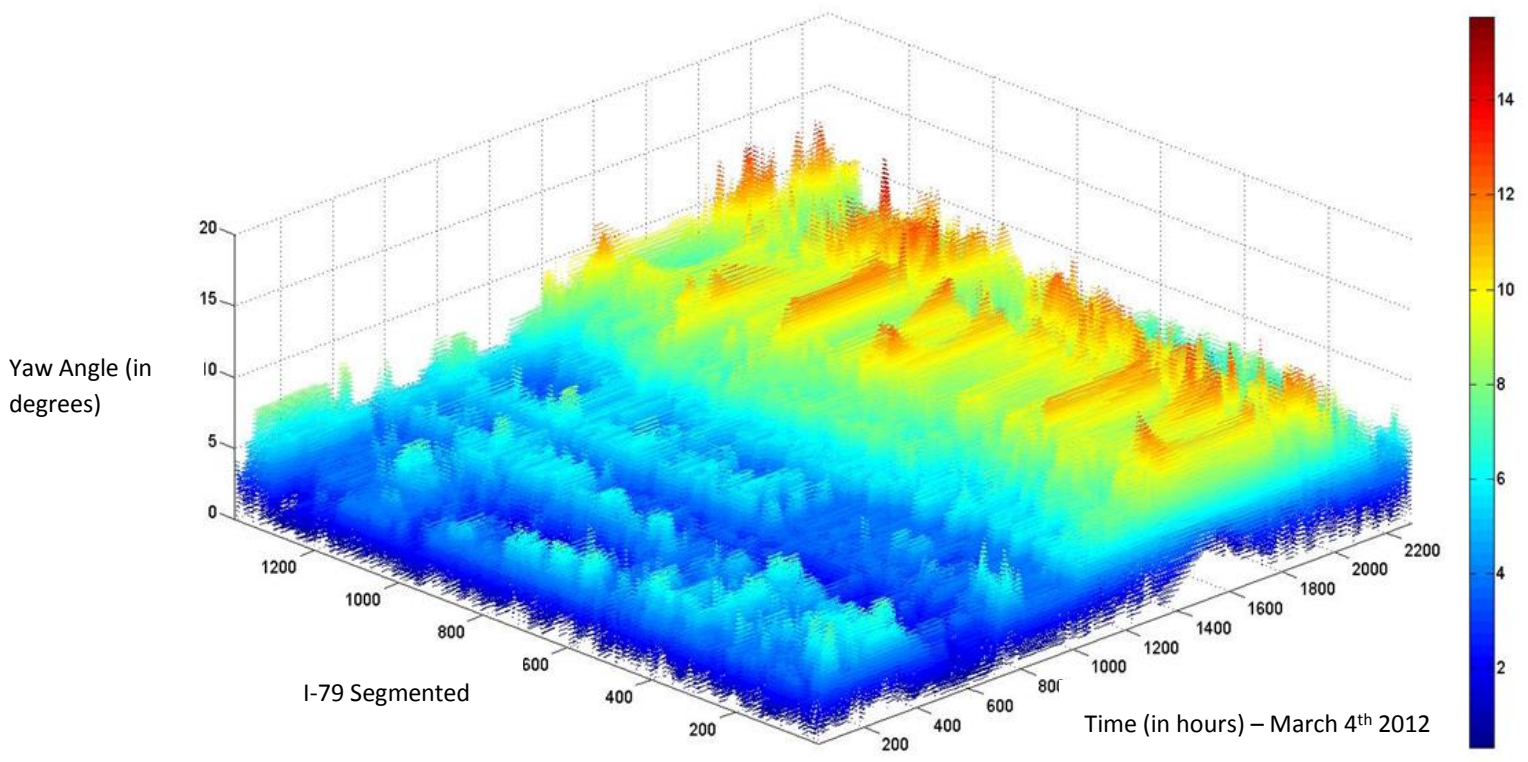

Figure 53. Yaw Angle Variation through Interstate 79, WV on March $4^{\text {th }} 2012$.

Higher peaks on the yaw graph were observed on 03/04/2012 mostly after 2 pm (1400) indicating that the conditions were comparatively windier than earlier that day. No tailwind was encountered on either day. By simply observing Figure 50 and Figure 51, the shift in the on-road yaw angle pattern on the same route can be seen due to variations in wind behavior and road curvature. The average on-road yaw angle for route on March $3^{\text {rd }}, 2012$ was 5.8 degrees but this is certainly not representative of yaw angles for several time periods through the day. The average yaw angle between 1500 and 2000 was 7.2 degrees and it was 4.6 degrees between 0900 and 1300 . Similarly, the average on March $4^{\text {th }}, 2012$ was 3.1 degrees through the route for the day, but the average during the time period 0000-1100 was 2.8 degrees and it was 5.6 degrees between 1330 and 2400 hours. To further elaborate the statement of temporal variations affecting the on-road yaw angles, another two days in March were chosen a year apart (in 2013). 


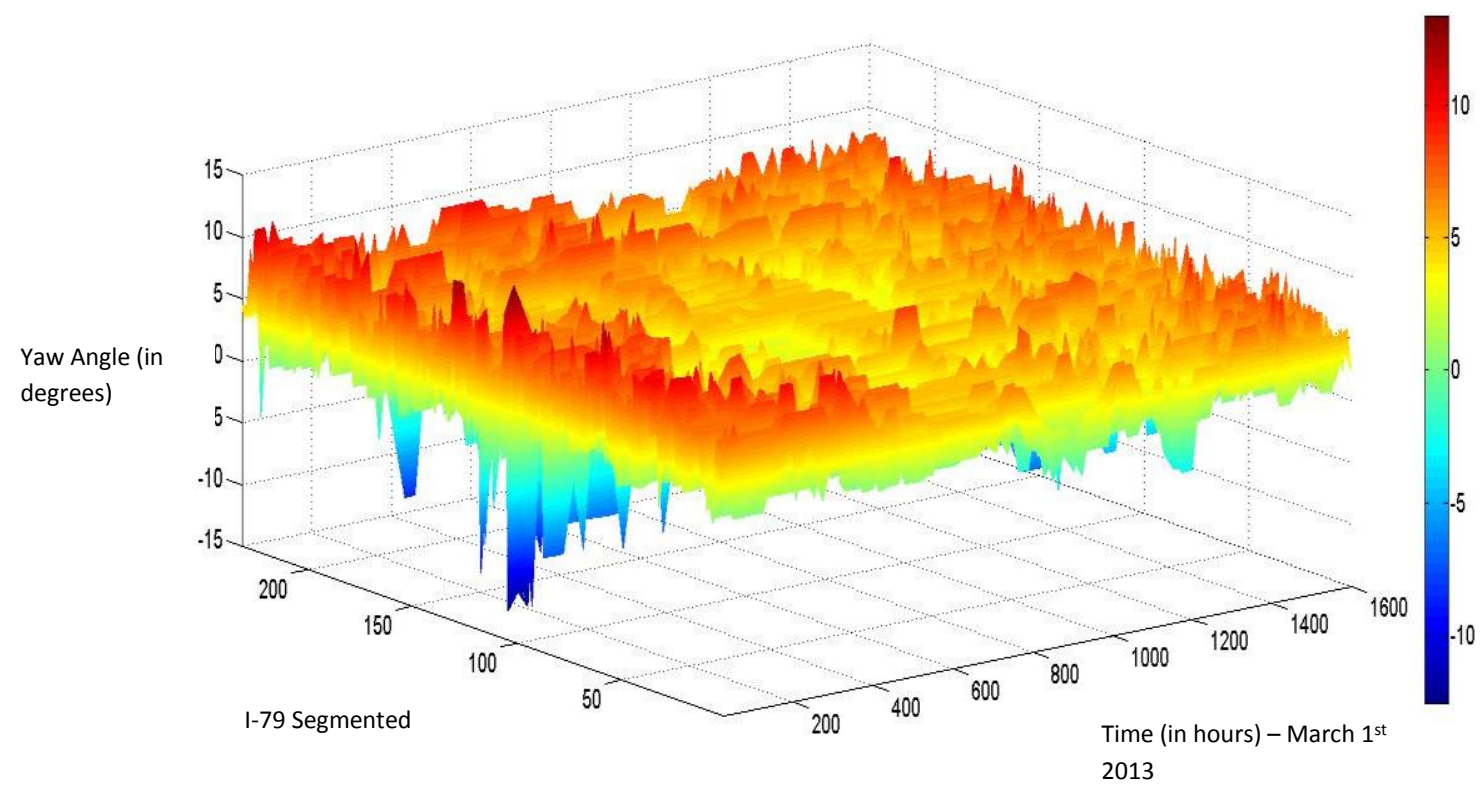

Figure 54. Yaw Angle Variation through Interstate 79, WV on March $1^{\text {st }} 2013$.

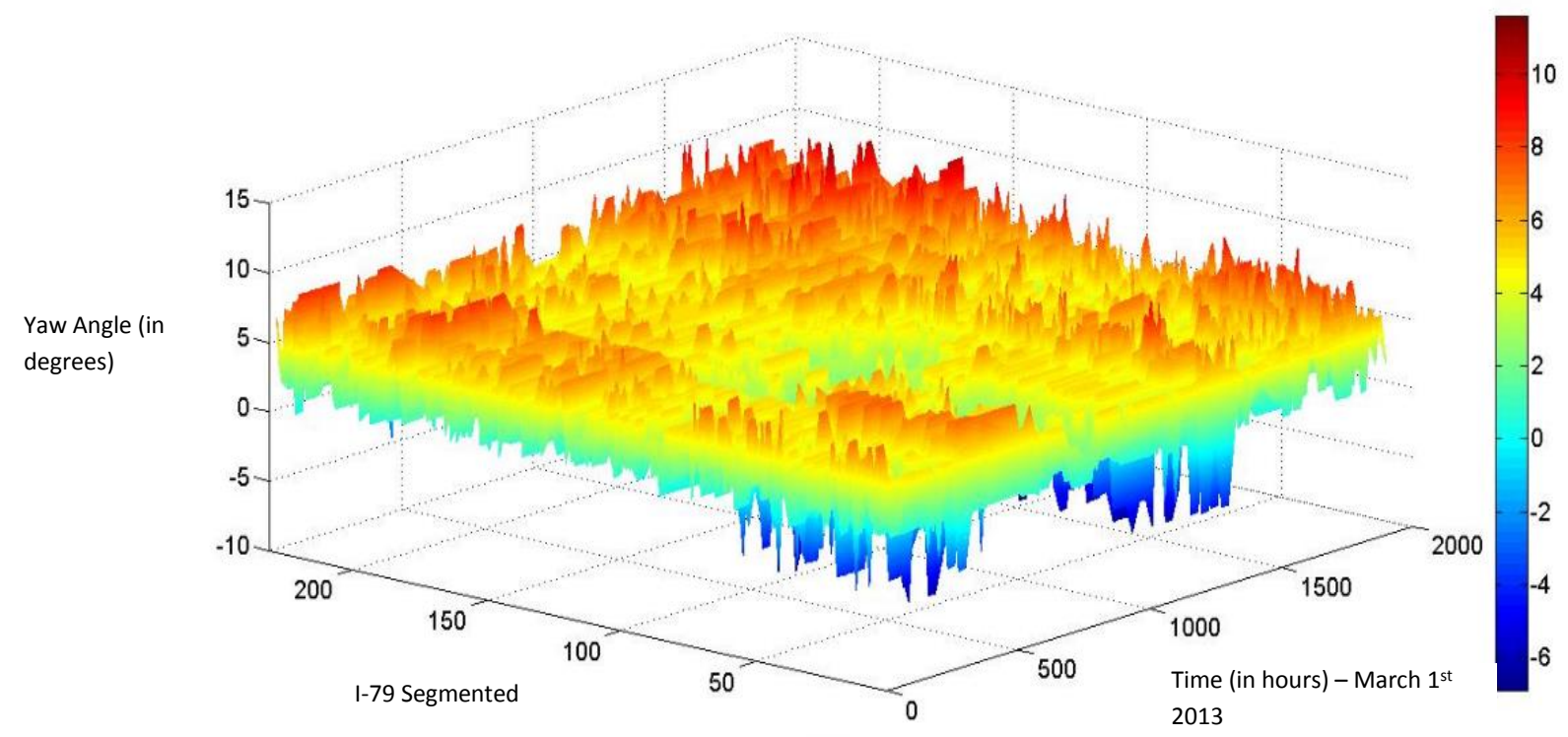

Figure 55. Yaw Angle Variation through Interstate 79, WV on March $2^{\text {nd }} 2013$. 
The chosen days, March $1^{\text {st }}$ and $2^{\text {nd }}, 2013$ were employed over the same $1-79$ segment to describe the variation in on-road yaw angle in the same season, over the same route. The average yaw angle on March 1 $1^{\text {st }}, 2013$ was 3.65 degrees but the maximum on-road yaw angle experienced was 13.43 degrees. It should also be noted that these two days unlike 03/03/2012 and 03/04/2012 provided tail wind assistance to vehicles, although not substantial enough to negate the head wind, it still reduced the overall impact. The time period chosen for analysis was limited to 0000 to 1600 hours. The average was slightly on the higher side (4.6 degrees) for the first few hours (0000 - 0300 hours) on March $1^{\text {st }}$ and stayed close to the average value after that time period. On March $2^{\text {nd }}$, 2013, the average on-road yaw angle was 3.5 degrees. The average on-road yaw angle between 1630 and 1900 hours was 4.3 degrees. The obvious difference between the onroad yaw angles between the days compared in 2012 and 2013 over the same region was the added tail wind conditions in 2013. Table 18 reflects the major differences between the days compared. The drag effects due to these differences in on-road yaw angles are discussed in the next chapter.

Table 18. Major Differences in On-Road Yaw Angle Conditions Through I-79 for the Days Studied

\begin{tabular}{|c|c|c|c|c|}
\hline $\begin{array}{c}\text { On-Road Yaw Angle-Full } \\
\text { Route (in degrees) }\end{array}$ & $\begin{array}{c}\text { March } 3^{\text {rd }} \\
2012\end{array}$ & $\begin{array}{c}\text { March } 4^{\text {th }}, \\
2012\end{array}$ & $\begin{array}{c}\text { March } 1^{\text {st }}, \\
2013\end{array}$ & $\begin{array}{c}\text { March 2 } \\
2013\end{array}$ \\
\hline Average & 5.8 & 3.1 & 3.65 & 3.5 \\
\hline $\begin{array}{c}\text { Average for high on-road } \\
\text { yaw conditions }\end{array}$ & 7.2 & 5.6 & 4.6 & 4.3 \\
\hline Tail wind & No & No & Yes & Yes \\
\hline Maximum yaw angle & 17.1 & 16.08 & 13.43 & 11.67 \\
\hline
\end{tabular}




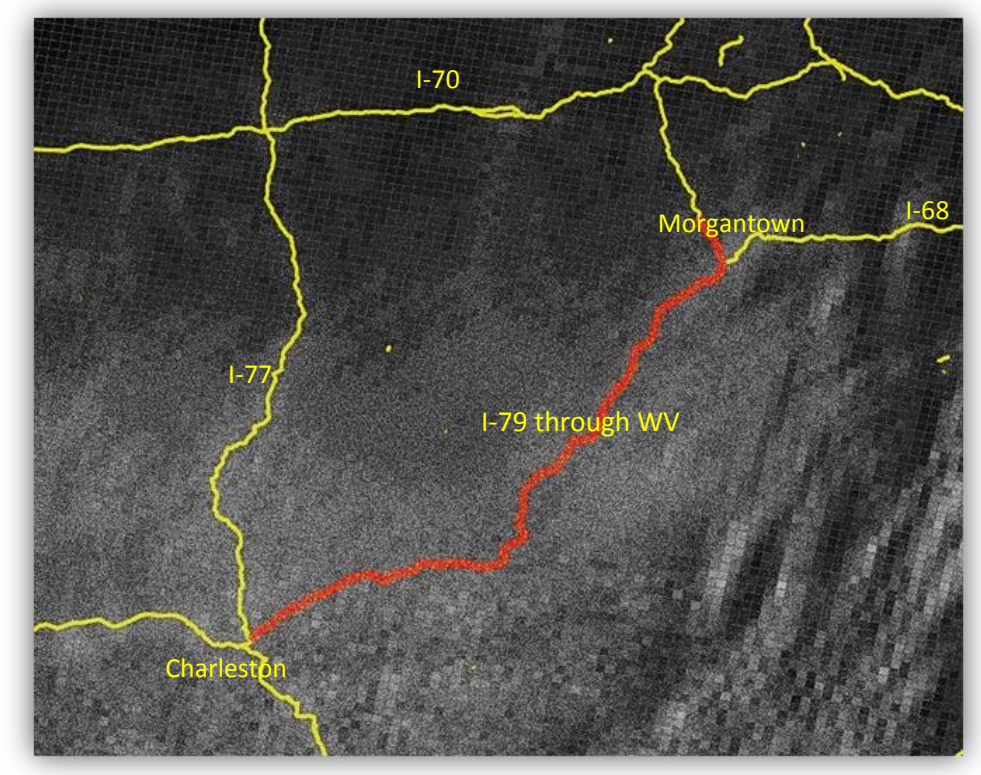

Figure 56. I-79 Running Through West Virginia Layered over Wind Maps in ArcGIS 10.1.

Figure 54 shows the route employed for the analysis and conclusions were made for vehicles travelling South bound from Morgantown towards Charleston. The analysis was done assuming a constant vehicle velocity of $55 \mathrm{mph}$. For the purpose of illustrating regional variations, a route across the country from the already employed, I-79 (marked in red) was chosen and utilized. This route chosen was based on a cross-country study West Virginia University conducted in 2011 [87], and so this route incorporated actual vehicle speed. 


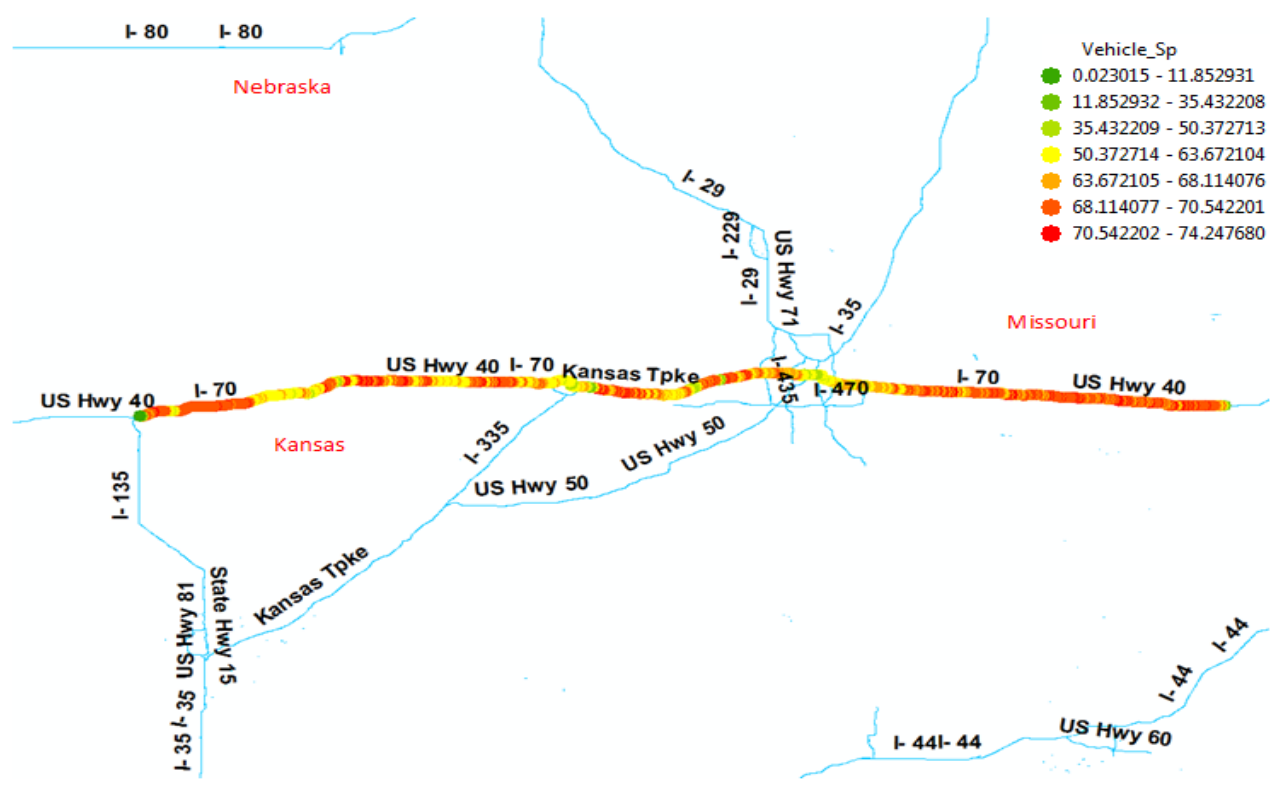

Figure 57. Cross Country Route Employed (I-70) with Varying Vehicle Speeds.

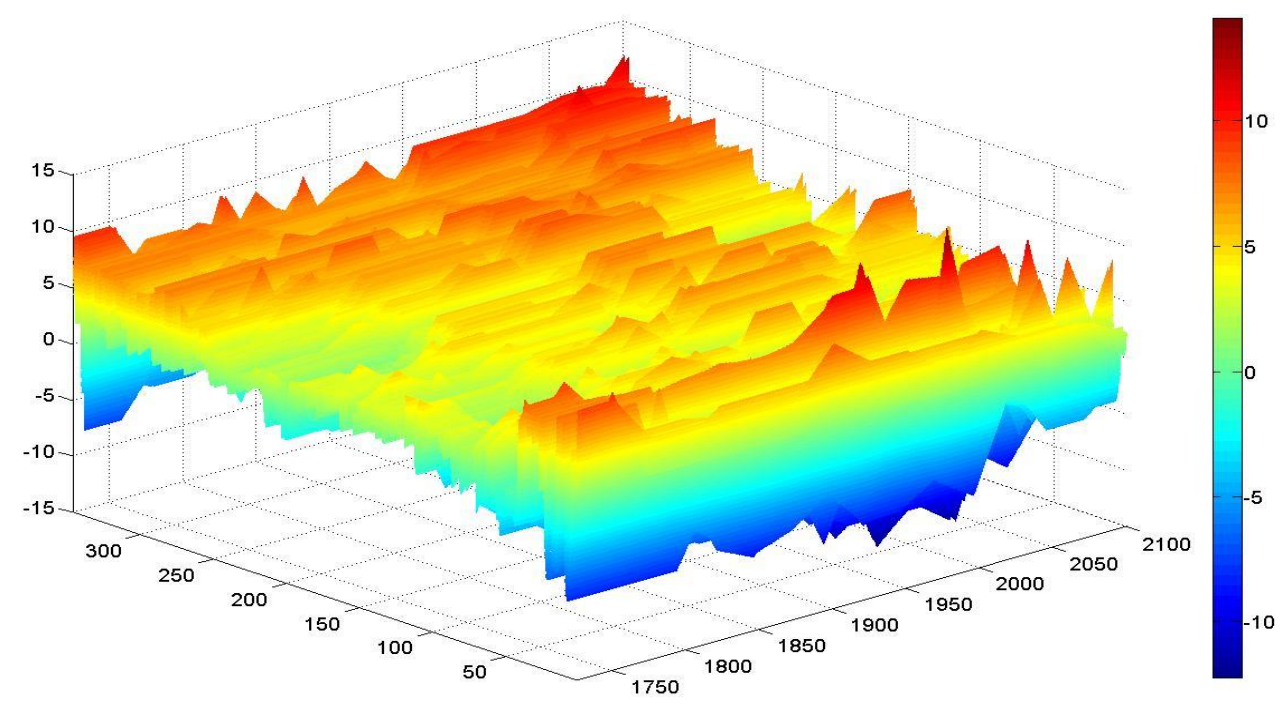

Figure 58. Yaw Angle Variation through Interstate 70 through Missouri and Kansas, October $10^{\text {th }} 2011$. 
The average on-road yaw angle experienced by the vehicle through this road segment on the cross country trip was 1.6 degrees. The vehicle travelled this route on October $10^{\text {th }}, 2011$ between $1730-2100$ hours covering 274 miles. From Figure 56 it is clear that, the average on-road yaw angle value is not representative of several regions or time periods on the travel route. Besides the several regions and time periods where the on-road yaw angle has climbed over 10 degrees, the average is low because it has been compensated by substantial tail wind. The vehicle travelled 110 miles in Missouri in 1.6 hours and entered Kansas (segments 113-347) after 1900 hours. The average onroad yaw angle in Kansas through the time the vehicle travelled in the region was 4.4 degrees and this can be seen in Figure 56 where the red peaks indicate the higher head wind conditions producing higher on-road yaw angles.

\subsection{Integrated Results and Discussion}

The on-road yaw angles for the various routes and time periods were obtained from the geo code and the coefficient of drag for the various configurations were obtained from the wind tunnel experiments. Now, the integration of these two databases would yield the on-road coefficient of drag corresponding to the wind conditions. Chapter 3.7 describes the on-road effectiveness of the several configurations in conjunction with the routes employed in Chapter 3.6. The $\mathrm{X}$-axis in Figures 59 - 93 represents time in hours (0000 - 2400), Y-axis represents road segments along I-79 and the color ramp represents coefficient of drag values from 0.7 to 2.5 . 


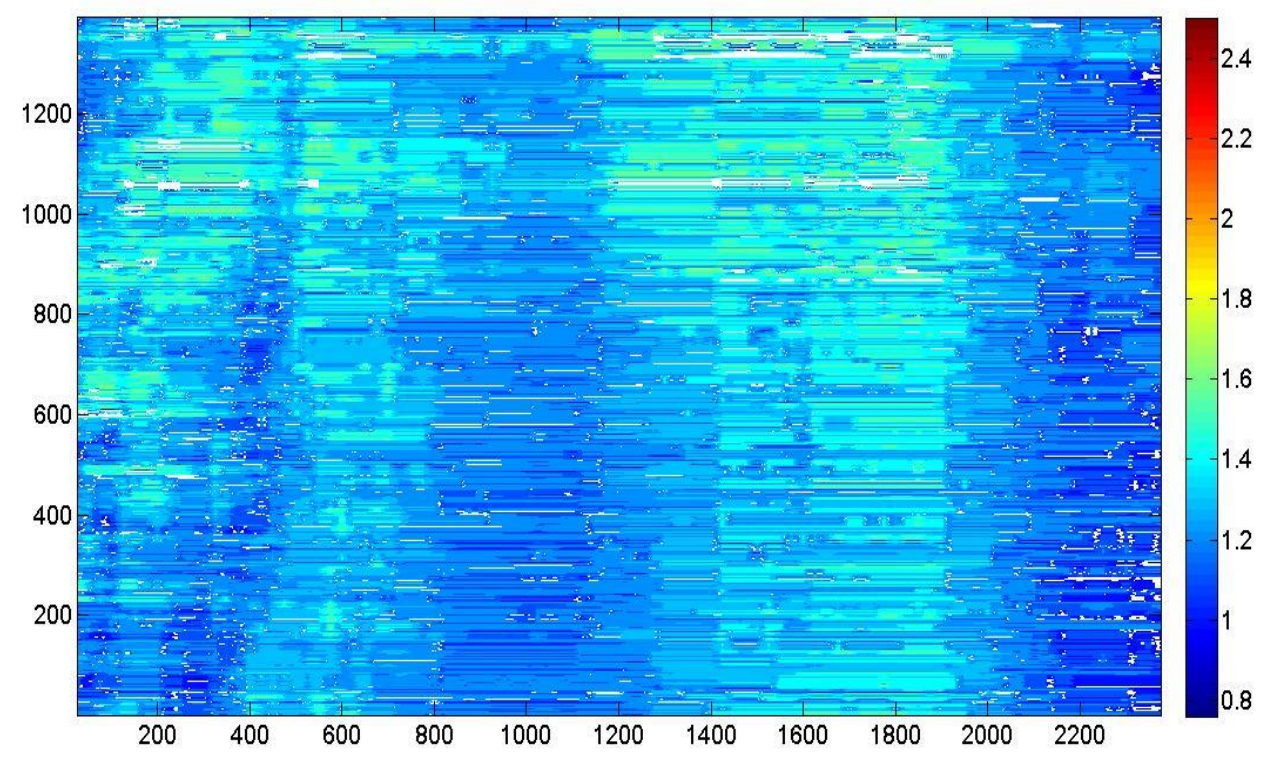

Figure 59. $C_{D}$ Variation on I-79, March $3^{\text {rd }} 2012$ for Baseline Configuration.

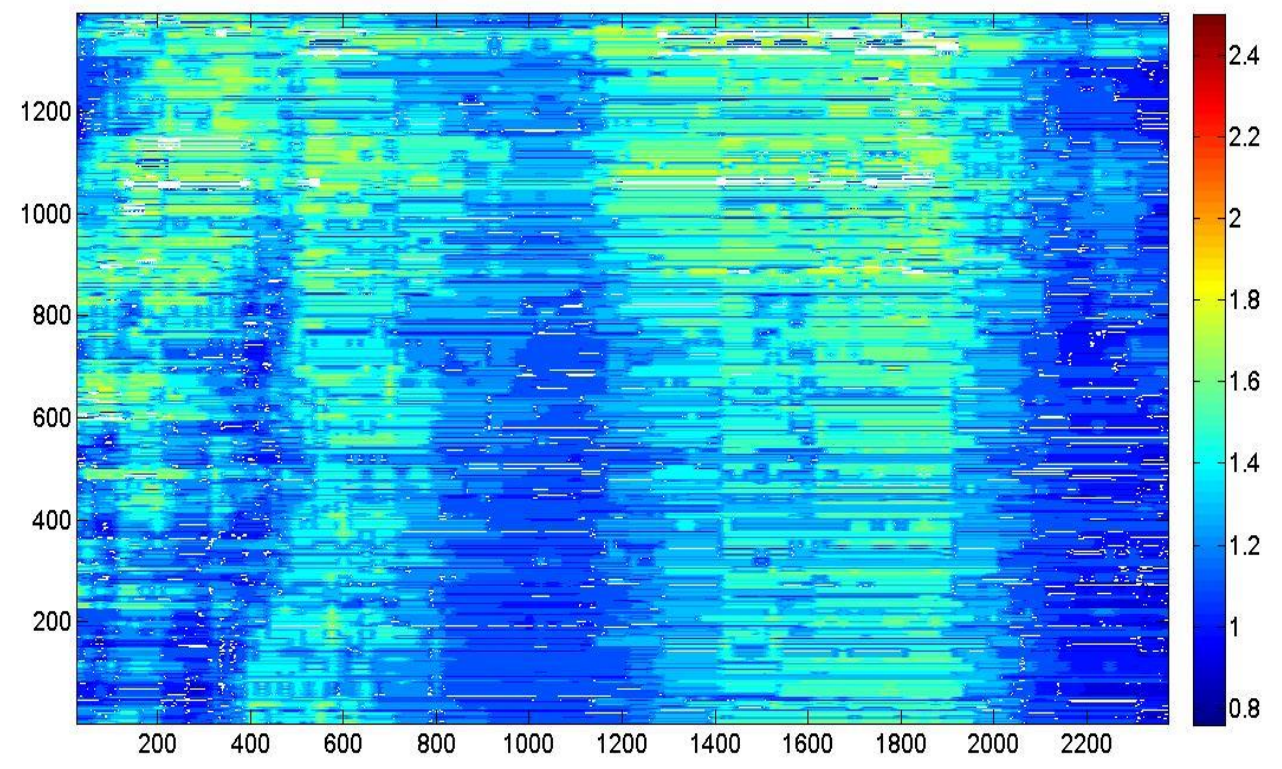

Figure 60. $C_{D}$ Variation on I-79, March $3^{\text {rd }} 2012$ for Baseline with Wind Deflector Placed at $30^{\circ}$. 


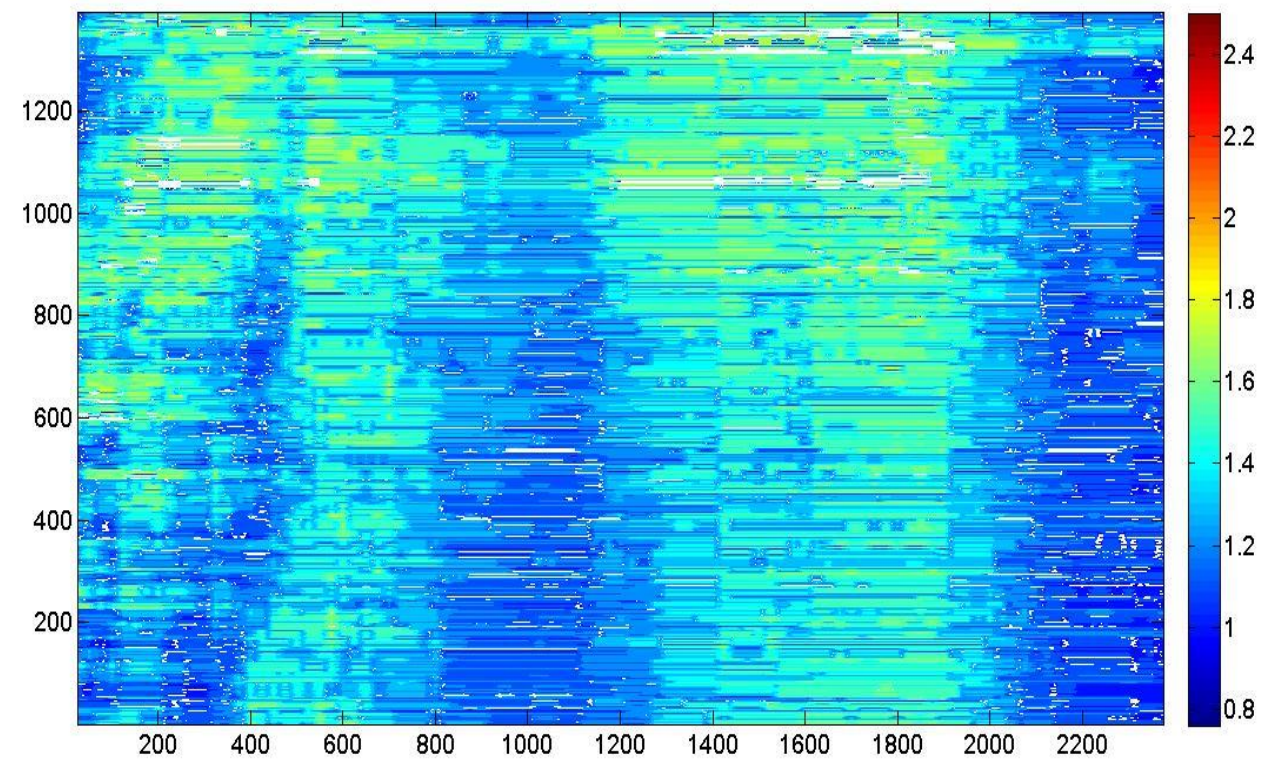

Figure 61. $C_{D}$ Variation on I-79, March $3^{\text {rd }} 2012$ for Baseline with Wind Deflector Placed at $45^{\circ}$.

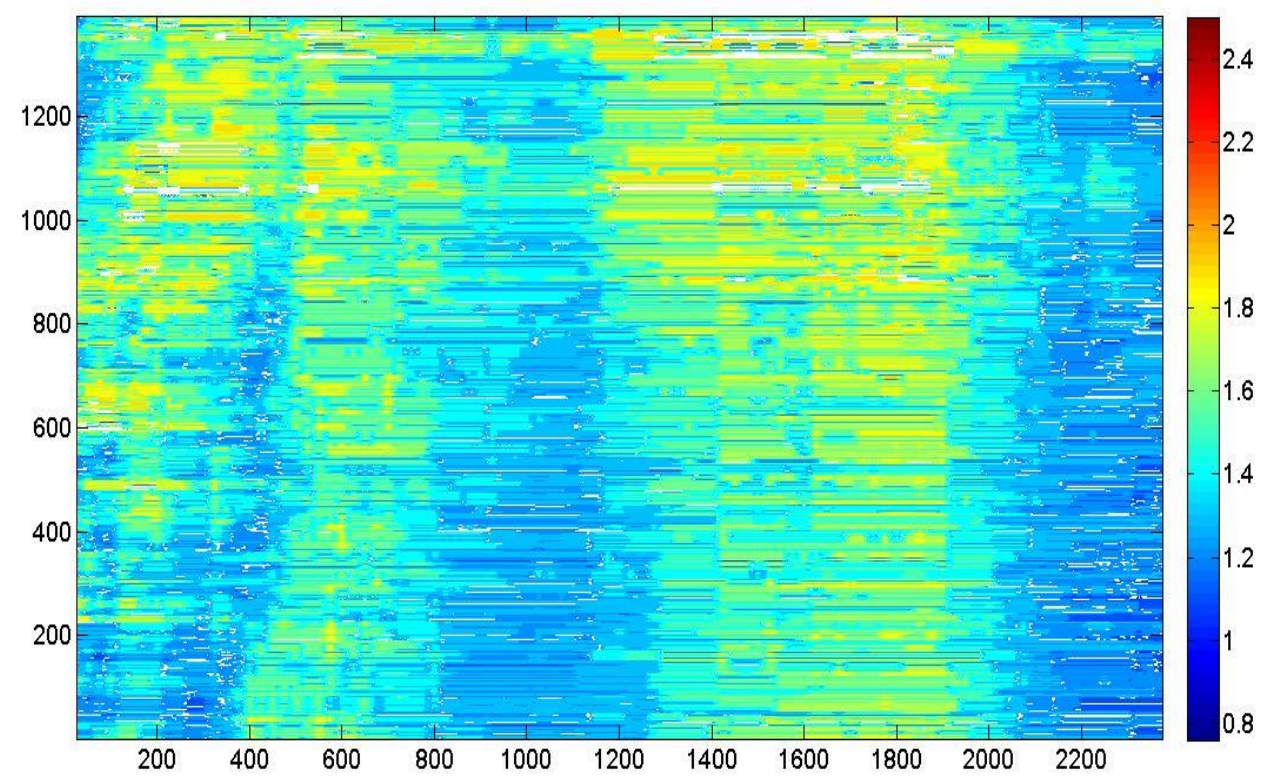

Figure 62. $C_{D}$ Variation on I-79, March $3^{\text {rd }} 2012$ for Baseline with Wind Deflector Placed at $60^{\circ}$. 


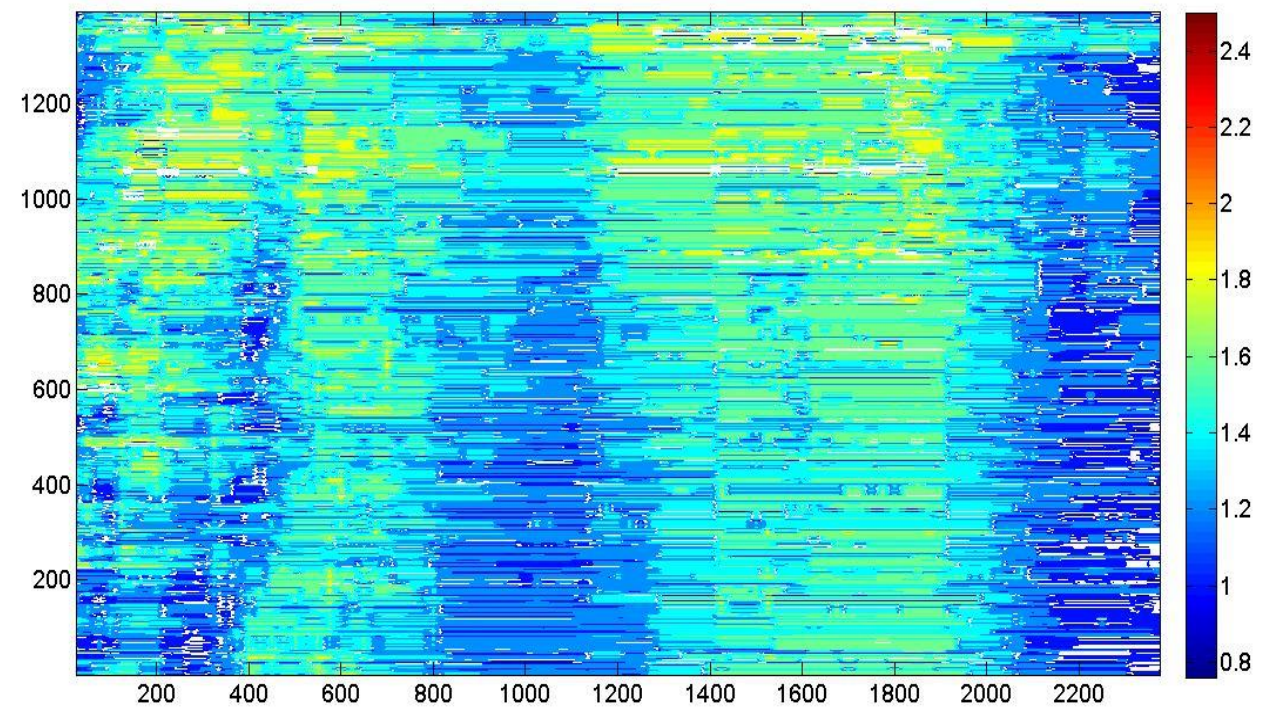

Figure 63. $C_{D}$ Variation on I-79, March $3^{\text {rd }} 2012$ for Baseline with Gap Fairings and Wind Deflector Placed at $30^{\circ}$.

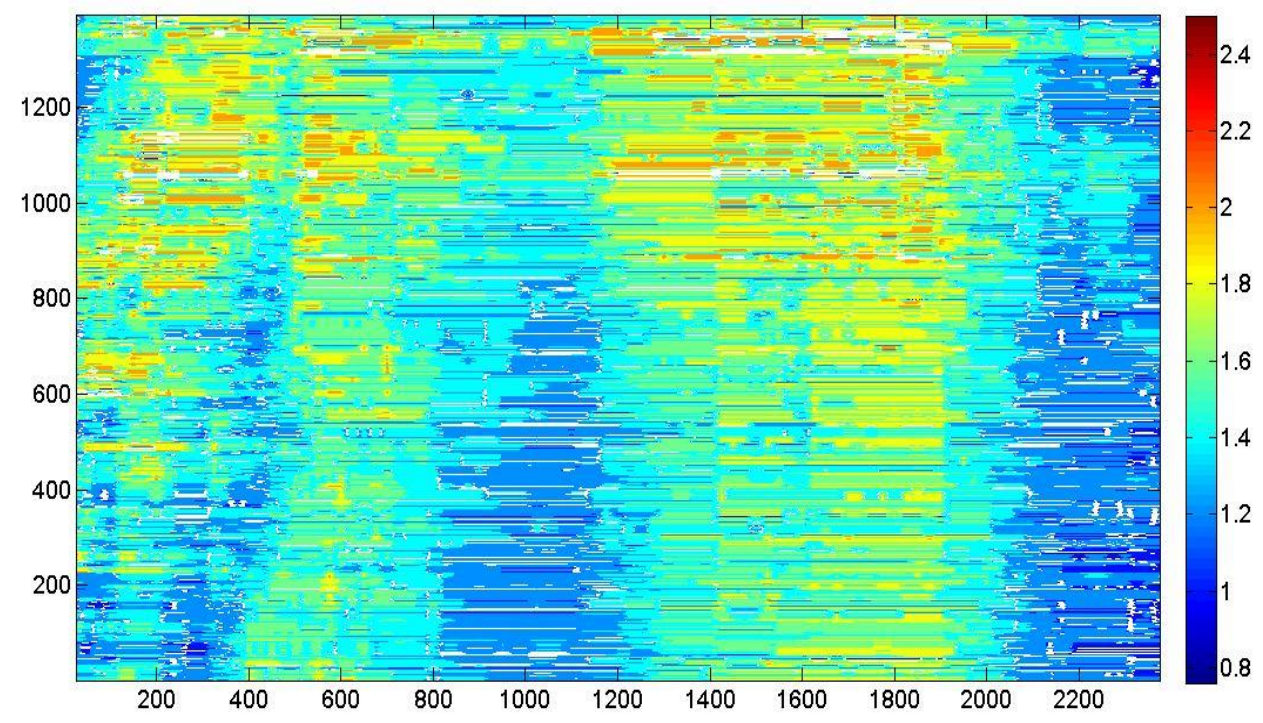

Figure 64. $C_{D}$ Variation on I-79, March $3^{\text {rd }} 2012$ for Baseline with Gap Fairings and Wind Deflector Placed at $45^{\circ}$. 


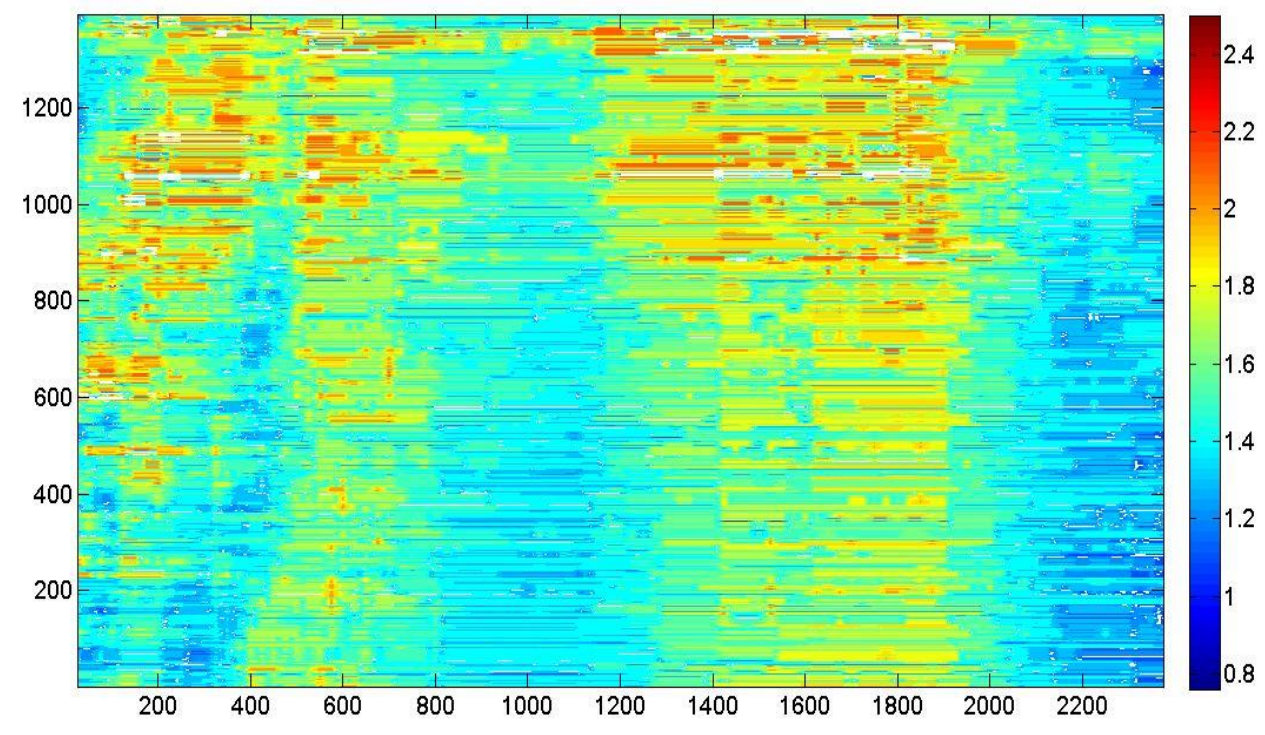

Figure 65. $C_{D}$ Variation on I-79, March $3^{\text {rd }} 2012$ for Baseline with Gap Fairings and Wind

\section{Deflector Placed at $60^{\circ}$.}

Figures 57, 58, 59, 60, 61, 62 and 63, portray the coefficient of drag variation on March $3^{\text {rd }}, 2012$ following the yaw angles in Figure 50 and $C_{D}$ for all configurations from Tables 7 through 13. It can be seen from the figures that the effectiveness of the aerodynamic add on devices are varied. The aerodynamic configuration, truck equipped with the wind deflector at $30^{\circ}$ (referred as Configuration A) shows higher effectiveness at lower yaw angles (marked in darker shades of blue, Fig. 58) but less effective compared to the baseline configuration (Fig. 57) at higher yaw angles (greater than 5.5 degrees).

Aerodynamic configuration with a wind deflector placed at $45^{\circ}$ (referred as Configuration B) resulted to more effective than the baseline configuration and less effective than Configuration $A$ at lower yaw angles ( $0-5.5$ degrees). However, at higher yaw angles, it is ineffective compared to both, baseline and Configuration $B$. The best configuration at lower levels of yaw angle ( $0-3$ degrees) was the truck equipped with wind deflector with $30^{\circ}$ and a gap fairing (referred as Configuration D) but does not 
respond as effective as configurations, A, B or baseline at yaw angles higher than 3 degrees. It can be concluded that configuration $A$ would be the best option for the whole route evaluating the performance of the other configurations on the route chosen (I-79 shown in Figure 54) on March $3^{\text {rd }}, 2012$.

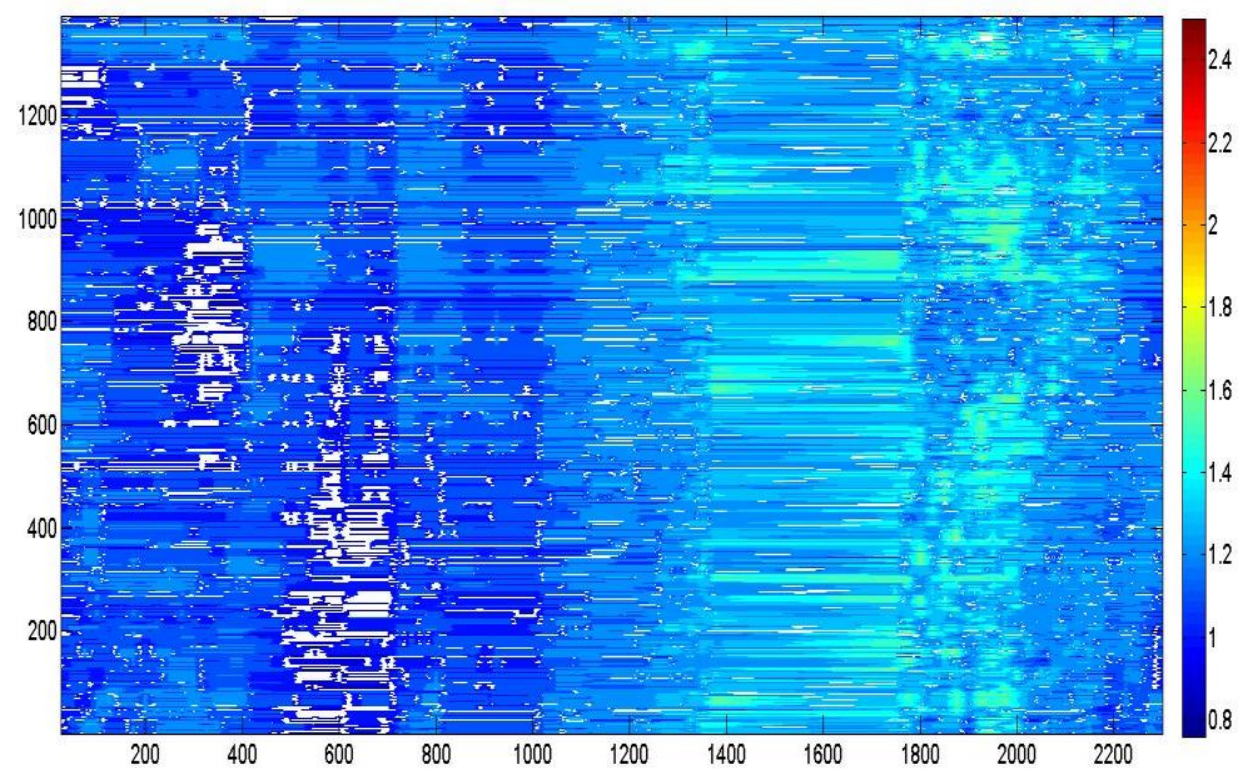

Figure 66. $C_{D}$ Variation on I-79, March $4^{\text {th }} 2012$ for Baseline Configuration. 


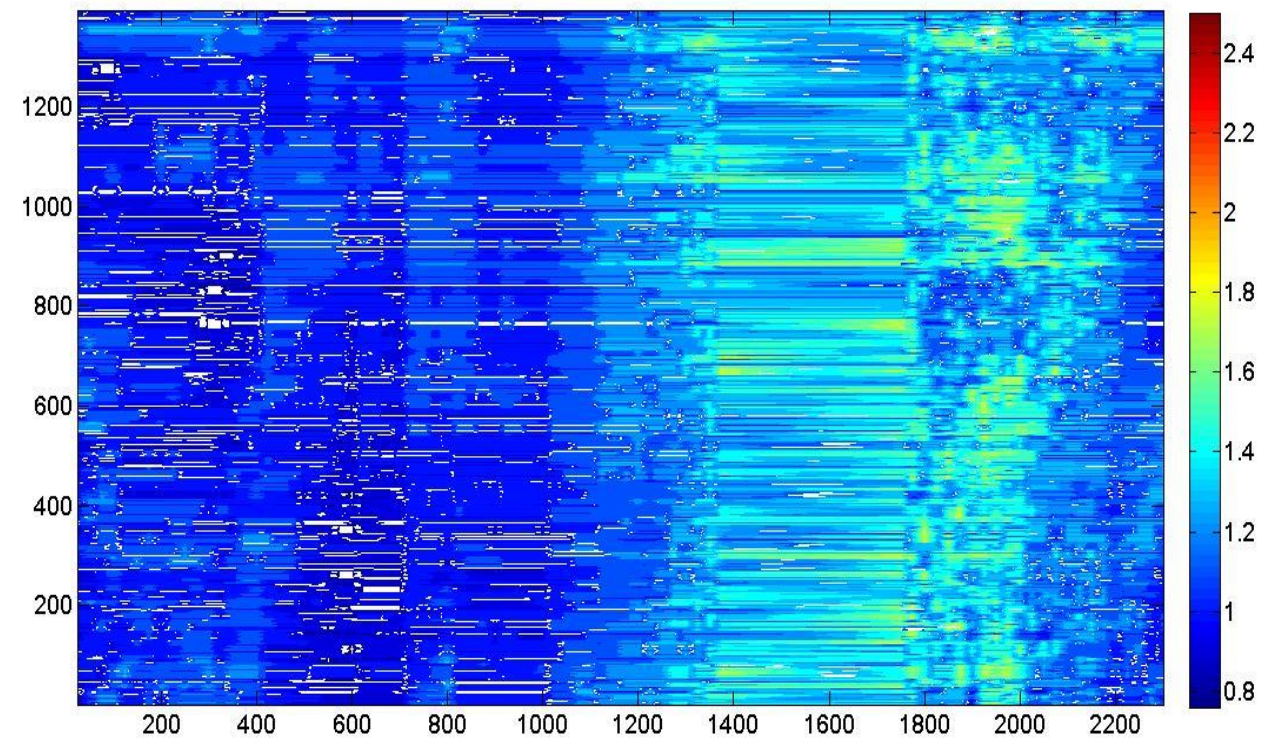

Figure 67. $C_{D}$ Variation on I-79, March $4^{\text {th }} 2012$ for Baseline with Wind Deflector Placed at $30^{\circ}$.

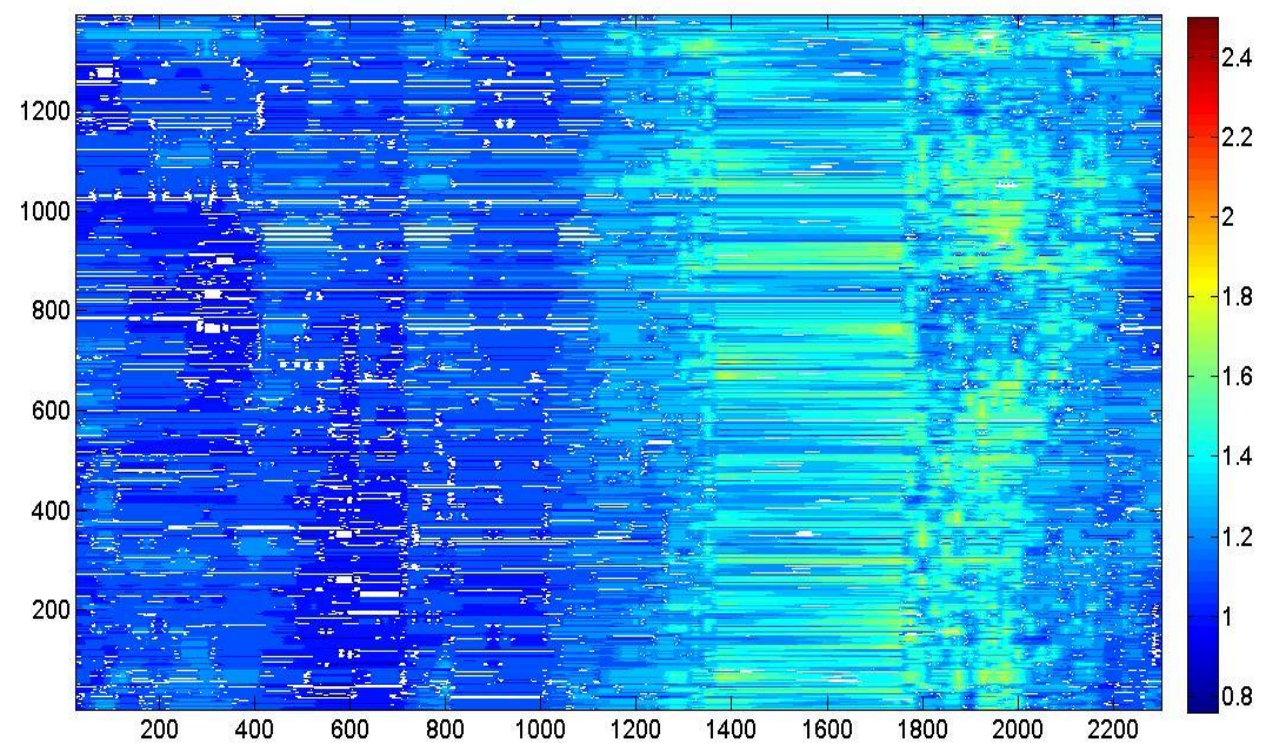

Figure 68. $C_{D}$ Variation on I-79, March $4^{\text {th }} 2012$ for Baseline with Wind Deflector Placed at $45^{\circ}$. 


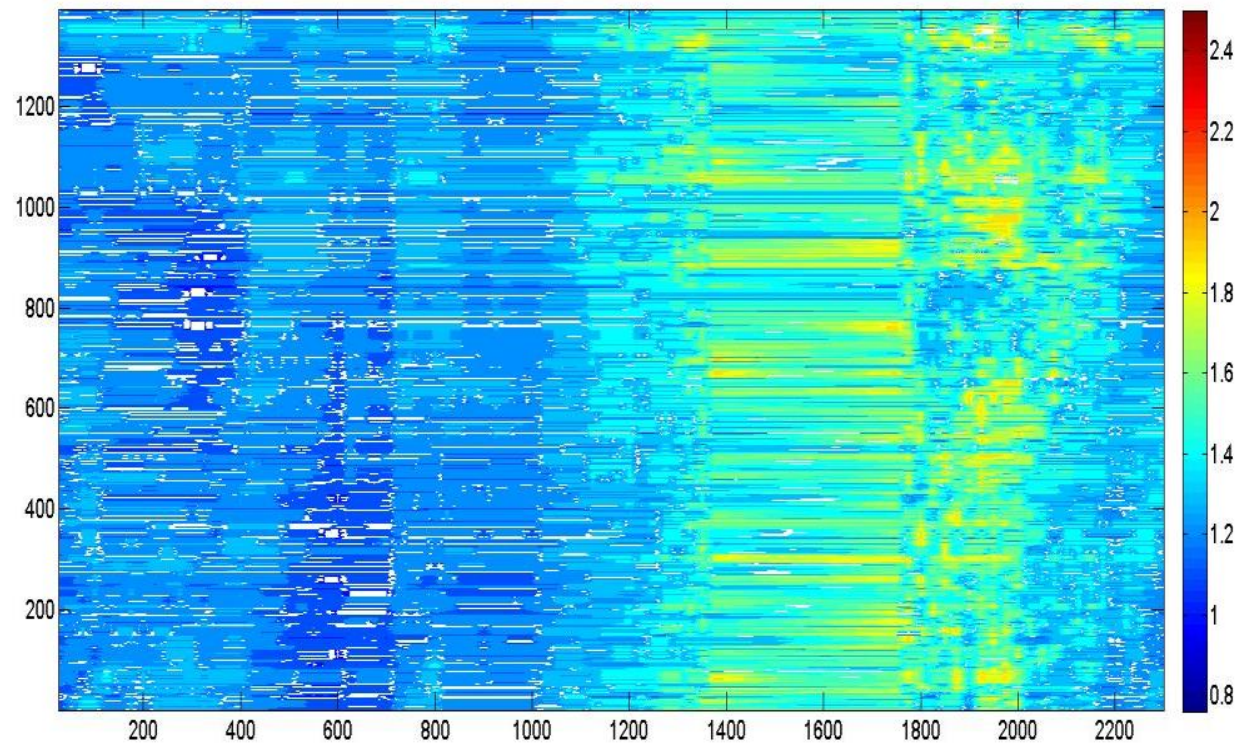

Figure 69. $C_{D}$ Variation on I-79, March $4^{\text {th }} 2012$ for Baseline with Wind Deflector Placed at $60^{\circ}$.

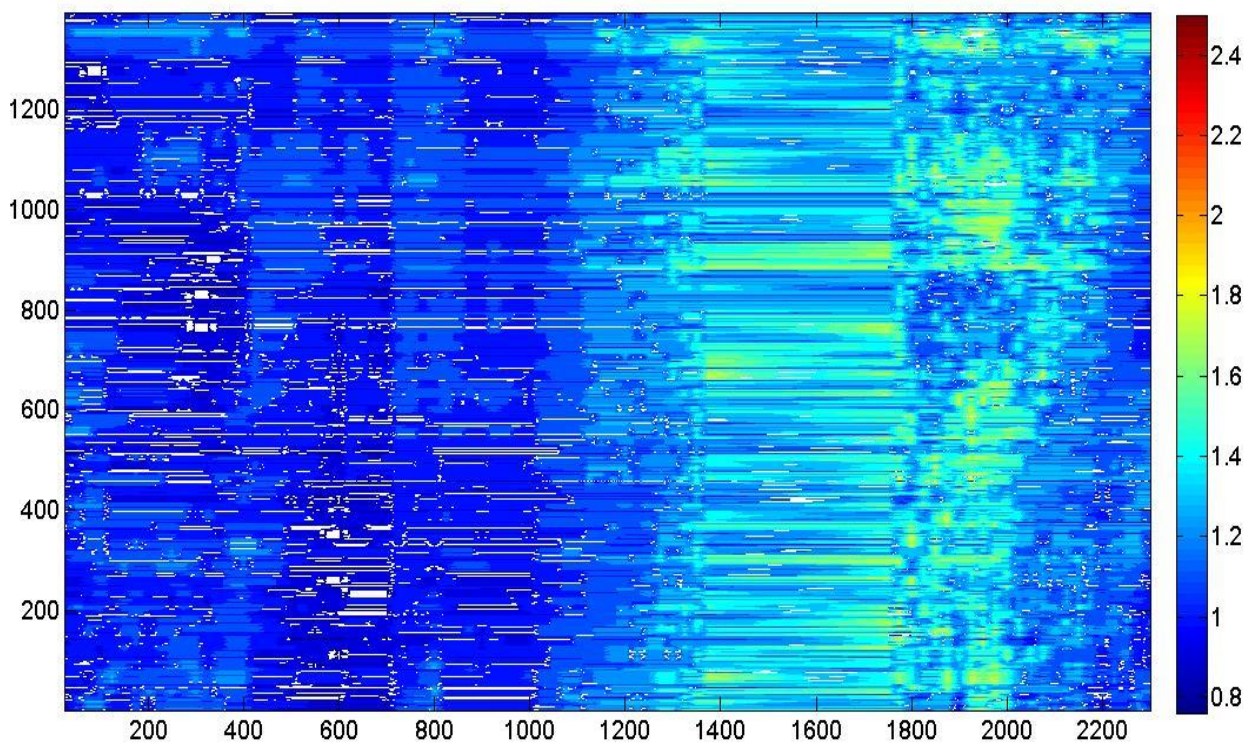

Figure 70. $C_{D}$ Variation on I-79, March $4^{\text {th }} 2012$ for Baseline with Gap Fairings and Wind Deflector Placed at $30^{\circ}$. 


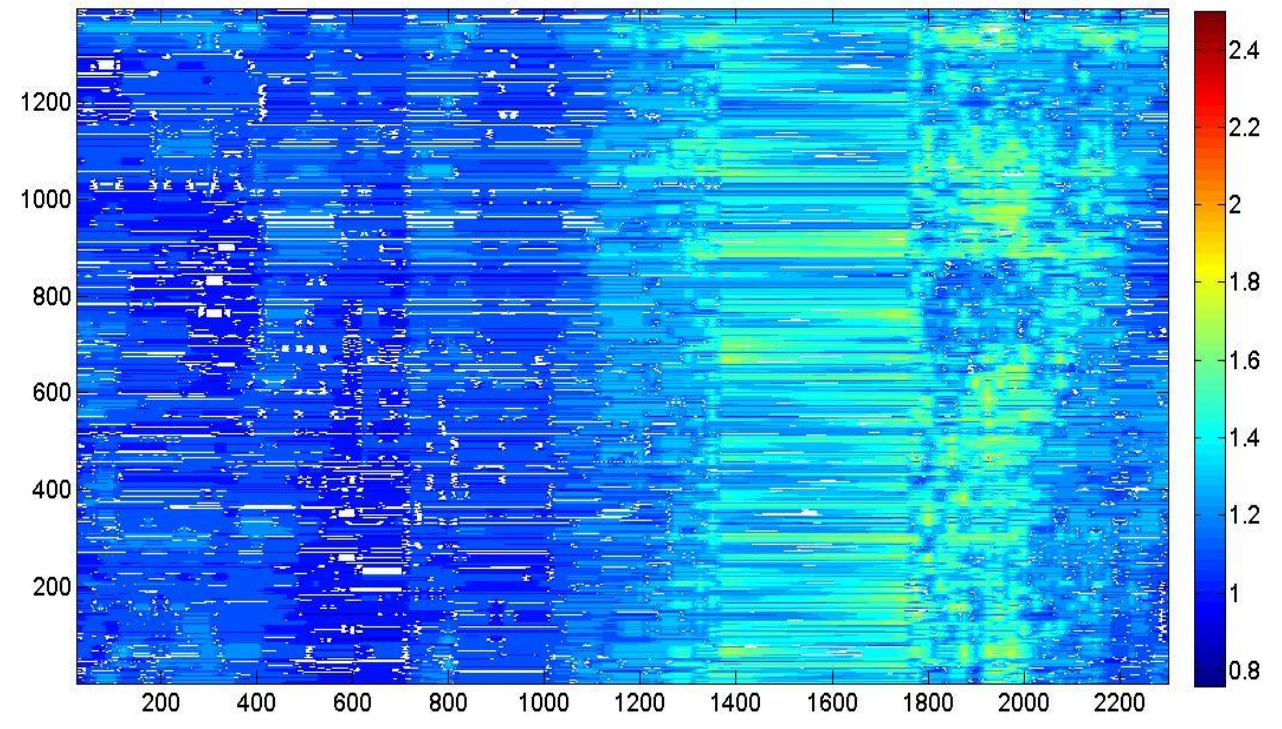

Figure 71. $C_{D}$ Variation on I-79, March $4^{\text {th }} 2012$ for Baseline with Gap Fairings and Wind Deflector Placed at $45^{\circ}$.

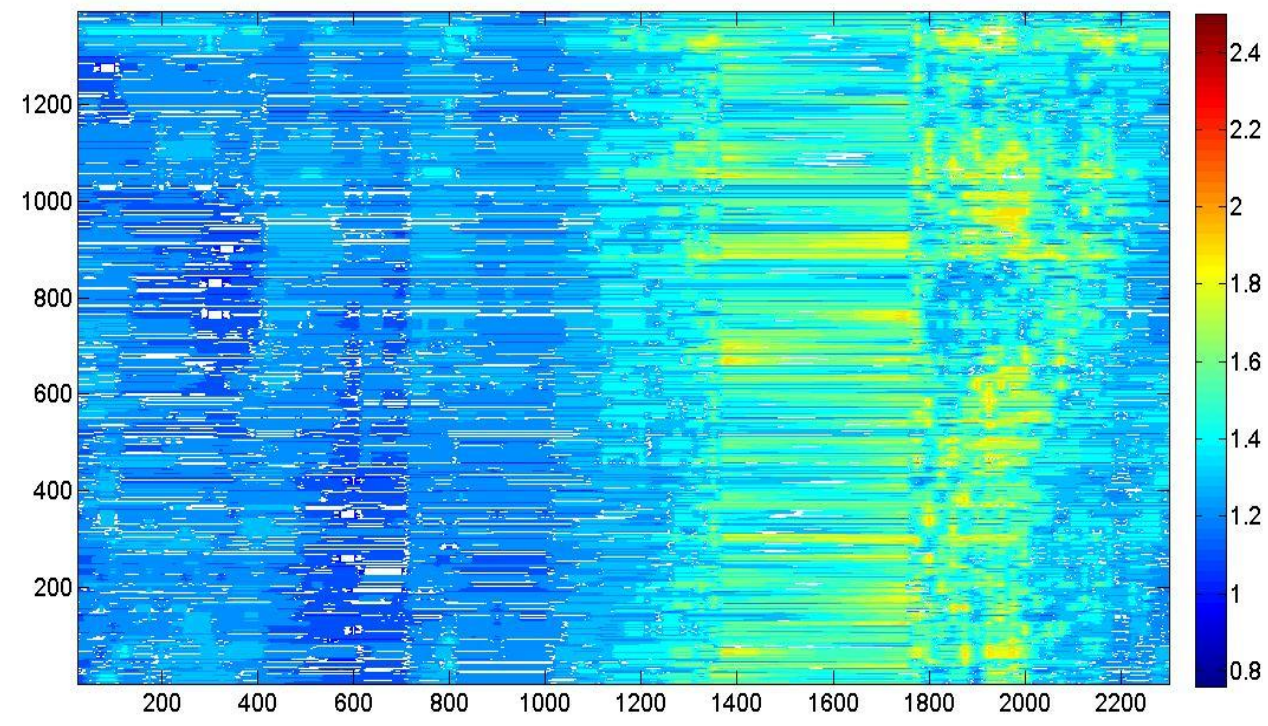

Figure 72. $C_{D}$ Variation on I-79, March $4^{\text {th }} 2012$ for Baseline with Gap Fairings and Wind Deflector Placed at $60^{\circ}$. 
The aerodynamic add on devices performed in similar fashion (as 03/03/2012) with configuration A being the most efficient through the day, for all regions on the route. From the analysis conducted, configuration $A$ or $D$ is recommended for trucks travelling the route between $0000-1200$ hours on 03/04/2012 and the baseline configuration is recommended for vehicles travelling between $1200-2345$ hours.

Following the yaw angles obtained for 03/01/2013 and 03/02/2013 in Figures 52 and 53, $C_{D}$ values were derived similarly to observe the varied nature of wind effects on on-road vehicles and how significantly it differed at the same period of the month.

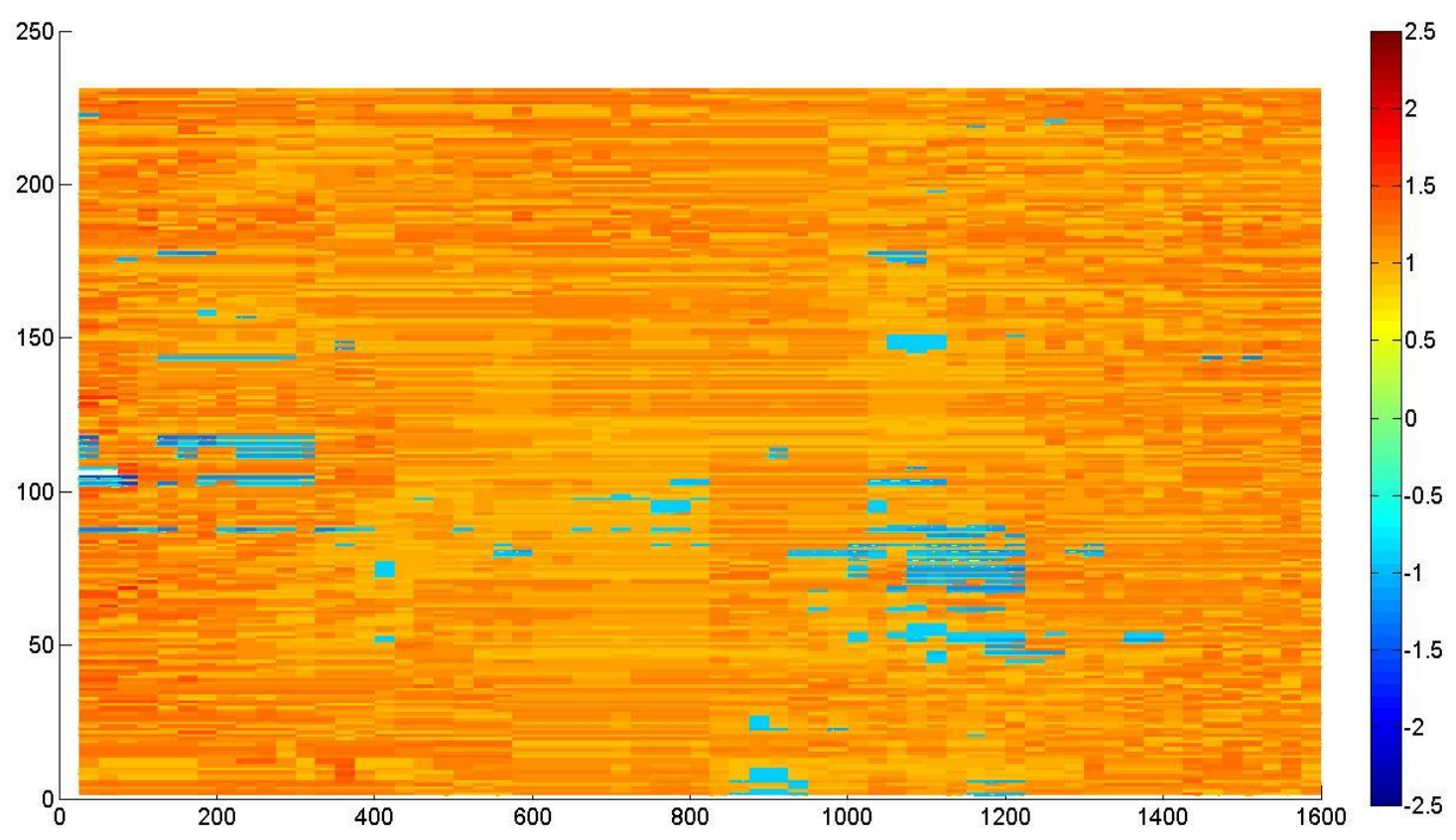

Figure 73. $C_{D}$ Variation on I-79, March $1^{\text {st }} 2013$ for Baseline Configuration. 


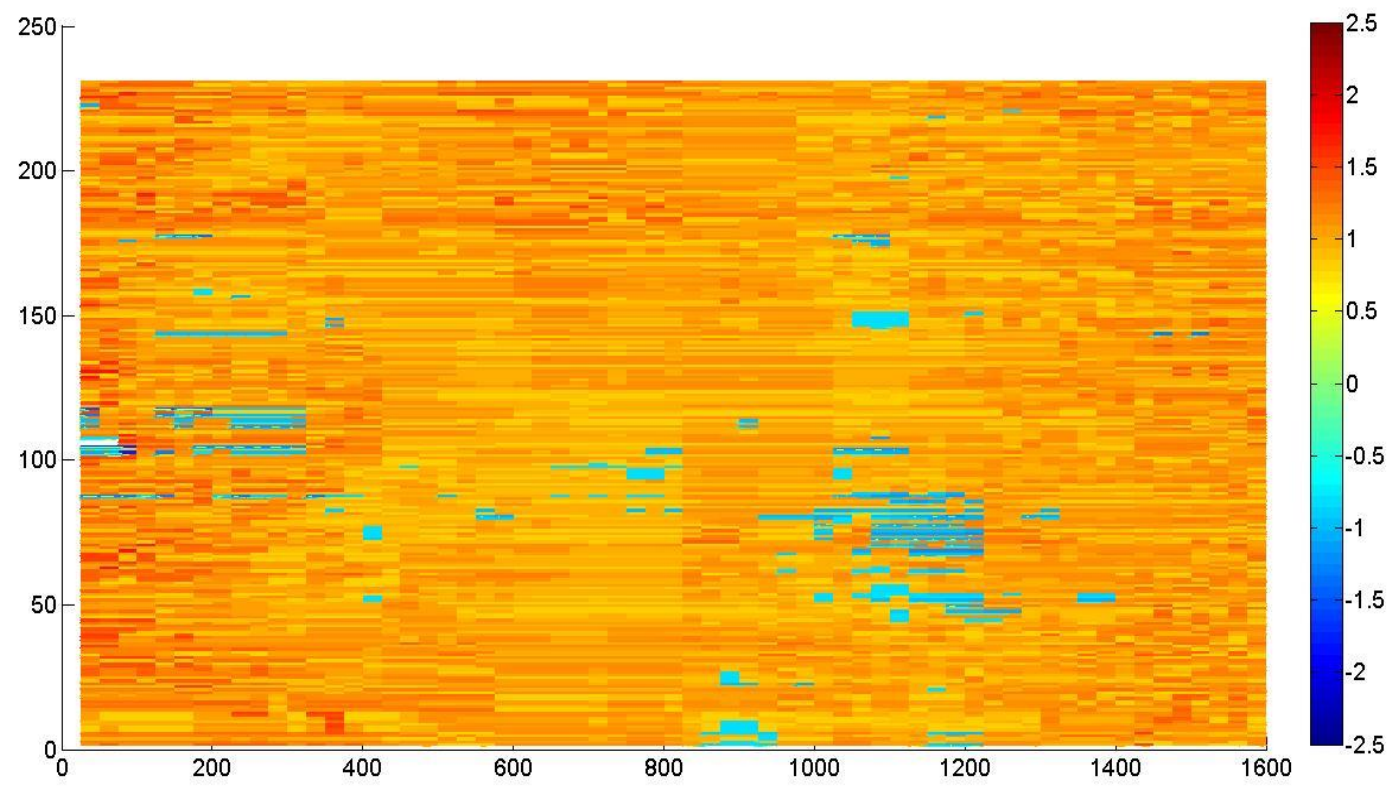

Figure 74. $C_{D}$ Variation on I-79, March $1^{\text {st }} 2013$ for Baseline with Wind Deflector Placed at $30^{\circ}$.

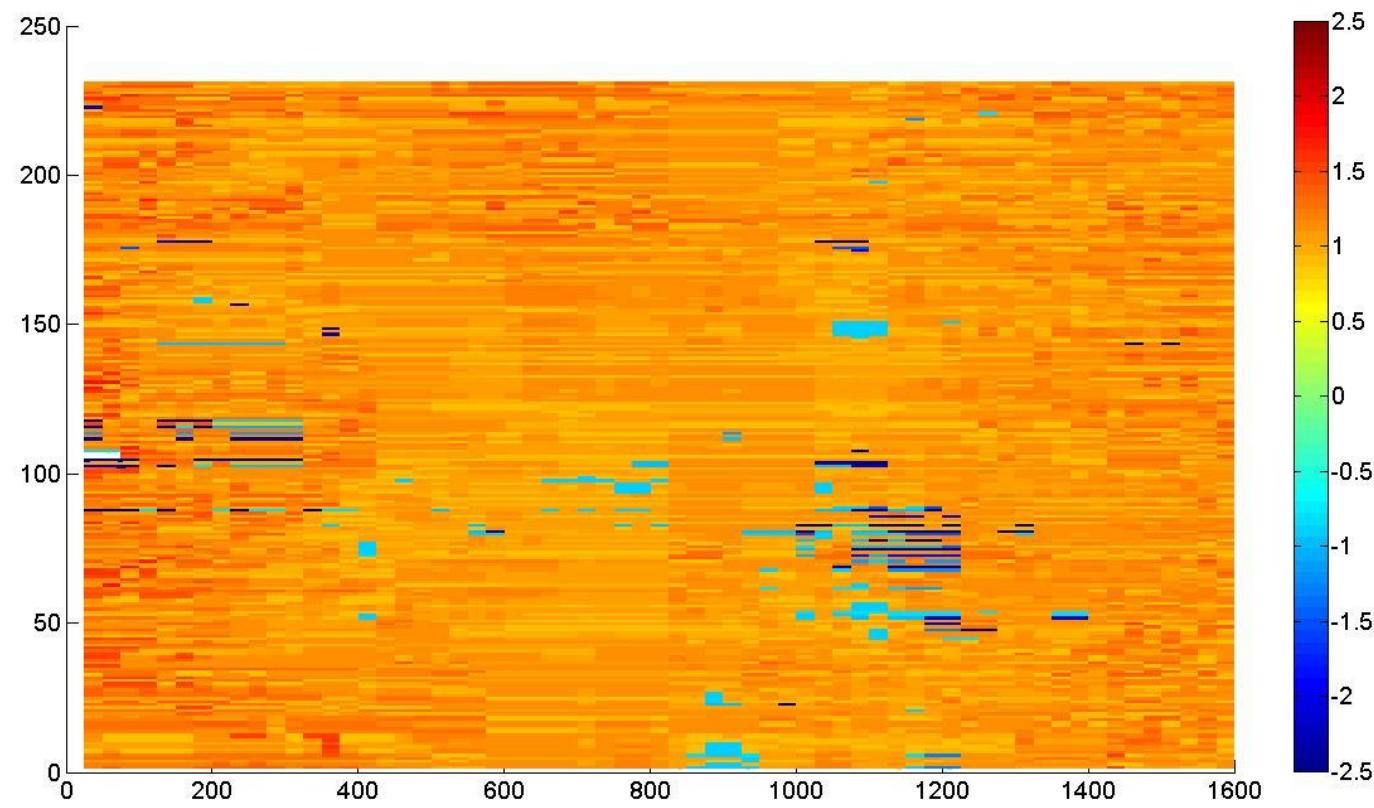

Figure 75. $C_{D}$ Variation on I-79, March $1^{\text {st }} 2013$ for Baseline with Wind Deflector Placed at $45^{\circ}$. 


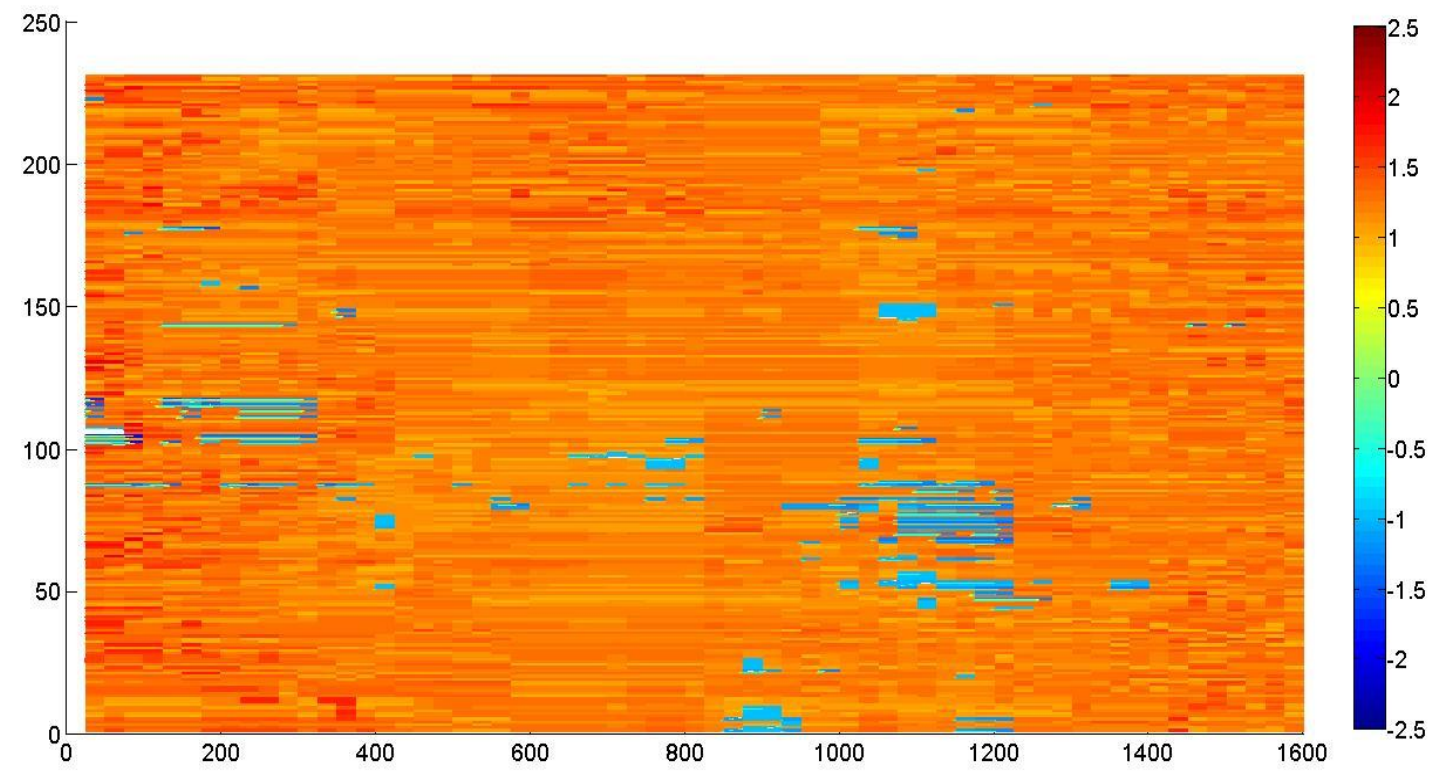

Figure 76. $C_{D}$ Variation on I-79, March $1^{\text {st }} 2013$ for Baseline with Wind Deflector Placed at $60^{\circ}$.

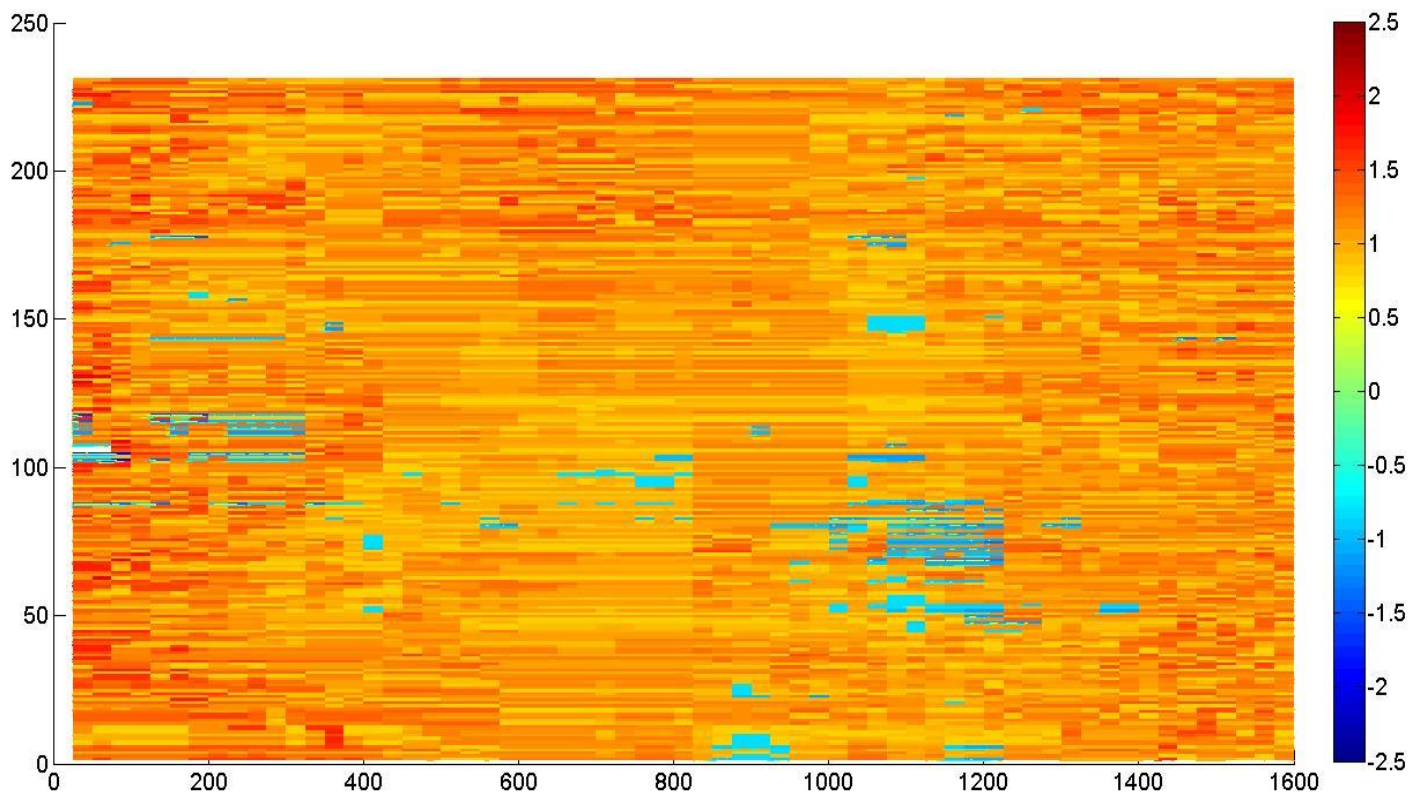

Figure 77. $C_{D}$ Variation on I-79, March $1^{\text {st }} 2013$ for Baseline with Gap Fairings and Wind Deflector Placed at $30^{\circ}$. 


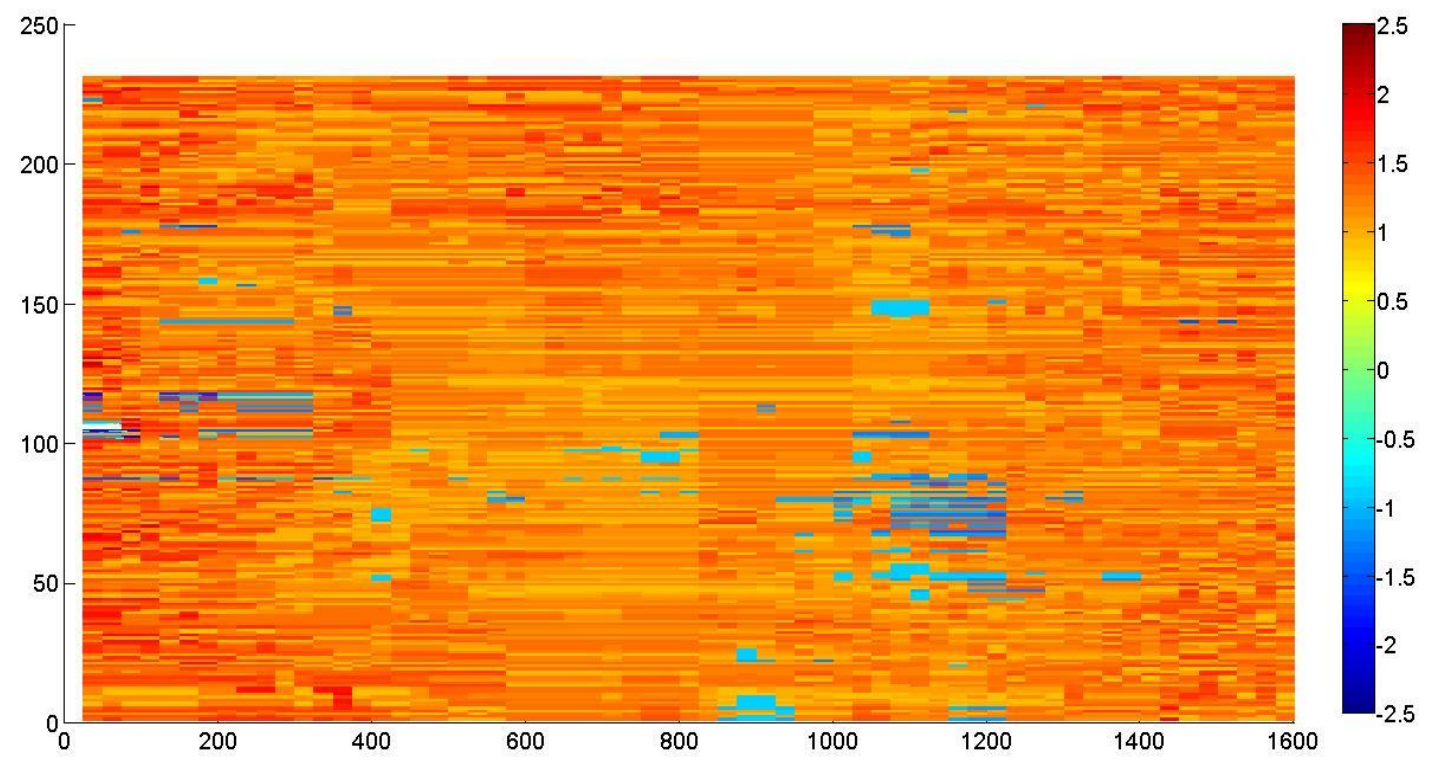

Figure 78. $C_{D}$ Variation on I-79, March 1st 2013 for Baseline with Gap Fairings and Wind Deflector Placed at $45^{\circ}$.

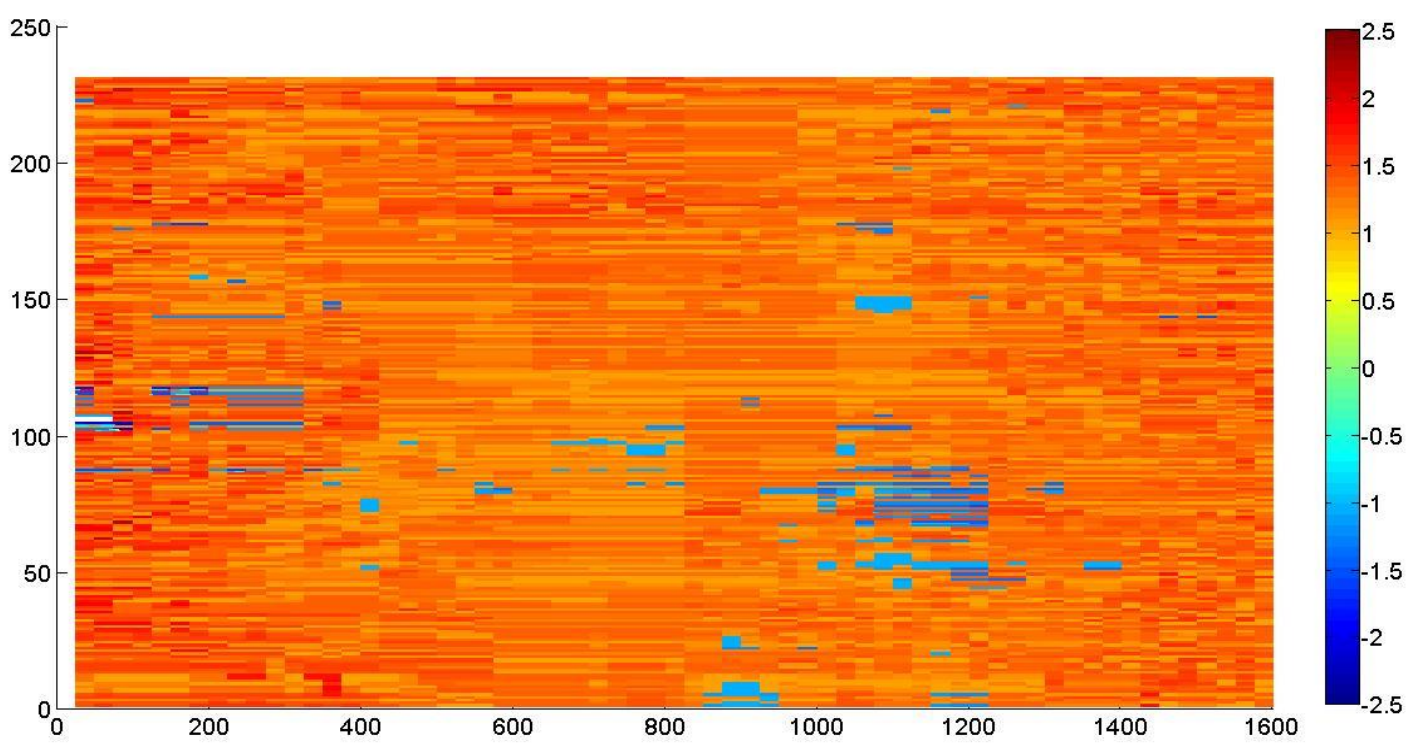

Figure 79. $C_{D}$ Variation on I-79, March $1^{\text {st }} 2013$ for Baseline with Gap Fairings and Wind Deflector Placed at $60^{\circ}$. 
The analysis concluded that fairings would not be effective on this route on March $1^{\text {st }}$, 2013 unlike 2012, where configuration D was a considerably effective of aerodynamic configuration in several cases. However, on March $1^{\text {st }}, 2013$, configuration A was the most efficient aerodynamic configuration with the wind deflector placed at 30 degrees. Configuration B was the second most efficient with a wind deflector placed at 45 degrees. Clear differences can be seen in the recommended choice of aerodynamic configurations compared to the recommended configurations for March $3^{\text {rd }}$ and $4^{\text {th }}$, 2012.

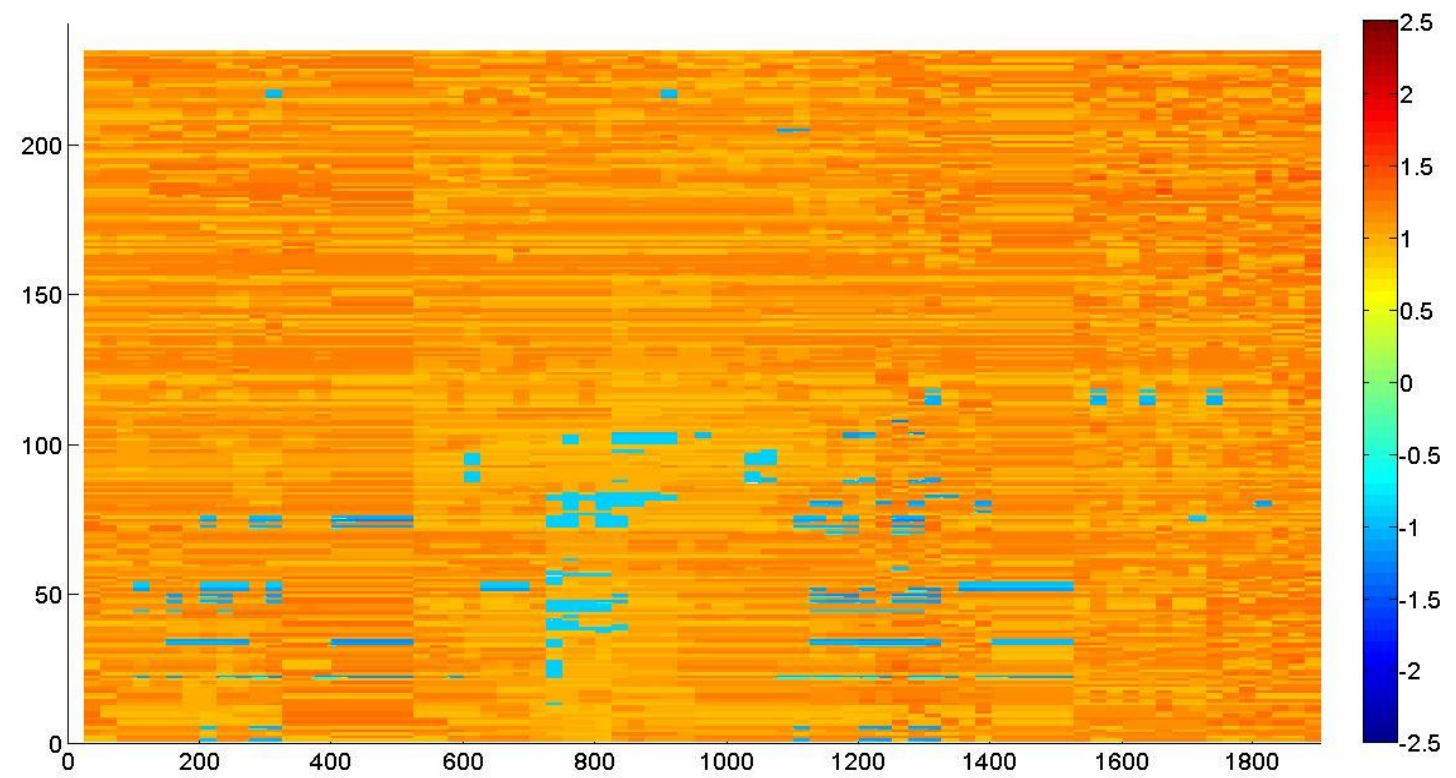

Figure 80. $C_{D}$ Variation on I-79, March $2^{\text {nd }} 2013$ for Baseline Configuration. 


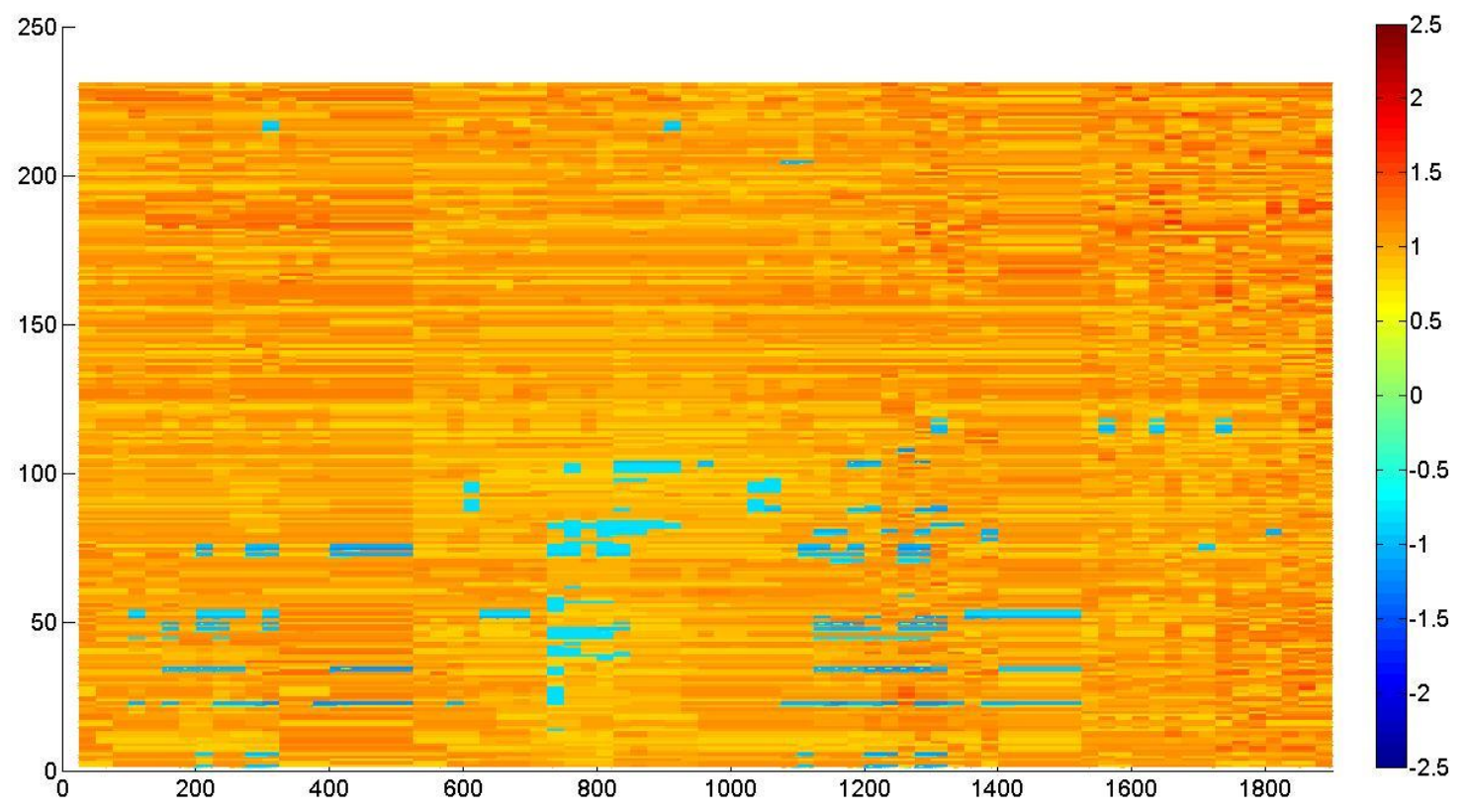

Figure 81. $C_{D}$ Variation on I-79, March $2^{\text {nd }} 2013$ for Baseline with Wind Deflector Placed at $30^{\circ}$.

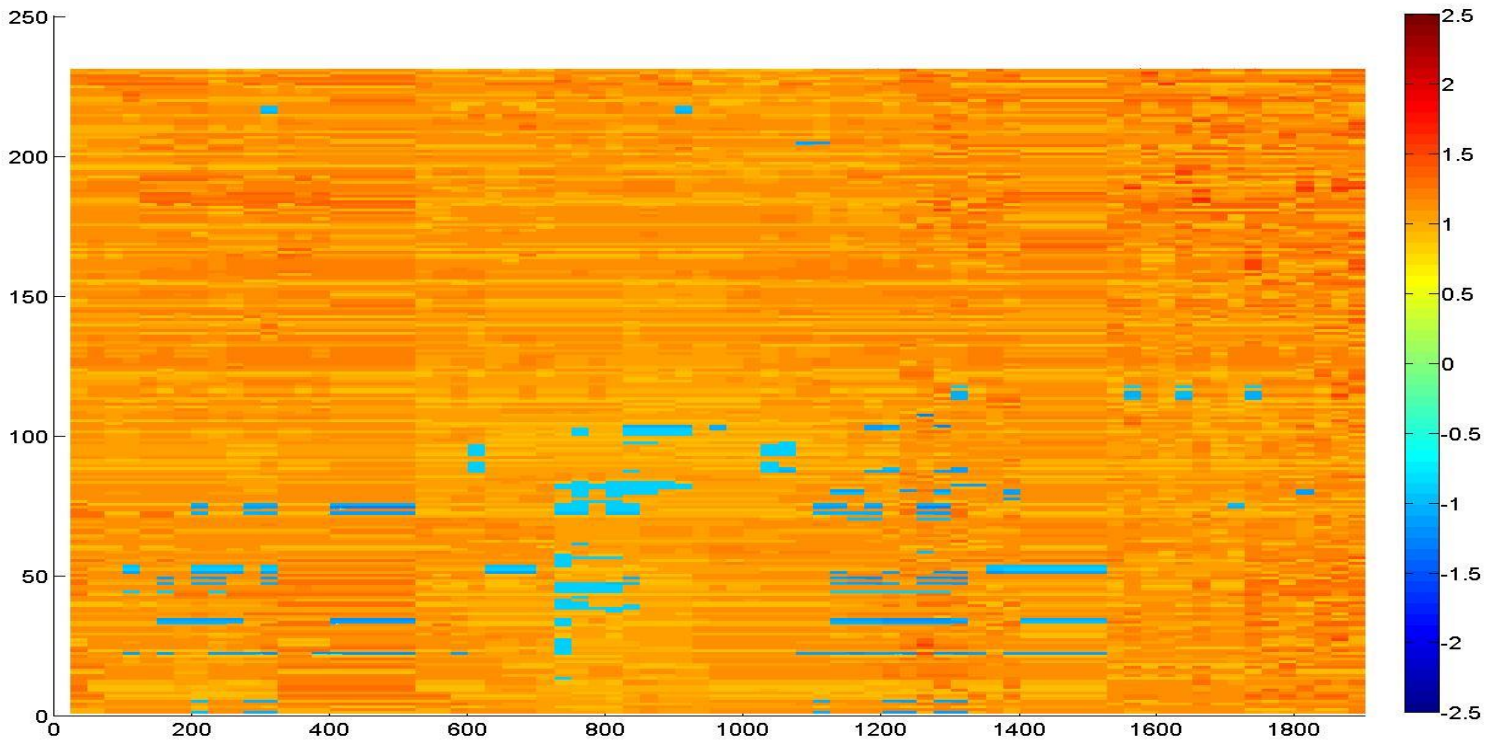

Figure 82. $C_{D}$ Variation on I-79, March $2^{\text {nd }} 2013$ for Baseline with Wind Deflector Placed at $45^{\circ}$. 


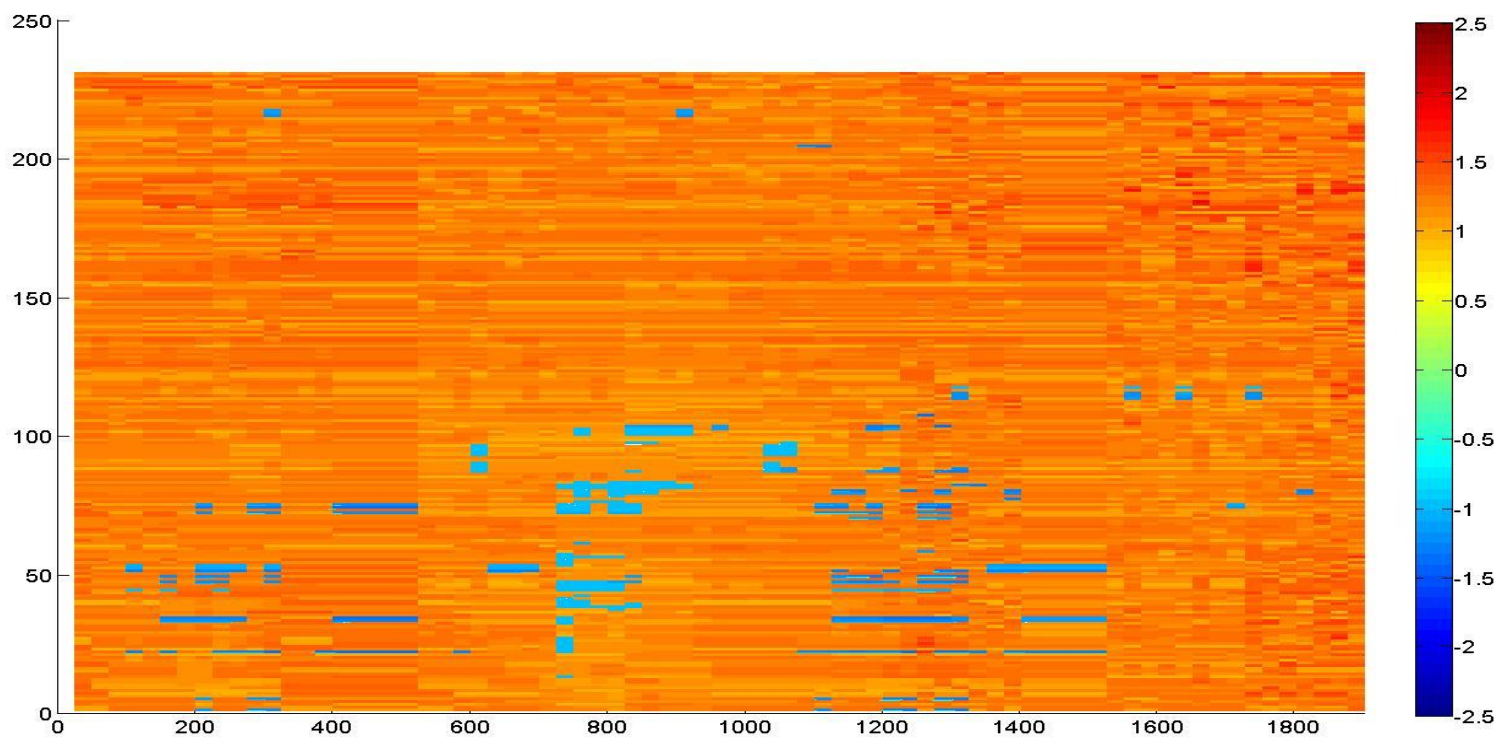

Figure 83. $C_{D}$ Variation on I-79, March $2^{\text {nd }} 2013$ for Baseline with Wind Deflector Placed at $60^{\circ}$.

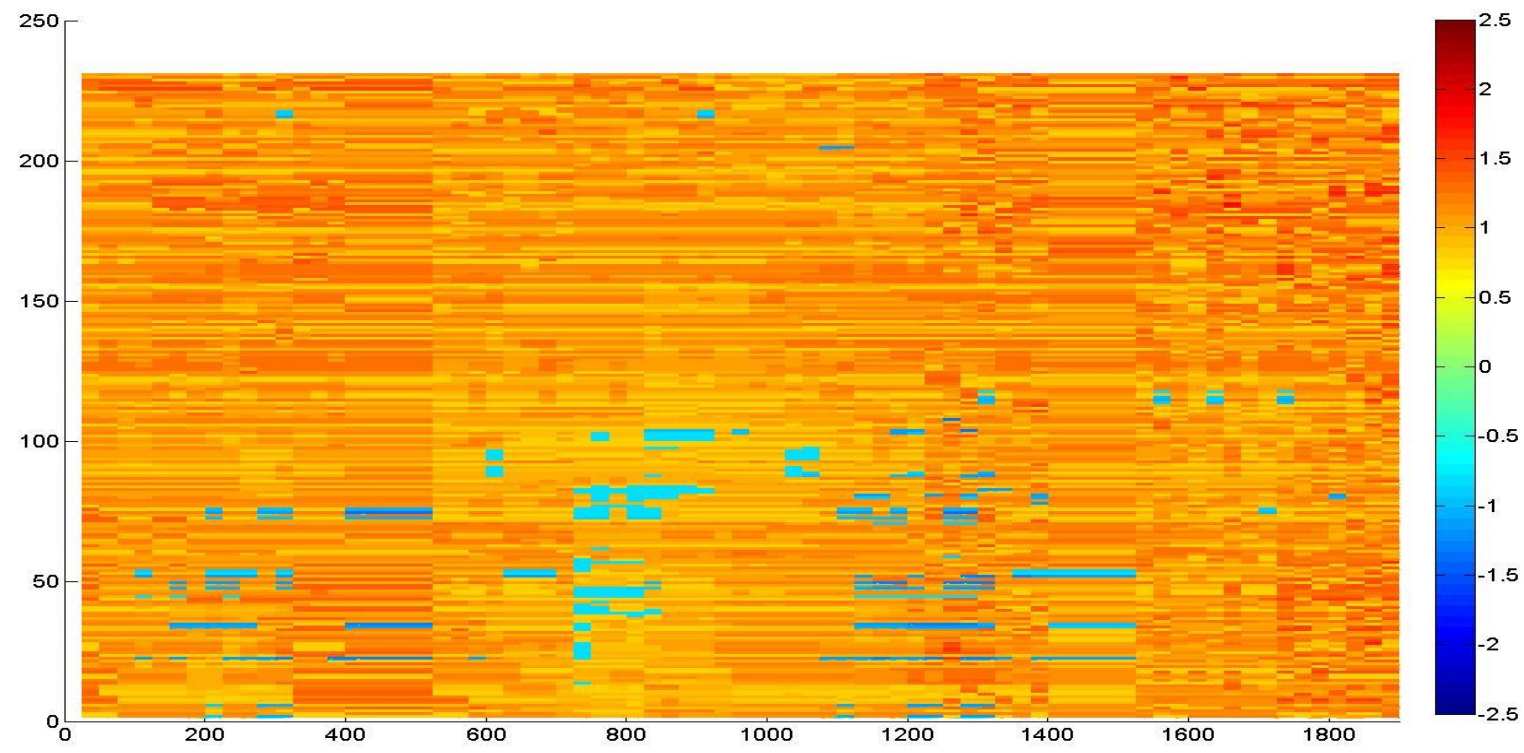

Figure 84. $C_{D}$ Variation on I-79, March $2^{\text {nd }} 2013$ for Baseline with Gap Fairings and Wind Deflector Placed at $30^{\circ}$. 


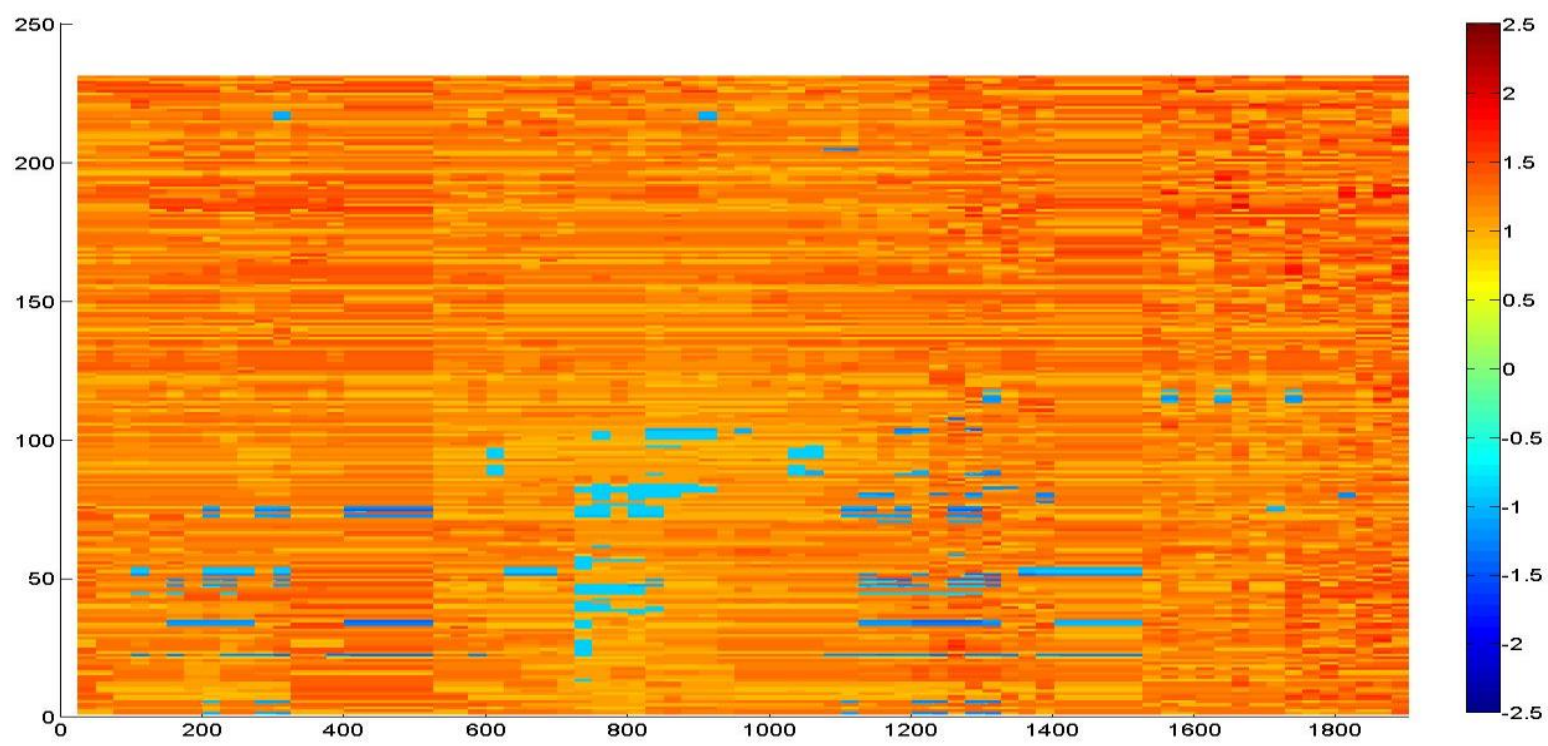

Figure 85. $C_{D}$ Variation on I-79, March $2^{\text {nd }} 2013$ for Baseline with Gap Fairings and Wind Deflector Placed at $45^{\circ}$.

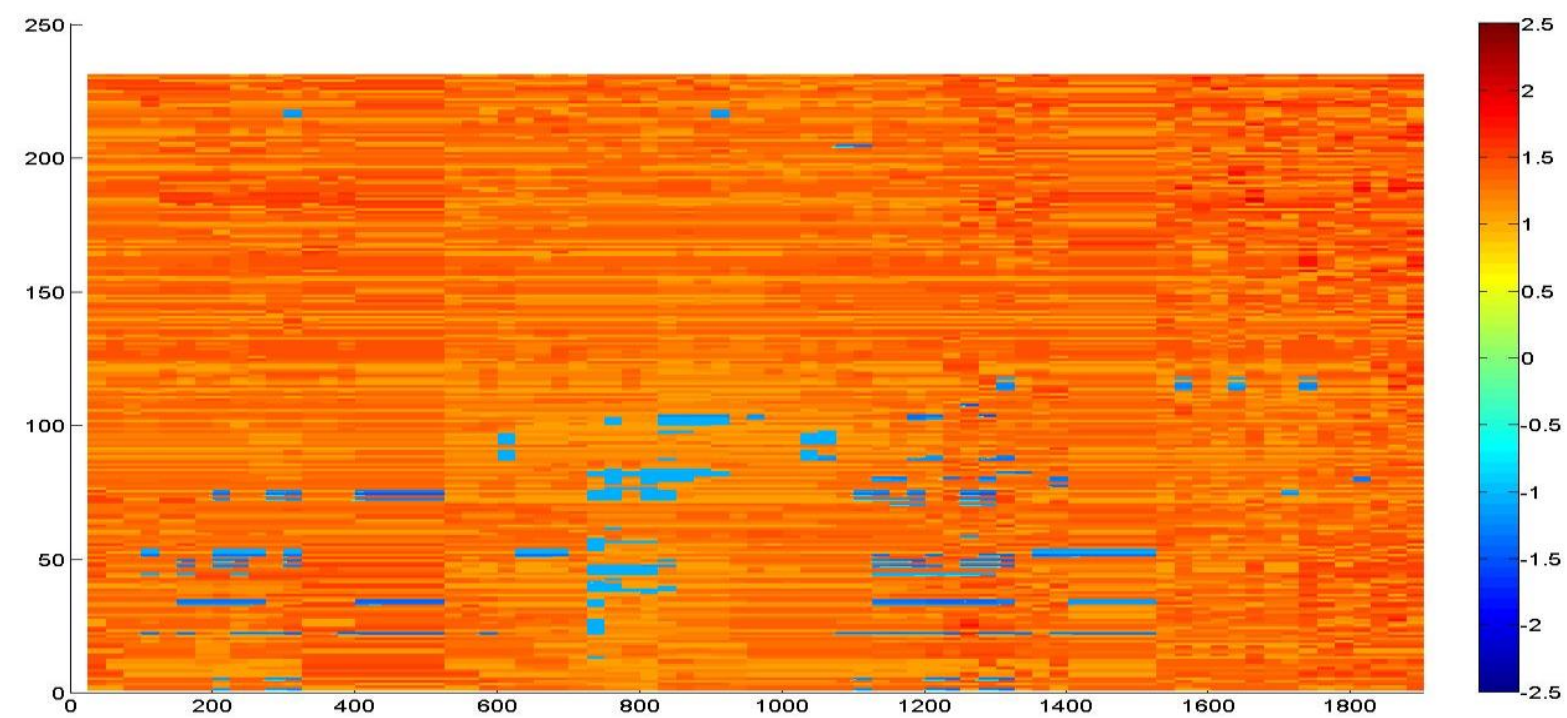

Figure 86. $C_{D}$ Variation on I-79, March $2^{\text {nd }} 2013$ for Baseline with Gap Fairings and Wind Deflector Placed at $60^{\circ}$. 
The baseline configuration or configuration A was the recommended choice of aerodynamic configurations. From the analysis, it is concluded that configuration $\mathrm{A}$ would be more effective for the time period $0000-1100$ and the baseline configuration would be effective for the rest of the day on March $2^{\text {nd }}, 2013$.

The $C_{D}$ values were obtained for yaw angles in Figure 56 following the speed trace (Figure 55) obtained for the trip made between Missouri and Kansa for the cross country study.

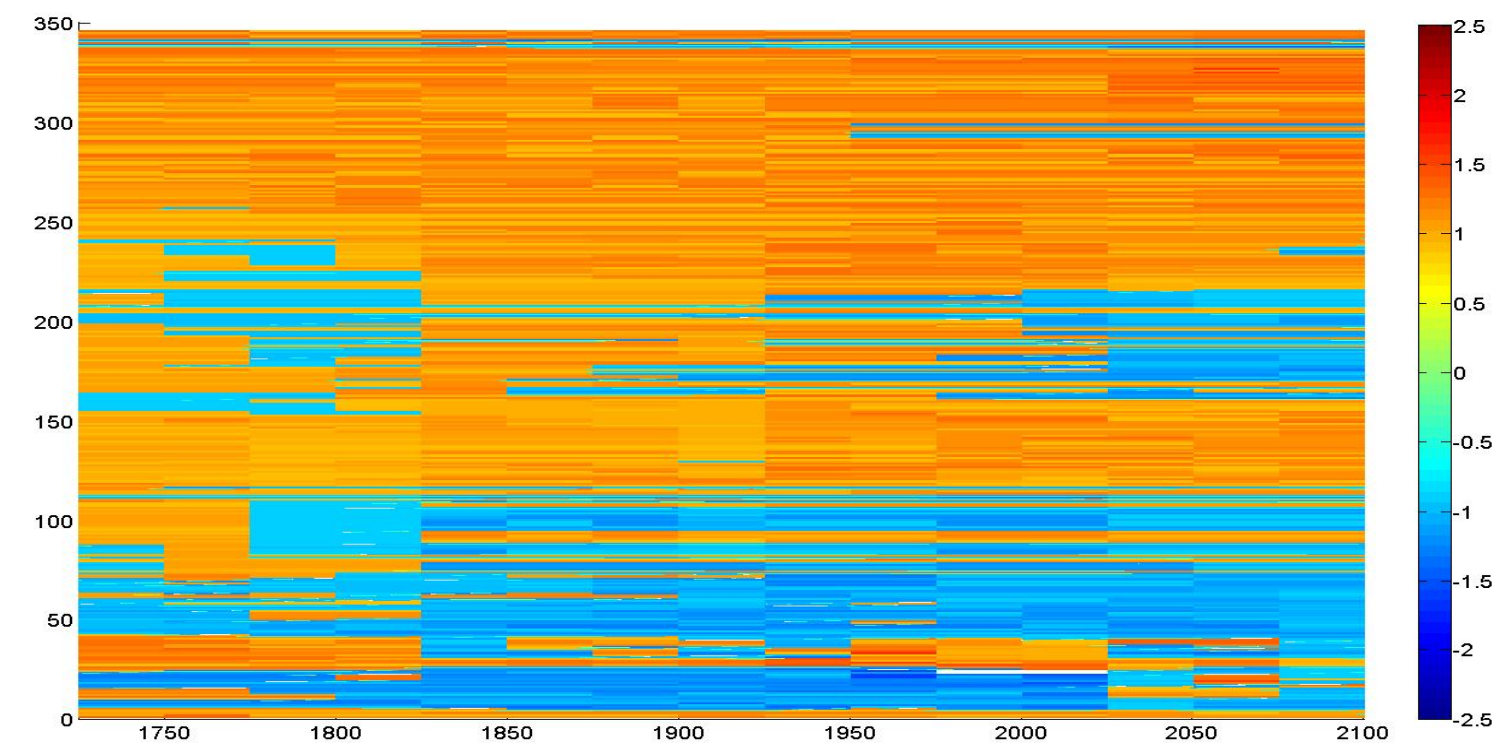

Figure 87. $C_{D}$ Variation in I-70 (Missouri-Kansas Cross Country Route), October 10 ${ }^{\text {th }}, 2011$ for Baseline Configuration. 


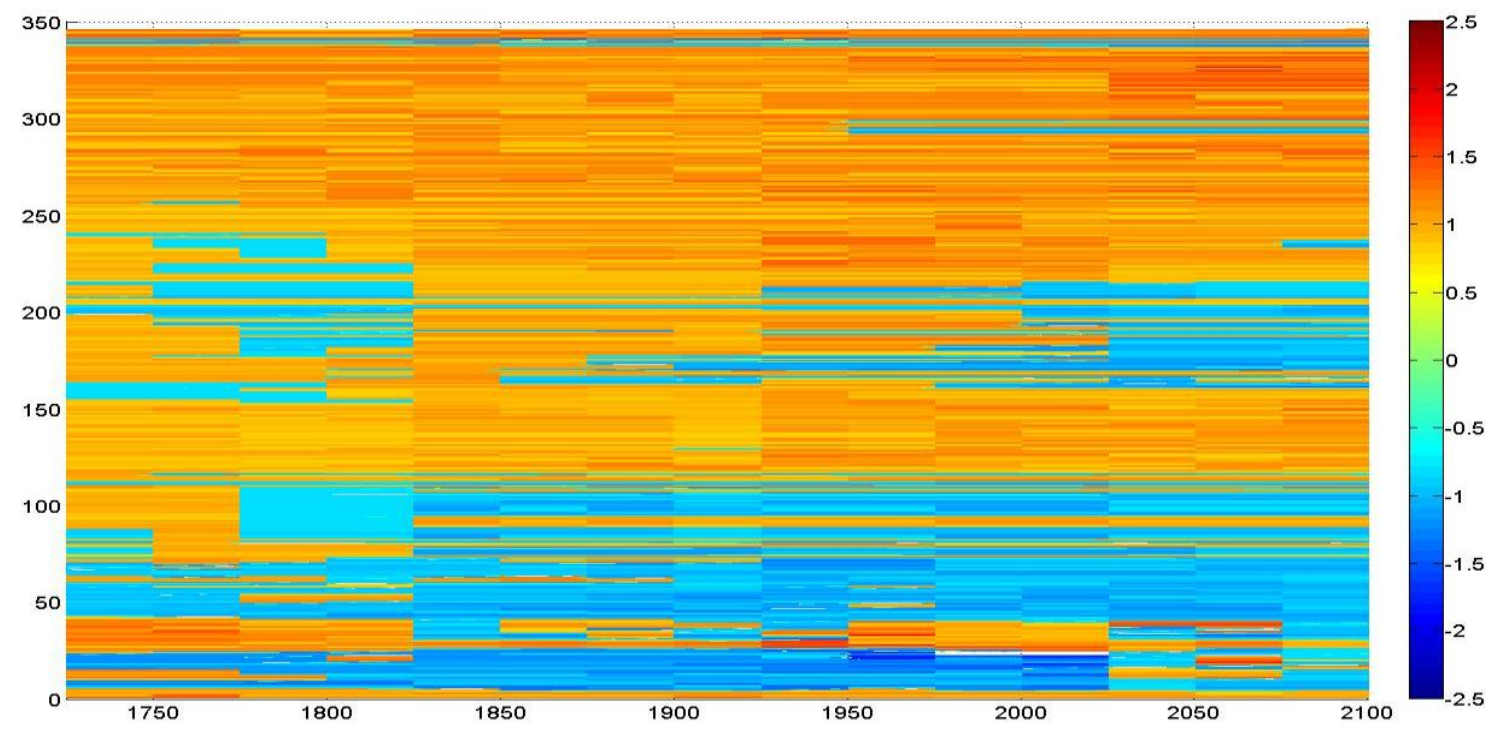

Figure 88. $C_{D}$ Variation in I-70 (Missouri-Kansas Cross Country Route), October 10 ${ }^{\text {th }}, 2011$ for Baseline Configuration with Wind Deflector at $30^{\circ}$.

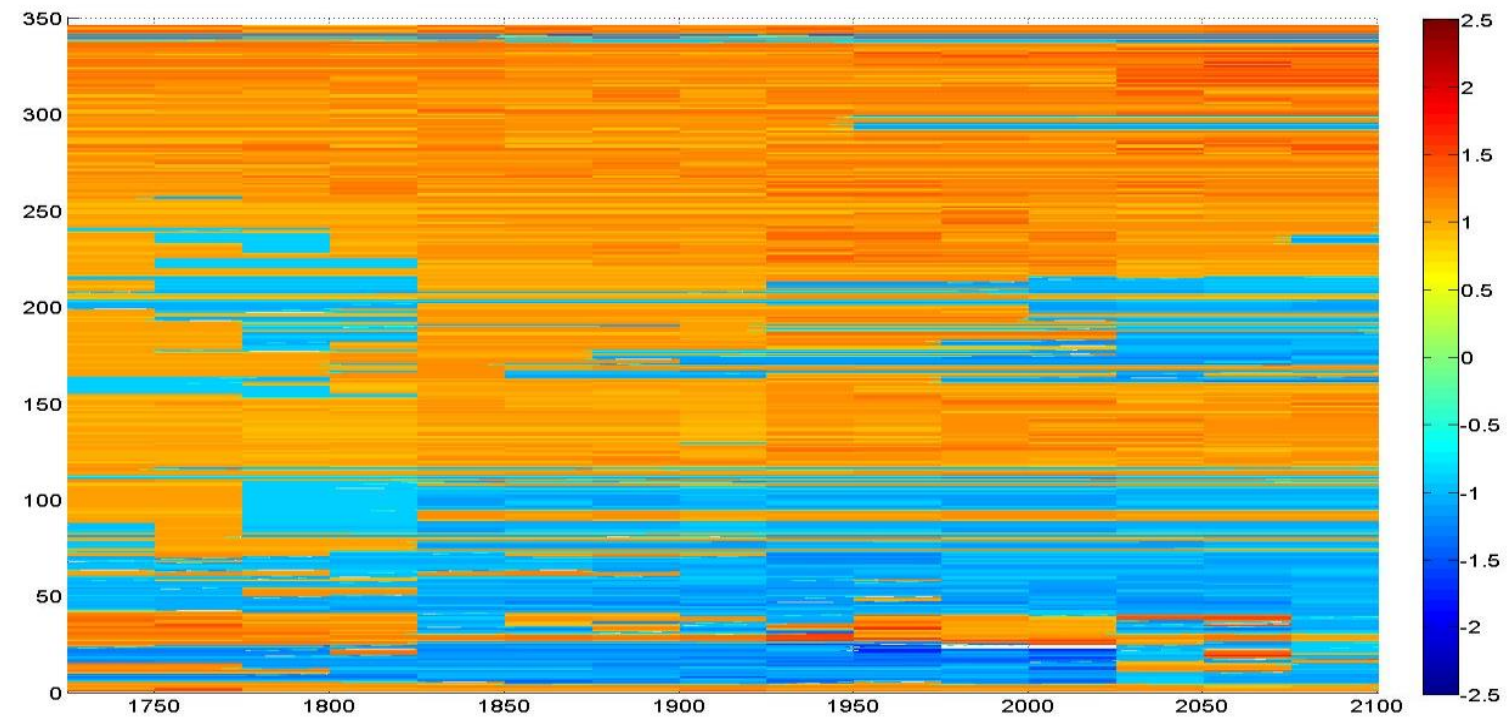

Figure 89. $C_{D}$ Variation in I-70 (Missouri-Kansas Cross Country Route), October $10^{\text {th }}, 2011$ for Baseline Configuration with Wind Deflector at $45^{\circ}$. 


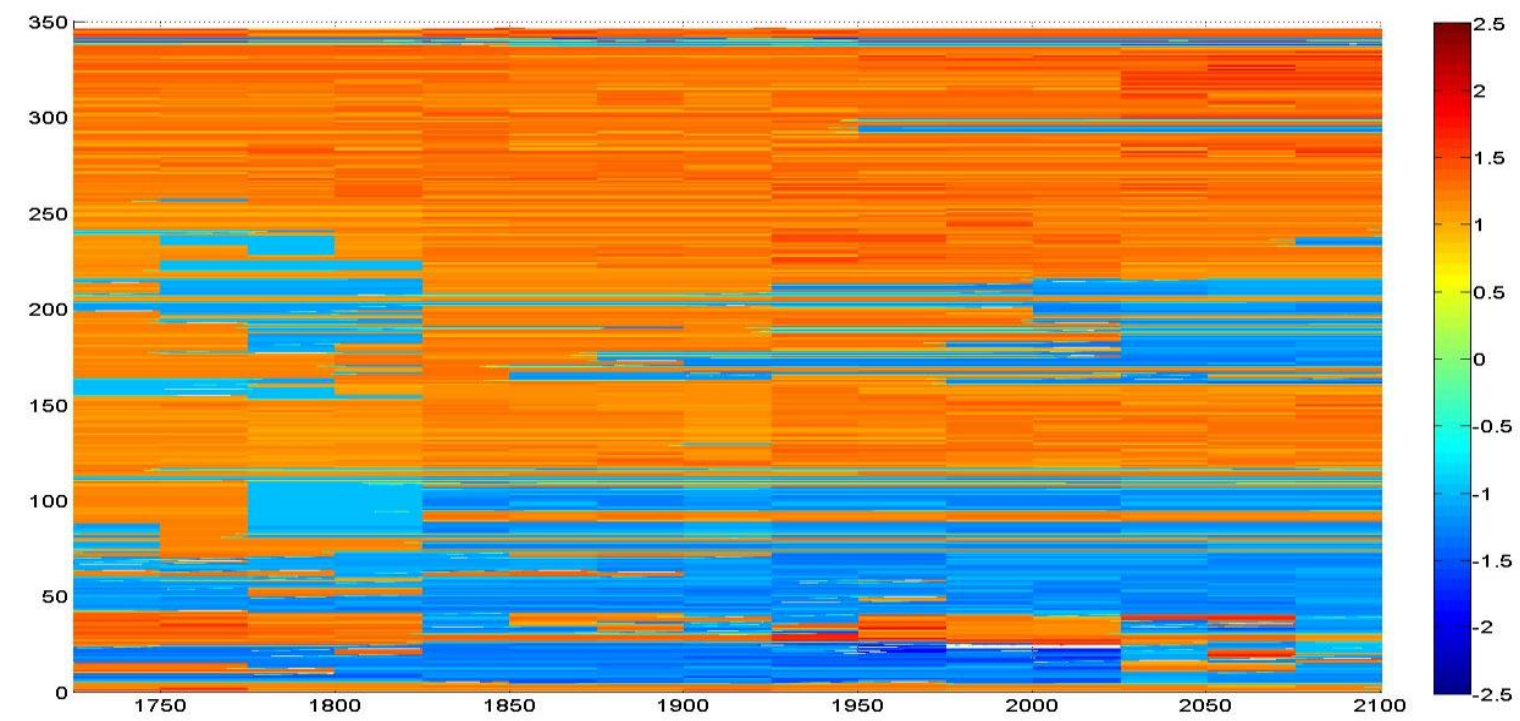

Figure 90. $C_{D}$ Variation in I-70 (Missouri-Kansas Cross Country Route), October 10 ${ }^{\text {th }}, 2011$ for Baseline Configuration with Wind Deflector at $60^{\circ}$.

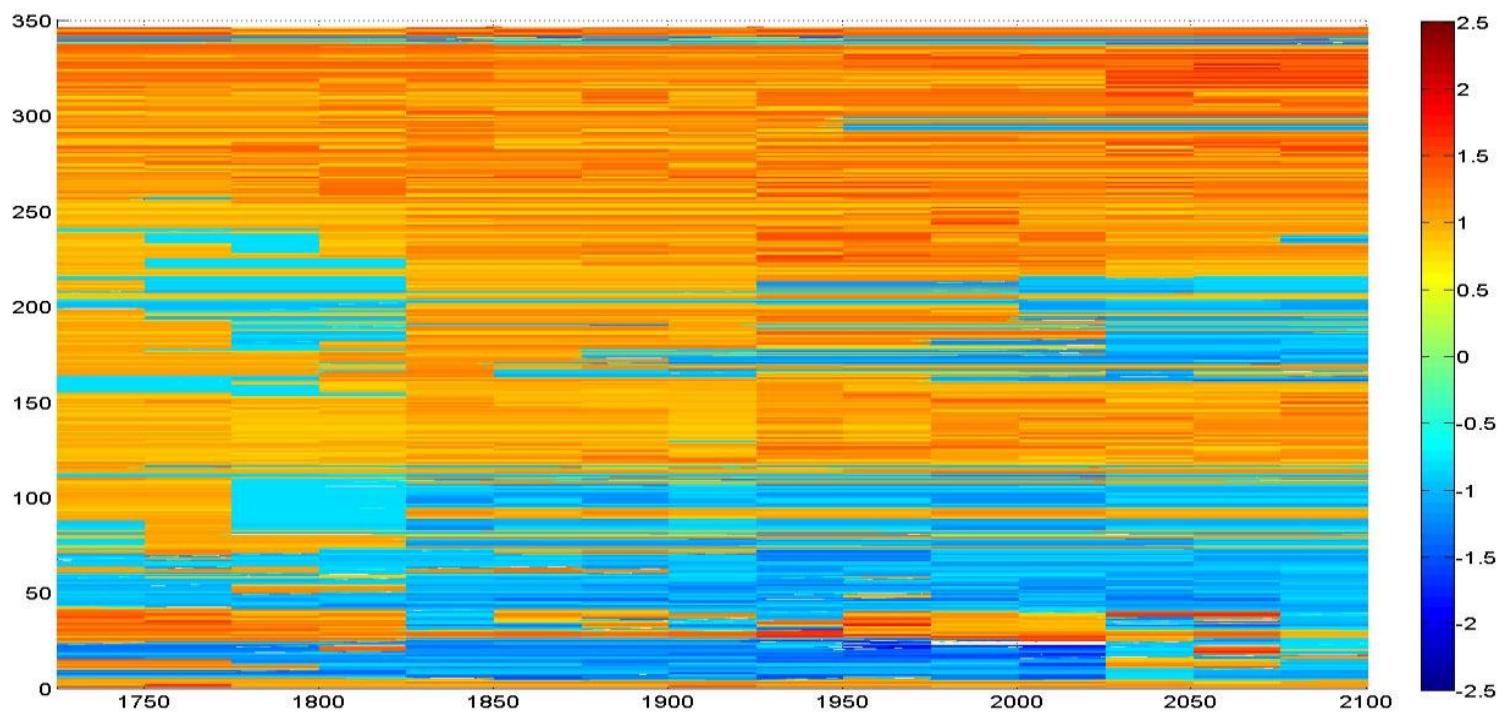

Figure 91. $C_{D}$ Variation in I-70 (Missouri-Kansas Cross Country Route), October 10 ${ }^{\text {th }}, 2011$ for Baseline Configuration with Wind Deflector at $30^{\circ}$ and Gap Fairings. 


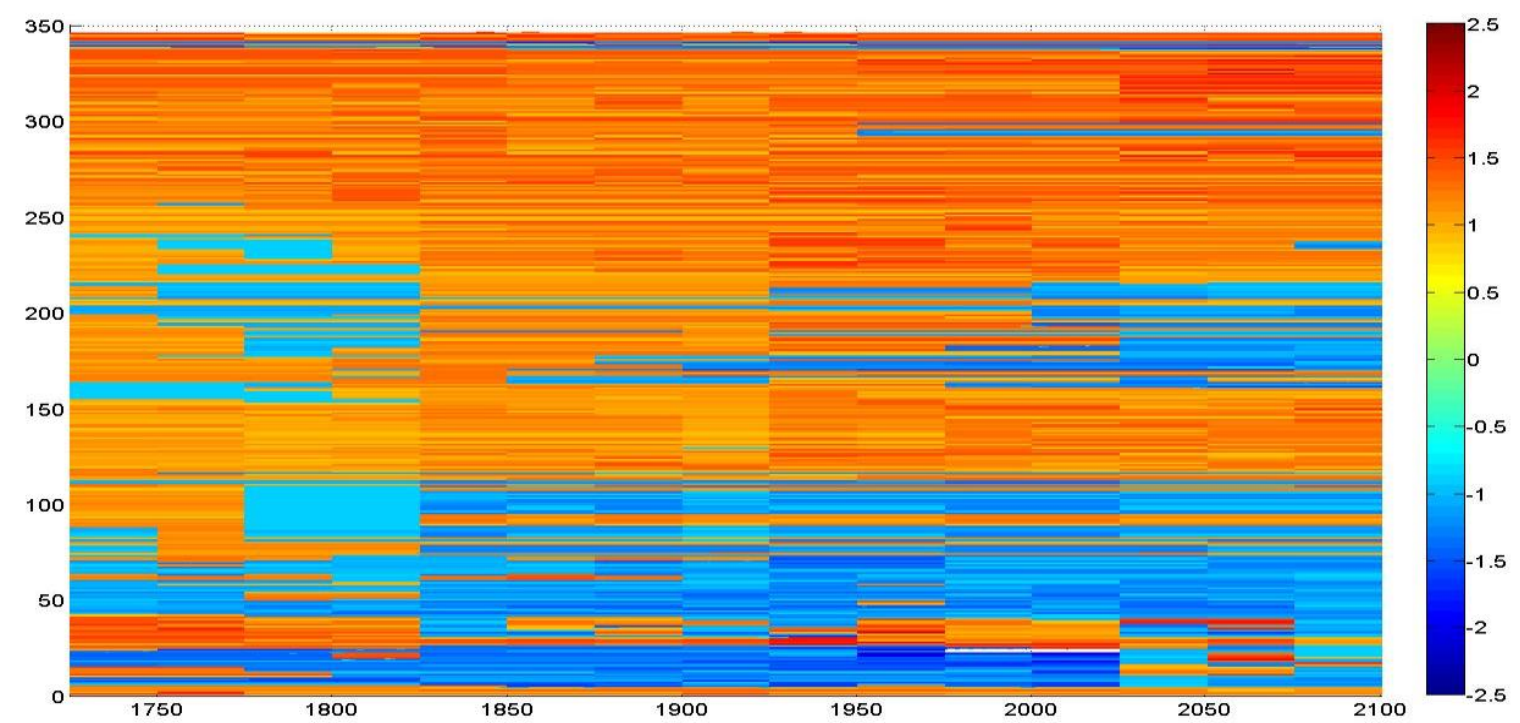

Figure 92. $C_{D}$ Variation in I-70 (Missouri-Kansas Cross Country Route), October 10 ${ }^{\text {th }}, 2011$ for Baseline Configuration with Wind Deflector at $45^{\circ}$ and Gap Fairings.

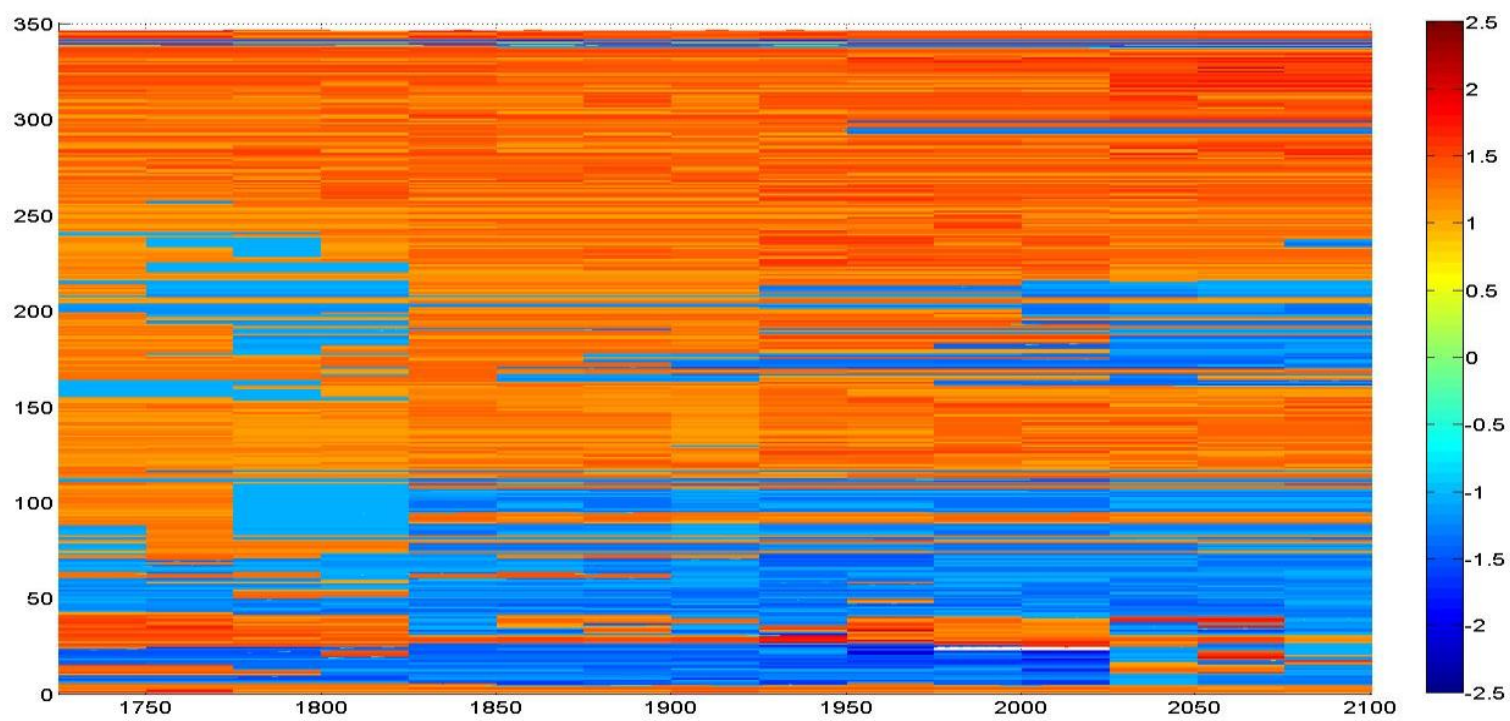

Figure 93. $C_{D}$ Variation in I-70 (Missouri-Kansas Cross Country Route), October 10 ${ }^{\text {th }}, 2011$ for Baseline Configuration with Wind Deflector at $45^{\circ}$ and Gap Fairings. 
Configuration $\mathrm{A}$ was the best recommendation given the yaw conditions on the route during this segment of the cross country travel. It is clear that the effect of on-road yaw angle differed between regions and time periods. This has a subsequent impact on the recommended aerodynamic configuration based on effectiveness. This analysis, using only two aerodynamic add on devices concluded that there are varied impacts for varied situations. Although configuration A was the recommended aerodynamic package in several situations, it is still less efficient compared to configuration B or the baseline configuration at higher yaw angles ( $7-14$ degrees).

For instance, a time based analysis for March $4^{\text {th }}, 2012$ was done assuming a vehicle which started at segment-560 on route $1-79$, travelling at $65 \mathrm{mph}$ for an hour. The transient yaw angle along its travel path was obtained.

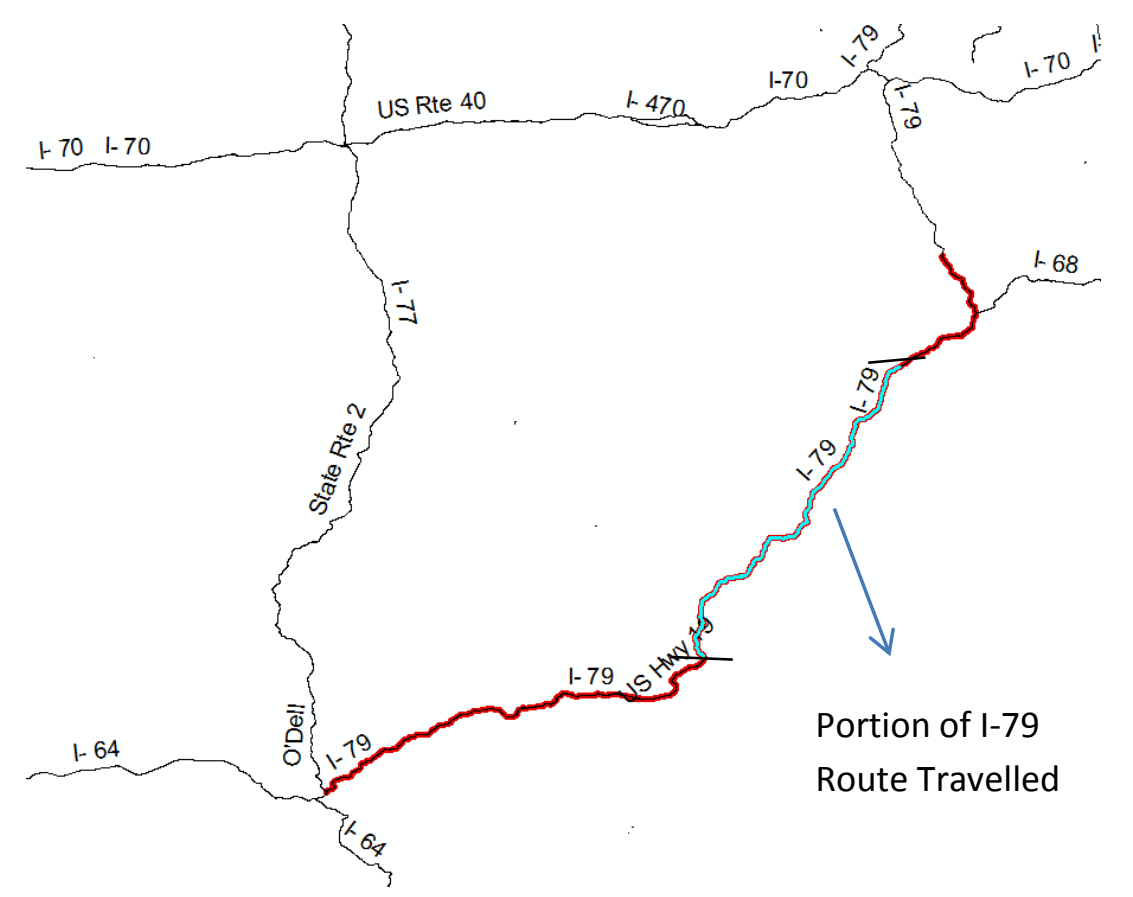

Figure 94. The Route Traced by the Vehicle with Input Starting Point and Vehicle Speed. 


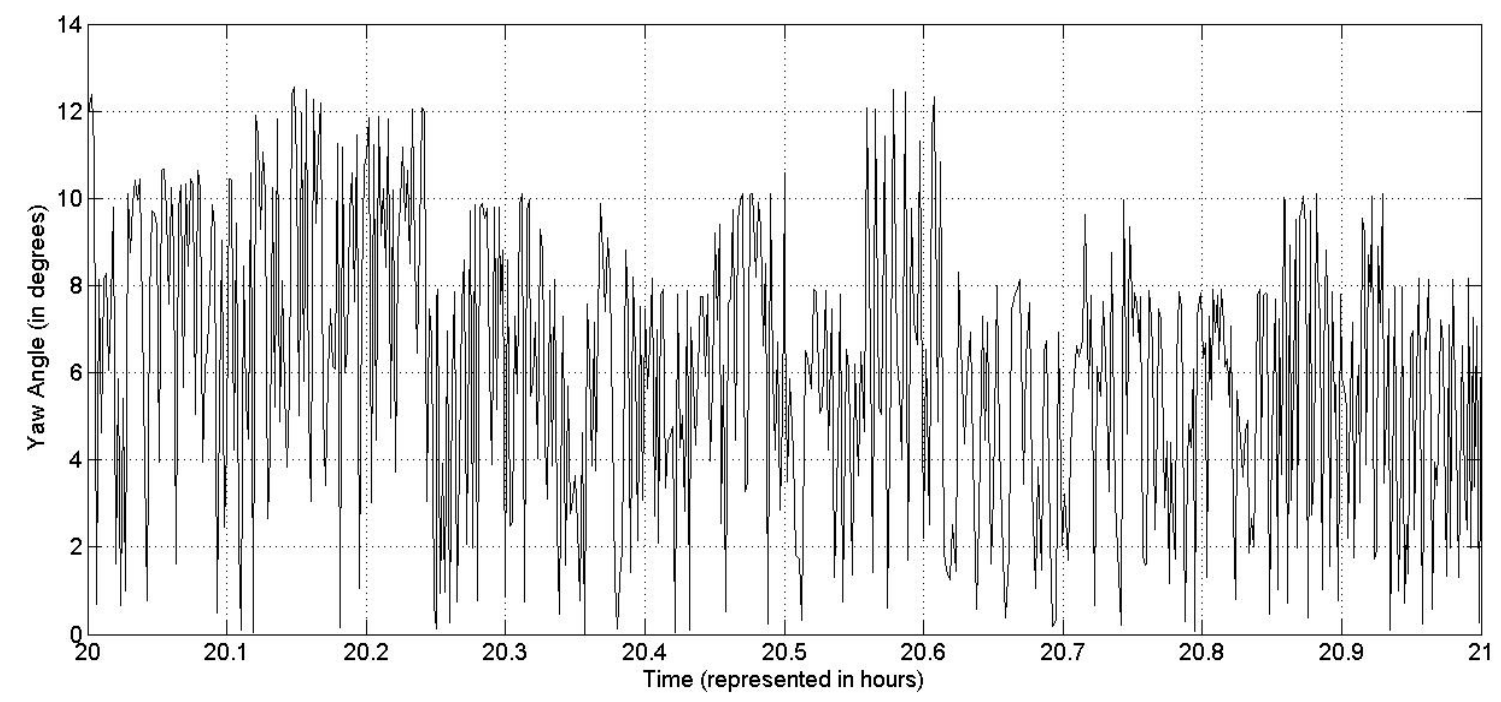

Figure 95. The Yaw Angles Experienced by the Vehicle along its Travel Path.

Configuration B or baseline configurations were the two aerodynamic package recommendations for this travel scenario. This implies that if more configurations were tested, the variations in individual and combined effectiveness of aerodynamic devices would be more varied with every device performing better than the other given its best spatial and temporal operating regime.

This analysis shows how vehicles experience varied yaw angles and consequently aerodynamic drag forces spatially and temporally. It was concluded that by making an informed decision in choosing what route to operate, at what time of the day, combined with the right choice of aerodynamic add on device could yield significant benefits. By observing the average yaw angle values and their corresponding coefficient of drag values discussed in Chapter 3.6 proved that using generic coefficient of drag values based on vehicle type as described in GEM and MOVES models may result in predicting inaccurate fuel economy or savings. The model developed in this study was based on 
the accuracy and frequency of the wind data provided by NOAA and it can be said that with improving wind forecasting models, this model can potentially be incorporated to predict continuously, accurate fuel consumption levels on vehicles.

\subsection{Impact of Variations in Velocity Used to Estimate Drag Coefficient}

Wind tunnel experiments are conducted at specified free-stream velocities and the drag coefficients are calculated based on these velocities. The velocity used to calculate the aerodynamic drag force or estimate drag coefficients in several studies [88] [89] [8] are used loosely and are not clearly defined causing a disguised barrier in interpretation. This means that the drag coefficient estimated could be under or overestimated. This reaffirms the importance to standardize the drag estimation methodology. The methodology used in this study is explained in this chapter using the forces described in Figure 29 and the accompanying illustration.

This study used the velocity, $\mathrm{V}_{\mathrm{r}}$ and force, $\mathrm{F}_{\mathrm{x}^{\prime}}$ in all the calculations. However, the true resultant force, $\mathrm{Fr}_{\mathrm{r}}$ is oriented differently and this is due to the force, $\mathrm{L}_{\mathrm{y}^{\prime}}$. This force is also referred to as side/lateral force and it skews the resultant force by an angle of ' $\alpha$ ' from $\mathrm{F}_{\mathrm{x}^{\prime}}$. The problem at hand is, which velocity should be used to determine which force in order to describe the aerodynamics of the tractor-trailers. There is no unique solution or a standardized method to this problem but it could be agreed that the truck velocity or vehicle velocity should be used uniformly since that is the most easily accessible velocity. However, this study uses, $V_{r}$ as reference velocity which factors both the vehicle speed and wind speed. The force measured is in the direction of the relative velocity $\mathrm{V}_{\mathrm{r}}$ and it does not account for the side/lateral force. This means that the values measured and calculated in this study may be overestimated than the actual quantitative values but the qualitative analysis and the inferences made, would still be 
accurate. To highlight the importance of this velocity issue, a few examples were made with arbitrary numbers. The components in Equation 7 and 8 were used for conducting the analysis in this study. Once this is available, the aerodynamic load aligned to the tractor-trailer's direction of motion may be found as a component of the overall aerodynamic load on the tractor-trailer:

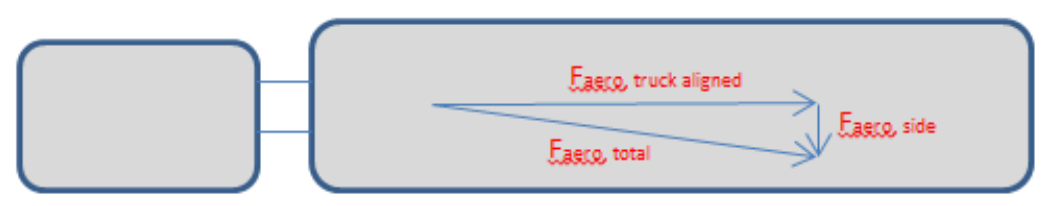

Figure 96. Vector Representation for Forces Measured and Analyzed in the Study.

With the assumption that the truck velocity and the wind velocity are known for onroad conditions and if the coordinate system is always selected such that the $\mathrm{x}$-axis is aligned directly opposing the direction of motion of the truck. Following which the calculations below were made:

\section{Example:}

$\vec{V}=24.6888 \frac{\mathrm{m}}{\mathrm{sec}} \vec{\imath}$

$$
\rho=1.223 \frac{\mathrm{kg}}{\mathrm{m}^{3}}
$$

Frontal Area $=7.153 \mathrm{~m}^{2}$

$$
\begin{aligned}
& \overrightarrow{V_{w}}=6.096 \frac{\mathrm{m}}{\sec } \vec{\imath}+7.62 \frac{\mathrm{m}}{\mathrm{sec}} \vec{\jmath} \\
& \left|\overrightarrow{V_{w}}\right|=\sqrt{\left(6.096^{2}+7.62^{2}\right)}=9.75 \mathrm{~m} / \mathrm{sec}
\end{aligned}
$$


$\theta=\cos ^{-1} \frac{6.096}{9.75}=51^{\circ}$

$V_{r}=\vec{V}+\overrightarrow{V_{w}}=30.7 \frac{m}{\sec } \vec{\imath}+7.62 \frac{m}{\sec } \vec{\jmath}$

$\left|V_{r}\right|=\sqrt{\left(30.7^{2}+7.62^{2}\right)}=31.63 \frac{\mathrm{m}}{\sec }$

$\psi=\sin ^{-1}\left(\frac{9.75}{31.63} \sin 51^{\circ}\right)=14^{\circ}$

$F_{\text {aero,truck aligned }}=C_{D}\left(14^{o}\right)\left(\frac{1}{2}\right)(1.223)\left(31.63^{2}\right)(7.153) \cos 14^{o}$

Assuming a baseline configuration, the value is $1677 \mathrm{lb}_{\mathrm{f}}$.

Based on the aerodynamic configuration chosen, this value could vary substantially.

However, it should be noted that this is just one way to represent the aerodynamic drag force on the vehicle and it is not comprehensive. It can be clearly seen that the $F_{\text {aero, total }}$ would be bigger than this value. Above all, the force values calculated do not account for side/lateral force. The force in the direction of the truck calculated here is corresponding to $F_{x^{\prime}}$ (perpendicular from $F_{x^{\prime}}$ on to $x$-axis) in Figure 29. This value of force would be lesser in magnitude along the same axis ( $x$ - axis in Figure 29) if side/lateral force was taken into account. With the assumption that the coefficient of drag in the direction in $\mathrm{F}_{\mathrm{y}}$ direction (Figure 29) is equal to 1.5 due to the side force, the net aerodynamic force accounting for the side force can be calculated.

Cross sectional side area $=55.649 \mathrm{~m}^{2}$

Slope of $F_{x^{\prime}}=d F_{y} / d F_{x}=-\left(\tan ^{-1} 14^{\circ}\right)=-4.010$ 
$d F_{y}=\left(F_{x^{\prime}} \sin 14\right)-\left((1.5)\left(\frac{1}{2}\right)(1.223)\left(7.62^{2}\right)(55.649)=-248.293 l b_{f}\right.$ (where the wind speed in $\mathrm{Y}$ direction is $7.62 \mathrm{~m} / \mathrm{sec}$ ).

$d F_{x}=-248.293 /_{-4.010}=61.918 l b_{f}$

This is a 3.7 percent decrease in the total in $F_{\text {aero, truck aligned. }}$

This shows that the side force reduces the total drag experienced by the vehicle. This is obviously subject to the wind speed impacting the vehicle but the fact that side force reduces total drag could be valuable for future aerodynamic research and development. This analysis also concludes that aerodynamic drag force can be defined in different ways and this could be misleading. For instance, the efficiency gain by reduction in $C_{D}$ values may not be as significant when side/lateral force is considered at higher yaw angles compared to aerodynamic drag reduction efficiency neglecting side/lateral force. In conclusion, defining aerodynamic drag force with respect to the vehicle and velocity used is very important.

\subsection{Conclusions and Recommendations}

This study conducted wind tunnel experiments, compared results using numerical analysis and obtained reliable coefficient of drag data. This data was used in conjunction with a spatial model built to predict on road yaw angle and the effects of on road wind and the benefits of different aerodynamic configurations were examined. The efficiencies of the different aerodynamic configurations were found to be dynamic. The truck employed with a wind deflector at 30 degrees angle (configuration 1) was observed to be very effective at low yaw angles (less than 4 degrees). Very similar efficiency was observed when a tractor-trailer gap fairing was added to configuration 1 
but at higher degrees of yaw angle, the gap fairings were detrimental to the aerodynamic drag efficiency with the increasing cross sectional area of wind exposure.

The analysis on the individual aerodynamic add on devices showed in almost all cases when the wind deflector is placed at an angle greater than 30 degrees, it has a detrimental effect on the aerodynamic efficiency of the vehicle. However, this does not mean placing a wind deflector at 35, 40 or 45 degrees is never useful. The observation is definitely subject to the truck (model) on which it is installed. Proper engineering analysis has to be considered to understand the most beneficial installation orientation. From the initial analysis of the data obtained from the wind tunnel results, the coefficient of drag values recorded increased with increasing yaw angles as expected. The rate at which the coefficient of drag increased with increasing yaw angles is noteworthy. The coefficient of drag increased at an average of 5.9 percent in the $0-5$ degrees yaw angle range and at 9.3 percent in the $10-13$ degrees range for the baseline and aerodynamic configurations with just the wind deflector. However, the coefficient of drag increased at an average of 6.1 percent in the $0-5$ degrees yaw angle range and at 12.4 percent in the $10-13$ degrees range for the aerodynamic configurations with the wind deflector and gap fairings. Several case studies were conducted in this research to further understand the on road impacts of crosswinds using the yaw angle prediction model developed in this study.

On road yaw angles which prevailed in the chosen times and areas of investigation were predicted and the corresponding coefficient of drag values were derived. The analysis concluded that yaw angles varied significantly both spatially and temporally which consequently the aerodynamic drag force experienced by the trucks travelling that route were significantly impacted. The analysis showed that the recommended choice of aerodynamic configurations varied depending on the day and time of travel and this depended on several influencing factors such as prevailing head and tail wind 
conditions, efficiencies of aerodynamic devices, vehicle speed, travel direction and road curvature (north, south, east or west bound). By making an informed decision in choosing the route, time of operation combined with the right choice of aerodynamic device could yield significant benefits. Given the transient on road impact on aerodynamic drag, the analysis concluded that using generic coefficient of drag values based on vehicle class as described in GEM and MOVES may result in inaccurate fuel savings prediction. With the help of current and future development work in developing the resolution of wind forecasting models, the model developed in this study can potentially be incorporated to predict continuously, accurate fuel consumption levels on vehicles. Future studies can focus on correlating emissions to aerodynamic drag force and on road wind conditions and thus help understand how reducing aerodynamic drag on a truck can impact emissions reductions.

The last and one of the most significant contributions of this study comes from chapter 3.8. The importance of establishing the velocity based on which drag coefficients are calculated was analyzed to expose the disguised barrier it causes in under or over estimating the drag coefficient. With the help of numerical illustrations, it was concluded that there is more than one way to represent the aerodynamic force on a vehicle. Since the tests done only measured the force in the direction of the truck, the study is not comprehensive. The side force was not measured and this lead to another discovery on the significance of side force in estimating total drag force. Another numerical analysis was conducted to analyze the side force issue and it was observed that the side force reduced the overall drag experienced by the vehicle and the magnitude of reduction could vary depending on the yaw angle and the side wind velocity. A numerical analysis showed that the total drag force would be reduced by 3.7 percent purely due to the lateral forces on the vehicle facing a $16 \mathrm{mph}$ wind at 14 degrees. Detailed studies need be conducted in this area and quantify the extent of side 
force impact at the different yaw angle ranges using wind tunnel experiments. These conclusions open new dimensions for research in the area of aerodynamic drag reduction devices. Future development studies should focus on determining the yaw angle range, wind velocity in which side force can maximize the overall drag reduction. Which can then create the platform for development of retractable aerodynamic devices to deploy based on threshold criteria. 


\section{APPENDIX I - Correction Factor for $C_{D}$}

Load Cell Calibration: Calibration was done using $1 \mathrm{lb}$ weight increments up to $5 \mathrm{lbs}$ and at $1 \mathrm{lb}$ decrements from $5 \mathrm{lbs}$ back to $1 \mathrm{lb}$. A stabilization period of 15 seconds was allowed before recording the load cell response values for each loading.

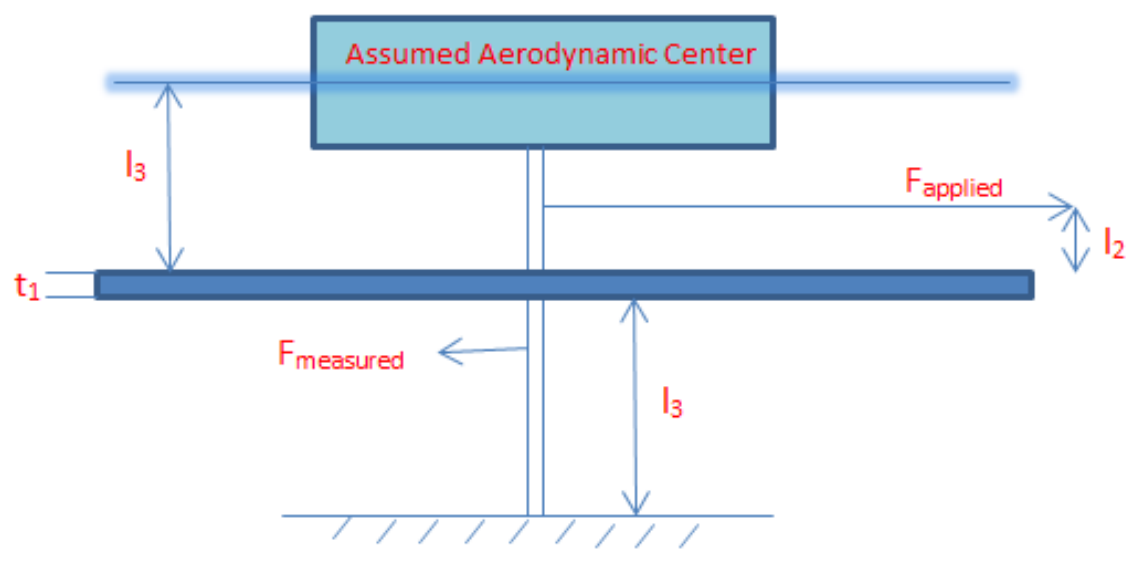

Figure 97. Force Diagram While Calculating the Load Cell Response Factor Based on Assumed Aerodynamic Center.

$\mathrm{LV}_{\mathrm{oi}}=$ Voltage recorded at no load condition

$\mathrm{LV}_{1 \mathrm{i}}=$ Voltage recorded during load after stabilization period.

$W T_{i}=$ Load applied (in Ibs)

The length and thickness follow the description in Figure 95.

$\mathrm{i}=1$ to $5 \mathrm{lbs}$.

The assumed response factor was then calculated using the formula below, 


$$
\sum_{i=1}^{5}\left(\frac{W T_{i}}{\left(L V_{1 i}-L V_{o i}\right)} \times \frac{\left(l_{1}+t_{1}+l_{2}\right)}{\left(l_{1}+t_{1}+l_{3}\right)}\right)
$$

The load cell response factor was calculated to be $18.93 \mathrm{lbs} /$ volt.

Wind Tunnel Correction Factor: The data obtained in all wind tunnel tests were subject to the correction factor obtained in this section since the correctional set up accounted for the actual aerodynamic center.

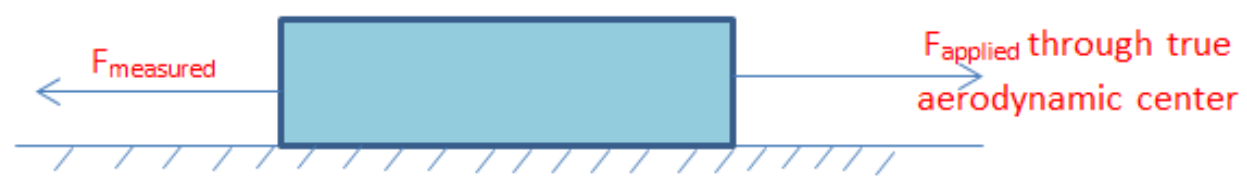

Figure 98. Force Diagram While Calculating the Load Cell Response Factor Based on Actual Aerodynamic Center.

The load cell response factor was calculated following the same procedure as before, but the response factor identified was defined as the response factor corresponding to the true aerodynamic center of the model following. The coefficient of drag is further calculated using this formula in both cases using the appropriate load cell response factors. The correction factor was calculated using the $C_{D}$ values obtained at zero degree yaw angles for all configurations as follows,

Actual response factor:

$$
\begin{gathered}
\sum_{i=1}^{5}\left(\frac{W T_{i}}{\left(L V_{1 i}-L V_{o i}\right)}\right) \\
C_{D}=\left(\frac{\text { Average Load Measured at Test Point } \times \text { Response Factor }}{q \times 5.20235 \times \text { Model Reference Width }}\right)
\end{gathered}
$$


The formula in Equation 23 was used with the assumed response factor to calculate the coefficient of drag for all configurations at all yaw angles and the same formula was used with the corrected response factor to calculate the coefficient of drag of all configurations at zero degree yaw angle. A coefficient of drag ratio was determined for each configuration using the $C_{D}$ values obtained only at zero degree yaw angle, and this correctional factor was applied to all subsequently tested yaw angles in each configuration. 


\section{APPENDIX II - Values Calculated for Numerical Simulation}

The numerical simulations were performed using COSMOS FloWorks, a commercial Computational Fluid Dynamics (CFD) package produced by Dassault Systems. The model used in this platform is referred to as Enhanced Turbulence Modeling (ETM) structure. The classical $k-\epsilon$ (turbulence-energy dissipation) turbulence model which includes the Lam-Bremhorst modification for better boundary layer profile fit when resolving boundary layers with computational meshes is integrated in this ETM structure. This is achieved by using a damping function and the modified turbulence model. The mathematical model can be viewed in COSMOS-FloWorks technical reference guide [90]. The initial turbulent kinetic energy, $k$, and its dissipation rate, $\varepsilon$, were calculated based on equations given below:-

$$
\begin{gathered}
k=\frac{3}{2}(U I)^{2} \\
\varepsilon={ }_{\mu}^{3 / 4} k^{3 / 2} / l_{\varepsilon}
\end{gathered}
$$

$U$, is the velocity magnitude or free stream velocity.

$l_{\varepsilon}$, turbulent length scale based on characteristic length.

Where, $I$ is the initial turbulence intensity (\%)

$$
=0.16(\text { Specified Reynolds Number })^{-1 / 8}
$$

Specified Reynolds number was equal to the Reynolds number values from Chapter 3.4, case I and II for low Reynolds number test and on-road Reynolds number test and free stream velocity corresponding to these Reynolds numbers were used as inputs to test 
the two cases. In this steady-state problem, the force tends to oscillate during the iterations. In order to obtain stabilization on the value determined, a convergence criterion was specified, and the iterations were continued until this criterion was attained. It was determined that if the values of subsequent iterations lay within a 1 percent difference then it would be passed a stabilized and valid result.

Criterion Satisfied for Case 1 (Chapter 3.4): Low Reynolds number test, $\left(62.761_{n} \sim 62.769_{n-1}\right) \leq\left(0.01 \times 62.769_{n-1}\right)$

Criterion Satisfied for Case 1 (Chapter 3.4): On-Road Reynolds number test, $\left(2818.552_{n} \sim 2818.549_{n-1}\right) \leq\left(0.01 \times 2818.549_{n-1}\right)$ 


\section{APPENDIX III - ERROR ANALYSIS}

A simple error analysis was performed to check the validity of the results reported in this study. The values reported in this study are all derived from averaged numbers and for the purpose of analyzing the error due to electrical noise or any other random error which may have occurred due to measurement inconsistency or any other reason, one standard deviation was used as reference. There is a two phase error analysis. The first phase accounts for the error in the calibration and response factor. The second phase analyzes the error in the computed $C_{D}$ values as a factor of both the calibration factor error and the measurement error (error propagation).

Equation 21 was recalculated with \pm 1 standard deviation $\left(\sigma_{\mathrm{i}}\right)$ for $L \mathrm{~V}_{1 \mathrm{i}}$ and $L \mathrm{~V}_{0 \mathrm{i}}$.

$$
\sum_{i=1}^{5}\left(\frac{W T_{i}}{\left(L V_{1 i} \pm \sigma_{i}\right)-\left(L V_{o i} \pm \sigma_{i}\right)} \times \frac{\left(l_{1}+t_{1}+l_{2}\right)}{\left(l_{1}+t_{1}+l_{3}\right)}\right)
$$

The value obtained from Equation 24 varied from the average load cell response factor calculated in Equation 21 by \pm 0.36 percent. This deviation was then carried over to Equation 23 to calculate the total deviation with one standard deviation in the actual response factor used to calculate $C_{D}$ values.

Now, in the seconds phase, Equation 23 was recalculated using one standard deviation for the load measured at each test point and the carried over \pm 0.36 percent deviation of the load cell response factor. Since there are a total of 91 ( 7 configurations $\times 13$ yaw angles) datasets of test points, a worst case scenario was chosen to calculate and represent the deviation. It was assumed that the magnitude of deviation will be highest when the value of load measured by the load cell is highest inside the tunnel. This scenario was encountered for configuration 6. 
Percentage deviation of load measured at test point

$$
=\operatorname{Max}\left\{{ }_{y=1}^{13}\left(\frac{\sigma_{y}}{\text { Average }_{y}} \times 100\right)\right\}=3.4 \text { percent }
$$

Now, using equations 23,24 and 25 , applying this maximum deviations to the average load measured at test point and the response factor, the deviation in $C_{D}$ was estimated,

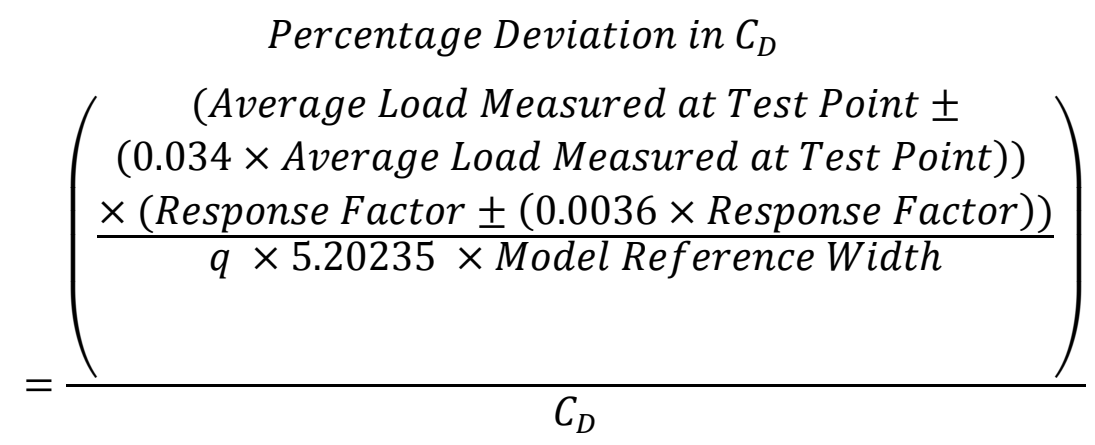

This value was estimated to be \pm 1.32 percent. 


\section{APPENDIX IV - Python Code for Calculating Transient Yaw Angles from User Defined Input Parameters}

The script was written in Python and was working in conjunction with MS-Excel, ArcGIS 10.1, ArcCatalog 10.1. A geodatabase to store results, retrieve temporary files and access source files was created prior to running the script.

\#\# This script takes wind data, works on it one month/day/hour at a time and runs a series of spatial joins to merge

\#\# That data with a segmented version of any chosen route.

import arcpy

import math

import csv

\#WORKSPACE-WIND SOURCE FILE LOCATION\#

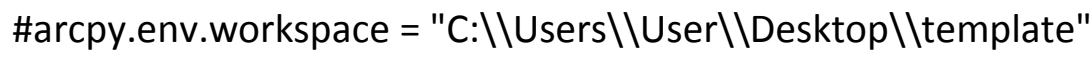

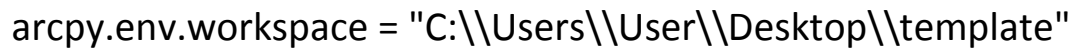

\#OUTPUT STORAGE AND DATABASE SOURCE LOCATION\#

\#ws = "C:\|Users\\User\|Desktop\|template"

ws = "C:\\Users \\User \|Desktop\\template"

\#GEODATABASE LOCATION\#

outputWS = ws+"\|testing.gdb"

\#OUTPUT PREFIX\#

\#prefix = "u2005"

prefix = "u2013" 


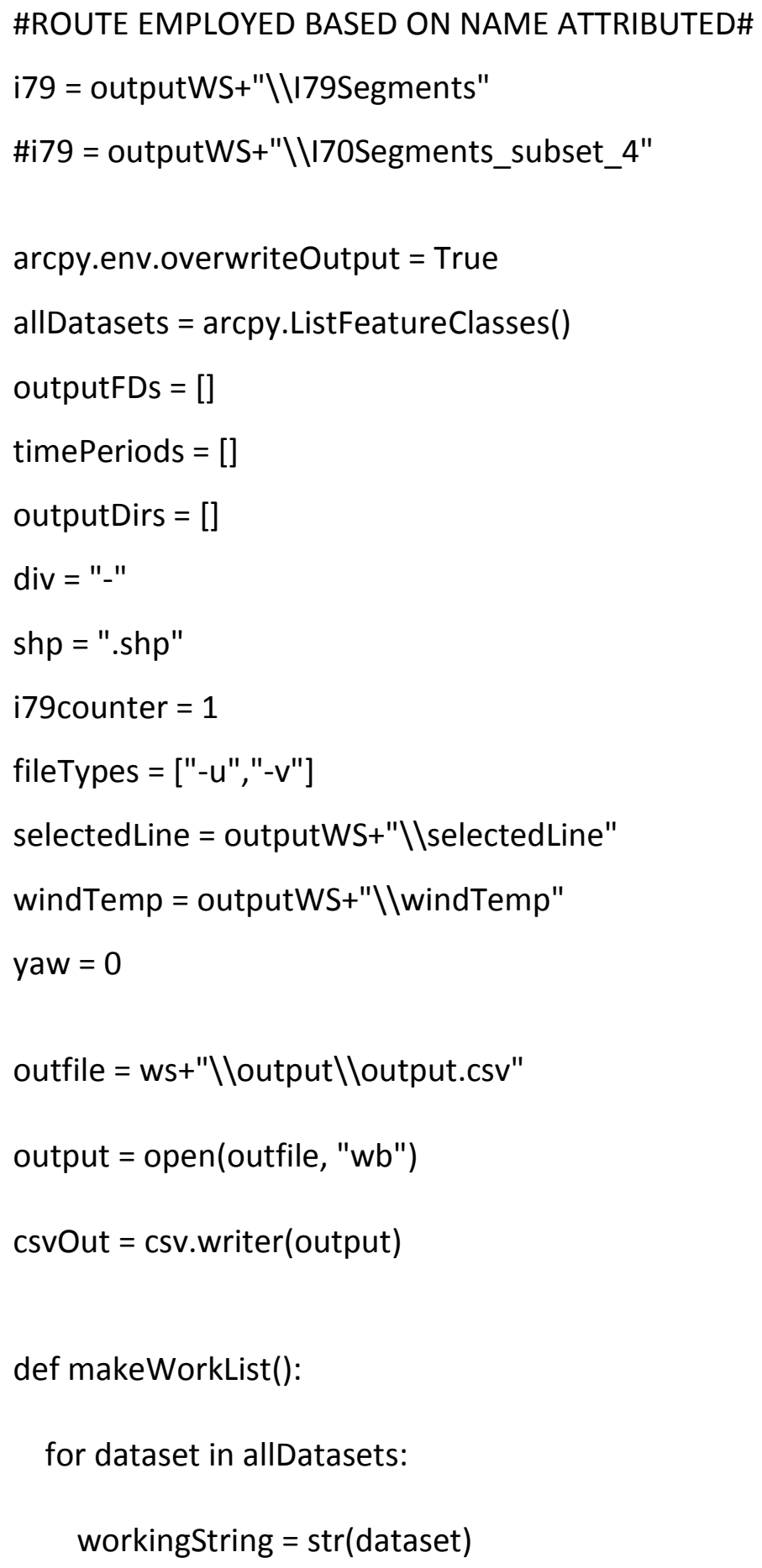


testOutputFD = workingString $[5: 9]$

print "checking FD: "+testOutputFD

if testOutputFD not in outputFDs:

outputFDs.append(testOutputFD)

testTimePeriod $=$ workingString[10:14]

print "checking TP: "+testTimePeriod

if testTimePeriod not in timePeriods:

timePeriods.append(testTimePeriod)

def union():

makeWorkList()

\#\# each outFD is 4 digits

for outFD in outputFDs:

print "I am working on outputFD: "+outFD

\#\# each timeP is 4 digits, military hours - $\mathrm{HHHH}$

for timeP in timePeriods:

print "I am working on timePeriod: "+timeP

union1 = prefix+outFD+div+timeP+fileTypes[0]+shp

union2 = prefix+outFD+div+timeP+fileTypes[1]+shp 


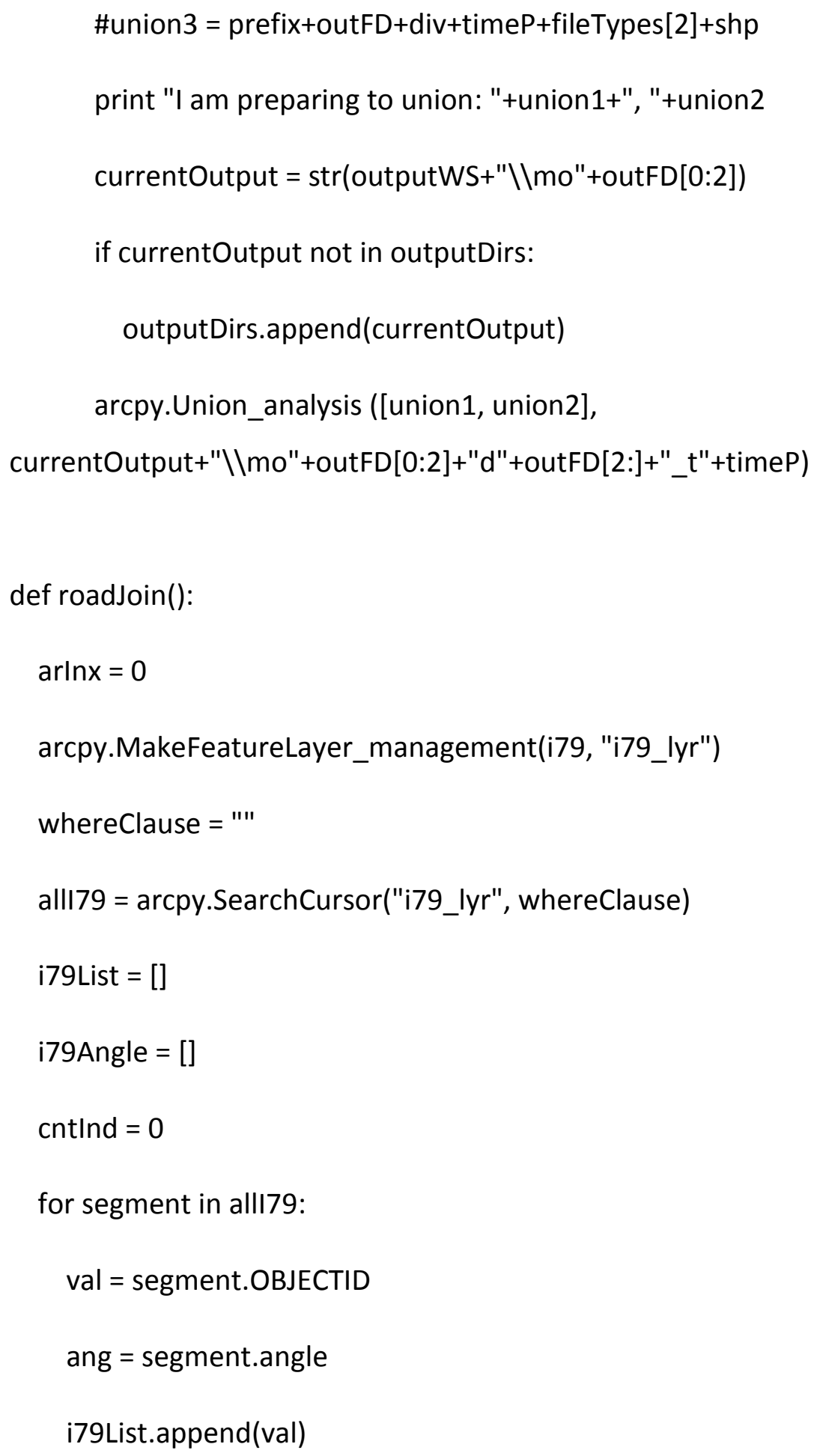


i79Angle.append(ang)

for direct in outputDirs:

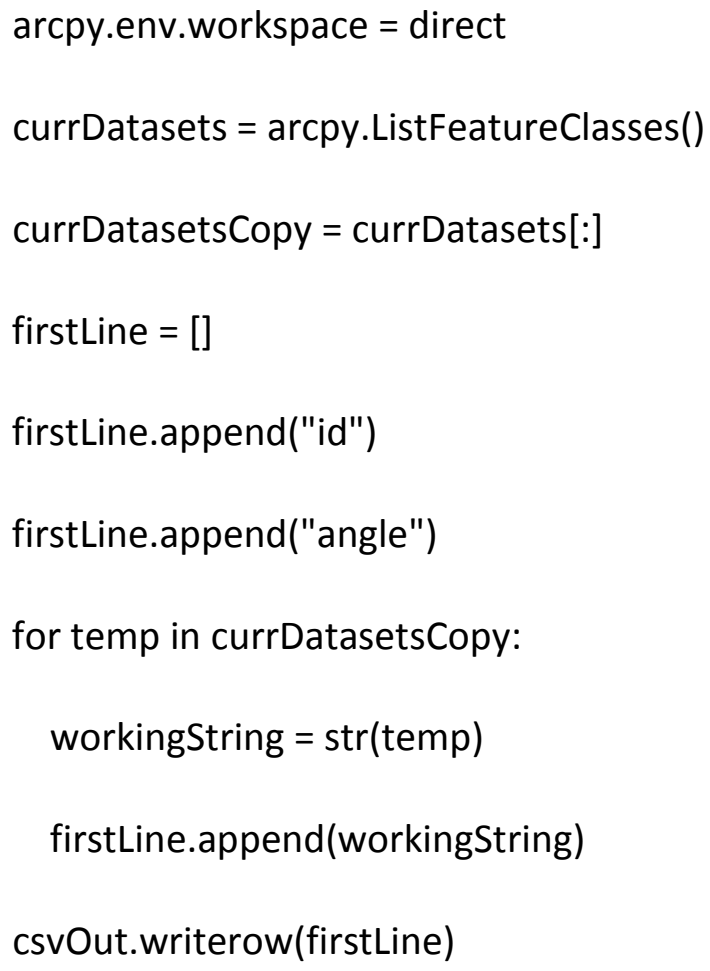


print "I am working on I-79 segment number "+str(idVal)+" which has an angle of "+str(segAngle)

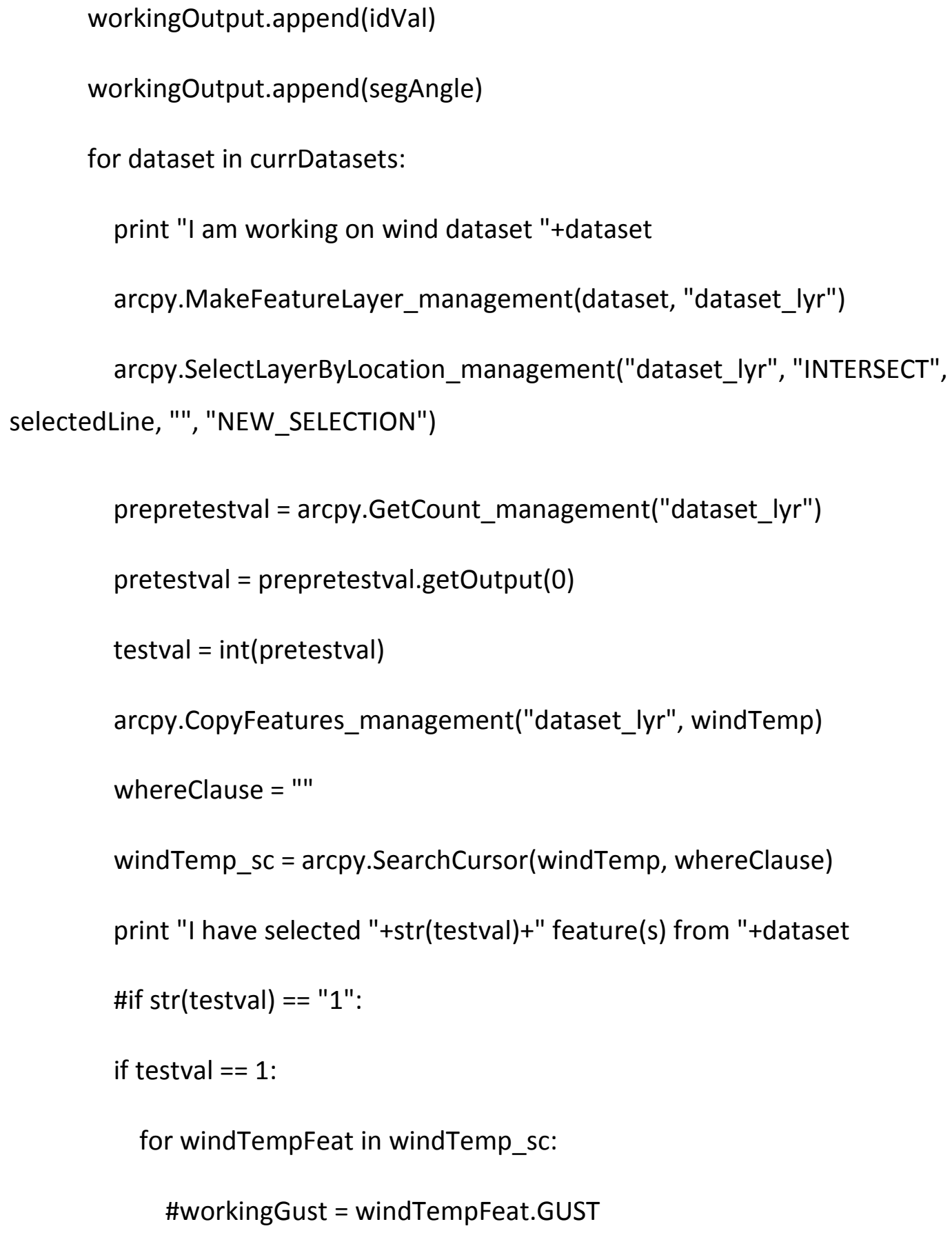


workingU $=$ windTempFeat.UGRD

workingV = windTempFeat.VGRD

print "I found a UGRD of "+str(workingU)+", and a VGRD of "+str(workingV)

else:

print "I found multiple selections."

counter $=0$

$\mathrm{tU}=[]$

$\mathrm{tV}=[]$

summing $=0$

summing $2=0$

for windTempFeat in windTemp_sc:

workingU $=$ windTempFeat.UGRD

tU.append(workingU)

print "I found this U: "+str(workingU)

workingV $=$ windTempFeat.VGRD

tV.append(workingV)

print "I found this V: "+str(workingV)

for $\mathrm{U}$ in $\mathrm{tU}$ :

summing $+=U$ 


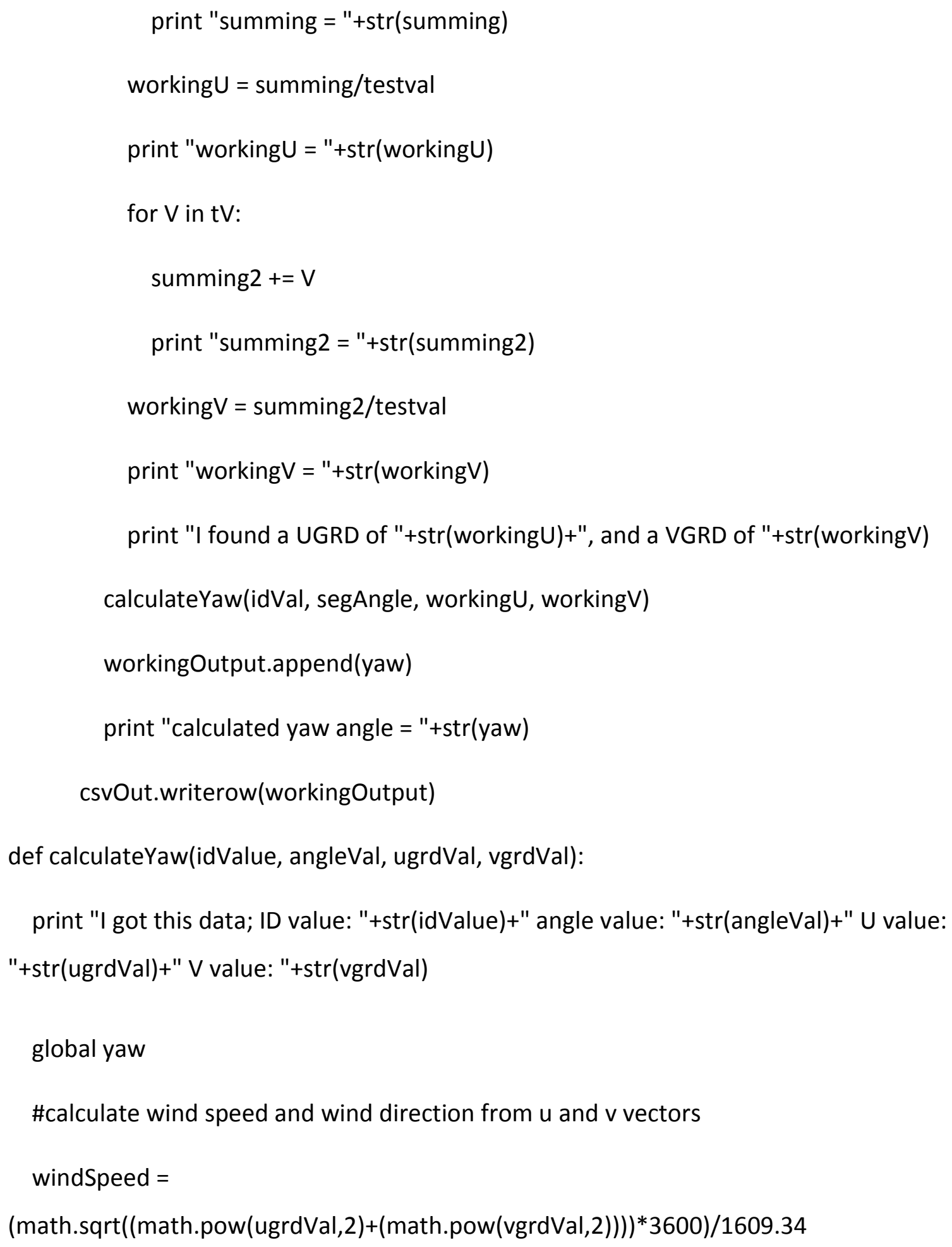




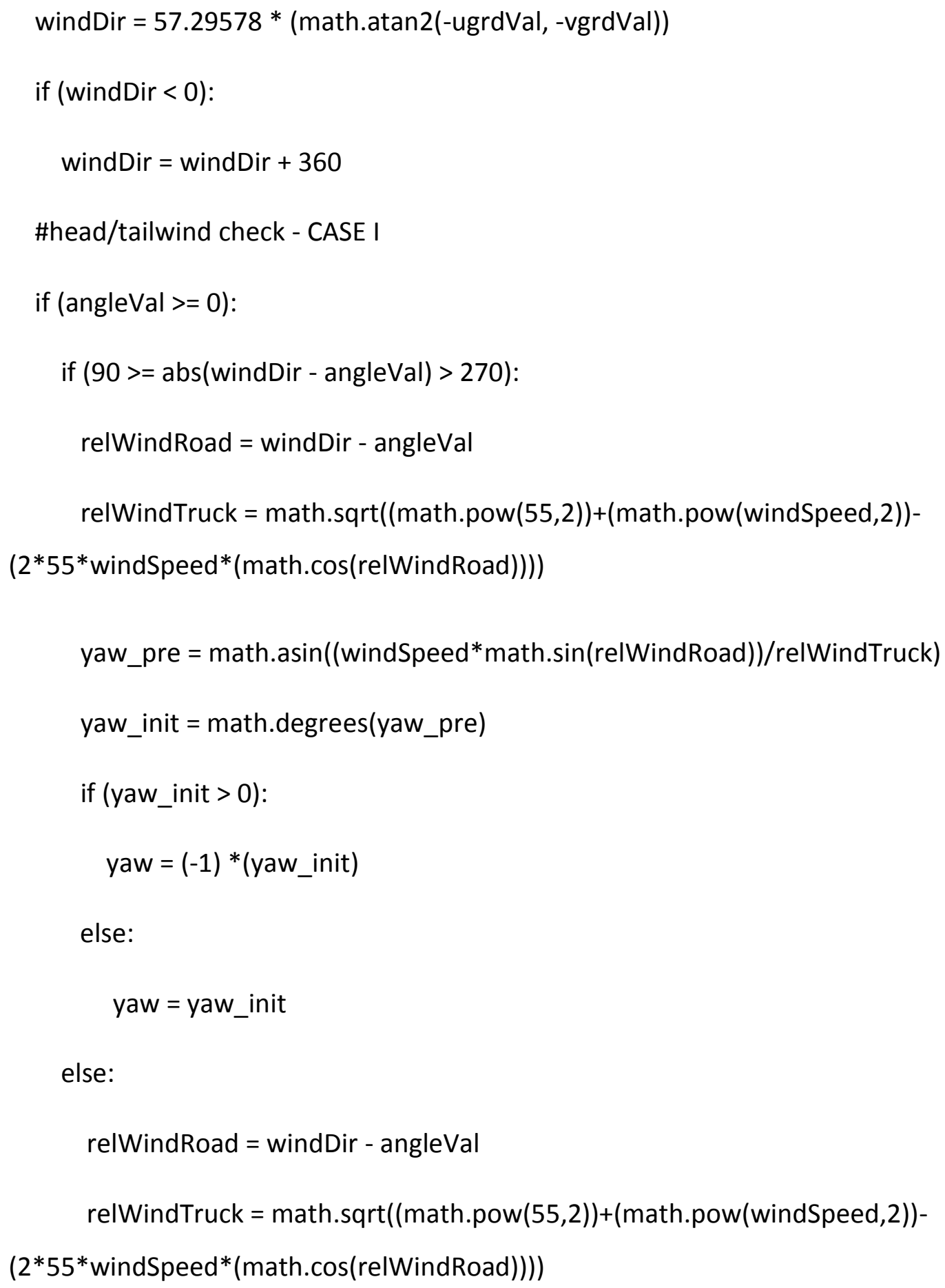




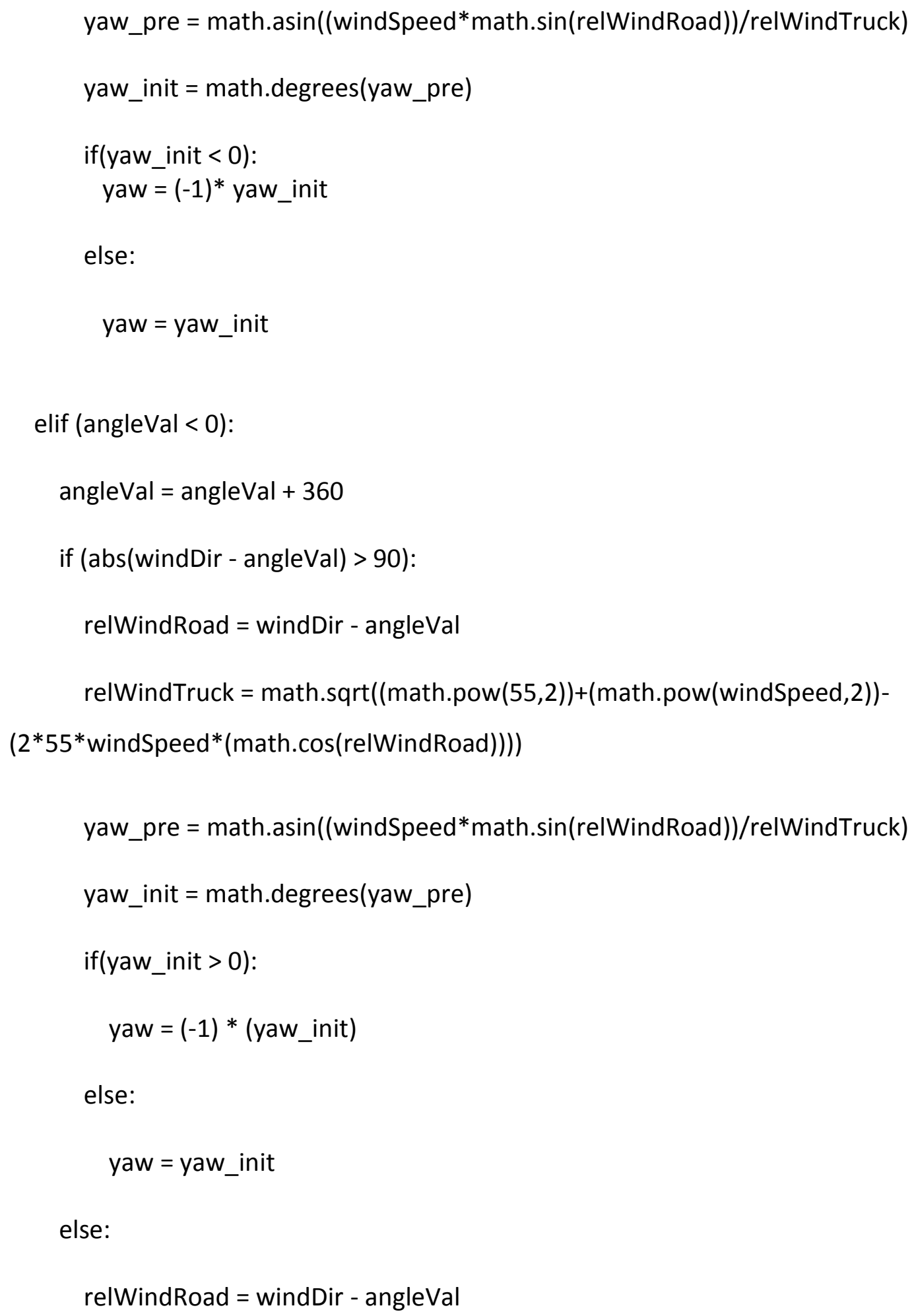


relWindTruck $=$ math.sqrt $(($ math.pow $(55,2))+($ math.pow $($ windSpeed, 2$))-$ $(2 * 55 *$ windSpeed*(math.cos(relWindRoad $))))$

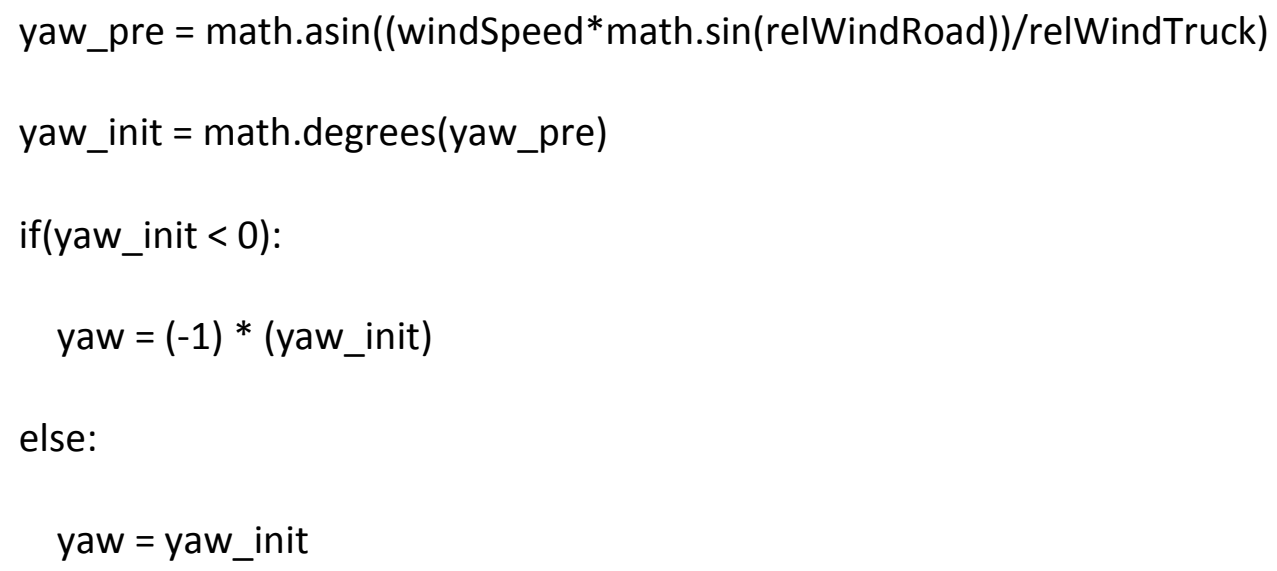




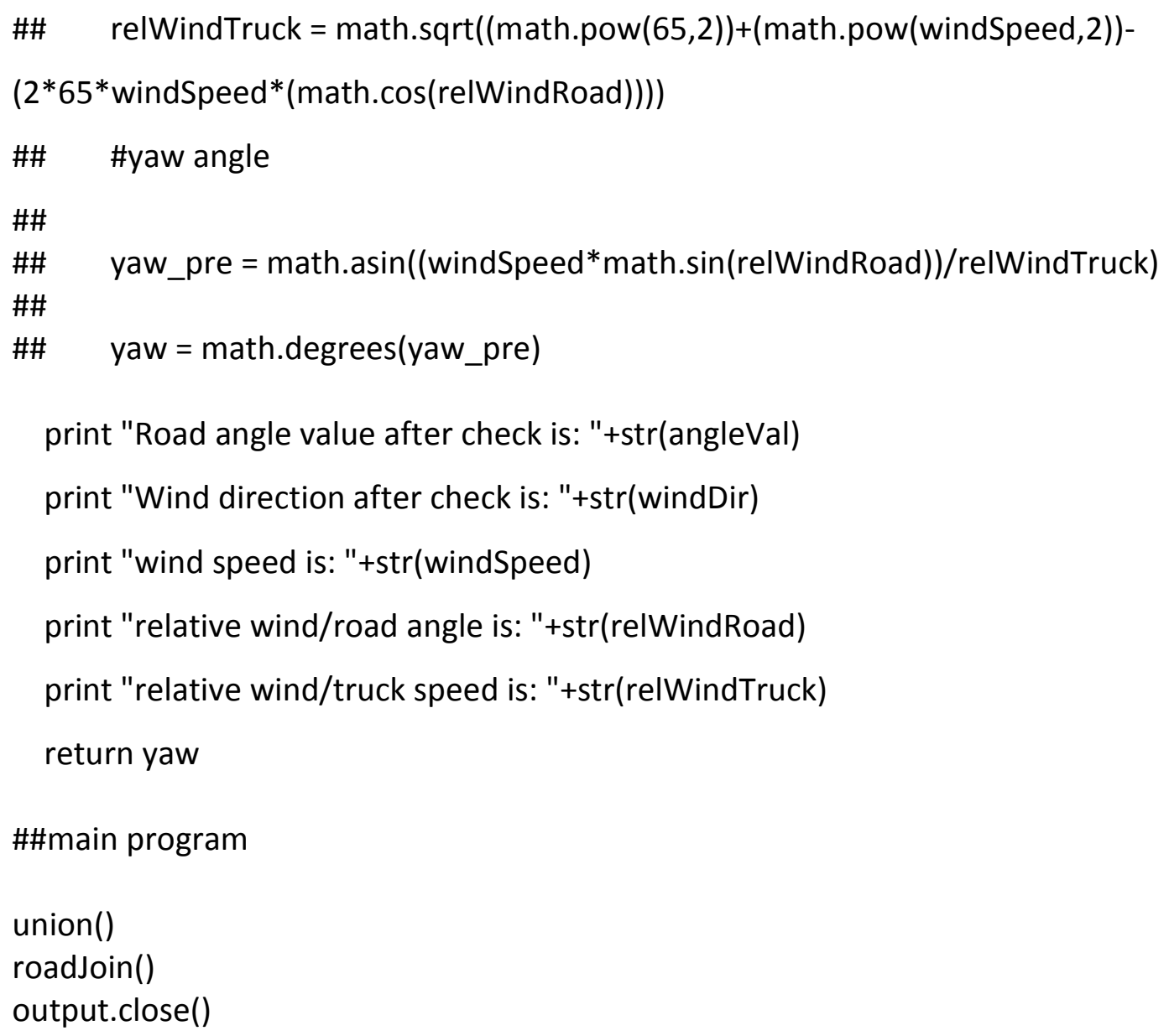




\section{References}

[1] American Transportation Research Institute. (Accessed - December, 2012) Critical Issues In the Trucking Industry. http://www.atri-online.org/2011_top_industry_issues.pdf [Online].

[2] Office of Transportation and Air Quaility, "Paving the Way Toward Cleaner, More Efficient Trucks," Office of Transportation and Air Quality, Regulatory Announcement EPA-420-F-11032, 2011.

[3] Sumon K. Sinha, "Improving Fuel Efficiency of Tractor Trailer Trucks with Deturbulator Aero-Drag Reduction," in SAE Commercial Vehicle Engineering Congress \& Exhibition, Chicago, SAE Technical Paper 2008-01-2602, 2008, DOI: 10.4271/2008-01-2602.

[4] US Department of Energy. (2013, January) Research and Development Opportunities for Heavy Trucks.

http://www1.eere.energy.gov/vehiclesandfuels/pdfs/truck_efficiency_paper_v2.pdf. [Online].

[5] Robert Bosch, Automotive Handbook, 4th ed., Society of Automobile Engineers, Ed. Warrendale, PA: Society of Automobile Engineers, 1996.

[6] Jeffrey Ang-Olson and Will Schroeer, "Energy Efficiency Strategies for Freight Trucking: Potential Impact on Fuel Use and Greenhouse Gas Emissions," Transportation Research Record: Journal of the Transportation Research Board, vol. 1815, no. 2002 Energy, Air Quality, and Fuels, pp. 11-18, January 2007.

[7] Richard Drollinger, "Heavy Duty Truck Aerodynamics," Warrendale, PA, SAE report ISBN 089883-959-9, 1987.

[8] Bruce L. Storms, James C. Ross, and Lee Slezak, "Aerodynamic Drag Reduction of the Underbody of a Class-8 Tractor-Trailer," in SAE Commercial Vehicle Engineering Congress \& Exhibition, Illinois, 2006-01-3532, 2006.

[9] Subrata Roy and Pradeep Srinivasan, "External Flow Analysis of a Truck for Drag Reduction," SAE International Journal of Commercial Vehicles, vol. 109, no. 2, pp. 808-812, 2000-01-3500, 2000.

[10] Richard M. Wood and Steven X.S. Bauer, "Simple and Low-Cost Aerodynamic Drag Reduction Devices for Tractor-Trailer Trucks," SAE International Journal of Commercial 
Vehicles, vol. 112, no. 2, pp. 143-160, 2003-01-3377, 2003.

[11] Kambiz Salari, Jason Ortega, Paul Castelucci, and Lee Sleezak, "Heavy Duty Flow Conditioning: Application to the Tractor/Trailer Gap and Trailer Base," U.S. Department of Energy - Energy Efficiency and Renewable Energy, Washington, DC, Annual Progress Report FY-2006, 2007.

[12] Richard Drollinger, "Heavy Duty Truck Aerodynamics," SAE report ISBN 0-89883-959-9, 1987.

[13] Bharadwaj Sathiamoorthy, Nigel Clark, Matthew Robinson, and Evan Fedorko, "Investigation of On-Road Crosswind Impact on Interstate Tractor-Trailer Aerodynamic Efficiency," in SAE 2014 World Congress and Exhibition, Vehicle Aerodynamics: Commercial Vehicles, SAE Technical Paper No. 2014-01-0608.

[14] Bharadwaj Sathiamorothy, Nigel Clark, and Evan Fedorko, "Methodology to Predict Real World Aerodynamic Drag Losses Due to On-Road Cross-Wind Effects," in 23rd CRC Real World Emissions Workshop, San Diego, CA, 2013.

[15] California Environmental Protection Agency, "Tractor-Trailer Greenhouse Gas Regulation," Air Resource Board, Sacramento, CA, Advisory 429, 2011.

[16] Tobias Muster, "Fuel Savings Potential and Costs Considerations for US Class 8 Heavy Duty Trucks through Resistance Reductions and improved Propulsion Technologies until 2020," Massachuesetts Institute of Technology, Massachuesetts, MIT-EL 00-001, 2000.

[17] National Research Council, "Review of U.S. Department of Energy's Heavy Vehicle Technologies Program," Commission on Engineering and Technical Systems, Washington , D.C. 2000.

[18] National Highway Traffic Safety Administration, "NHTSA Tire Fuel Efficiency Consumer Information Program Development: Phase 2 - Effects of Tire Rolling Resistance Levels on Traction, Treadwear, and Vehicle Fuel Economy," U.S. Department of Transportation, Washington, DC, Technical Report DOT HS 811 154, 2009.

[19] Energy and Environmental Analysis, "Analysis of Heavy Duty Truck Fuel Efficiency to 2001," Environmental Protection Agency, 1991. 
[20] U.S. Department of Energy, "21st Century Truck Partership: Roadmap and Technical White Papers," Energy Efficiency and Renewable Energy, Technical 21CTP-0003, 2006.

[21] Michael Ogburn, Laurie Ramorth, and Amory Lovins, "Transformational Trucks: Determining the Energy Efficiency Limits of a Class-8 Tractor-trailer," Rocky Mountain Institute, Technical 2008.

[22] National Academy of Sciences, "Technologies and Approches to Reducing the Fuel Consumption of Medium- and Heavy Duty Vehicles.," National Research Council, Washington, D.C., 0-309-14982-7, 2001.

[23] Byron Bunker, Houshun Zhang, Byungho Lee, and Suduk Lee, "Integrated Virtual Lab in Supporting Heavy Duty Engine and Vehicle Emision Rulemaking," U.S. Department of Energy, U.S. EPA, DEER Conference Presentation 2011.

[24] Rose McCallen, Fred Browand, and James Ross, The Aerodynamics of Heavy Vehicles: Trucks, Buses, and Trains, 19th ed., James Ross, Ed.: Springer, 2004.

[25] Frank White, Viscous Fluid Flow, 3rd ed., Frank White, Ed.: Tata McGraw-Hill Education, 1974.

[26] Bryan Thwaites and R.E. Meyer, "Incompressible Aerodynamics," Journal of Applied Mechanics, vol. 27, no. 4, p. 760, 1960.

[27] G.L. Larose and A.D. Auteuil, "On the Reynolds number sensitivity of the aerodynamics of bluff bodies with sharp edges," Journal of Wind Engineering and Industrial Aerodynamics, vol. 94, no. 5, pp. 365-376, May 2006.

[28] Kevin Cooper, "Commercial Vehicle Aerodynamic Drag Reduction: Historical Perspective as a Guide," in The Aerodynamics of Heavy Vehicles: Trucks, Buses, and Trains, Rose McCallen, Fred Browand, and James Ross, Eds., 2004, ch. Applied and Computational Mechnanics Vol. 19, p. 11.

[29] Louis Steers and Lawrence Montoya, "Study of Aerodynamic Drag Reduction on a Full-Scale Tractor-trailer," Transportation Systems Center, DOT Technical Report DOT-TSC-OST-76-13, 1976.

[30] Wiley Sherwood, "Wind Tunnel Test of Trailmobile Trailers," University of Maryland, 
College Park, MD, Report No. 85, 1974.

[31] Selden Walter Saunders, "Drag Reducer for Land Vehicles," Grant US 3697120 A, November 3, 1969.

[32] Edwin Saltzman and Robert R Meyer, "A Reassessment of Heavy-Duty Truck Aerodynamic Design Features and Priorities," NASA, Edwards, CA, Report no. 206574, 1999.

[33] Kevin Cooper, "A Wind Tunnel Investigation into the Fuel Savings Available from the Aerodynamic Drag Reduction of Trucks," DME/NAE Quarterly Bulletin No. 1976(3), vol. 3, 1976.

[34] F.T. Buckley, C.H. Marks, and W.H. Walston, "A Study of Aerodynamic Methods for Improving Truck Fuel Economy," Maryland University, College Park, Technical Report No. PB80-101272, 1978.

[35] Kevin Cooper, "The Wind Tunnel Testing of Heavy Trucks to Reduce Fuel Consumption," in SAE Commercial Vehicle Engineering Congress \& Exhibition, SAE Technical Paper 821285, 1982, doi:10.4271/821285.

[36] Robert Englar, "Advanced Aerodynamic Devices to Improve the Performance, Economics, Handling and Safety of Heavy Vehicles," in SAE International Government/Industry Meeting, Warrenale, PA, SAE Technical Paper 2001-01-2072, 2001, doi:10.4271/2001-012072.

[37] M Gohlke, J Beaudoin, M Amielh, and F Anselmet, "Experimental Analysis of Flow Structures and Forces on a 3-D Bluff Body in Constant Cross-Wind," Experiments in Fluids, vol. 43, no. 4, pp. 579-594, October 2007.

[38] Fred Browand and Rose McCallen, The Aerodynamics of Heavy Vehicles II: Trucks, Buses and Trains, James Ross, Ed.: Springer, 2009.

[39] Xiaolong Yang and Jixiang Tang, "The Effects of Truck Structure on the Aerodynamic Drag and Optimization," Applied Mechanics and Materials, vol. 224, pp. 138-141, November 2012.

[40] Sighard Hoerner, Fluid Dynamic Drag, 2nd ed.: Hoerner Fluid Dynamics, 1965. 
[41] Wolf-Heinrich Hucho et al., Aerodynamics of Road Vehicles, 4th ed., Wolf-Heinrich Hucho, Ed. Warrendale, PA: SAE, 1998.

[42] Department of Energy, "Multiyear Program Plan for 1998-2002," Office of Heavy Duty Technology and Heavy Vehicle Industry Partners, Technical DOE/ORO-2071, 1998.

[43] James Ehlbeck and Michael Mayenburg, "Increasing Heavy-Duty Truck Fuel Economy," in International Truck and Bus Meeting and Exposition, SAE Technical Paper 912662, 1991, doi:10.4271/912662.

[44] Bahram Khalighi, S Zhang, C Koromilas, and S Balkanyi, "Experimental and Computational Study of Unsteady Wake Flow Behind a Bluff Body with a Drag Reduction Device," International Journal of Commercial Vehicles, vol. 110, no. 6, pp. 1209-1222, 2001.

[45] Environmental Protection Agency, "Using MOVES to Prepare Emission Inventories in State Implementation Plans and Transportation Conformity," Office of Transportation and Air Quality, Technical EPA-420-B-12-028, 2010.

[46] Environmental Protection Agency, "Proposed Rulemaking to Establish Greenhouse Gas Emissions Standards and Fuel Efficiency Standards for Medium- and Heavy-Duty Engines and Vehicles," Office of Transportaion and Air Quality, Technical EPA-420-D-10-901, 2010.

[47] Environmental Protection Agency, "Heavy-Duty Engine and and Vehicle, and Nonroad Technical Amendments; Final Rule," Department of Transportation: 49 CFR Parts 523 and 535, vol. 78, no. 116, June 2013.

[48] Environmental Protection Agency, "Greenhouse Gas Emissions Standards and Fuel Efficiency Standards for Medium-and Heavy-Duty Engines and Vehicles," 49 CFR Part 523, 534 and 535, vol. 76, no. 179, September 2011.

[49] R Giannelli et al., "Hevay-Duty Diesel Vehicle Fuel Consumption Moedling Based on Road Load and Power Train Parameters," in SAE Commercial Vehicle Engineering Conference, Illinois, Jan. 2005-01-3549, 2005.

[50] V Petrushov, "Coast Down Method in Time-Distance Variables," SAE Special PublicationSAE Transactions, vol. 106, no. 6, pp. 663-685, SAE 970408, 1997.

[51] Environmental Protection Agency, "Fuel Consumption Modelling of Conventional and Advanced Technology Vehicles in the Physical Emission Rate Estimator (PERE)," Office of 
Transportation and Air Quality, Technical EPA420-P-05-001, 2005.

[52] International Bussines Machines Corporation. (Accessed - December, 2013) IBM 1800 for Wind Tunnel Data Acquisition. http://www.ieeeghn.org/wiki/images/6/6f/AppWindTunnel.pdf [Online].

[53] R.D. Mehta, "The aerodynamic design of blower tunnels with wide-angle diffusers," Progress in Aerospace Sciences, vol. 18, pp. 59-120, 1979.

[54] P Bradshaw and R.C. Pankhurst, "The design of low-speed wind tunnels," Progress in Aerospace Sciences, vol. 5, pp. 1-69, 1964.

[55] Jewel Barlow, William Rae, and Alan Pope, Low-Speed Wind Tunnel Testing, 3rd ed., Jewel Barlow, Ed. New York: Wiley-Interscience, 1999.

[56] Bjorn Lindgren and Arne Johansson, "Design and Evaluation of a Low-Speed Wind Tunnel with Expanding Corners," Royal Institute of Technology, Stockholm, Sweden, Technical Report 2002.

[57] SAE Standards J1252, "SAE Wind Tunnel Test Procedure for Trucks and Buses, Recomended Practice, SAE J1252," 1979.

[58] Harold Boudreau, "Design, Construction, and Testing of an Open Atmospheric Boundary Layer Wind Tunnel," University of Florida, Gainesville, Dissertation 2009.

[59] J.H. Bell and R.D. Mehta, "Contraction Design for Small Low-Speed Wind Tunnels," National Aeronautics and Space Administration, Washington D.C., NASA Contractor Report NASA CR-177488, 1988.

[60] C. Gavirluta, S. Spataru, I. Mosincat, and C. Citro, "Complete Methodology on Generating Realistic Wind Speed Profiles Based on Measurements," in International Conference on Renewable Energies and Power Quality, Satiago De Compostela, 81ea3cd2-1360-4394bd99-2e20802b0f7c, 2012.

[61] Mustapha Hammache, Mark Michaelian, and Fred Broward, "Aerodynamic Forces on Truck Models, Including Two Trucks in Tandem," Institute of Transportation Studies, University of California, Berkley, California Path Program Research Report No. UCB-ITS-PRR-2001-27, 2001. 
[62] Ira Abbott and Albert Doenhoff, Theory of Wing Sections Including a Summary of Airfoil Data, 1st ed., Ira Abbott and Albert Doenhoff, Eds. Mineola, NY, USA: McGraw-Hill Book Company, 1949.

[63] U.S. Department of Transportation - Federal Highway Administration, "Frieght Facts and Data 2012," Office of Frieght Management and Operations, Washington DC, Technical FHWA-HOP-12-001, 2012.

[64] U.S. Department of Transportation - Federal Highway Administration, "Federal Size Regulations for Commercial Motor Vehicles," Office of Frieght Management and Operations, Washington D.C., Technical FHWA-HOP-04-022, 2004.

[65] Michael Paidoussis, Stuart Price, and Emmanuel Langre, Fluid Structure Interactions-Cross Flow-Induced Instabilities, 1st ed., Michael Paidoussis, Ed. New York, New York, United State of America: Cambridge University Press, 2011.

[66] Harun Chowdhury, Hazim Moria, Abdulkadir Ali, and Simon Watkins, "A Study on Aerodynamic Drag of a Semi-Trailer Truck," in 5th BSME International Conference on Thermal Engineering, Dhaka, Bangladesh, 2013, pp. 201-205.

[67] Kevin R. Cooper and R.A. Drollinger, "Truck Aerodynamics Reborn - Lessons from the Past," in SAE Internaltion Truck \& Bus Meeting \& Exhibition, Ft. Worth, Texas, SAE Technical Paper 2003-01-3376, 2003, DOI: 10.4271/2003-01-3376.

[68] Kevin Cooper, "Bluff-body Aerodynamics as Applied to Vehicles," journalof Wind Engineering and Industrial Applications, vol. 49, no. 1-3, pp. 1-21, December 1993.

[69] A Roshko, "Perspective on Bluff Body Aerodynamics," Journal of Wind Engineering and Industrial Aerodynamics, vol. 49, no. 1-3, pp. 79-100, December 1993.

[70] Gunter Schewe, "Reynolds-number Effects in Flow Around More-or-Less Bluff Bodies," Journal of Wind Engineering and Industrial Aerodynamics, vol. 89, no. 14-15, pp. 12671289, December 2001.

[71] Jason Ortega and Kambiz Salari, "An Experimental Study of Drag Reduction Devices for a Trailer Underbody and Base," in 34th AIAA Fluid Dynamics Conference and Exhibit, Portland, Oregon, AIAA 2004-2252, 2004. 
[72] Bruce Storms, Dale Satran, James Heineck, and Stephen Walker, "A Study of Reynolds Number Effects and Drag-Reduction Concepts on a Generic Tractor-Trailer," in 34th AIAA Fluid Dynamics Conference and Exhibit, Portland, Oregon, AIAA 2004-2251.

[73] A Roshko and K Koenig, "Interaction Effects on the Drag of Bluff Bodies in Tandem," in Aerodynamic Drag Mechanisms of Bluff Bodies and Road Vehicles, Gino Sovran, Thomas Morel, and William Mason, Eds. USA: Springer US, 1978, pp. 253-286.

[74] J.P. Kehs and K.D. Visser, "Tractor Trailer Drag Reduction Using Aft Cavities," in 1000 Is/and Fluid Mechanics Meeting, Potsdam, NY, 2012.

[75] David Pointer, Tanju Sofu, and David Weber, "Development of Guidelines for the Use of Commercial CFD in Tractor-Trailer Aerodynamic Design," in SAE Commercial Vehicle Engineering Congress and Exhibition, Rosemont, SAE Technical Paper 2005-01-3513, 2005, DOI: 10.4271/2005-01-3513.

[76] David Pointer, J. Chang, S. Singh, and E. Dringenebrg, "Commercial CFD Code for Validation for External Aerodynamics Simulations of Realistic Heavy-Vehicle Configurations," U.S. Department of Energy - Energy Efficiency and Renewable Energy, Washington, DC, Annual Progress Report FY-2007, 2007.

[77] David Pointer, Tanju Sofu, jimmy Chang, and David Weber, "Applicability of Commercial CFD Tools for Assessment of Heavy Vehicle Aerodynamic Characterstics," in The Aerodynamics of Heavy Vehicles II Book: Trucks, Buses and Trains.: Springer-Verlag Berlin Heidelberg, 2009, pp. 349-361.

[78] Josh Doyle, Roy Hartfield, and Christopher Roy, "Aerodynamic Optimization for Frieght Trucks Using a Genetic Algorithm and CFD," in 46th AIAA Aerospace Sciences Meeting and Exhibit, Reno, Nevada, AIAA Paper no. 323, 2008, pp. 7-10.

[79] US dept of Commerce - NOAA/NWS. (Accessed - April, 2012) Degrib (NDFD GRIB2 Decoder). [Online]. http://www.nws.noaa.gov/mdl/degrib/txtview.php?file=tkdegrib.txt\&dir=base [Online]

[80] National Center for Environmental Prediction - Earth System Research Laboratory. (Accessed - May, 2012) Rapid Refresh Review - Hourly Updated Models. http://ruc.noaa.gov/pdf/RR.NCEP-PSR-7dec2011.pdf [Online]. 
[81] Xiang Yu Huang, Wei Wang, Ju Won Kim, Bill Skamarock, and Tom Henderson, "Development of Digital Filter Initialization for WRF and its Implementation at IUM," in Preprints: 8th Annual WRF User's Workshop, Boulder, 2007.

[82] Tracy Lorraine Smith, Stanley G. Benjamin, John M. Brown, and Steven Weygandt, "Convection Forecasts From the Hourly Updated, 3-KM High resolution Rapid Refresh (HRRR) Model," in Preprints 24th Conference on Severe Local Storms, Amer. Meteor. Soc., Savannah, 2008.

[83] Curtis Alexander, Steve Weygadnt, Sten Benjamin, and Eric James, "High Resolution Rapid Refresh (HRRR) Model and Production Advancements for 2013 with Targeted Improvements for Reliable Convective Weather Guidance in the National Airspace System," in 16th Conference on Aviation, Range, and Airspace Meteorology, Austin, TX, 2013.

[84] Timothy Liu, Kristina Katsaros, and Joost Businger, "Bulk Parameterization of Air-Sea Exhchanges of Heat and Water Vapor Including the Molecular Constraints at the Interface," Journal of Atmospheric Sciences, vol. 36, pp. 1722-1735, April 1979.

[85] S.A. Hsu, Eric Meindl, and David Gilhousen, "Determining the Power-Law Wind-Profile Exponent under Near-Stability Conditions at Sea," Journal of Applied Meteorology, vol. 33, no. 6, pp. 757-765, 1994.

[86] D.H. Maling, "Measuring from Maps: Principles and Methods of Cartometry," in Coordinate Systems and Map Projections Book, 2nd edition.: Oxford: Pergamon Press, 1989, p. 476.

[87] Marc Besch, Arvind Thiruvengadam, Arvind Carder, Adewale Oshinuga, and Mridul Gautam, "Real-World Particulate Emissions from a 2010 Compliant HD Diesel Truck Travelling Across the Continental United States.," in 16th ETH-Conference on Combustion Generated Nanoparticles, Zurich, Switzerland, 2012.

[88] Subrata Roy and Pradeep Srinivasan, "External Flow Analysis of a Truck for Drag Reduction," SAE International, pp. 2000-01-3500, 2000.

[89] Rose McCallen et al., "Progress in Reducing Aerodynamic Drag for Higher Efficiency of Heavy Duty Trucks (Class 7-8)," in Society of Automotive Engineers Government/Industry Meeting, Washington, D.C., April 1999. 
[90] Dassault Systems Inc. (Accessed - April, 2014) COSMOSFloWorks Fundamentals. [Online]. http://www.personal.psu.edu/jah5420/Misc/SolidWorks/COSMOSFloWorks/FloWorks/lan g/english/Docs/Fundamentals.pdf

[91] Katherine J. Fender and David A. Pierce. (Accessed - May, 2013) An Analysis of the Operational Costs of Trucking. http://www.glostone.com/wpcontent/uploads/2012/09/ATRI-Operational-Costs-of-Trucking-2012.pdf [Online]. 